UNIVERSIDADE DE SÃO PAULO

FACULDADE DE ECONOMIA, ADMINISTRAÇÃO E CONTABILIDADE DEPARTAMENTO DE ADMINISTRAÇÃO PROGRAMA DE PÓS-GRADUAÇÃO EM ADMINISTRAÇÃO

HEDGE DE OPÇÃO UTILIZANDO ESTRATÉGIAS DINÂMICAS MULTIPERIÓDICAS AUTOFINANCIÁVEIS EM TEMPO DISCRETO EM MERCADO INCOMPLETO

Iuri Lazier Orientador: José de Oliveira Siqueira 
Profa. Dra. Suely Vilela

Reitor da Universidade de São Paulo

Prof. Dr. Carlos Roberto Azzoni

Diretor da Faculdade de Economia, Administração e Contabilidade

Prof. Dr. Isak Kruglianskas

Chefe do Departamento de Administração

Prof. Dr. Lindolfo Galvão de Albuquerque

Coordenador do Programa de Pós-Graduação em Administração 
IURI LAZIER

\title{
HEDGE DE OPÇÃO UTILIZANDO ESTRATÉGIAS DINÂMICAS MULTIPERIÓDICAS AUTOFINANCIÁVEIS EM TEMPO DISCRETO EM MERCADO INCOMPLETO
}

\author{
Dissertação apresentada ao Departamento \\ de Administração da Faculdade de \\ Economia, Administração e Contabilidade \\ da Universidade de São Paulo como \\ requisito para a obtenção do título de \\ Mestre em Administração.
}

Orientador: Prof. Dr. José de Oliveira Siqueira 
Dissertação defendida e aprovada no Departamento de Administração da Faculdade de Economia, Administração e Contabilidade da Universidade de São Paulo - Programa de Pós-Graduação em Administração, pela seguinte banca examinadora:

Prof. Dr. Joe Akira Yoshino

Prof. Dr. José de Oliveira Siqueira

Prof. Dr. Richard Saito

\section{FICHA CATALOGRÁFICA}

Elaborada pela Seção de Processamento Técnico do SBD/FEA/USP

Lazier, Iuri

Hedge de opção utilizando estratégias dinâmicas multiperiódicas autofinanciáveis em tempo discreto em mercado incompleto / Iuri Lazier. -- São Paulo, 2009.

$263 \mathrm{p}$.

Dissertação (Mestrado) - Universidade de São Paulo, 2009

Bibliografia.

1. Administração de risco 2. Hedging (Finanças) 3. Sistemas e métodos 4. Simulação 5. Econometria I. Universidade de São Paulo. Faculdade de Economia, Administração e Contabilidade II. Título. 
Aos melhores presentes da minha vida: Nara Beatriz de Araújo Silva, Júlia de Albuquerque Lazier, Thomás de Araújo Lazier. 


\section{AGRADECIMENTOS}

Aos meus pais, Leovina Lima Lazier e Hermógenes Lazier, por sempre terem me incentivado a estudar, ensinando-me a ver esse ato como inerente ao ser humano.

Ao Mestre Hermógenes Lazier, pelo seu exemplo de inabalável entusiasmo acadêmico.

À minha esposa Nara Beatriz de Araújo Silva e ao meu filho Thomás Araújo Lazier que tiveram participação compulsória no desenvolvimento do trabalho.

À Mestra Nara, que me mostrou a importância da supremacia do uso do verbo sobre o substantivo e sobre o adjetivo como marca da boa conduta humana.

Ao meu orientador Dr. José de Oliveira Siqueira, que iluminou o caminho trilhado e compartilhou sua respeitável capacidade acadêmica e seus admiráveis princípios e idéias que considera indissociáveis da prática.

Ao meu colega da USP, Claudinei de Paula, com quem tive a oportunidade de discutir muitas questões teóricas para sedimentação do apredizado e que me ajudou nesse processo de trabalho, sempre aberto à troca de informações e experiências.

A todos os professores que tive ao longo de minha vida de estudante, cuja soma de contribuições possibilitou a execução deste trabalho.

Aos professores Dra. Adriana Backx Noronha Viana, Dra. Bernadete de Lourdes Marinho, Dr. Cláudio Felisoni de Angelo, Dr. Joe Akira Yoshino, Dr. José Augusto Giesbrecht da Silveira, Dr. José Roberto Securato, Dr. Naércio Aquino Menezes Filho, Dr. Ricardo Rezende Gomes Avelino e Dra. Vera Lucia Fava, com quem cursei disciplinas durante o mestrado e consolidei os conhecimentos mais avançados para a realização do trabalho.

A todos os funcionários das bibliotecas da FEA/USP e do IME/USP, fontes fundamentais de material de pesquisa. 
Às secretarias do Departamento de Administração e da FEA pelo suporte durante todo o mestrado.

À FIA, todos os colegas do Labfin e o Dr. José Roberto Securato, que me proporcionaram agradáveis experiências acadêmicas.

À USP que me permitiu participar desse grande centro de excelência acadêmica, disponibilizando os melhores recursos materiais e humanos que apoiaram a realização do trabalho. 
"Price changes would always be consequences of new information, unavailable as a basis for prediction before the price change occurred."

Holbrook Working 1953 


\section{RESUMO}

Este trabalho analisa três estratégias de hedge de opção, buscando identificar a importância da escolha da estratégia para a obtenção de um bom desempenho do hedge.

O conceito de hedge é analisado de forma retrospectiva e uma teoria geral de hedge é apresentada. Em seguida, são descritos alguns estudos comparativos de desempenho de estratégias de hedge de opção e suas metodologias de implementação. Para esta análise comparativa três estratégias de hedge de opção de compra do tipo européia são selecionadas: a primeira utiliza o modelo Black-Scholes-Merton de precificação de opções, a segunda utiliza uma solução de programação dinâmica para hedge dinâmico multiperiódico e a terceira utiliza um modelo GARCH para precificação de opções. As estratégias são comentadas e comparadas do ponto de vista de suas premissas teóricas e por meio de testes comparativos de desempenho. O desempenho das estratégias é comparado sob uma perspectiva dinâmicamente ajustada, multiperiódica e autofinanciável. Os dados para comparação de desempenho são gerados por simulação e o desempenho é avaliado pelos erros absolutos médios e erros quadráticos médios, resultando na carteira de hedge. São feitas ainda considerações a respeito de alternativas de estimação e suas implicações no desempenho das estratégias.

Palavras-chave: hedge, hedge de opção, Black-Scholes, GARCH, Heston-Nandi, Cerny, programação dinâmica, estratégia de hedge, estratégia autofinanciável, hedge dinâmico, hedge multiperiódico, carteira replicante, teoria de hedge, mercado completo, mercado incompleto. 


\begin{abstract}
This work analyzes three option hedging strategies, to identify the importance of choosing a strategy in order to achieve a good hedging performance. A retrospective analysis of the concept of hedging is conducted and a general hedging theory is presented. After which, some comparative papers of hedging performance and their implementation methodologies are described. For the present comparative analysis, three hedging strategies for European options have been selected: the first one based on the Black-Scholes-Merton model for option pricing, the second one based on a dynamic programming solution for dynamic multiperiod hedging and the third one based on a GARCH model for option pricing. The strategies are compared under their theoric premises and through comparative performance tests. The performance of the strategies is compared under a dynamically adjusted multiperiodic and self-financing perspective. Data for performance comparison are generated by simulation and performance is evaluated by average absolute errors and average squared errors resulting in the hedging portfolio. An analysis is also done regarding estimation approaches and their implications over the performance of the strategies.
\end{abstract}

Key-words: hedge, option hedging, Black-Scholes, GARCH, Heston-Nandi, Cerny, dynamic programming, hedging strategy, self-financing strategy, dynamic hedging, multiperiod hedging, replicating portfolio, hedging theory, complete market, incomplete market. 


\section{SUMÁRIO}

1. INTRODUÇÃO

1.1 Motivação......................................................................................................................................................... 13

1.2 Do que estamos falando ................................................................................................................... 14

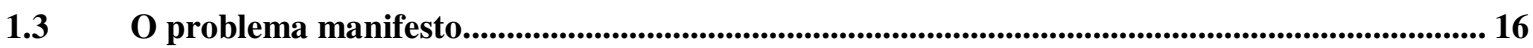

1.4 Objetivos e Justificativa do Trabalho....................................................................................................... 17

1.5 Delimitação do trabalho ......................................................................................................................... 18

1.6 Procedimentos metodológicos ............................................................................................... 20

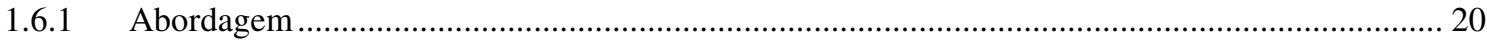

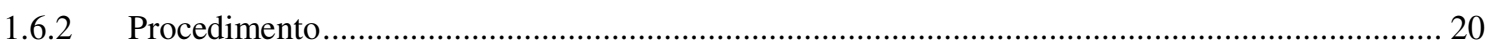

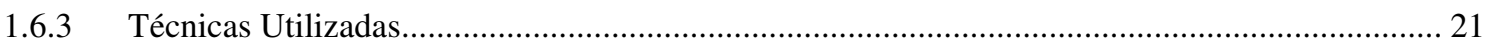

1.6.4 Delimitação da População e Amostragem................................................................................... 21

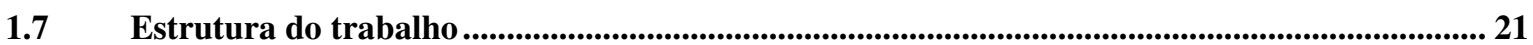

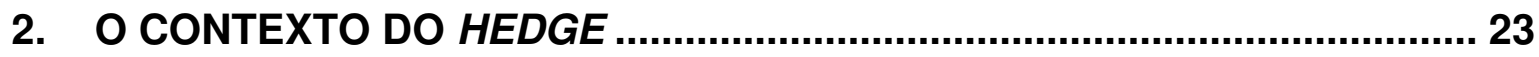

$2.1 \quad$ A teoria tradicional .............................................................................................................................. 24

$2.2 \quad$ A hipótese de Working............................................................................................................................ 26

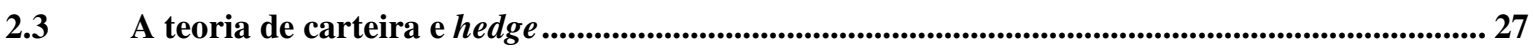

2.4 A visão contemporânea ........................................................................................................................ 31

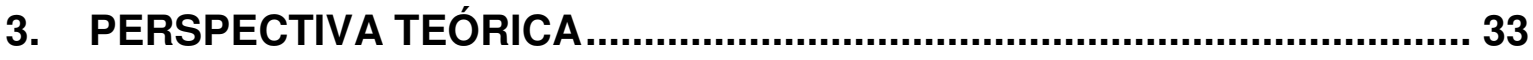

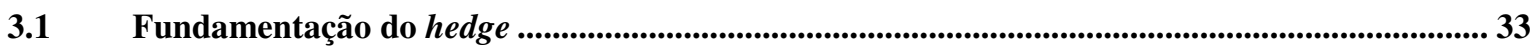

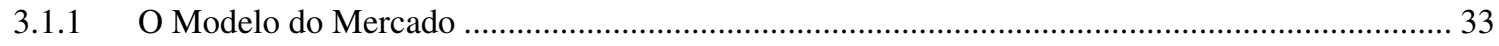

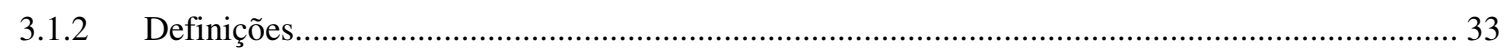

3.1.3 Subespaço de Mercado e Subespaço Ampliado .......................................................................... 34

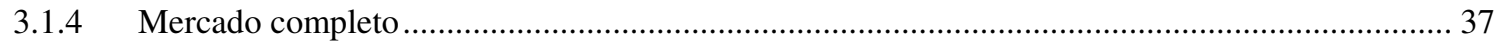

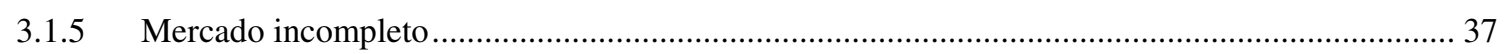

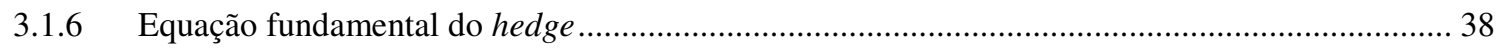




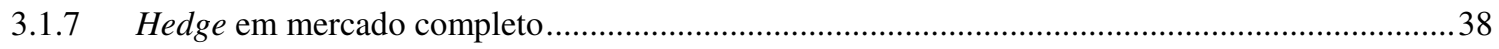

3.1.7.1 $m=n$ ativos-base linearmente independentes e $m=n$ estados da natureza .................38

3.1.7.2 $\quad n-m$ ativos-base redundantes e $m$ estados da natureza .............................................39

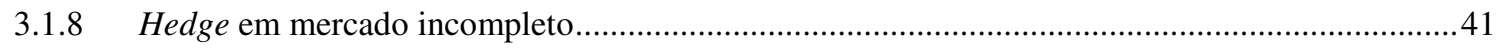

3.1.8.1 $n$ ativos-base linearmente independentes e $m>n$ estados da natureza........................41

3.1.8.2 $n-r(\mathbf{A})$ ativos-base redundantes e $m>r(\mathbf{A})$ estados da natureza............................43

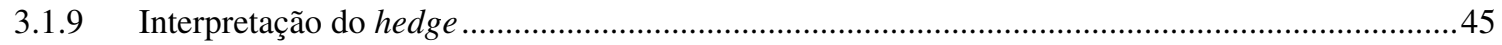

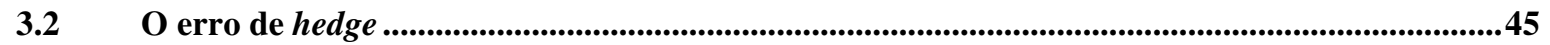

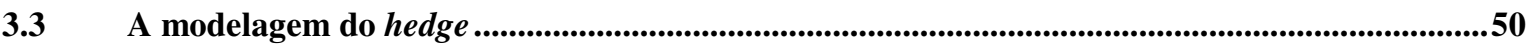

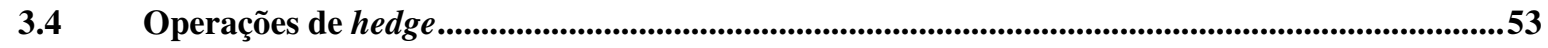

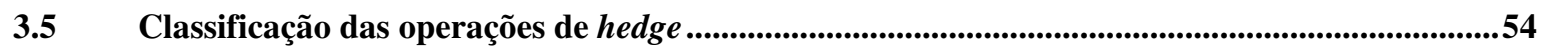

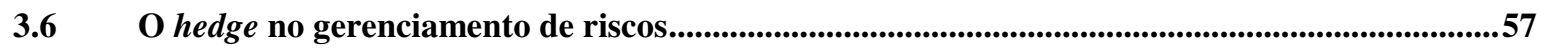

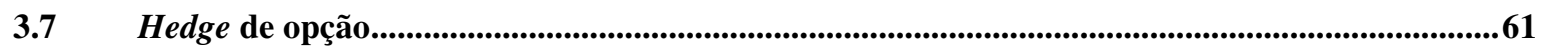

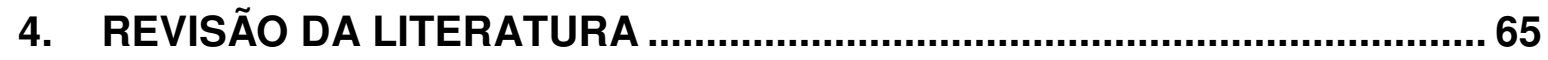

4.1 O trabalho de Dumas, Fleming e Whaley .....................................................................................66

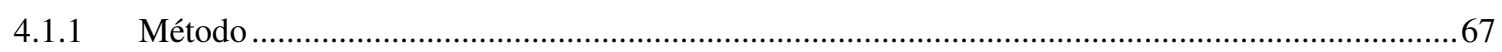

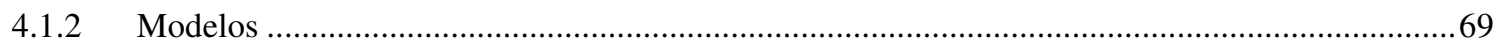

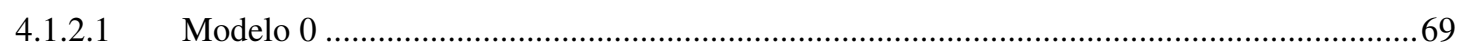

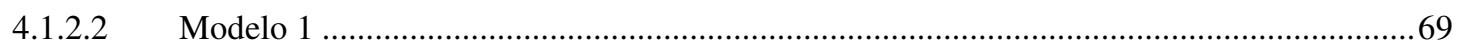

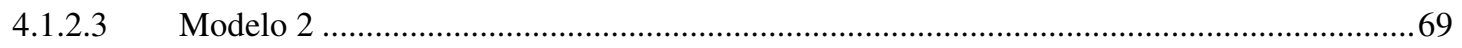

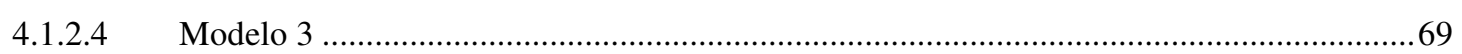

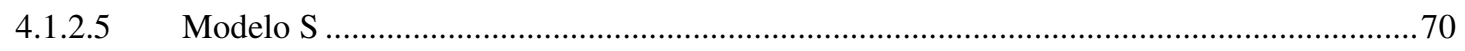

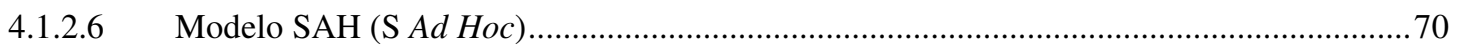

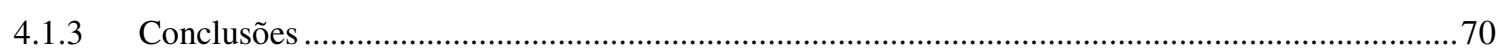

4.2 O trabalho de Nandi e Waggoner..................................................................................................71

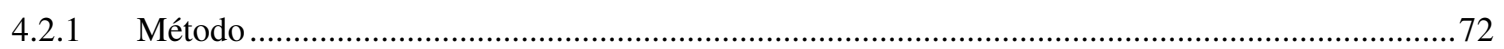

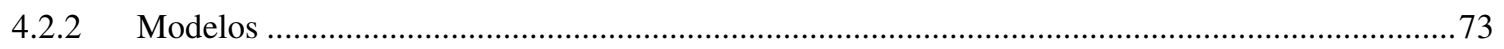

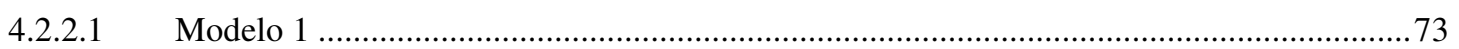

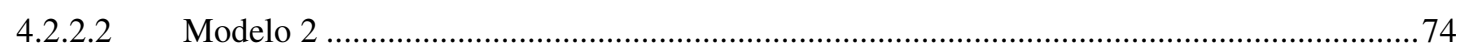

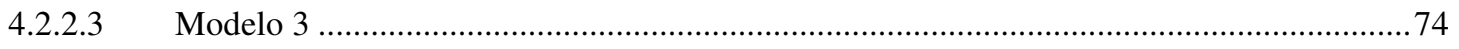

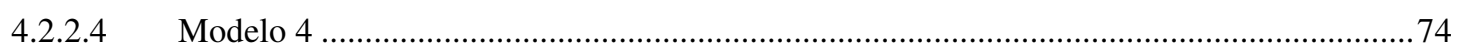

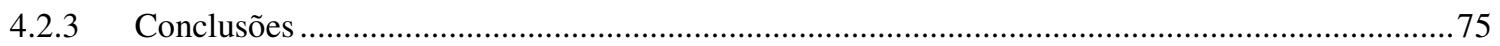

4.3 0 trabalho de Heston e Nandi .............................................................................................. 


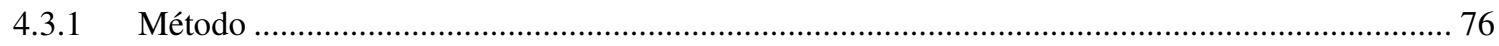

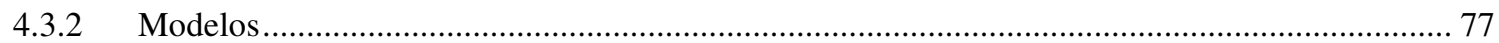

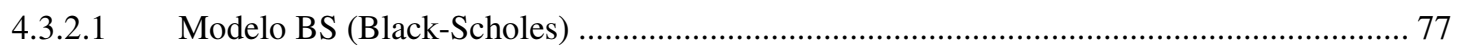

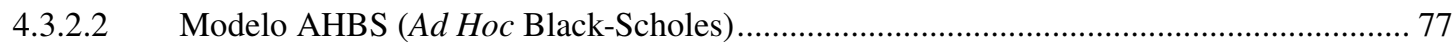

4.3.2.3 Modelo GARCH (Generalized Autoregressive Conditional Heteroskedasticity)............... 78

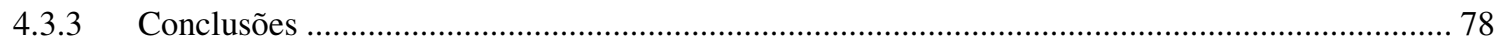

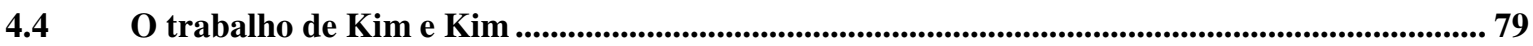

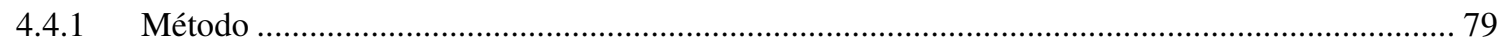

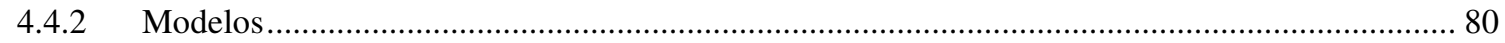

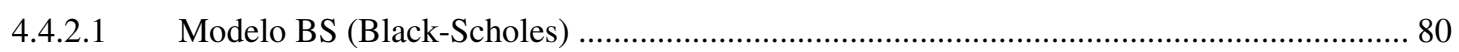

4.4.2.2 Modelo AHBS (Ad Hoc Black-Scholes) ........................................................................ 80

4.4.2.3 Modelo GARCH (Generalized Autorregressive Conditional Heteroskedasticity) .............. 81

4.4.2.4 Modelo de SV (Stochastic Volatility) ............................................................................... 81

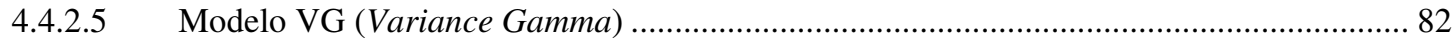

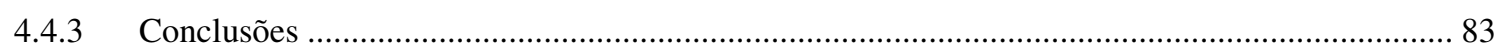

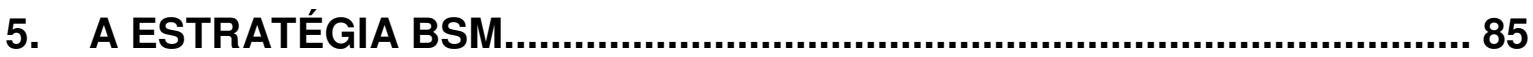

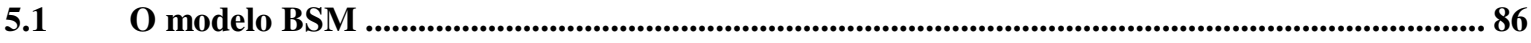

5.2 Dinâmica de preços dos ativos no modelo BSM ....................................................................8 88

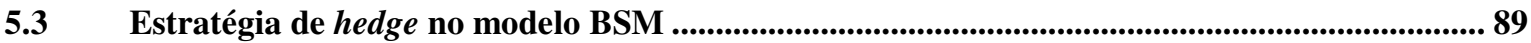

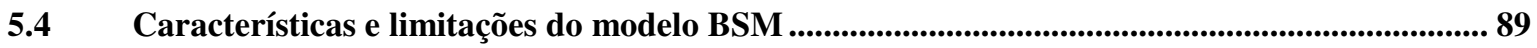

5.5 Erro de hedge devido ao ajuste em tempo discreto da carteira replicante................................. 91

5.6 Resumo das características da estratégia de hedge BSM..................................................97

6. A ESTRATÉGIA AC ........................................................................ 99

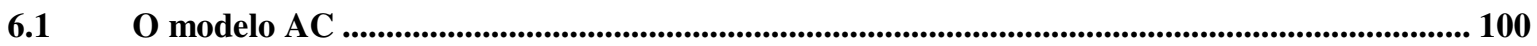

6.2 Dinâmica de preços dos ativos no modelo $\mathrm{AC}$............................................................................... 100

6.3 solução de programação dinâmica da estratégia de hedge AC ............................................... 102

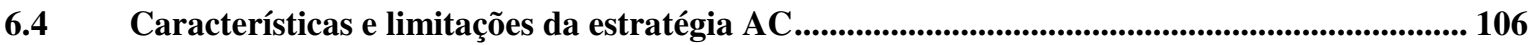

6.5 Resumo das características da estratégia de hedge $\mathrm{AC}$.............................................................. 107 


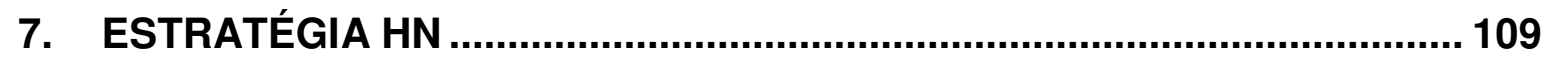

7.1 O modelo GARCH aplicado a opções .......................................................................................................109

7.2 A dinâmica de preços do modelo GARCH HN ...................................................................112

7.3 O modelo GARCH da estratégia de hedge $\mathrm{HN}$...................................................................................114

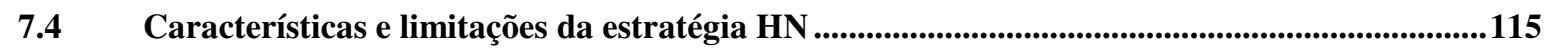

7.5 Resumo das características da estratégia de hedge $\mathrm{HN}$..................................................................116

8. AVALIAÇÃO COMPARATIVA

8.1 Discussão teórica

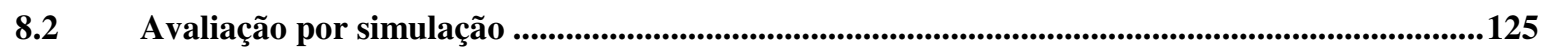

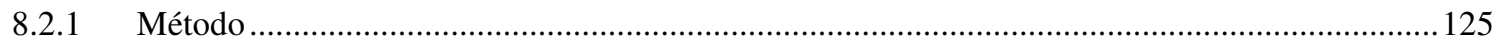

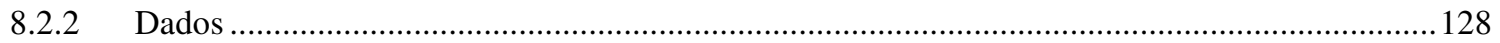

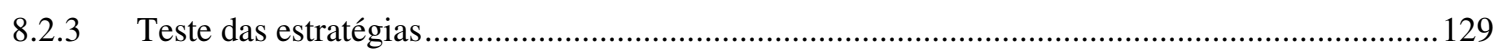

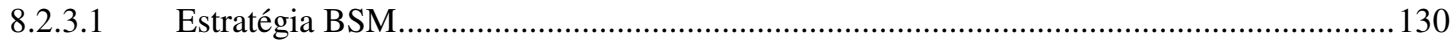

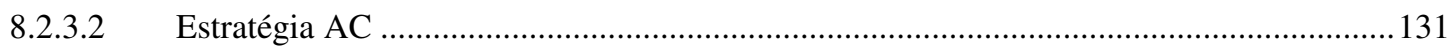

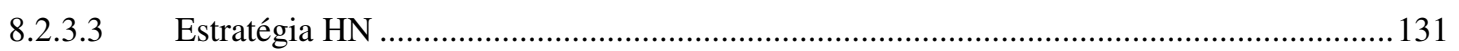

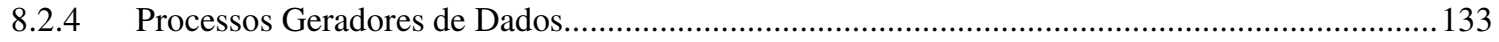

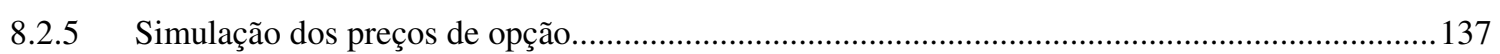

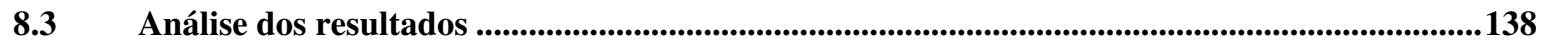

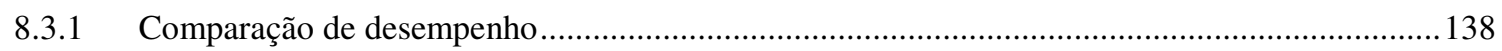

8.4 Considerações finais .............................................................................................................141

8.4.1 A escolha da estratégia de hedge faz diferença? ......................................................................... 141

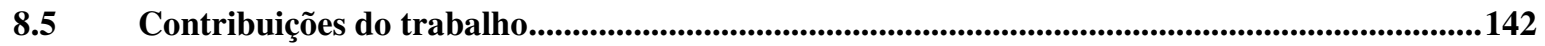

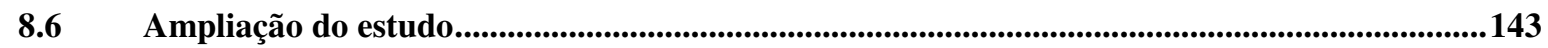

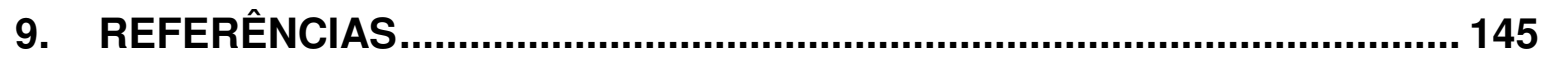

10. APÊNDICE 1 - DEMONSTRAÇÕES - ESTRATÉGIA BSM ......................153

$10.1 \quad$ Premissas do Modelo ................................................................................................................................153

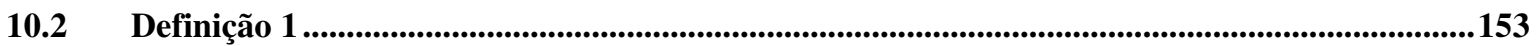




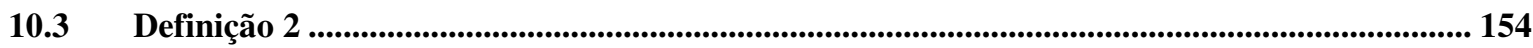

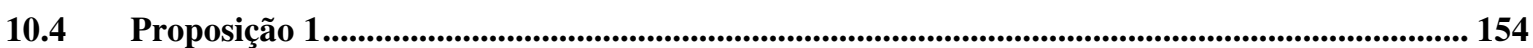

11. APÊNDICE 2 - DEMONSTRAÇÕES ESTRATÉGIA AC......................... 177

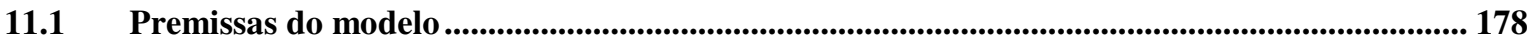

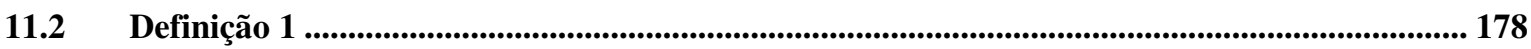

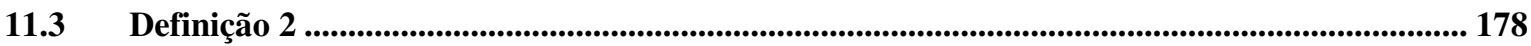

11.4 Proposiçã̃ 1 1............................................................................................................................................. 179

11.5 Proposição 2

11.6 Proposiçã̃ 3 ........................................................................................................................................ 181

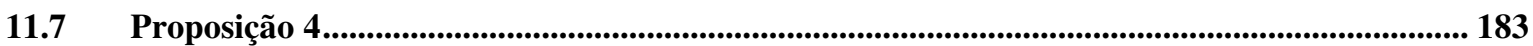

12. APÊNDICE 3 - DEMONSTRAÇÕES - ESTRATÉGIA HN ..................... 203

$12.1 \quad$ Premissas do modelo ............................................................................................................................. 203

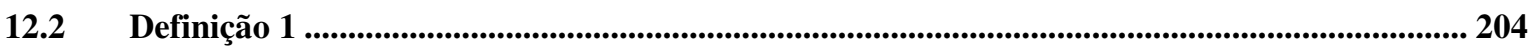

12.3 Definiçã̃ 2 ................................................................................................................................................... 204

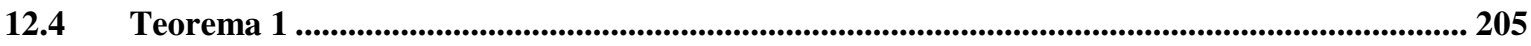

12.5 Proposição 1

12.6 Definiçã̃ 3 ................................................................................................................................................. 209

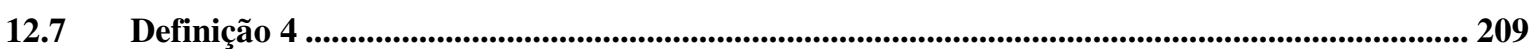

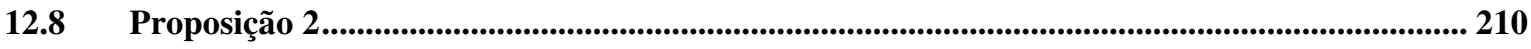

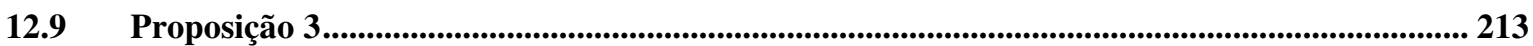

13. APÊNDICE 4 - PROGRAMAS UTILIZADOS ...................................... 219

13.1 Programa para geração das séries de estimação e validação ………………………….................... 219

13.2 Programa para cálculo de preços de opção......................................................................................... 226 
13.3 Programa para estimação e teste da estratégia BSM .......

13.4 Programa para estimação e teste da estratégia AC ...........................................................236

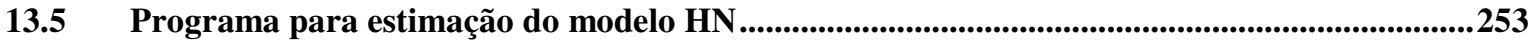

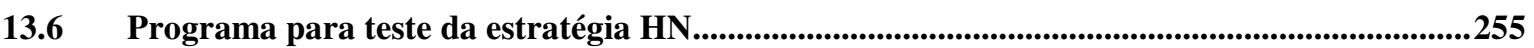




\section{LISTA DE ABREVIATURAS}

AC: Ales Cerny.

BSM: Black-Merton-Scholes.

e. g.: exempli gratia, por exemplo.

ESRE: expected sum of squared replication error.

GARCH: Generalized Autoregressive Conditional Heteroskedaticity.

GED: Generalized Error Distribution.

HN: Heston e Nandi.

i. e.: id est, ou seja.

ID: identicamente distribuídos.

IID: independentes e identicamente distribuídos.

PGD: processo gerador de dados.

q. e. d.: quod erat demonstrandum, com era para ser demonstrado.

SSRE: sum of squared replication error.

TGARCH: Treshold Generalized Autoregressive Conditional Heteroskedaticity. 


\section{LISTA DE FIGURAS}

FIGURA 3.1 - SUBESPAÇO DO MERCADO 37

FIGURA 3.2 - ERRO DE REPLICAÇÃO

FIGURA 6.1 - RETORNOS E PROBABILIDADES 101

FIGURA 6.2 - ÁRVORE DE ESTADOS DE PREÇOS 101

FIGURA 8.1 - MÉTODO DE SIMULAÇÃO

FIGURA 8.2 - ESTRATÉGIA BSM 130

FIGURA 8.3 - ESTRATÉGIA AC 131

FIGURA 8.4 - ESTRATÉGIA HN 133 


\section{LISTA DE TABELAS}

TABELA 3.1 - CARACTERÍSTICAS DOS MERCADOS 58

TABELA 4.1 - TABELA DE DESEMPENHO DE HEDGE. 71

TABELA 4.2 - TABELA DE DESEMPENHO DE PRECIFICAÇÃO ……………………............................ 71

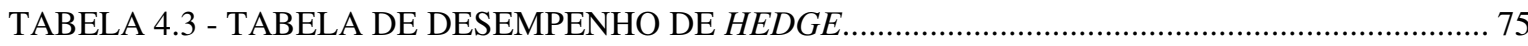

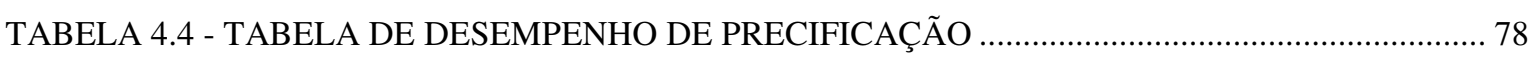

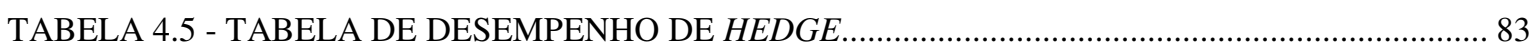

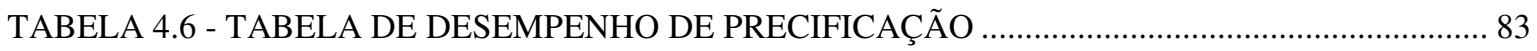

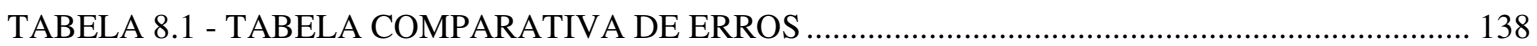

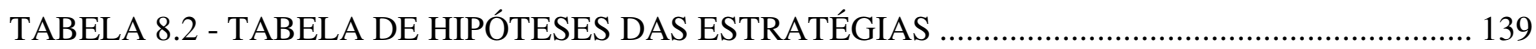




\section{INTRODUÇÃO}

\subsection{Motivação}

O avanço do conhecimento na área de Finanças, entendido como a interpretação das variáveis do mercado, das relações entre elas e a modelagem de seu comportamento, é acompanhado pelo desenvolvimento e aumento de complexidade dos mercados.

Podemos apontar como dois dos fenômenos mais marcantes em Finanças nas últimas décadas, por um lado, o aumento da volatilidade ou oscilação nos preços dos ativos nos mercados, e, por outro lado, a enorme sofisticação dos conceitos e ferramentas teóricas de análise quantitativa, impulsionada pela tecnologia da informação.

Farhi (1999, p. 93) destaca um forte aumento na volatilidade das taxas de câmbio e de juros, registradas após o fim dos acordos de Bretton Woods em 1971, que deram impulso à expansão do mercado de derivativos e mudaram o comportamento dos agentes econômicos em relação às operações de cobertura de risco.

Kariya e Liu (2003, p. 1) afirma que a teoria de precificação de ativos ganhou sofisticação marcadamente nas décadas de 80 e 90 . Para corroborar com essa afirmação, podemos observar a partir dos trabalhos seminais de Black e Scholes (1973, p.637-654) e Merton (1973, p. 141-183) sobre precificação racional de derivativos (obtenção de um preço único e livre de arbitragem), o surgimento de diversos trabalhos que expandiram o tema. Entre os mais marcantes, Harrison e Kreps (1979, p. 381-408) e Harrison e Pliska (1981, p. 215260) sobre precificação com martingales, Engle (1982, p. 987-1007) e Bollerslev (1987, p. 307-327) sobre modelos ARCH e GARCH, Hull e White (1987, p. 281-300) sobre precificação com volatilidade estocástica e Duan (1995, p. 13-32) sobre precificação com modelos GARCH, apenas para citar alguns, que deram origem a uma infinidade de outros estudos e aperfeiçoamentos na aplicação de métodos quantitativos em finanças.

Impossível não vincular esses desenvolvimentos à evolução da tecnologia da informação, principalmente a proliferação dos computadores pessoais a partir da criação do IBM-PC no 
início da década de 80, sem os quais a maior parte desses estudos e muitos testes e simulações não seriam possíveis.

$\mathrm{O}$ aumento da volatilidade dos mercados implica aumento nos riscos de mercado a que os agentes econômicos estão expostos, entendendo riscos de mercado, neste contexto, como a variação nos resultados de uma operação financeira, devida à mudança nos preços dos ativos.

As operações de hedge revestem-se, pois, de maior importância, dado que constituem importante ferramenta de gestão de diversos tipos de riscos. No caso de riscos de mercado, são importantes na gestão de riscos de carteiras de investimentos em ativos financeiros, diretamente expostos à volatilidade de preços dos ativos que os compõem e importantes na gestão das empresas, expostas à volatilidade de seus ativos e passivos.

Mas o que viria a ser um hedge?

\subsection{Do que estamos falando}

Hedge é um elegante substantivo utilizado na sua forma original, extraída diretamente do idioma bretão. Foi completamente absorvido e consta no Houaiss (2001), mas sem equivalente em português.

Sua variante mais utilizada é o verbo substantivado hedging, o ato de fazer o hedge, que embora não conste nos dicionários, também será utilizado neste trabalho na sua forma original.

Para o verbo, preferimos "fazer hedge", à adaptação lingüística pouco satisfatória de "hedgear".

Como este trabalho analisa estratégias de hedge, não queremos prescindir de uma breve avaliação dos significados e conceitos sintetizados na palavra. 
Segundo o Merriam-Webster (2006), significa "a means of protection" ou "um meio de proteção", "to evade the risk of commitment" ou "eliminar o risco do compromisso", "to protect oneself financially by a counterballancing transaction" ou "proteger-se financeiramente através de uma transação contrária equivalente" e ainda "barrier" ou "barreira".

Houaiss (2001) define como "transação compensatória que visa proteger (um operador financeiro) contra prejuízos na oscilação de preços".

Quando entramos na literatura financeira, encontramos desde definições mais abrangentes, até definições técnicas específicas.

Koziol (1990, p.3) define hedge como um processo dinâmico que gerencia riscos específicos, com um mecanismo adequado de compensação ao longo do tempo, capaz de gerar respostas financeiras que ocorrem inversamente às respostas financeiras dos itens tomados como objeto de hedge.

Para Wilmott (2001, p. 186), hedge é a redução do risco por meio da exploração de relações ou correlação entre vários investimentos de risco.

Para Duffie (1989, p. 201), é a tomada de posição em contratos futuros que anulem alguns riscos associados a algum compromisso de mercado, ou ainda, adoção de uma posição em futuros que, em média, gere lucros quando o valor de mercado do compromisso está abaixo do esperado e perdas quando o valor de mercado do compromisso está acima do esperado.

A ANCOR (2008) define o hedge do ponto de vista dos riscos incorridos, diferenciando-o da diversificação. Define diversificação como uma operação de mitigação do risco específico dos ativos e hedge como uma operação de mitigação do risco sistemático.

Neste momento não cabe criar mais uma definição. Melhor é interpretar e sintetizar a essência das definições apresentadas, que nos interessa no contexto deste trabalho:

- $\quad$ A redução do risco de uma operação financeira.

- $\quad$ O estabelecimento de transações compensatórias que neutralizam perdas e ganhos. 
- $\quad$ A exploração de correlações nos preços dos ativos.

Esses são os fundamentos que podemos retirar das definições, sobre os quais está assentada a teoria do hedge e que serão explorados ao longo do trabalho. Mas para construir uma operação de hedge existe uma infinidade de instrumentos e estratégias, algumas similares entre si, outras bastante distintas. A construção requer o equacionamento do problema e a identificação da solução mais adequada. Essa construção da operação é a situação que expõe nosso problema de investigação.

\section{3 $O$ problema manifesto}

Em meio a tantos desenvolvimentos já realizados, tantas possibilidades existentes na estruturação de operações de hedge, tantos modelos matemáticos para mimetizar o comportamento dos ativos financeiros, tantas otimizações passíveis de serem incorporadas, a questão que se apresenta é: a escolha da estratégia de hedge faz diferença?

O que queremos investigar é se, do ponto de vista de resultados, dado o atual nível de desenvolvimento das diversas ferramentas teóricas, a escolha da estratégia de hedge desempenha um papel importante, e, se desempenhar, queremos identificar sob que condições uma ou outra é mais adequada para levar ao melhor desempenho. Essas são as questões que este trabalho pretende investigar.

Para o trabalho em questão, consideramos hedge como sendo a redução do risco de uma operação financeira por meio do estabelecimento de transações compensatórias que neutralizam perdas e ganhos, explorando correlações nos preços dos ativos. A palavra risco será utilizada sempre com o significado restrito de possibilidade de oscilação nos preços dos ativos financeiros, exceto quando explicitamente qualificado de forma distinta.

Escolha é o processo de decisão por uma ou outra estratégia possível na construção de uma operação de hedge. 
Estratégia é o método utilizado para construção e cálculo do hedge. São tratadas 3 propostas de estratégia denominadas BSM (Black-Scholes-Merton), AC (Ales Cerny) e HN (Heston e Nandi), daqui em diante identificadas pelos respectivos acrônicos. As estratégias são aplicadas a opções de compra do tipo européia. O hedge pelo delta calculado é a quantidade do ativo que deve ser comprada ou vendida e é denominada genericamente de razão de hedge, sendo definida pelo modelo matemático associado a cada estratégia implementada.

Por diferença, entendemos o desempenho de resultados obtido, avaliado teoricamente segundo os fatos estilizados incorporados por cada estratégia e avaliado praticamente segundo a correspondência entre os resultados esperados e os resultados verificados sobre um conjunto de dados simulados.

\subsection{Objetivos e Justificativa do Trabalho}

O propósito geral deste trabalho é investigar as diferenças fundamentais entre as estratégias de hedge.

Os objetivos primários deste trabalho são:

- Discutir uma conceituação de hedge adequada ao estado-da-arte da teoria e prática.

- Investigar a existência de dominância entre as estratégias de hedge, por meio da avaliação teórica e da realização de testes por simulação.

- Comparar estratégias de hedge desenvolvidas a partir de fundamentos distintos.

Como objetivos secundários temos:

- $\quad$ Expor de forma compilada e ordenada a evolução da teoria do hedge.

- Apresentar as alternativas e especificidades que requerem decisões práticas de implementação das estratégias de hedge.

- Analisar e explicitar as características das estratégias de hedge estudadas.

- Demonstrar aspectos do desenvolvimento das estratégias de hedge não apresentados nos trabalhos publicados. 
Muitas estratégias de hedge foram desenvolvidas e muitas delas constituem apenas variantes umas das outras. Diversos estudos comparativos também já foram realizados, entretanto, é muito mais comum a comparação entre estratégias desenvolvidas com princípios semelhantes, do que entre estratégias desenvolvidas com princípios distintos. A razão para tal, possivelmente seja que boa parte dos estudos comparativos tem por finalidade validar aperfeiçoamentos que constituem contribuições marginais sobre estratégias já desenvolvidas, ou, somente a comparação de uma nova estratégia com o padrão consagrado pela prática, que é o modelo BSM.

E. g., tratando opções, Engle e Rosenberg (1995, p. 1-25) compara um modelo GARCH com o modelo BSM, Dumas, Fleming e Whaley (1998, p. 2059-2106) compara alternativas de funções determinísticas no cálculo de volatilidade para implementação do modelo BSM, Hafner e Herwartz (1999, p. 1-34) compara variantes de implementação de modelos GARCH, Nandi e Waggoner (2000, p. 24-39) compara alternativas de cálculo de volatilidade para implementação do modelo BSM, Cerny (2004b, p. 1-25) compara um modelo de programação dinâmica com o modelo BSM, Heston e Nandi (2000, p. 585-625) compara variantes de implementação de modelos GARCH, Christoffersen e Jacobs (2004, p. 1204-1221) compara variantes de implementação de modelos GARCH, Hsieh e Ritchken (2005) compara variantes de implementação de modelos GARCH e Kim e Kim (2004, p. 117-142) compara modelos de volatilidade estocástica. Tratando futuros, (Brooks e Cerny e Miffre (2007, p. 1-36) compara OLS com otimização por utilidade, Bueno (1999, p. 1-142) compara OLS com modelos GARCH.

Este trabalho analisa estratégias de hedge de opção, compara seus princípios, interpreta suas diferenças e avalia sua eficácia, buscando agregar aos estudos uma perspectiva multiperiódica e autofinanciável.

\subsection{Delimitação do trabalho}

O cálculo do hedge será limitado ao hedge composto por uma ação e pelo ativo livre de risco com ativos-base e uma opção de compra européia como ativo-objeto. 
Serão tratados mercados incompletos, mas na condição de mercado perfeito. Para definir mercado perfeito podemos compilar as características apresentadas por Cox e Rubinstein (1985, p. 268), Cvitanic e Ma (1996, p. 370), Black e Scholes (1973, p. 640), Siqueira (1999, p. 111-112), Smith (1990, p. 346) e Wilmott (1997, p. 41-42):

- $\quad$ Inexistência de custos de transação e armazenamento.

- $\quad$ Não pagamento de dividendos ou outras bonificações.

- $\quad$ Sem regulamentação limitante quanto a depósito de margens e tamanho de posições compradas e vendidas.

- $\quad$ Possibilidade de aplicar e captar qualquer quantia à taxa livre de risco.

- $\quad$ Liquidez perfeita dos ativos no mercado, que podem ser comprados e vendidos em qualquer quantidade.

- $\quad$ Inexistência de diferença entre oferta compra e oferta de venda.

- $\quad$ Contratos infinitamente divisíveis.

- $\quad$ Investidores pequenos, no sentido de que sua condição financeira e estratégia de investimento não afetam os preços do mercado.

- $\quad$ Os preços dos ativos não são afetados pela existência do mercado de derivativos.

- $\quad$ Não há possibilidade de arbitragem.

As estratégias de hedge tomadas como objeto de investigação são: a estratégia BSM, derivada do modelo de precificação de opções de Black e Scholes, a estratégia AC derivada de uma solução de programação dinâmica proposta por Ales Cerny e a estratégia HN derivada do modelo GARCH proposto por Heston e Nandi. Fazemos uma descrição e uma análise dos princípios, identificando os principais fatos estilizados incorporados e as premissas utilizadas no seu desenvolvimento. Realizamos testes de hedge pelo delta sobre conjuntos simulados de séries de preços de ação e opção para comparação do desempenho das estratégias de hedge. Finalizamos com considerações a respeito de suas diferenças. 


\subsection{Procedimentos metodológicos}

Conforme critérios de classificação apresentados em Marconi e Lakatos (2007, p. 223,241), este trabalho é uma dissertação científico-argumentativa.

Trata-se, pois, de um estudo reflexivo, que analisa o problema de construção de uma operação de hedge à luz de teorias existentes.

Trata de um assunto específico, que são estratégias de hedge, foi desenvolvido com metodologia própria resultante de pesquisa aplicada, pois analisa as estratégias de hedge através de testes sistematizados e resulta em um posicionamento quanto à comparação das estratégias avaliadas.

É um estudo original sob o aspecto de que não é de conhecimento a existência de outro trabalho desenvolvido sobre os mesmos objetos de estudo.

\subsubsection{Abordagem}

O método de argumentação é essencialmente dedutivo. As análises serão conduzidas a partir da interpretação de resultados existentes apresentados na bibliografia e de constatações resultantes dos testes de desempenho de hedge pelo delta sobre conjuntos de dados simulados, todos derivados e demonstrados a partir da teoria que fundamenta sua concepção.

\subsubsection{Procedimento}

O método é comparativo. As análises serão fundamentadas na identificação e analogia entre as características das estratégias de hedge avaliadas, com o objetivo de verificar suas similaridades e diferenças no tratamento das informações e sua adequação à solução do problema de otimização do hedge. 


\subsubsection{Técnicas Utilizadas}

São utilizadas predominantemente duas técnicas de pequisa:

- $\quad$ A pesquisa bibliográfica em livros e publicações científicas sobre os desenvolvimentos realizados na precificação de opções e estratégias de hedge e publicações de trabalhos comparativos já realizados.

- Simulação programada em computador.

\subsubsection{Delimitação da População e Amostragem}

O conjunto de dados utilizado foi gerado por meio de técnicas de simulação. Foram utilizados modelos da literatura para geração das séries de preços e retornos de ativos financeiros. Séries de preços de opção foram calculadas por simulação de Monte Carlo, a partir dos processos geradores de dados (PGD) para geração de preços e retornos. Os modelos matemáticos foram estimados e testados sobre os conjuntos de dados gerados por simulação.

\subsection{Estrutura do trabalho}

Este trabalho está organizado conforme a descrição a seguir.

Este capítulo 1, a introdução, contém a motivação da realização do trabalho, a questão problema de pesquisa, definições operacionais, delimitação da abrangência do trabalho, objetivos e justificativa, procedimentos metodológicos utilizados e situa a perspectiva sob a qual o hedge é analisado no trabalho, dentro do conceito geral de hedge.

O capítulo 2 contextualiza a evolução do conceito de hedge ao longo do tempo até atingir o atual nível de sofisticação teórica.

O capítulo 3 apresenta os conceitos e fundamentos do hedge, estabelecendo um arcabouço teórico que generaliza e descreve a estrutura básica comum a todas as estratégias de hedge, e que dá sustentação às estratégias de hedge avaliadas. 
O capítulo 4 apresenta uma revisão da literatura que trata a comparação entre estratégias de hedge.

O capítulo 5 é uma descrição e análise da estratégia de hedge derivada do modelo BSM, destacando e interpretando suas principais características e alternativas de implementação.

O capítulo 6 é uma descrição e análise da estratégia de hedge AC, derivada de uma solução de programação dinâmica desenvolvida em Cerny (2004b).

O capítulo 7 é uma descrição e análise da estratégia de hedge HN derivada do modelo GARCH, desenvolvida em Heston e Nandi (2000).

Por fim, o capítulo 8 compara aspectos teóricos e empíricos das estratégias analisadas explorando o problema de pesquisa, apresenta a metodologia de implementação das estratégias utilizada neste trabalho, desenvolve os testes comparativos das estratégias por simulação, apresenta as conclusões do trabalho, destaca suas contribuições e aponta questões que permanecem em aberto. 


\section{O CONTEXTO DO HEDGE}

O hedge constitui um conjunto de conceitos, métodos e aplicações que foram sendo modificados e aperfeiçoados ao longo do tempo. Resultado da própria amplitude do tema, a literatura é bastante fragmentada, dificultando a visualização de um panorama mais geral sobre o assunto. Para termos essa visão, é mister uma discussão conceitual prévia, para então aprofundarmos o estudo específico das estratégias de hedge selecionadas para este trabalho. Neste capítulo faremos uma exposição do conceito de hedge em diversas fases evolutivas de Finanças e descreveremos a perspectiva atual sob a qual o hedge é interpretado.

Embora tenhamos sintetizado os fundamentos do hedge, o conceito do que vem a ser hedge não foi sempre claro e universalmente aceito ao longo da história das Finanças, como pode ser observado nos trabalhos de Working (1953a, p. 320), Working (1953b, p. 555), Johnson (1960, p. 142-144), Ederington (1979, p. 159-163), Duffie (1989, p. 205) e Farhi (1999, p. 93).

O aspecto de maior controvérsia residia no objetivo básico do hedge, tido ou não, como neutralização de riscos. Essa delimitação implica a distinção entre hedge, arbitragem e especulação, que constituem operações com fronteiras pouco delimitadas, pois as duas últimas são essencialmente operações com formato de hedge conduzidas com objetivo de gerar ganhos e não de reduzir riscos. Para apoiar a definição adotada neste trabalho e esclarecer essas fronteiras, lançamos mão da conceituação de Farhi (1999, p. 94), que delimita o hedge como uma operação essencialmente de cobertura de riscos.

Segundo Kaldor (1939), apud Farhi (1999 p. 103-105), especulação é a compra ou venda de mercadorias, para revenda ou recompra posterior, antecipando uma vantagem resultante de uma variação de preços esperada. Portanto, uma operação de especulação é uma operação estruturada com base em expectativas quanto ao comportamento de preços em determinada direção. Logo, mesmo que tenham a mesma forma de operações de hedge, mantendo posições contrárias sobre ativos com preços correlacionados, não podem ser classificadas como tal. Essas operações mantêm transações compensatórias que não se 
compensam completamente dada a expectativa de uma mudança favorável de preços, gerando posições descobertas.

Para Farhi (1999, p. 107), arbitragem é a estruturação de posições opostas sobre uma mesma mercadoria ou mercadorias diversas com preços correlacionados, com temporalidade diferente ou em praças diferentes, visando tirar proveito de distorções nas relações de preços. Aqui também são utilizadas operações com a mesma forma de operações de hedge, porém com a expectativa de que a compensação entre as transações se desfaça pela correção de preços, gerando ganhos.

A necessidade de separação desses conceitos está vinculada ao critério de avaliação do desempenho de uma operação de hedge. O hedge de melhor desempenho não é aquele que proporciona ganhos, mas aquele que reduz tanto perdas, quanto ganhos.

Ederington (1979, p.158) divide a evolução do conceito de hedge em três teorias:

- $\quad$ Teoria Tradicional.

- $\quad$ Hipótese de Working.

- $\quad$ Teoria de Carteira e Hedge.

\subsection{A teoria tradicional}

Notação:

$S_{t}:$ posição à vista.

$\Delta S$ : variação da posição à vista.

$F_{t}:$ posição futura.

$\Delta F$ : variação da posição descoberta futura.

$\theta:$ quantidades de contratos à vista.

$\lambda$ : quantidades de contratos futuros.

$V_{t}:$ posição de hedge.

$\Delta V$ : variação da posição de hedge.

$B_{t}$ : base. 
$h:$ razão de hedge.

$<<$ : muito menor.

Tanto Ederington (1979, p. 159-160) como Working (1953a, p. 320-321) explicam que a teoria tradicional enfatiza a redução de riscos através da utilização de mercados à vista e futuro. Segundo essa teoria, preços à vista e preços futuros de um ativo movem-se juntos. Uma operação de hedge é estruturada tomando-se posições de mesma magnitude e sinal contrário nos mercados à vista e futuro sobre um mesmo ativo, e. g., uma posição comprada no mercado à vista de determinada quantidade de contratos em uma commodity e uma posição vendida no mercado futuro com a mesma quantidade de contratos, sobre a mesma commodity.

Seja a posição à vista inicial é $S_{t}$, a posição à vista final $S_{t+1}$, a posição futura inicial $F_{t}$ e a posição futura final $F_{t+1}$.

A variação da posição descoberta à vista é $\Delta S=S_{t+1}-S_{t}$.

Sejam $\theta$ e $\lambda$ são as quantidades de contratos à vista e futuros, respectivamente.

A posição de hedge inicial é $V_{t}=\theta S_{t}-\lambda F_{t}$.

A posição de hedge final é $V_{t+1}=\theta S_{t+1}-\lambda F_{t+1}$.

A variação da posição de hedge é denominada base, denotada por

$$
\begin{aligned}
B_{t+1} & =\Delta V \\
& =V_{t+1}-V_{t} \\
& =\theta\left(S_{t+1}-S_{t}\right)-\lambda\left(F_{t+1}-F_{t}\right) \\
& =\theta \Delta S-\lambda \Delta F .
\end{aligned}
$$

A relação entre a quantidade de contratos futuros e contratos à vista é denominada razão de hedge, $h=\frac{\lambda}{\theta}$. Logo, $B_{t+1}=\theta(\Delta S-h \Delta F)$.

Na teoria tradicional, a razão de hedge era considerada como sendo sempre igual a 1, pois postulava que as variações nos preços à vista e futuro tendem a ser iguais em valor absoluto. Esperava-se, portanto, que o valor da base fosse zero em um hedge perfeito. Como o mundo real não é perfeito e os preços não variam simultaneamente em paralelo, esperava-se pelo menos que a oscilação da base fosse significantemente inferior à variação 
da posição descoberta $B<<\theta \Delta S$. Por conta dessa premissa, a teoria tradicional é atualmente qualificada como ingênua (naive).

Johnson (1960, p. 144) apresenta como forma de medir o desempenho do hedge na teoria tradicional a relação entre a variação absoluta do preço (ganho ou perda de uma posição descoberta) e a variação da base (ganho ou perda de uma posição de hedge), e apresenta como forma de medir o risco o valor absoluto da variação do preço. Já Working (1953b, p. 544) também faz referência à forma de medir o desempenho do hedge na teoria tradicional, porém pelo grau de correspondência entre mudanças simultâneas nos preços à vista e futuro.

Podemos observar que, embora de grande simplicidade e com uma fragilidade a ponto de ser considerada ingênua, a teoria tradicional é um conceito de redução de risco que se coaduna com o conceito que adotamos na discussão inicial do trabalho.

\subsection{A hipótese de Working}

Working (1953a, p. 314-343) e Working (1953b, p. 544-561), mostram os resultados de diversos trabalhos de observação das operações no mercado de commodities, principalmente na bolsa de Chicago (Chicago Board of Trade). Essas operações combinavam posições à vista e futuras, principalmente em grãos e farinha de trigo, realizadas por produtores, moinhos e intermediários.

Working (1953a, p. 548-549) critica a teoria tradicional, principalmente em relação à suposição de que preços à vista e futuro devem ter variações absolutas iguais. Segundo ele essa suposição é teórica, pois na prática os agentes econômicos, conscientes desse fato, não realizavam operações com a finalidade exclusiva de redução de riscos, mas com expectativas de ganhos. Quando tinham uma expectativa desfavorável de mudança na relação entre preços à vista e futuro, realizavam operações de cobertura de riscos e quando tinham uma expectativa favorável, mantinham posições descobertas. Analisando essas operações e suas motivações, Working (1953a, p. 326) conceitua hedge com contratos futuros de commodities como sendo uma operação de compra ou venda de contratos 
futuros, em conjunto com outro compromisso, na expectativa de uma mudança favorável na relação entre preços à vista e futuros. Working (1953b, p. 555) complementa o trabalho anterior, aprofundando a análise e conceituando hedge como um suporte para a realização de uma operação de compra e venda eficiente e lucrativa.

Essa mudança do foco na correlação entre preços à vista e futuro da teoria tradicional para o foco na relação entre preços à vista e futuro, juntamente com as definições apresentadas, caracterizam o hedge como uma operação de arbitragem, pois busca tirar proveito da identificação de um desequilíbrio entre os preços à vista e futuro.

Uma das operações descritas no trabalho era realizada pelos moinhos, que não utilizavam a compra de trigo futuro como proteção contra variações de preço. Imediatamente após cada venda de farinha, compravam trigo futuro como substituto temporário para uma compra de trigo à vista para um novo ciclo de produção. De posse dos contratos futuros, buscavam oportunidades de compra de trigo à vista explorando uma relação favorável entre preço à vista e futuro, para em seguida desfazer-se da posição em futuros.

Working (1953a, p. 342) qualifica diretamente o hedge como uma operação de arbitragem. Essa visão não corresponde à conceituação atual do hedge.

\subsection{A teoria de carteira e hedge}

Notação:

$S_{t}$ : posiçãa à vista.

$\Delta S$ : variação da posição à vista.

$F_{t}:$ posição futura.

$\Delta F$ : variação da posição descoberta futura.

$\theta$ : quantidades de contratos à vista.

$\lambda$ : quantidades de contratos futuros.

$U_{t}$ : posição descoberta.

$B_{t}$ : base. 
$\sigma_{S}^{2}$ : variância da posição à vista.

$\sigma_{F}^{2}$ : variância da posição futura.

$\sigma_{S F}$ : covariância entre a posição à vista e a posição futura.

$\rho_{S F}$ : coeficiente de correlação entre a posição à vista e a posição futura.

$e$ : indicador de efetividade do hedge.

Johnson (1960, p. 142) argumenta que a Hipótese de Working explica o comportamento dos agentes econômicos nas situações em que eles decidem por fazer hedge ou não fazer hedge, dependendo de sua avaliação a respeito da possibilidade de arbitrar no mercado. Mas não explica situações que também podiam ser observadas, em que os agentes econômicos mantinham posições parciais de hedge, mostrando uma preocupação com expectativas de mudanças nos valores absolutos dos preços, não na relação entre os preços à vista e futuro. Para explicar esse fato, Johnson (1960, p. 142-150) propõe uma nova visão do hedge. Segundo essa visão, os agentes econômicos realizam operações de hedge com os mesmos princípios que regem a formação de carteiras, $i . e$., suas expectativas de otimização da combinação retorno e risco.

A operação de hedge é descrita como uma carteira composta por duas posições, uma no mercado à vista e outra no mercado futuro, sobre o mesmo ativo.

Seja a posição à vista inicial $S_{t}$, a posição à vista final $S_{t+1}$, a posição futura incial $F_{t}$ e a posição futura final $F_{t+1}$.

O retorno esperado e a variância de uma posição descoberta $U$ de $\theta$ contratos à vista são dados por: 


$$
\begin{gathered}
\begin{array}{c}
U_{t+1}=\theta\left(S_{t+1}-S_{t}\right) \\
=\theta \Delta S
\end{array} \\
E_{t}\left[U_{t+1}\right]=\theta E_{t}[\Delta S] \\
\operatorname{Var}_{t}\left[U_{t+1}\right]=\theta^{2} \sigma_{S}^{2} .
\end{gathered}
$$

O retorno esperado e a variância de uma posição de hedge $B$ são dados por:

$$
\begin{gathered}
B_{t+1}=\theta\left(S_{t+1}-S_{t}\right)+\lambda\left(F_{t+1}-F_{t}\right) \\
=\theta \Delta S+\lambda \Delta F \\
E_{t}\left[B_{t+1}\right]=\theta E_{t}[\Delta S]+\lambda E_{t}[\Delta F] \\
\operatorname{Var}_{t}\left[B_{t+1}\right]=\theta^{2} \sigma_{S}^{2}+\lambda^{2} \sigma_{F}^{2}+2 \theta \lambda \sigma_{S F} .
\end{gathered}
$$

Estabelecendo a condição de primeira ordem para obtenção da quantidade de contratos futuros que minimiza a variância da posição de hedge:

$$
\begin{aligned}
& \frac{\partial \operatorname{Var}_{t}\left[B_{t+1}\right]}{\partial \lambda}=0 \\
& \lambda^{*}=-\frac{\theta \sigma_{S F}}{\sigma_{F}^{2}} .
\end{aligned}
$$

A variância mínima da posição de hedge é então dada por:

$$
\operatorname{Var}_{t}^{*}\left[B_{t+1}\right]=\theta^{2}\left(\sigma_{S}^{2}-\frac{\sigma_{S F}^{2}}{\sigma_{F}^{2}}\right)
$$

Johnson (1960, p. 144) propõe uma avaliação da efetividade do hedge ex ante facto, pela consideração da razão entre a variância ótima da posição de hedge e a variância da posição 
descoberta, propondo o quadrado do coeficiente de correlação entre preços à vista e futuros como indicador da efetividade:

$$
\begin{aligned}
& e^{*} \equiv 1-\frac{\operatorname{Var}_{t}{ }^{*}\left[B_{t+1}\right]}{\theta^{2} \sigma_{S}^{2}} \\
& e^{*}=1-\frac{\theta^{2}\left(\sigma_{S}^{2}-\frac{\sigma_{S F}^{2}}{\sigma_{F}^{2}}\right)}{\theta^{2} \sigma_{S}^{2}}=1-\frac{\sigma_{S}^{2} \sigma_{F}^{2}-\sigma_{S F}^{2}}{\sigma_{S}^{2} \sigma_{F}^{2}}=\frac{\sigma_{S F}^{2}}{\sigma_{S}^{2} \sigma_{F}^{2}}=\rho_{S F}^{2} .
\end{aligned}
$$

Johnson (1960, p. 144) argumenta que essa perspectiva de avaliação da efetividade do hedge ex ante facto, frente à avaliação somente ex post facto da Teoria Tradicional e da Hipótese de Working, constitui a principal diferenciação conceitual. Faltou um complemento no trabalho, pois essa avaliação ex ante facto não é realmente uma medida de desempenho, mas um critério para estruturação da operação supostamente ótima. Uma real avaliação do desempenho, para efeitos comparativos, somente pode ser realizada $e x$ post facto, sobre os resultados obtidos com a estratégia.

O trabalho estabelece um novo paradigma, segundo o qual o hedge passa a ser completamente avaliado em relação à expectativa de comportamento dos preços, descrita por suas características de retorno esperado e variância. É importante observar, como ressaltado em Johnson (1960, p. 144), que a carteira não deve necessariamente ter retorno esperado nulo para que o hedge seja considerado perfeito. O hedge perfeito é aquele que resulta na melhor previsão da correlação entre os preços à vista e futuro.

Consolida-se assim um conceito de hedge como especulação, em que a operação é estruturada segundo a expectativa de um movimento de preços, buscando-se minimizar o risco incorrido. Essa visão não corresponde à conceituação atual do hedge, conforme destacam Farhi (1999 p. 93-114) e Duffie (1989, p. 205) e como veremos no desenvolvimento de Cerny (2004 p. 1-54). 


\subsection{A visão contemporânea}

Podemos agregar às teorias de hedge descritas mais uma teoria que denominamos teoria contemporânea, descrita em Cerny (2004 p. 1-54). Nesta teoria já estão embutidos todos os conceitos que possibilitam uma generalização da definição de uma operação de hedge.

Segundo essa teoria as operações de hedge, quaisquer que sejam sua natureza, complexidade e quantidade de elementos envolvidos, critérios de otimização ou redução de risco e métodos de cálculo, são todas combinações de um mesmo princípio básico: a replicação do rendimento de um ativo, denominado ativo-objeto, através de uma combinação linear de outros ativos, denominados ativos-base.

O objetivo da estratégia de hedge é a melhor replicação possível, de tal forma que o risco seja minimizado segundo algum critério, pela adoção de uma posição comprada ou vendida no ativo-objeto e posições compradas e vendidas nos ativos-base que compõem uma carteira replicante de rendimentos.

Uma das formas mais comuns de estabelecimento de transações compensatórias é o estabelecimento de posições contrárias, comprada e vendida nos mercados à vista e futuro, sobre um mesmo ativo, conforme explorado pelas teorias de hedge apresentadas. A teoria aqui denominada contemporânea transcende o o conceito de posições contrárias em mercados à vista e futuro, que é apenas uma possibilidade. Esta constitui a visão clássica de uma operação de hedge, mas a operação pode diferir significativamente desse formato. Basta que ativos tenham preços correlacionados para que a operação de hedge possa ser estruturada sobre ativos de tipos diferentes e em quantidades diferentes, tanto em mercados à vista, quanto em mercados futuros.

A operação de hedge pode ser composta exclusivamente de posições à vista ou futuras, sendo a diferença entre o preço do ativo-objeto e o preço da carteira replicante o fator determinante na otimização do hedge. Evidentemente, a força do paradigma clássico reside em que posições em mercados à vista e futuro sobre um mesmo ativo constituem posições intrinsecamente correlacionadas. 
A teoria contemporânea assemelha-se a um tipo de operação de hedge que anteriormente já havia sido avaliado, porém sem aprofundamento. Trata-se do cross-hedging, que aparece em Working (1953a, p. 341-342), que relata que negociantes de cevada no mercado à vista estruturavam operações de hedge no mercado futuro de milho. Buscavam os benefícios de alta liquidez e menores custos de transação do milho, aproveitando-se da alta correlação entre os preços da cevada e do milho. O cross-hedging era visto como uma solução alternativa e não como uma estratégia com uma carteira replicante composta por somente um ativo-base e um ativo-objeto.

A visão contemporânea, conforme exposto em Cerny (2004 p. 1-54), distante do paradigma teórico e tecnológico das décadas de 50, 60 e 70 expressos nos trabalhos analisados, carrega um salto de sofisticação conceitual e matemática ocorridos nas décadas seguintes, que serão apresentados e utilizados no desenvolvimento do trabalho.

Somente para contrastar os trabalhos do período seguinte com a simplicidade das teorias apresentadas, cujos fundamentos não foram além dos conceitos básicos de probabilidade e cálculo, o arsenal teórico aportado à avaliação das estratégias de hedge é composto de uma série de fundamentos, alguns dos quais serão utilizados neste trabalho, tais como:

- $\quad$ Modelagem de mercado.

- $\quad$ Distribuições de probabilidade.

- $\quad$ Conceitos de mercado completo e incompleto.

- $\quad$ Espaços vetoriais.

- $\quad$ Equações diferenciais parciais.

- $\quad$ Equações diferenciais estocásticas.

- $\quad$ Teoria martingale.

- $\quad$ Otimização e programação dinâmica.

- $\quad$ Modelagem de séries temporais.

- $\quad$ Teoria da utilidade.

O que ainda não parece muito claro é a adeuação das novas ferramentas à realidade, para que proporcionem ganhos de desempenho, tema que pretendemos explorar neste trabalho. 


\section{PERSPECTIVA TEÓRICA}

O objetivo deste capítulo é apresentar a estrutura teórica que retrata a visão contemporânea do hedge referenciada no capítulo anterior. Consiste na fundamentação de uma modelagem suficientemente generalizada para contemplar todas as formas de hedge possíveis, independente de suas características específicas. Todas as estratégias de hedge analisadas neste trabalho constituem particularizações desta teoria.

Trata-se de uma descrição de um modelo de mercado em tempo discreto, com preços discretos, no qual são construídas operações de hedge. O modelo foi apresentado em Cerny (2004a, p. 1-54).

\subsection{Fundamentação do hedge}

\subsubsection{O Modelo do Mercado}

O mercado é representado por um modelo uniperiódico com número finito de estados, i.e., existem somente dois instantes de tempo, presente e futuro, com uma quantidade finita de estados da natureza ou cenários possíveis de preços que podem ser assumidos pelos ativos financeiros do mercado.

Existe uma distribuição de probabilidades para os preços de cada ativo, que descreve as probabilidades de mudança do estado inicial para os estados finais possíveis.

\subsubsection{Definições}

As definições apresentadas a seguir constituem os conceitos que vinculam o modelo matemático aos componentes e fenômenos do mercado.

- Ativo: qualquer instrumento financeiro disponível no mercado para compra e venda. 
- $\quad$ Carteira: combinação de ativos que define as quantidades que devem ser compradas ou vendidas de cada um.

- $\quad$ Ativo-base: qualquer ativo utilizado para compor uma carteira com o objetivo de replicar o valor de outro ativo.

- $\quad$ Ativo-objeto: qualquer ativo que venha a ter seu valor replicado por uma carteira de ativos-base.

- Estados da Natureza: todos os rendimentos possíveis dos ativos-base ou todos os cenários possíveis de rendimento dos ativos-base.

- $\quad$ Ativos Linearmente Independentes: ativos cujos rendimentos não podem ser reproduzidos por uma combinação linear de ativos-base.

- Ativos Linearmente Dependentes ou Redundantes: ativos que constituem combinações lineares de ativos-base linearmente independentes.

- Carteira Replicante: carteira constituída por uma combinação linear de ativos não redundantes, que tem o mesmo rendimento de uma combinação linear de ativos redundantes.

\subsubsection{Subespaço de Mercado e Subespaço Ampliado}

Notação:

$n$ : quantidade de ativos no mercado.

$m:$ quantidade de estados da natureza.

$\mathbf{A}_{\bullet k}$ : vetor-coluna de rendimentos do $k$-ésimo ativo em $m$ estados da natureza.

$a_{i j}$ : rendimento do $j$-ésimo ativo no $i$-ésimo estado da natureza.

$\mathbf{x}$ : vetor-coluna carteira de quantidades de $n$ ativos.

$r$ : posto da matriz de rendimentos dos ativos do mercado.

O mercado é formado por um conjunto de qualquer quantidade de ativos-base e qualquer quantidade de estados da natureza mercado.

Cada ativo-base é representado por um vetor de rendimentos em numerário em cada estado da natureza possível, resultante da observação do mercado no início e no final do período.

Assim, cada ativo-base é representado por um vetor de estados de rendimentos possíveis: 


$$
\mathbf{A}_{\bullet k}=\left[\begin{array}{llll}
\mathbf{a}_{1 k} & \mathbf{a}_{2 k} & \ldots & \mathbf{a}_{m k}
\end{array}\right]
$$

A matriz formada pelo conjunto dos rendimentos de todos os ativos-base existentes no mercado, incluindo todos os ativos linearmente independentes e redundantes em todos os estados da natureza possíveis representa o mercado.

$$
\mathbf{A}=\left[\begin{array}{llll}
\mathbf{A}_{\bullet 1} & \mathbf{A}_{\bullet 2} & \ldots & \mathbf{A}_{\bullet n}
\end{array}\right]=\left[\begin{array}{cccc}
a_{11} & a_{12} & \ldots & a_{1 n} \\
a_{21} & a_{22} & \ldots & a_{2 n} \\
\cdot & \cdot & \cdot & \cdot \\
\cdot & \cdot & \cdot & \cdot \\
\cdot & \cdot & & \cdot \\
a_{m 1} & a_{m 2} & \ldots & a_{m n}
\end{array}\right]
$$

Um subespaço é o conjunto de todos os vetores possíveis de serem gerados a partir de um conjunto de vetores linearmente independentes.

Seja um vetor-coluna carteira, que representa quantidades de ativos-base $\mathbf{x}^{\dagger}=\left[\begin{array}{llll}x_{1} & x_{2} & \ldots & x_{n}\end{array}\right]$ e uma matriz de rendimentos dos ativos-base $\mathbf{A}_{m \times n}$.

Um conjunto de vetores ou ativos-base é linearmente independente se a única solução para o sistema de equações

$$
\mathbf{A}_{\bullet 1} x_{1}+\mathbf{A}_{\bullet 2} x_{2}+\ldots+\mathbf{A}_{\bullet n} x_{n}=0
$$

é o vetor nulo $\mathbf{x}^{\dagger}=\left[\begin{array}{llll}0 & 0 & \ldots & 0\end{array}\right]$.

O subespaço de dimensão $r$, que corresponde a um subespaço gerado a partir dos ativosbase linearmente independentes de uma matriz de rendimentos $m \times n$, é representado por $\operatorname{span}\left(\begin{array}{llll}\mathbf{A}_{\bullet 1} & \mathbf{A}_{\bullet 2} & \ldots & \mathbf{A}_{\bullet r}\end{array}\right)$, sendo que span é o operador geração do subespaço vetorial a partir dos vetores linearmente independentes. 


$$
\mathbf{A}=\left[\begin{array}{llll}
\mathbf{A}_{\bullet 1} & \mathbf{A}_{\bullet 2} & \ldots & \mathbf{A}_{\bullet r}
\end{array}\right]=\left[\begin{array}{cccc}
a_{11} & a_{12} & \ldots & a_{1 r} \\
a_{21} & a_{22} & \ldots & a_{2 r} \\
\cdot & \bullet & \cdot & \cdot \\
\cdot & \bullet & \cdot & \cdot \\
\cdot & \cdot & & \cdot \\
a_{r 1} & a_{r 2} & \ldots & a_{r r}
\end{array}\right] .
$$

O subespaço do mercado é o subespaço gerado pelos ativos-base linearmente independentes do mercado e sua dimensão é determinada pela quantidade de ativos-base linearmente independentes. Portanto a dimensão do subespaço do mercado é dada pelo posto da matriz de rendimentos que representa o mercado.

O subespaço ampliado é o subespaço de dimensão corrrespondente à quantidade de estados da natureza do mercado.

É importante observar que o subespaço do mercado pode coincidir com o subespaço ampliado ou corresponder a uma parte dele de dimensão inferior.

O ativo-objeto não é integrante do mercado por definição. É um ativo à parte, com a mesma quantidade de estados da natureza dos ativos-base, portanto pertence ao subespaço ampliado, mas que pode ou não pertencer ao subespaço do mercado.

O subespaço do mercado pode ser ilustrado como no gráfico 3.1, sendo que:
$\mathbf{A}_{\cdot 1}=a_{11}+a_{21}+a_{31}$
$\mathbf{A}_{\bullet 2}=a_{12}+a_{22}+a_{32}$
$\mathbf{A}_{\bullet 3}=a_{13}+a_{33}+a_{33}$ 


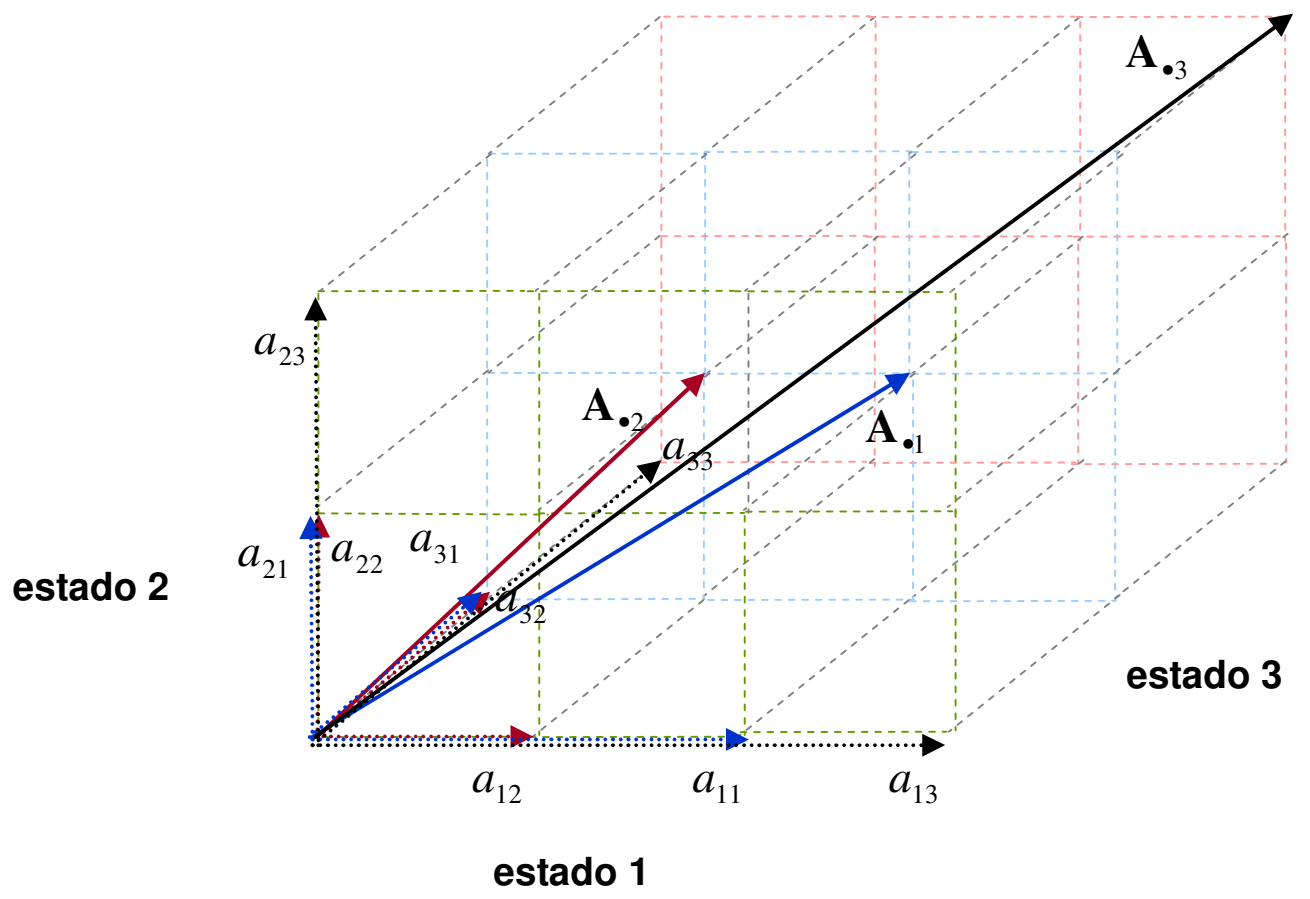

Figura 3.1 - Subespaço do Mercado

\subsubsection{Mercado completo}

O mercado é dito ser completo quando o conjunto de ativos-base linearmente independentes gera todo o subespaço ampliado, i. e., o subespaço de mercado coincide com o subespaço ampliado. Neste caso o ativo-objeto, que tem a mesma dimensão dos ativos-base, faz parte do subespaço do mercado. Num mercado completo, qualquer ativoobjeto pode ter um hedge perfeito, pois qualquer ativo-objeto pode ser replicado através de uma combinação linear de ativos-base.

\subsubsection{Mercado incompleto}

O mercado é dito ser incompleto quando o o conjunto de ativos-base linearmente independentes não gera todo o subespaço ampliado, i. e., o subespaço de mercado tem dimensão inferior ao subespaço ampliado e existem ativos linearmente independentes que não fazem parte do subespaço de mercado. Neste caso o ativo-objeto pode ou não fazer parte do subespaço do mercado. Num mercado incompleto, não existe hedge perfeito, pois um ativo-objeto nem sempre pode ser replicado através de uma combinação linear de ativos-base. 


\subsubsection{Equação fundamental do hedge}

Notação:

$n$ : quantidade de ativos no mercado.

$m$ : quantidade de estados da natureza.

A : matriz de rendimentos $m \times n$ de todos os ativos-base do mercado (excluindo o ativoobjeto).

b : vetor-ativo-objeto $m \times 1$, representando um ativo qualquer do mercado.

$\mathbf{x}$ : vetor-carteira replicante $n \times 1$, representando quantidades de ativos-base.

$r(\mathbf{A})$ : posto da matriz de rendimentos.

Y : matriz de vetores-carteira $\mathbf{y} m \times 1$, representando quantidades de ativos-base.

A equação fundamental do hedge é dada por:

$$
\mathbf{A x}=\mathbf{b} .
$$

A solução da equação fundamental do hedge fornece o vetor-carteira de ativos do mercado que replica os rendimentos do vetor-ativo-objeto.

Em mercado completo a equação fundamental do hedge sempre tem solução. Em mercado incompleto a equação fundamental do hedge em geral não tem solução. A avaliação da solução da equação é realizada através do posto da matriz de rendimentos.

\subsubsection{Hedge em mercado completo}

\subsubsection{1 $m=n$ ativos-base linearmente independentes e $m=n$ estados da natureza}

- Hipótese:

$$
r(\mathbf{A})=m=n \text {. }
$$

O posto da matriz de rendimentos dos ativos é igual à quantidade de ativos do mercado e igual à quantidade de estados da natureza. O mercado é constituído somente por ativos- 
base linearmente independentes e o subespaço do mercado tem a mesma dimensão do subespaço ampliado. O ativo-objeto faz parte do subespaço do mercado.

A matriz A é quadrada de posto completo, sendo, portanto, inversível.

$$
\left[\begin{array}{cccc}
a_{11} & a_{12} & \ldots & a_{1 n} \\
a_{21} & a_{22} & \ldots & a_{2 n} \\
\cdots & \ldots & \ldots & \cdots \\
a_{1 n} & a_{2 n} & \ldots & a_{m n}
\end{array}\right] \cdot\left[\begin{array}{c}
x_{1} \\
x_{2} \\
\ldots \\
x_{n}
\end{array}\right]=\left[\begin{array}{l}
b_{1} \\
b_{2} \\
\ldots \\
b_{m}
\end{array}\right] .
$$

O hedge é dado por um sistema de $m=n$ equações e $m=n$ incógnitas.

$$
\mathbf{x}=\mathbf{A}^{-1} \mathbf{b} .
$$

\section{- Consequência:}

$\mathbf{x}$ tem solução única.

b é redundante e pode ser replicado.

\subsubsection{2 $n-m$ ativos-base redundantes e $m$ estados da natureza}

- Hipótese:

$$
r(\mathbf{A})=m, \quad m<n .
$$

Existem mais ativos-base do que estados da natureza. O mercado é constituído por ativosbase linearmente independentes e ativos-base redundantes e o subespaço do mercado tem a mesma dimensão do subespaço ampliado. O ativo-objeto faz parte do subespaço do mercado.

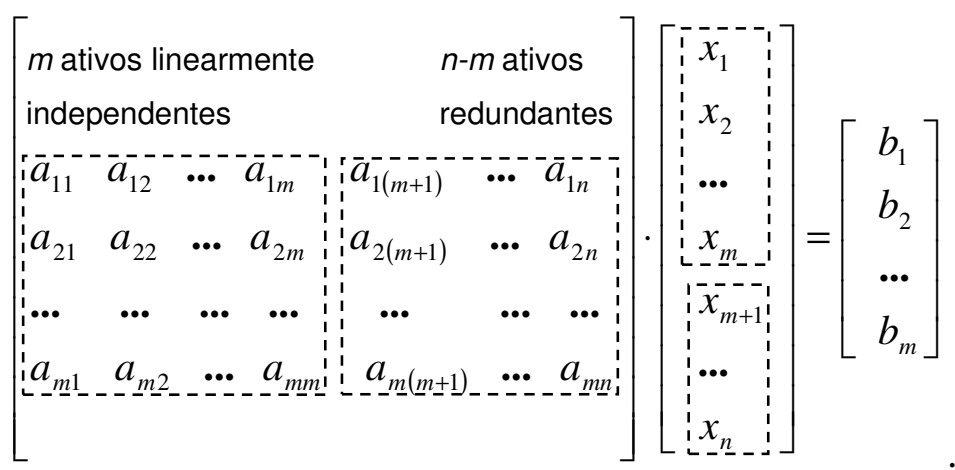


O hedge é dado por um sistema de $m$ equações e $n>m$ incógnitas.

A matriz $\mathbf{A}$ pode ser particionada em duas matrizes ativos $\mathbf{A}_{1} m \times m$ e $\mathbf{A}_{2} m \times n-m$, com ativos linearmente independentes e ativos redundantes respectivamente.

$$
\mathbf{A}=\left[\begin{array}{ll}
\mathbf{A}_{1} & \mathbf{A}_{2}
\end{array}\right]
$$

Como a matriz $\mathbf{A}_{2}$ representa combinações lineares das colunas da matriz $\mathbf{A}_{1}$, existe, portanto, um conjunto de carteiras replicantes de ativos redundantes tais que:

$$
\begin{gathered}
\mathbf{A}_{1} \mathbf{Y}=\mathbf{A}_{2} . \\
{\left[\begin{array}{llll}
a 1_{11} & a 1_{12} & \ldots & a 1_{1 m} \\
a 1_{21} & a 1_{22} & \ldots & a 1_{2 m} \\
\ldots & \ldots & \ldots & \ldots \\
a 1_{m 1} & a 1_{m 2} & \ldots & a 1_{m m}
\end{array}\right] \cdot\left[\begin{array}{llll}
y_{11} & y_{12} & \ldots & y_{1(n-m)} \\
y_{21} & y_{22} & \cdots & y_{2(n-m)} \\
\ldots & \ldots & \cdots & \cdots \\
y_{m 1} & y_{m 2} & \ldots & y_{m(n-m)}
\end{array}\right]=\left[\begin{array}{lll}
a 2_{11} & \ldots & a 2_{1(n-m)} \\
a 2_{21} & \ldots & a 2_{2(n-m)} \\
\ldots & \ldots & \ldots \\
a 2_{m 1} & \ldots & a 2_{m(n-m)}
\end{array}\right] .}
\end{gathered}
$$

Para solucionar a equação fundamental do hedge, o vetor carteira também deve ser particionado de forma correspondente:

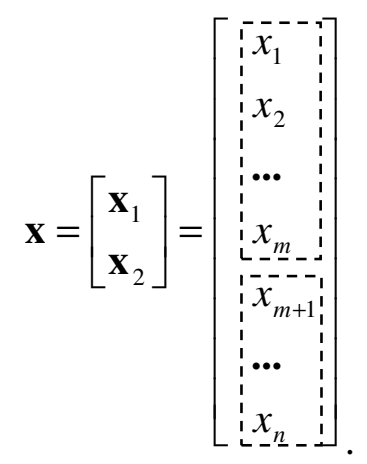


A equação fundamental do hedge torna-se então:

$$
\begin{aligned}
& \mathbf{A} \mathbf{x}=\mathbf{b} \\
& \mathbf{A}_{1} \mathbf{x}_{1}+\mathbf{A}_{2} \mathbf{x}_{2}=\mathbf{b} \\
& \mathbf{A}_{1} \mathbf{x}_{1}+\mathbf{A}_{1} \mathbf{Y} \mathbf{x}_{2}=\mathbf{b} \\
& \mathbf{x}_{1}=\mathbf{A}_{1}{ }^{-1} \mathbf{b}-\mathbf{Y} \mathbf{x}_{2} .
\end{aligned}
$$

- Consequência:

$\mathbf{x}_{1}$ tem infinitas soluções com $n-m$ parâmetros livres (arbitrários) no vetor carteira $\mathbf{x}_{2}$ de ativos redundantes.

b é redundante e pode ser replicado através de infinitas combinações de ativos-base.

\subsubsection{Hedge em mercado incompleto}

\subsubsection{1 $n$ ativos-base linearmente independentes e $m>n$ estados da natureza}

- Hipótese:

$r(\mathbf{A})=n, \quad m>n$.

Existem menos ativos-base do que estados da natureza. O mercado é constituído somente por ativos-base linearmente independentes e o subespaço do mercado tem dimensão inferior ao subespaço ampliado. O ativo-objeto pode ou não fazer parte do subespaço do mercado. 


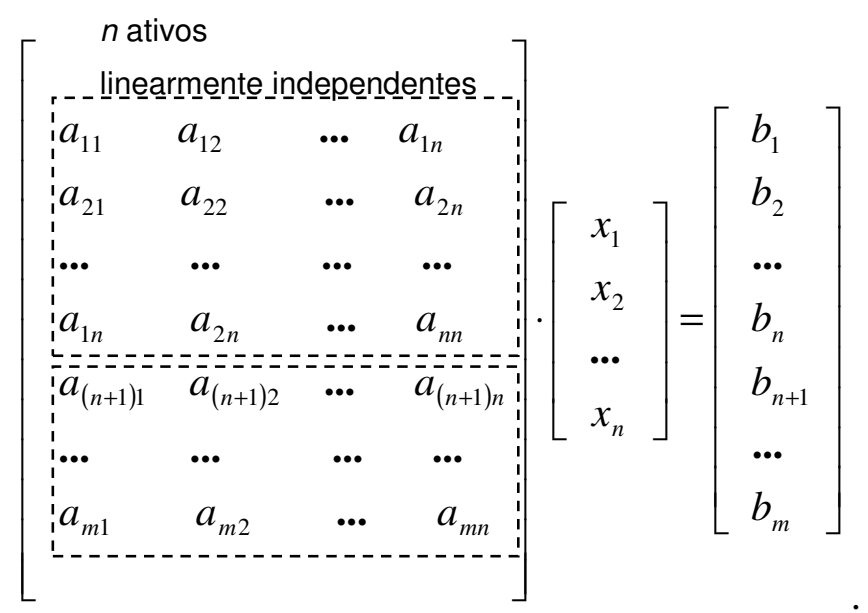

O hedge é dado por um sistema de $m$ equações e $n<m$ icógnitas. Portanto um sistema a princípio sem solução.

A matriz A na equação fundamental do hedge não é inversível, mas como é de posto completo, é possível obter uma matriz inversível através da transformação:

$$
\mathbf{A x}=\mathbf{b}
$$

$$
\begin{aligned}
& \mathbf{A}^{\dagger} \mathbf{A} \mathbf{x}=\mathbf{A}^{\dagger} \mathbf{b} \\
& \mathbf{x}=\left(\mathbf{A}^{\dagger} \mathbf{A}\right)^{-1} \mathbf{A}^{\dagger} \mathbf{b} .
\end{aligned}
$$

- Consequência:

A relação pode ou não ser satisfeita.

Sendo satisfeita,

$\mathbf{x}$ tem solução única.

b pode ser replicado.

Não sendo satisfeita,

x não tem solução.

b não pode ser replicado. 


\subsubsection{2 $n-r(\mathrm{~A})$ ativos-base redundantes e $m>r(\mathrm{~A})$ estados da natureza}

- Hipótese:

$r(\mathbf{A})<m, \quad r(\mathbf{A})<n$.

Existem mais estados da natureza do que ativos-base linearmente independentes e o mercado é composto por ativos-base linearmente independentes e redundantes. $\mathrm{O}$ subespaço do mercado tem dimensão inferior ao subespaço ampliado. O ativo-objeto pode ou não fazer parte do subespaço do mercado e pode ou não fazer parte do subespaço ampliado.

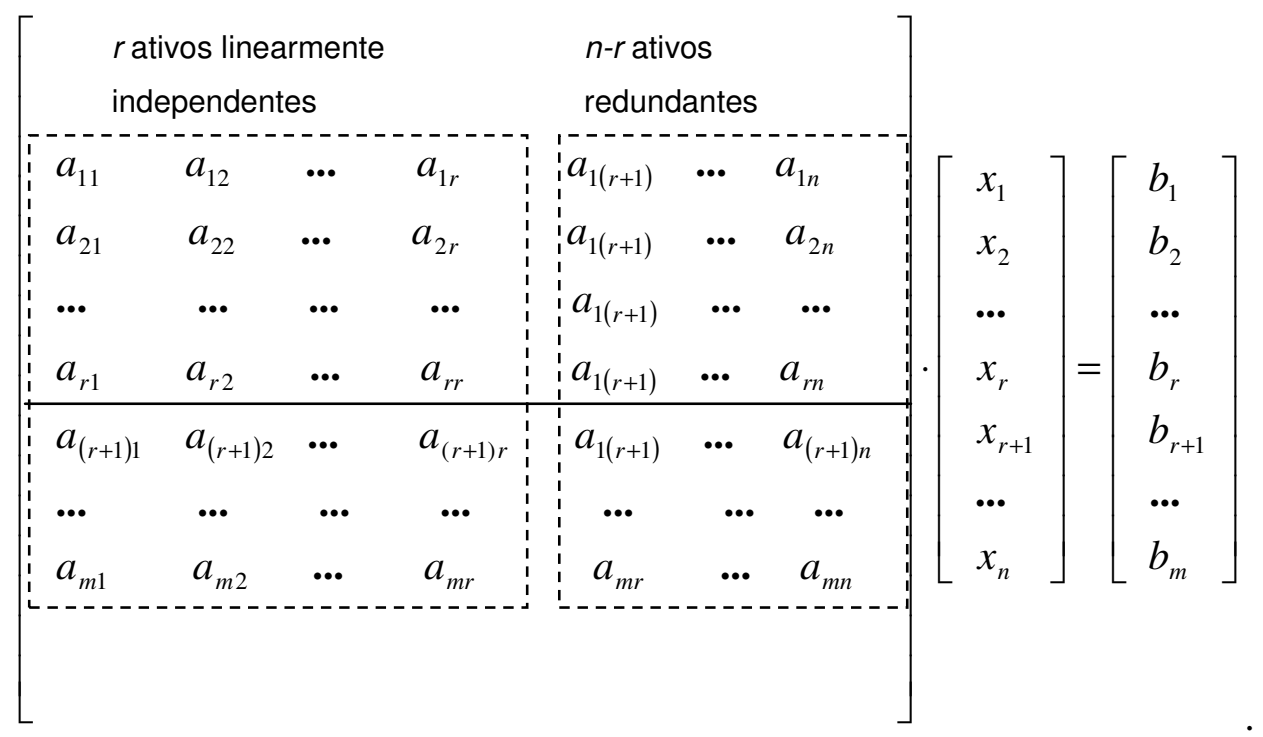

A matriz $\mathbf{A}$ pode ser particionada em duas matrizes $\mathbf{A}_{1}$ com dimensão $m \times r$ e $\mathbf{A}_{2}$ com dimensão $m \times n-r$, com ativos linearmente independentes e ativos redundantes, respectivamente.

$$
\mathbf{A}=\left[\begin{array}{ll}
\mathbf{A}_{1} & \mathbf{A}_{2}
\end{array}\right]
$$

Como a matriz $\mathbf{A}_{2}$ representa combinações lineares das colunas da matriz $\mathbf{A}_{1}$, existe, portanto, um conjunto de carteiras replicantes de ativos redundantes tais que:

$$
\mathbf{A}_{1} \mathbf{Y}=\mathbf{A}_{2}
$$


Para solucionar a equação fundamental do hedge, o vetor carteira também deve ser particionado de forma correspondente:

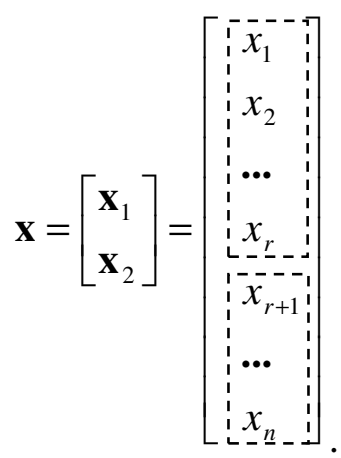

A equação fundamental do hedge torna-se então:

$$
\mathbf{A x}=\mathbf{b}
$$

$$
\mathbf{A}_{1} \mathbf{x}_{1}+\mathbf{A}_{2} \mathbf{x}_{2}=\mathbf{b}
$$

Como $\mathbf{A}_{2}=\mathbf{A}_{1} \mathbf{Y}$, então:

$$
\begin{aligned}
& \mathbf{A}_{1} \mathbf{x}_{1}+\mathbf{A}_{1} \mathbf{Y} \mathbf{x}_{2}=\mathbf{b} \\
& \mathbf{A}_{1}\left(\mathbf{x}_{1}+\mathbf{Y} \mathbf{x}_{2}\right)=\mathbf{b} .
\end{aligned}
$$

Como a matriz $\mathbf{A}_{1}$ não é quadrada, não é inversível, mas como é de posto completo, é possível obter uma matriz inversível através da transformação:

$$
\begin{aligned}
& \mathbf{A}_{1}{ }^{\dagger} \mathbf{A}_{1}\left(\mathbf{x}_{1}+\mathbf{Y} \mathbf{x}_{2}\right)=\mathbf{A}_{1}^{\dagger} \mathbf{b} \\
& \mathbf{x}_{1}+\mathbf{Y} \mathbf{x}_{2}=\left(\mathbf{A}_{1}^{\dagger} \mathbf{A}_{1}\right)^{-1} \mathbf{A}_{1}{ }^{\dagger} \mathbf{b} \\
& \mathbf{x}_{1}=\left(\mathbf{A}_{1}^{\dagger} \mathbf{A}_{1}\right)^{-1} \mathbf{A}_{1}{ }^{\dagger} \mathbf{b}-\mathbf{Y} \mathbf{x}_{2} .
\end{aligned}
$$

As quantidades de ativos redundantes $\mathbf{x}_{2}$ podem ser tomadas arbitrariamente. 
- Consequência:

A relação pode ser satisfeita.

Sendo satisfeita,

$\mathbf{x}_{1}$ tem infinitas soluções com $n-m$ parâmetros livres (arbitrários) no vetor carteira $\mathbf{x}_{2}$ de ativos redundantes.

b é redundante e pode ser replicado através de infinitas combinações de ativos-base.

Não sendo satisfeita,

$\mathbf{x}_{1}$ não tem solução.

b não pode ser replicado.

\subsubsection{Interpretação do hedge}

A representação do mercado como partição de um subespaço vetorial ampliado possibilita a visualização do problema de replicação de um ativo-objeto a partir da combinação linear de um conjunto de ativos-base. A quantidade de linhas da matriz de rendimentos determina a dimensão do subespaço ampliado e o posto da matriz de rendimentos determina a dimensão do subespaço de mercado. Sempre que o ativo-objeto pertencer a um subespaço vetorial de dimensão superior à dimensão do subespaço ampliado, a replicação não é possivel. O resultado é claro quando observado sob o prisma de que uma combinação linear de vetores de dimensão inferior não pode resultar em um vetor de dimensão superior. Quando o ativo-objeto pode ser replicado, pertence ao subespaço de mercado, de dimensão igual ou inferior ao subespaço ampliado.

\subsection{O erro de hedge}

Em consonância com a perspectiva apresentada podemos concluir que em mercados completos é possível a obtenção de um hedge perfeito. Hedge perfeito, conforme Siqueira (1999, p. 86), é aquele que elimina totalmente a possibilidade de flutuações do preço de uma carteira, i. e., a carteira tem valor constante independente da flutuação dos preços dos ativos. 
Mas mercado completo é uma abstração e uma operação de hedge nunca é perfeita, estando sempre sujeita a um desvio ou erro, que se traduz em risco para a operação de hedge. Os mercados financeiros são na realidade incompletos, conforme aponta Cerny (2004a, p. 267). Em mercados incompletos, como visto, a equação fundamental do hedge não tem solução, pois o ativo-objeto não pode ser replicado por uma combinação linear de ativos-base, $i$. e., não faz parte do subespaço vetorial gerador do mercado, mas de um subespaço de maior dimensão.

O problema que se coloca então é, em não sendo possível uma solução para a equação fundamental do hedge, como buscar a melhor solução aproximada. Dados um vetor de rendimentos de um ativo-objeto, uma matriz de rendimentos de ativos-base e um vetorcarteira, a desigualdade observada na equação fundamental do hedge constitui o erro de replicação. A melhor solução de hedge é o vetor-carteira-replicante que minimiza esse erro de replicação segundo algum critério.

Da equação fundamental do hedge podemos derivar a equação do erro de replicação:

$$
\begin{aligned}
& \mathbf{A x} \neq \mathbf{b} \\
& \boldsymbol{\varepsilon}=\mathbf{b}-\mathbf{A x} .
\end{aligned}
$$

O erro de replicação pode ser avaliado pela distância entre o vetor que representa a carteira replicante e o vetor que representa o ativo-objeto, medida no subespaço vetorial do ativoobjeto, que tem dimensão maior do que o subespaço vetorial dos ativos-base.

Uma distância possível é a norma do vetor de erro, que corresponde à soma dos quadrados dos erros.

$$
S S R E=\|\boldsymbol{\varepsilon}\|^{2}=\boldsymbol{\varepsilon}^{\dagger} \boldsymbol{\varepsilon}
$$

A minimização do erro introduzido na equação fundamental do hedge torna-se um problema de mínimos quadrados ordinários em que: 


$$
\left(\mathbf{A}^{\dagger} \mathbf{A}\right)^{-1} \mathbf{A}^{\dagger} \mathbf{b}=\arg \min _{\mathbf{x}} S S R E=\arg \min _{\mathbf{x}} \boldsymbol{\varepsilon}^{\dagger} \boldsymbol{\varepsilon} .
$$

Sendo que:

$$
\boldsymbol{\varepsilon}=\mathbf{b}-\mathbf{A} \mathbf{x}
$$

Podemos visualizar o problema de mínimos quadrados ordinários no gráfico 3.2. O erro mínimo é um vetor ortogonal ao subespaço vetorial da carteira replicante, o que remete às conclusões do item anterior de que em mercado incompleto o ativo-objeto b pertence a um subespaço vetorial de dimensão superior ao subespaço vetorial dos ativos-base $\mathbf{A}$, cuja combinação linear se propõe a aproximar o ativo-objeto.

$$
\mathbf{x}^{*}=\arg \min _{\mathbf{x}} \operatorname{SSRE} \quad \Rightarrow \quad\left(\mathbf{A} \mathbf{x}^{*}\right)^{\dagger} \boldsymbol{\varepsilon}=0
$$

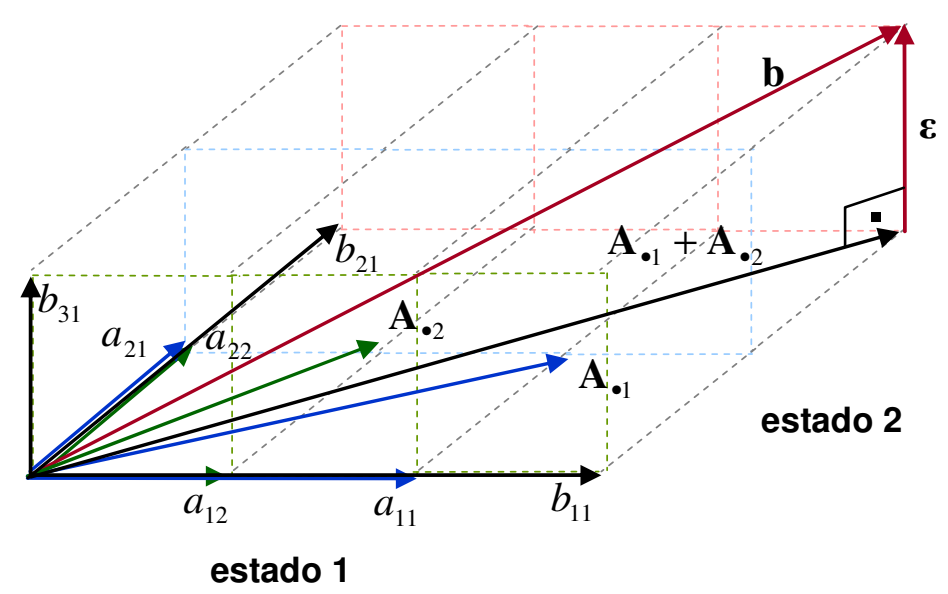

Subespaço de Mercado

Subespaço do Ativo Objeto

dimensão 2

dimensão 3
$\mathbf{A}=\left[\begin{array}{ll}\mathbf{A}_{\bullet 1} & \mathbf{A}_{\bullet 2}\end{array}\right]$
$\mathbf{A}_{\bullet 1}=a_{11}+a_{21}$
$\mathbf{A}_{\cdot 2}=a_{12}+a_{22}$
$\mathbf{b}=\left[\begin{array}{l}b_{11} \\ b_{21} \\ b_{31}\end{array}\right]$

Figura 3.2 - Erro de Replicação

Até este momento, a incerteza foi tratada pela representação dos possíveis estados da natureza que definem os rendimentos dos ativos. Os estados da natureza podem ser interpretados como cenários possíveis de resultado. Em mercado completo, no qual hedge 
é perfeito, o risco pode ser completamente neutralizado e suas características tornam-se irrelevantes.

Em mercado incompleto, essas características, representadas pela distribuição de probabilidades dos estados da natureza, que representam cenários possíveis, passam a desempenhar um papel fundamental. A otimização do hedge deixa de ser a minimização do erro de replicação e assume sua verdadeira forma, que é a de minimização do risco. Consequentemente, o critério de otimização do hedge depende de uma definição de risco e de preferências em relação ao risco.

Tomando como critério de minimização do risco a minimização do erro quadrático esperado de hedge, temos:

$$
\begin{aligned}
\min _{x} E S R E & =p_{1} \varepsilon_{1}^{2}+p_{2} \varepsilon_{2}^{2}+\ldots+p_{m} \varepsilon_{m}^{2} \\
& =\sum_{i=1}^{m} p_{i} \varepsilon_{i}^{2} \\
\min _{\mathbf{x}} \operatorname{ESRE} & =\left(\sqrt{p_{1}} \varepsilon_{1}\right)^{2}+\left(\sqrt{p_{2}} \varepsilon_{2}\right)^{2}+\ldots+\left(\sqrt{p_{m}} \varepsilon_{m}\right)^{2} \\
& =\sum_{i=1}^{m}\left(\sqrt{p_{i}} \varepsilon_{i}\right)^{2} .
\end{aligned}
$$

Como o erro de hedge é dado por:

$$
\begin{aligned}
& \varepsilon_{i}=\mathbf{A}_{i \bullet} \mathbf{x}-b_{i} \\
& \sqrt{p_{i}} \varepsilon_{i}=\sqrt{p_{i}} \mathbf{A}_{i \bullet} \mathbf{x}-\sqrt{p_{i}} b_{i} .
\end{aligned}
$$

Definindo as tranformações de variáveis a seguir, dadas pela ponderação das variáveis pelas respectivas probabilidades: 


$$
\begin{aligned}
& \tilde{\varepsilon}_{i}=\sqrt{p_{i}} \varepsilon_{i} \\
& \tilde{b}_{i}=\sqrt{p_{i}} b_{i} \\
& \tilde{\mathbf{A}}_{i \bullet}=\sqrt{p_{i}} \mathbf{A}_{i \bullet} \\
& \widetilde{\varepsilon}_{i}=\tilde{\mathbf{A}}_{i \bullet} \mathbf{x}-\tilde{b}_{i} .
\end{aligned}
$$

O problema de minimização do erro quadrático esperado passa a ter a forma de um problema de minimização da soma dos quadrados dos erros ponderados pelas probabilidades:

$$
\begin{aligned}
\min _{\mathbf{x}} \operatorname{ESRE}= & p_{1} \varepsilon_{1}^{2}+p_{2} \varepsilon_{2}^{2}+\ldots+p_{m} \varepsilon_{m}^{2} \\
& =\left(\sqrt{p_{1}} \varepsilon_{1}\right)^{2}+\left(\sqrt{p_{2}} \varepsilon_{2}\right)^{2}+\ldots+\left(\sqrt{p_{m}} \varepsilon_{m}\right)^{2} \\
& =\widetilde{\varepsilon}_{1}^{2}+\widetilde{\varepsilon}_{2}^{2}+\ldots+\widetilde{\varepsilon}_{m}^{2} .
\end{aligned}
$$

Com a ponderação dos erros, o problema volta a ter a forma de um problema de mínimos quadrados ordinários em que:

$$
\begin{aligned}
& \min _{\mathbf{x}} \operatorname{ESRE}=\min _{\mathbf{x}} \operatorname{SSRE} \\
& S S R E=\widetilde{\varepsilon}_{1}^{2}+\widetilde{\varepsilon}_{2}^{2}+\ldots+\widetilde{\varepsilon}_{m}^{2} .
\end{aligned}
$$

Nesse caso a minimização ocorre pela ortogonalização do erro em relação ao plano dos rendimentos:

$$
\underset{\mathbf{x}}{\arg \min } \operatorname{SSRE} \quad \Rightarrow \quad\left(\tilde{\mathbf{A}} \mathbf{x}^{*}\right)^{\dagger} \widetilde{\mathbf{\varepsilon}}=0
$$




$$
\mathbf{x}^{*}=\left(\tilde{\mathbf{A}}^{\dagger} \tilde{\mathbf{A}}\right)^{-1} \tilde{\mathbf{A}}^{\dagger} \tilde{\mathbf{b}}
$$

A solução é a mesma de um cenário sem incertezas, porém os estados da natureza estão ponderados pelas probabilidades de ocorrência.

\subsection{A modelagem do hedge}

Na definição de Kenourgios, Panagiotis e Samitas (2005, p. 4), a razão de hedge consiste na razão entre a quantidade de unidades negociadas no mercado futuro e a quantidade de unidades negociadas no mercado à vista.

Koziol (1990, p.11-15) define como processo primário do hedge a conversão do risco no nível de preço, entendido como a incerteza na variação dos preços, em um risco mais estreito no nível da base, entendida como a relação matemática entre os preços do ativoobjeto e dos ativos-base. Koziol (1990, p. 39), estabelece que a base pode ser determinada por diferença, razão ou mesmo estipulado segundo algum critério específico.

$\mathrm{Na}$ abordagem deste trabalho, podemos definir a base como o erro absoluto de hedge e a razão de hedge como as quantidades de ativos-base a serem incluídos na carteira replicante.

Definimos estratégia, para os fins deste trabalho, como o método utilizado para o cálculo do hedge, ou mais especificamente da razão de hedge. Essa é uma ligeira ampliação da definição de estratégia utilizada na literatura, que corresponde às quantidades de ativos incluídos na carteira de hedge.

Baxter e Rennie (2000, p. 80) define estratégia como as quantidades de ativos mantidas em determinado instante de tempo. É uma especificação de carteira em determinado instante de tempo. Uma estratégia alterada ao longo do tempo é denominada estratégia dinâmica. 
Toda a fundamentação do hedge apresentada até agora baseia-se em um modelo de mercado uniperiódico. A abordagem em mercado multiperiódico requer uma estratégia dinâmica. Uma característica desejável da estratégia de hedge dinâmica é que ela seja autofinancável. Baxter e Rennie (2000, p. 80) define estratégia autofinanciável como uma carteira em que alterações no seu valor são devidas somente a alterações no valor de seus componentes, sem fluxos de caixa entrantes ou saintes.

Nandi and Waggoner (2000, p. 27) observa que uma carteira replicante perfeita, em mercado completo, é sempre autofinanciável. Uma vez construída, não requer fluxos de caixa entrantes ou saintes durante sua vigência. Mas em mercado incompleto a condição de autofinanciabilidade em geral é uma imposição na otimização do hedge.

$\mathrm{Na}$ fundamentação do hedge apresentada, não foi dado tratamento à dinâmica dos preços. Assumimos simplesmente uma distribuição de probabilidades de rendimentos dos ativos associada à matriz de rendimentos correspondentes aos possíveis estados da natureza. Também não consideramos a existência de relações pré-estabelecidas entre os preços dos ativos, como no caso de derivativos.

As formas de representação da dinâmica dos preços constituem uma das razões que conduzem à diversidade de estratégias e critérios de otimização do erro de hedge. Essa dinâmica pode ser representada por processos estocásticos, contínuos ou discretos.

Koziol (1990, p. 6-9) considera os seguintes fatores como essenciais na modelagem do hedge:

- $\quad$ O tempo, que identifica a distância temporal entre decisões e ações.

- $\quad$ A taxa de juros que determina o custo de carregamento das posições.

- A volatilidade, representada na dinâmica dos preços, que é o potencial de mudança nas condições da operação.

Segundo ele, a interação e influência mútua entre esses três componentes é a essência refletida pelas estratégias de hedge.

Mas o componente central resultante da modelagem do hedge é o erro de hedge. Galai (1983), apud Dumas, Fleming e Whaley (1998, p. 2088-2089), interpreta o erro de hedge como sendo oriundo de três fatores: 
- $\quad$ O retorno livre de risco da carteira de hedge. Esse fator é facilmente eliminado pelo uso de valores descontados à taxa livre de risco.

- $\quad$ O modelo de precificação da opção não caracteriza adequadamente o processo real de preços devido às simplificações assumidas. Esse fator refere-se às premissas de distribuição de preços na modelagem de retornos, assimetria, curtose e à premissa de mercado perfeito.

- $\quad$ O modelo de precificação pode assumir que o ajuste do hedge é contínuo no tempo, quando na realidade somente pode ser realizado em intervalos discretos. Esse fator está diretamente vinculado à premissa de mercado completo de alguns modelos.

O tratamento do erro de hedge implica a determinação de critérios de otimização. No cálculo do melhor hedge, apresentado anteriormente na fundamentação do hedge, o método escolhido foi a minimização do erro quadrático esperado em uma estratégia uniperiódica, mas não existe critério universal.

Cont e Tankov (2004, p. 350) relaciona métodos de precificação, métodos de hedge e critérios de risco. Entre os métodos de hedge, cita superhedging, que consiste no cálculo de limites de oscilação do hedge que determinam o hedge perfeito, a maximização da utilidade esperada, que incorpora as preferências do investidor, média-variância, que é a minimização do erro quadrático esperado de hedge e seleção de uma medida martingale ótima, mínima ou minimizadora da entropia relativa.

Independente do tratamento, a otimização do erro de hedge compõe o núcleo da modelagem de uma estratégia. Koziol (1990, p.15) observa que, matematicamente, a estratégia de hedge é uma tarefa de solução de um problema de otimização multivariado.

Por fim, é necessário avaliar a eficácia do hedge, pois a essência da avaliação das estratégias de hedge é a avaliação do erro de hedge. Kenourgios, Panagiotis e Samitas (2005, p. 4), define o desempenho do hedge como a capacidade da estratégia de compensar as variações nos preços do ativo-objeto e dos ativos-base. Koziol (1990, p. 13) é um pouco mais específico e sugere que o grau de eficiência do hedge pode ser avaliado pela comparação entre o risco no nível de preço e o risco no nível da base. 
Aqui cabe separar a avaliação da eficácia do hedge ex ante facto, que é determinada pelo critério de otimização utilizado na busca da melhor estratégia de hedge frente à incerteza, da avaliação da eficácia ex post facto, que é a avaliação do resultado obtido pela estratégia utilizada. Neste trabalho fazemos uma comparação ex post facto, analisando as razões teóricas que podem levar a diferenças de desempenho, dadas as informações e características incorporadas na otimização ex ante facto. No tratamento da eficácia ex post facto é que são necessários os estudos comparativos, pois não há outra forma de avaliação mais significativa do que o teste das estratégias para avaliação do erro de hedge resultante.

Um dos problemas na avaliação comparativa de estratégias é que para uma mesma estratégia, não existe uma solução única ou um conjunto único ou ótimo de ativos-base que devam ser incluídos no hedge. Os resultados não dependem somente da estratégia, mas também dos critérios utilizados na sua implementação.

Com base no exposto, podemos descrever o processo de modelagem do hedge como composto pelas seguintes etapas:

- $\quad$ Especificação do risco que se quer minimizar e definição do ativo-objeto que o representa.

- $\quad$ Definição dos ativos-base correlacionados, que se deseja utilizar para minimização do risco. Essa especificação requer uma análise prévia de correlação de preços dos ativos-base com o ativo-objeto.

- $\quad$ Especificação de modelos matemáticos que representem a dinâmica dos preços dos ativos com suas distribuições de probabilidade associadas.

- $\quad$ Estabelecimento de um critério de otimização do hedge.

- Derivação da estratégia para cálculo do hedge.

- $\quad$ Estabelecimento de um critério de avaliação de desempenho.

\subsection{Operações de hedge}

Agora, já de posse de conceitos mais específicos, podemos fazer definições de hedge e de operações de hedge e classificá-las. 


\section{Definição: Hedge}

Redução do risco de variação de preço de um ativo em uma operação financeira, estabelecendo transações compensatórias que exploram correlações nos preços dos ativos e neutralizam retornos, por meio da construção de uma carteira replicante autofinanciável dos rendimentos de um ativo-objeto, através da combinação linear de ativos-base.

\section{Definição: Operação de Hedge}

Tomada de posições compradas ou vendidas em ativos financeiros para formação de um hedge contra o risco de mercado, estruturadas segundo determinada estratégia.

\subsection{Classificação das operações de hedge}

Wilmott (2001, p. 186-188) classifica os tipos de hedge quanto aos fatores de sensibilidade, quanto à vinculação a um modelo de variação de preços de ativos e quanto à administração da operação.

Classificação quanto aos fatores de sensibilidade:

- $\quad H e d g e$ pelo Delta

Hedge que busca eliminar a sensibilidade de uma carteira a variações no preço dos ativosbase.

- Hedge pelo Gama

Hedge que busca eliminar a sensibilidade de uma carteira a variações na taxa de variação do preço dos ativos-base. O hedge pelo gama busca neutralizar a sensibilidade do hedge pelo delta, tendo, portanto, a função de reduzir a frequência de ajuste da carteira replicante composta pelos ativos-base.

\section{- $\quad$ Hedge pelo Vega}

Hedge que busca eliminar a sensibilidade de uma carteira a variações na volatilidade do preço dos ativos-base.

Wilmott (2001, p. 187) observa que a sensibilidade pode ser considerada em relação a variáveis do modelo, mas não em relação a parâmetros que são, por definição, fixos. O hedge pelo vega, portanto, somente é consistente em teorias em que a volatilidade é 
variável, o que exclui o modelo BSM, embora na prática seja possível o tratamento do hedge pelo vega violando as premissas do modelo.

- Hedge pelo Teta

Hedge que busca eliminar a sensibilidade de uma carteira à passagem do tempo. O preço do ativo-objeto pode variar, mesmo que não haja movimento no preço dos ativos-base. Da mesma forma que o hedge pelo vega, não é consistente com o modelo BSM.

\section{- $\quad$ Hedge pelo Rô}

Hedge que que busca eliminar a sensibilidade de uma carteira a variações no preço do ativo livre de risco. Da mesma forma que o hedge pelo vega, não é consistente com o modelo BSM.

Classificação quanto à vinculação a um modelo de dinâmica de preços:

- $\quad$ Hedge Independente de Modelo

Existe uma relação direta entre os preços dos ativos. A relação é completamente independente do mecanismo de variação do valor do ativo subjacente. Um exemplo é a paridade entre opções de compra e venda, em que não é necessária a especificação da dinâmica do ativo.

\section{- $\quad$ Hedge Dependente de Modelo}

A estratégia de hedge depende do modelo do comportamento do valor do ativo-base. O exemplo paradigmático é o modelo BSM.

Classificação quanto à administração da posição:

\section{- $\quad$ Hedge Estático}

O hedge é estabelecido e mantido inalterado até a expiração do prazo de vigência do hedge.

\section{Hedge Dinâmico}

O hedge é continuamente monitorado e freqüentemente ajustado por meio da compra ou venda dos ativos-base, até a expiração do prazo de vigência do hedge. A frequiência pode ser contínua ou discreta, dependendo do modelo e da análise em questão, sendo que a freqüência de ajuste contínua é uma abstração teórica. Na prática o ajuste do hedge dinâmico é sempre discreto.

Whalley e Wilmott (1999, p. 2) sub-divide o hedge dinâmico de acordo com o momento de ajuste do hedge, que pode ser baseado no tempo, caso em que o ajuste é realizado em 
instantes de tempo pré-estabelecidos, ou baseado em valor, caso em que o ajuste é realizado na ocorrência de um desvio de valor superior a um limite pré-estabelecido.

Koziol (1990, p. 4-6), ao definir os instrumentos de hedge, sugere uma classificação quanto ao instrumento de hedge. Segundo ele, os principais instrumentos de hedge são:

\section{- $\quad$ Arranjos Contratuais}

Contratos não padronizados de compra e venda a serem liquidados em data futura, especificados segundo termos próprios e com penalidades específicas para não cumprimento, em que ambas as partes estão expostas a riscos.

- Contratos a Termo

Contratos de compra e venda de ativos financeiros e não financeiros a serem liquidados em data futura, conforme especificação, não padronizados, mas que seguem convenções usuais no mercado.

\section{- $\quad$ Contratos Futuros}

Contratos de compra e venda de ativos financeiros e não financeiros a serem liquidados em data futura, padronizados quanto a quantidades, qualidade, datas, prêmios e descontos e procedimentos de liquidação, negociados em bolsa, que assume os riscos da transação.

- Contratos de Opções

Contratos padronizados, negociados em bolsa ou não, em que o comprador adquire o direito, mas não a obrigação, de exercer a compra ou venda de um ativo em data futura a um preço pré-estabelecido.

Farhi (1999, p. 94) classifica o hedge quanto à posição:

\section{- Hedge de Venda}

Posição comprada no mercado à vista e vendida no mercado futuro, que consiste na posse de ativos representados por bens ou recebíveis em divisas associada à venda de contratos futuros ou compra de opção de venda sobre os ativos.

\section{- $\quad$ Hedge de Compra}

Posição vendida no mercado à vista e comprada no mercado futuro, que consiste na posse de dívida em bens ou divisas associada à compra de contratos futuros ou compra de opção de compra sobre os ativos.

A existência do erro de hedge, que descrevemos como resultante do conceito de mercado incompleto, também pode ser interpretada como resultado da não-linearidade entre o preço 
do ativo-objeto e a carteira de ativos-base. É como se houvesse um risco residual, não perfeitamente compensado pelo hedge pelo delta, seja por incompletude do mercado, seja por deficiência do modelo de representação da realidade. Para complementar o hedge pelo delta surgiram as proposições de hedge pelo gama, hedge pelo vega, hedge pelo teta e hedge pelo rô. Essas estratégias, embora possam ser construídas de forma isolada, não tem sentido prático sem o complemento do hedge pelo delta, pois não há porque eliminar a sensibilidade de uma carteira a esses fatores, sem proteção contra a variação de preços.

Também é importante salientar que a forma essencial de hedge é o hedge pelo delta-teta, ques busca eliminar os efeitos da oscilação do preço do ativo-objeto ao longo do tempo, pois o preço somente varia se houver passagem de tempo.

A introdução de um fator adicional à variação de preço na estratégia requer a utilização de ativos adicionais. No caso de hedge de opção, em geral uma opção adicional. Para Nandi e Waggoner (2000, p. 31), as principais desvantagens dessas estratégias são a menor liquidez do mercado de opções em relação ao mercado de ações, a maior diferença entre oferta de comra e oferta de venda das opções relativamente a seus preços e o aumento nos custos de transação. Esses fatores, ainda que não incorporados aos modelos e não quantificados explicitamente, não deixam de constituir uma preocupação constante na avaliação de qualquer estratégia.

\subsection{O hedge no gerenciamento de riscos}

Gerenciamento de riscos é o controle da exposição ao risco, conforme Jorion e Khouri (1996, p. 179), que aponta os derivativos como ferramentas essenciais para o gerenciamento de riscos por permitirem um estreito controle sobre a exposição.

De acordo com Brockhaus et al. (1999, p. 222), não existe um algoritmo geral para gerenciamento de riscos. Somente é possível delinear pricípios gerais, pois cada situação requer a análise de seus detalhes particulares. Essa afirmação constrasta com uma teoria geral de hedge, mas somente na aparência, pois trata-se de conceitos distintos. O hedge, conforme definido em 3.4, é um método de redução de riscos, implementado por meio de 
operações de hedge. O gerenciamento de riscos é mais abrangente, sendo o hedge uma ferramenta para a implementação do gerenciamento de riscos.

Brockhaus et al. (1999, p. 222) analisa o gerenciamento de riscos classificando os mercados de acordo com duas fases de desenvolvimento. Um fase 1, na qual o mercado tem liquidez somente para ações e produtos de taxa de juros, e uma fase 2 , na qual o mercado tem liquidez também para opções européias e americanas.

As características das fases de desenvolvimento são apresentadas na tabela a seguir:

\begin{tabular}{|l|l|l|}
\hline \multicolumn{1}{|c|}{ CARACTERÍSTICA } & \multicolumn{1}{c|}{ FASE 1 } & \multicolumn{1}{c|}{ FASE 2 } \\
\hline $\begin{array}{l}\text { Ativos-base negociados } \\
\text { (líquidos): }\end{array}$ & Ações, produtos de taxa de juros. & $\begin{array}{l}\text { Ações, produtos de taxa de juros, opções } \\
\text { européias e americanas. }\end{array}$ \\
\hline Novos derivativos introduzidos: & Opções de compra e opções de venda. & $\begin{array}{l}\text { Derivativos de segunda geração } \\
\text { (barreira, asiáticas, lookback, } \\
\text { compostas, callable }) .\end{array}$ \\
\hline $\begin{array}{l}\text { Riscos reduzidos por meio de } \\
\text { hedge }:\end{array}$ & Delta, rô. & Delta, rô, gama e vega. \\
\hline Riscos residuais: & Gama, vega e dividendos. & Correlação, gama cruzado, dividendos. \\
\hline
\end{tabular}

Tabela 3.1 - Características dos Mercados

Brockhaus et al. (1999, p. 221-222) define risco como quaisquer mudanças nas variáveis de mercado que resultem em mudança no valor de um ativo e coloca à frente do gerenciamento de riscos duas questões centrais. A primeira refere-se à identificação do risco que se quer reduzir, expresso pelos fatores de sensibilidade do preço em relação a eles, e a segunda refere-se à viabilidade proporcionada pelos mecanismos que o mercado oferece, expressos pelos ativos financeiros disponíveis, o que depende de seu estágio de desenvolvimento. Os riscos para os quais não é possível fazer hedge são denominados riscos residuais.

As não-linearidades nas relações entre os preços dos ativos são devidas às oscilações nos valores das variáveis que definem o modelo de mercado, como a volatilidade, a taxa de juros ou a velocidade das oscilações, descritas como efeitos de segunda ordem da oscilação das variáveis. Para Brockhaus et al. (1999, p. 221-222), cada um desses fatores determina um risco para o qual é possível estabelecer um hedge. Cabe ao processo de gerenciamento de risco definir quais são os fatores de risco importantes e quais as operações de hedge necessárias para reduzi-los. 
Podemos estabelecer um paralelo entre a teoria geral do hedge apresentada neste trabalho e a estrutura de gerenciamento de riscos de Brockhaus et al. (1999, p. 224-225). Um mercado na fase 1 oferece liquidez somente para ações e não para opções, que não podem ser utilizadas como ativos-base. Como o hedge consiste em uma combinação linear de ativos-base para replicar os rendimentos de um ativo-objeto, a relação não linear entre os preços das ações e opções inviabiliza a estruturação de uma operação de hedge satisfatória, que tenha ações como ativos-base e uma opção como ativo-objeto. Somente mercados na fase 2, que oferecem liquidez suficiente uso de opções como ativos-base permitem o hedge pelo gama e o hedge pelo vega, mais satisfatórios, pois a não-linearidade entre os preços de opções é significativamente menor.

Brockhaus et al. (1999, p. 224-225) conceitua hedge conforme descrito a seguir.

Formalmente define:

$X$ : contrato de derivativo.

$M$ : conjunto de variáveis do mercado.

$V$ : mecanismo de precificação do derivativo.

$V(X, M)$ : valor do derivativo dado o conjunto de valores das variáveis do mercado.

Y : carteira de hedge.

$V$ é um mecanismo de precificação viável se forem respeitadas as seguintes restrições:

- $\quad$ Os elementos de M são conhecidos ou obtidos por meio de estimação ou calibração.

- $\quad$ Todos os rendimentos do contrato $X$ devem ser refletidos por mudanças no valor $V(X, M)$.

- $\quad$ O mesmo mecanismo de precificação $V$ deve ser usado para avaliar todos os contratos similares a $X$.

Qualquer alteração nas variáveis do mercado afeta o preço do contrato $X$ e constitui um risco para o qual pode ser estruturado um hedge.

O hedge é dito global se o valor da carteira de hedge Y é o mesmo para qualquer valor possível das variáveis $M$, i. e.: 


$$
V(Y, M)=\text { const para todo } M
$$

O hedge é dito local se o valor da carteira de hedge $\mathrm{Y}$ não se altera para pequenas oscilações nas variáveis $M$, i. e.:

$$
\frac{\partial V(Y, M)}{\partial M_{m}}=0 \text { para todo } M_{m} \in M
$$

O hedge local é instantâneo e requer um ajuste contínuo.

Brockhaus et al. (1999, p. 225) propõe a estruturação de hedge para todos os riscos que se deseje mitigar, através das derivadas do valor da carteira de hedge em relação às variáveis de interesse, assumindo posições opostas em ativos correspondentes. Na prática é o hedge para as gregas de interesse, razão pela qual essa forma de gestão de risco requer mercados financeiros em estágio avançado de maturidade, que ofereçam os ativos financeiros exóticos necessários ao hedge.

Brockhaus et al. (1999, p. 227) apresenta uma equação de ganhos e perdas de uma carteira de hedge, ou uma carteira de hedge em função da estratégia adotada, aplicável a ações. A versão adaptada ao tempo discreto é dada por:

$$
P \& L\left(\theta_{t-1}\right)=\sum_{t=1}^{T}\left(\sum_{i=1}^{n}\left(d_{t}^{i}-r f_{t-1}\right) S_{t}^{i} \theta_{t-1}^{i}+r f_{t-1} V_{t-1}\right)+\sum_{t=1}^{T}\left(\sum_{i=1}^{n} \theta_{t-1}^{i} \Delta S_{t}^{i}\right)
$$

Sendo:

$P \& L\left(\theta_{t-1}\right):$ ganhos ou perdas da carteira de hedge.

$\theta_{t-1}^{i}$ : quantidade do ativo $i$ no período $t-1$ na carteira de hedge.

$d_{t}^{i}$ : taxa de dividendos paga pelo ativo $i$ no período $t$.

$S_{t}^{i}$ : preço do ativo $i$ no período $t$.

$\Delta S_{t}^{i}$ : diferença de preço do ativo $i$ no período $t$ em relação ao período $t-1$.

$r f_{t-1}$ : taxa livre de risco no período $t-1$. 
$V_{t-1}$ : valor da carteira de hedge no período $t-1$.

Podemos alterar a forma da equação e identificar na equação os seguintes componentes:

$$
P \& L(\theta)=\sum_{t=1}^{T}\left(\sum_{i=1}^{n}\left(d_{t}^{i} S_{t}^{i} \theta_{t-1}^{i}\right)+r f_{t-1}\left(-\sum_{i=1}^{n} S_{t-1}^{i} \theta_{t-1}^{i}+V_{t-1}\right)\right)+\sum_{t=1}^{T}\left(\sum_{i=1}^{n} \theta_{t-1}^{i} \Delta S_{t}^{i}\right)
$$

sendo que:

- $\quad$ O elemento $\sum_{i=1}^{n}\left(d_{t}^{i} S_{t}^{i} \theta_{t-1}^{i}\right)$ é a receita de dividendos dos ativos, dada pela soma dos valores dos ativos multiplicados pela quantidade dos ativos e pela taxa de dividendos paga por cada um.

- O elemento $r f_{t-1}\left(-\sum_{i=1}^{n} S_{t-1}^{i} \theta_{t-1}^{i}+V_{t-1}\right)$ é o rendimento de juros, dado pela multiplicação da taxa livre de risco pelo valor em numerário da carteira.

- $\quad$ O elemento $\sum_{i=1}^{n} \theta_{t-1}^{i} \Delta S_{t}^{i}$ é a soma dos rendimentos dos ativos da carteira no período.

A operação de hedge consiste na construção de uma carteira replicante composta por posições compradas e vendidas em ações e no ativo livre de risco, cujo resultado de ganhos e perdas deve ser igual à variação de preço do ativo-objeto. As quantidades de ativos-base necessárias são definidas pela estratégia de hedge, que determina a forma de cálculo dessas quantidades.

Essa é a forma geral das operações de hedge que serão simuladas para comparação entre as estratégias de hedge neste trabalho.

\subsection{Hedge de opção}

As estratégias que tratamos neste trabalho são contratos de opções de compra do tipo européia e estratégias dinâmicas, dependentes de modelo e do tipo delta. 
O hedge de opção consiste na replicação do rendimento de uma opção, que é o ativoobjeto, por meio de uma combinação linear entre a ação correspondente e o ativo livre de risco, que são os ativos-base.

A estratégia pode considerar mercado incompleto, pois há uma relação não-linear entre o preço da opção e os preços da ação e do ativo livre de risco, mas também pode considerar mercado completo, pois essa relação é linear no limite de um intervalo de tempo infinitesimal.

O erro de hedge de opção de um período das estratégias consideradas neste trabalho tem sempre o formato:

$$
\varepsilon_{t}=r f_{t-1}\left(-S_{t-1} \theta_{t-1}+V_{t-1}\right)+\theta_{t-1} \Delta S_{t}-C_{t}
$$

$\varepsilon_{t}$ : erro de hedge.

$\theta_{t-1}$ : quantidade da ação no período $t$ na carteira de hedge fornecida pela estratégia de hedge adotada.

$S_{t-1}$ : preço da ação no período $t-1$.

$\Delta S_{t}$ : diferença de preço da ação no período $t$ em relação ao período $t-1$.

$r f_{t-1}$ : taxa livre de risco no período $t-1$.

$V_{t-1}$ : valor da carteira de hedge ou carteria replicante no período $t-1$.

$C_{t}$ : valor da opção no período $t$.

Essa equação é precisamente a equação de ganhos e perdas da carteira de hedge apresentada anteriormente, porém destacando o valor da opção, que é o ativo-objeto a ser replicado.

Na comparação entre as estratégias de hedge, agregando as restrições multiperiódica e autofinanciável, os erros de hedge são cumulativos ao longo dos períodos, ou seja, o valor da carteria replicante e da opção, iguais no instante inicial de construção da carteira, distanciam-se ao longo do tempo, não sendo igualados a cada período. Igualar o valor da carteira replicante ao valor da opção implicaria a injeção ou retirada de recursos na 
carteira. Esse é o cenário no qual as estratégias tratadas neste trabalho são comparadas e testadas. 


\section{REVISÃO DA LITERATURA}

Neste capítulo analisaremos alguns trabalhos que abordam diversas estratégias de hedge de opção e formas variadas de implementação, e realizam estudos comparativos.

Indentificaremos seus métodos e apresentaremos alguns de seus resultados e conclusões.

Estratégias de hedge de opção estão sempre vinculadas a modelos de precificação de opção quando derivados do argumento de replicação do preço da opção, por meio de uma carteira replicante na condição de não-arbitragem. Os métodos de precificação, entretanto, nem sempre são acompanhados diretamente do argumento de replicação para a obtenção do preço, como no caso da teoria martingale na precificação de derivativos. Neste caso, o preço é calculado pelo valor esperado do preço descontado na medida neutralizadora do risco, sem recorrer diretamente a um argumento de replicação.

Os trabalhos que comparam desempenho de estratégias de hedge, em geral, também apresentam resultados de comparação de desempenho de precificação, como veremos nos estudos apresentados. O oposto não é tão comum, e. g., Hsieh e Ritchken (2006, p. 129150), Hafner e Herwartz (1999, p.1-25), Härdle e Hafner (2000, p.189-207), Heston e Nandi (2000, p.585-625), Christoffersen e Jacobs (2004, p.1204-1221) e Araújo, Barbedo, Figueiredo e Lemgruber (2004, p. 43-57), que comparam somente desempenho de precificação.

Muitos dos estudos sobre estratégias de hedge são apresentados no contexto de um desenvolvimento que propõe uma nova estratégia ou o aperfeiçoamento de uma estratégia existente. Por isso, concentram-se na avaliação do ganho marginal obtido com a proposição em relação à estratégia existente, ou na comparação com o modelo BSM, sendo este uma referência universal.

Mais difícil é encontrar estudos que comparam estratégias desenvolvidas com princípios diferentes, como Kim e Kim (2004, p. 117-142). Esse estudo compara um modelo GARCH em tempo discreto com modelos em tempo contínuo, um com reversão à média da volatilidade e outro que incorpora assimetria e curtose. Mas mesmo esse estudo, parte 
da premissa de comparação de modelos de volatilidade estocástica, visando essa semelhança e não as diferenças.

Para diferenciar a concepção teórica do modelo BSM das aplicações e implementações do modelo, que são tratadas nos trabalhos descritos, daqui em diante faremos referência ao arcabouço teórico simplesmente por modelo BSM e utilizaremos a nomenclatura específica de cada trabalho para identificar suas implementações.

\subsection{O trabalho de Dumas, Fleming e Whaley}

Notação:

$t$ : instante de observação.

$S_{t}$ : preço à vista do índice S\&P 500 no instante $t$.

$F_{T}$ : preço do índice S\&P 500 corrigido pela taxa livre de risco para o instante $T$.

$D_{t}$ : valor dos dividendos pagos corrigidos pela taxa livre de risco para o instante $t$.

$C\left(S_{t}, t\right)$ : preço da opção no instante $t$.

$K_{t}$ : preço de exercício da opção corrigido pela taxa livre de risco para o instante $t$.

$T$ : instante de expiração da opção.

$\sigma$ : volatilidade dos log-retornos da ação.

$a_{i}$ : coeficiente $i$ que representa um instante de tempo.

Dumas, Fleming e Whaley (1998, p. 2059-2106) é uma referência na literatura quando se trata de implementação do modelo BSM.

O estudo propõe a modelagem da volatilidade através de uma função determinística de volatilidade. O modelo preserva o argumento de não arbitragem, que constitui a base do modelo BSM, possibilitando a precificação através da equação diferencial parcial de Black-Scholes, embora não permita a utilização direta da fórmula de Black-Scholes, uma vez que as funções que compõem a equação diferencial parcial são alteradas. 
A idéia central do estudo é que o único parâmetro não observável do modelo BSM é a volatilidade média até a expiração da opção, que precisa ser estimada. O estudo propõe alternativas de estimação, seja através de funções determinísticas de volatilidade, seja através de artifícios de implementação, ainda que teoricamente inconsistentes.

Dumas, Fleming e Whaley (1998, p. 2068) apresenta a equação diferencial parcial forward de Black-Scholes com uma função determinística de volatilidade acoplada, dependente do preço de exercício e prazo para expiração:

$$
\frac{1}{2} \sigma^{2}\left(K_{T}, T-t\right) K_{T}{ }^{2} \frac{\partial^{2} C\left(S_{t}, t\right)}{\partial K_{T}{ }^{2}}=\frac{\partial C\left(S_{t}, t\right)}{\partial T}
$$

Como não há solução analítica para a equação, foi solucionada numericamente para obtenção dos preços. Partindo dessa equação, o estudo propõe três alternativas de implementação de função determinística de volatilidade e três alternativas de implementação direta do modelo BSM. As equações determinísticas de volatilidade são dependentes do preço de exercício e do prazo para expiração da opção. Os coeficientes das equações são estimados por regressão das volatilidades implícitas nos dados observados de preço de exercício e prazo de expiração para diversas opções sobre o mesmo ativo. As volatilidades implícitas são calculadas para cada função determinística de volatilidade correspondente, pela solução da equação diferencial parcial a partir dos dados observados de preço de exercício e prazo de expiração das diversas opções e respectivos preços. As funções determinísticas de volatilidade foram arbitrariamente definidas como quadráticas e dependentes do preço de exercício e prazo de expiração, com base no argumento de que o sorriso de volatilidade do modelo BSM assemelha-se a uma parábola.

\subsubsection{Método}

- O estudo utiliza dados do mercado norte americano de opções do tipo européia sobre o índice S\&P 500, no período de junho de 1988 a dezembro de 1993.

- Todos os dados para estimação dos modelos são tomados num mesmo dia (quarta-feira), ou dia seguinte de negociação se não houver mercado. 
- $\quad$ Os preços das opções são tomados em um intervalo de 30 minutos, pelo ponto médio observado entre oferta de compra e oferta de venda.

- Cada opção com respectivos preço de exercício e prazo de expiração é representada uma única vez na amostra, pela primeira cotação no intervalo de tempo de observação.

- $\quad$ Somente opções com mais de 6 dias e menos de 100 dias para expiração são incluídas na amostra.

- $\quad$ A taxa livre de risco é representada pela taxa interpolada de $T$ bills com maturidades diferentes, cotados no ponto médio entre oferta de compra e oferta de venda.

- $\quad$ O preço do índice é inferido de preços de contratos futuros e descontado pelo valor presente dos dividendos pagos durante a vigência da opção até a data de observação, às taxas correspondentes às datas ex-dividendo.

- $\quad$ Somente opções com moneyness menor ou igual a $10 \%$ são incluídos na amostra.

$$
\left|\frac{K_{T}}{F_{T}}-1\right| \leq 0,1 .
$$

- $\quad$ Somente opções cujo preço satisfaz a condição de não-arbitragem são incluídas na amostra.

$$
C\left(S_{t}, t\right) \geq S_{t}-D_{t}-K_{t}
$$

- $\quad$ As equações de volatilidade são reestimadas semanalmente ou a cada duas semanas em dois processos de avaliação distintos, utilizando os valores forward do preço do índice S\&P 500 e da opção. O preço da opção e o hedge são calculados diariamente para avaliação.

- $\quad$ O desempenho foi avaliado numa amostra de validação pelo erro quadrático médio de hedge e pelo erro quadrático médio de previsão de preço. 


\subsubsection{Modelos}

\subsubsection{Modelo 0}

É o modelo BSM com volatilidade constante. É estimada uma única volatilidade implícita que minimiza o erro quadrático médio entre o preço de mercado e o preço de modelo para todas as opções.

\subsubsection{Modelo 1}

Modelo que utiliza uma função determinística de volatilidade que captura a volatilidade atribuída ao preço de exercício:

$$
\sigma\left(K_{T}, T-t\right)=\max \left\{0,01, a_{0}+a_{1} K_{T}+a_{2} K_{T}^{2}\right\} .
$$

É estimada uma única volatilidade implícita que minimiza o erro quadrático médio entre o preço de mercado e o preço de modelo para todas as opções, dado pela equação diferencial parcial forward de Black-Scholes, utilizando a função determinística de volatilidade.

\subsubsection{Modelo 2}

Modelo que utiliza uma função determinística de volatilidade que captura a volatilidade atribuída ao preço de exercício e a variação adicional atribuída ao tempo para expiração:

$$
\sigma\left(K_{T}, T-t\right)=\max \left\{0,01, a_{0}+a_{1} K_{T}+a_{2} K_{T}^{2}+a_{3}(T-t)-t+a_{5}(T-t) K_{T}\right\} .
$$

A volatilidade é estimada como a volatilidade implícita que minimiza o erro quadrático médio entre o preço de mercado e o preço de modelo para todas as opções, dado pela equação diferencial parcial forward de Black-Scholes, utilizando a função determinística de volatilidade.

\subsubsection{Modelo 3}

Modelo que utiliza uma função determinística de volatilidade que captura a volatilidade atribuída ao preço de exercício, a variação adicional atribuída ao tempo para expiração e insere uma dependência quadrática do tempo:

$$
\sigma(K, T-t)=\max \left\{0,01, a_{0}+a_{1} K+a_{2} K^{2}+a_{3}(T-t)+a_{4}(T-t)^{2}+a_{5}(T-t) K\right\} .
$$

A volatilidade é estimada como a volatilidade implícita que minimiza o erro quadrático médio entre o preço de mercado e o preço de modelo para todas as opções, dado pela 
equação diferencial parcial forward de Black-Scholes, utilizando a função determinística de volatilidade.

\subsubsection{Modelo $S$}

Modelo que utiliza a função determinística de volatilidade dos modelos 1, 2 ou 3, dependendo de haver 1, 2 ou 3 datas de expiração disponíveis para a regressão de mínimos quadrados.

\subsubsection{Modelo SAH (S Ad Hoc)}

O modelo $\mathrm{S}$ ad hoc é o modelo $\mathrm{S}$ modificando a estimação da volatilidade. Primeiramente são calculadas as volatilidades implícitas obtidas com fórmula de Black-Scholes para todas as opções. Em seguida é minimizado o erro quadrático médio entre os preços de mercado e preços de modelo utilizando a função determinística de volatilidade na fórmula de BlackScholes, sem a resolução da equação diferencial parcial forward de Balck-Scholes. Essa solução é viável e facilita a implementação, mas é teoricamente inconsistente, pois a volatilidade deveria ser a mesma para todas as opções, além disso, utiliza uma fórmula de cálculo de preço da opção para cálculo das volatilidades implícitas, e outra fórmula para cálculo de preços da opção e hedge.

\subsubsection{Conclusões}

À exceção dos modelos S e SAH que utilizam mais de uma função de volatilidade, as alternativas foram implementadas com base na teoria que fundamenta o modelo BSM, i. e., mantêm todas as premissas do modelo e incluem uma função determinística de volatilidade na equação diferencial parcial de Black-Scholes, utilizando um método numérico para solução. A exceção do modelo SAH, todas as alternativas apresentam uma única volatilidade para todas as opções, independente de prazo para expiração e preço de exercício.

O estudo apresentou duas comparações com estimação semanal das volatilidades. Uma realizada sobre toda a amostra e outra realizada quebrando a amostra em períodos de um 
ano. O fato surpreendente do estudo foi o desempenho do modelo SAH tanto em hedge como em precificação.

A conclusão do estudo é dada nas tabelas 4.1 e 4.2, ordenada do maior para o menor desempenho na amostra de validação, para opções de compra, com reestimação semanal e tendo como medida de desempenho o erro quadrático médio de hedge e precificação em numerário (root mean squared dollar hedging error - RMSHE e root mean squared dollar valuation error - RMSVE).

\begin{tabular}{|c|c|c|c|c|c|c|}
\hline & & & & & \\
& & & & & & \\
modelo 0 & modelo S ad hoc & modelo 1 & modelo 2 & modelo S & modelo 3 \\
\cline { 2 - 7 } RMSVE & 0,445 & 0,454 & 0,491 & 0,5 & 0,503 & 0,505 \\
\hline
\end{tabular}

Tabela 4.1 - Tabela de Desempenho de Hedge

\begin{tabular}{|c|c|c|c|c|c|c|}
\hline \multicolumn{2}{|c|}{ PRECIFICAÇÃO } & & \\
\hline \multirow{2}{*}{ RMSVE } & modelo S ad hoc & modelo S ad hoc & modelo 2 & modelo 3 & modelo 1 & modelo 0 \\
\cline { 2 - 7 } & 0,491 & 0,548 & 0,549 & 0,551 & 0,556 & 0,79 \\
\hline
\end{tabular}

Tabela 4.2 - Tabela de Desempenho de Precificação

A alteração da estimação da função de volatilidade de semanal para duas semanas melhorou pouco o desempenho de precificação e substancialmente o desempenho de hedge de todos os modelos.

Um aspecto interessante a observar é que as disparidades na precificação foram maiores do que no hedge e um melhor desempenho em precificação não implica melhor desempenho em hedge.

\section{2 $O$ trabalho de Nandi e Waggoner}

Notação:

$t$ : instante de observação.

$S_{t}$ : preço à vista do índice no instante $t$. 
$F_{T}$ : preço forward do índice S\&P 500, i. e., corrigido pela taxa livre de risco para o instante $T$.

$C\left(S_{t}, t\right)$ : preço da opção no instante $t$.

$D_{t}$ : valor dos dividendos pagos corrigidos pela taxa livre de risco para o instante $t$.

$K_{t}$ : preço de exercício da opção corrigido pela taxa livre de risco para o instante $t$.

$T$ : instante de expiração da opção.

$\sigma$ : volatilidade dos log-retornos da ação.

$a_{i}$ : coeficiente $i$ que representa um instante de tempo.

$R_{i}$ : log-retorno no período $i$.

$\mu: \log$-retorno esperado no intervalo de períodos $n$.

$n$ : quantidade de períodos.

$e_{i}$ : diferença entre preço de mercado e o preço de modelo da opção.

Nandi e Waggoner (2000, p. 24-39) replica parcialmente Dumas, Fleming e Whaley (1998, p. 2059-2106). Aqui também o objeto de estudo é a estimação do único parâmetro não observável do modelo, i. e., a volatilidade. O estudo, entretanto, não tem como foco a implementação de uma função determinística de volatilidade, apenas trata alternativas de estimação da volatilidade para o modelo BSM na sua forma original, sem preocupação quanto à consistência teórica da proposição de implementação.

Nandi e Waggoner (2000, p. 24-39) propõe quatro alternativas de implementação do modelo BSM e compara seu desempenho quanto ao hedge.

\subsubsection{Método}

- $\quad$ O estudo utiliza dados do mercado norte americano de opções do tipo européia sobre o índice S\&P 500, no período de janeiro de 1994 a outubro de 1994.

- $\quad$ Todos os dados para estimação dos modelos são tomados num mesmo dia (quarta-feira), ou dia seguinte de negociação se não houver mercado.

- $\quad$ Os preços das opções são tomados em um intervalo de 45 minutos, pelo ponto médio observado entre oferta de compra e oferta de venda. 
- $\quad$ Cada opção com respectivos preço de exercício e prazo de expiração é representada uma única vez na amostra, pela primeira cotação no intervalo de tempo de observação.

- $\quad$ Somente opções com mais de 6 dias e menos de 100 dias para expiração são incluídas na amostra.

- A taxa livre de risco é representada pela taxa contínua interpolada de $T$ bills com maturidades diferentes, cotados no ponto médio entre oferta de compra e oferta de venda.

- $\quad$ O preço do índice S\&P 500 corrente é descontado pelo valor presente dos dividendos pagos durante a vigência da opção até a data de observação, à taxa livre de risco correspondente a cada data ex-dividendo.

- $\quad$ Somente opções com moneyness menor ou igual a 10 \% são incluídos na amostra.

$$
\left|\frac{K_{T}}{F_{T}}-1\right| \leq 0,1 .
$$

- $\quad$ Somente opções cujo preço satisfaz a condição de não arbitragem são incluídas na amostra.

$$
C\left(S_{t}, t\right) \geq S_{t}-D_{t}-K_{t}
$$

- $\quad$ As equações de volatilidade são reestimadas semanalmente utilizando os valores forward de preço do índice e da opção. O preço da opção e o hedge calculados diariamente.

- $\quad$ O desempenho foi avaliado na amostra de estimação pelo erro médio absoluto de hedge.

\subsubsection{Modelos}

\subsubsection{Modelo 1}

É o modelo BSM com volatilidade constante. É estimada uma única volatilidade para todas as opções, através da série histórica de preços, utilizando dados de fechamento do índice S\&P 500 dos últimos 60 dias.

Nesse caso, simplesmente: 


$$
\hat{\sigma}^{2}=\frac{\sum_{i=1}^{n}\left(R_{i}-\hat{\mu}\right)^{2}}{n-1} .
$$

\subsubsection{Modelo 2}

É o modelo BSM com a volatilidade constante, modificando a estimação da volatilidade.

É estimada uma única volatilidade para todas as opções, através de uma regressão nãolinear de mínimos quadrados dos preços de mercado nos preços de modelo das opções. Os preços de modelo são calculados com a volatilidade implícita obtida pela fórmula de Black-Scholes, e a volatilidade é estimada pela minimização do erro quadrático médio entre o preço de mercado e o preço de modelo:

$$
\hat{\sigma}^{2}=\min _{\sigma^{2}} \sum_{i=1}^{N_{t}} e_{i}\left(\sigma^{2}\right) .
$$

\subsubsection{Modelo 3}

É o modelo BSM com a volatilidade constante, modificando a estimação da volatilidade. A volatilidade é estimada separadamente para cada opção, simplesmente como a volatilidade impícita obtida com a fórmula de Black-Scholes. Esse modelo é teoricamente inconsistente, pois a volatilidade deveria ser a mesma para todas as opções.

\subsubsection{Modelo 4}

É o modelo BSM com a volatilidade constante, modificando a estimação da volatilidade. A volatilidade é estimada como uma única volatilidade para todas as opções, através de uma regressão das volatilidades implícitas, obtidas com a fórmula de Black-Scholes, nos dados de preço de exercício e prazo de expiração das opções sobre o índice S\&P 500. Utiliza a equação do modelo 3 de Dumas, Fleming e Whaley (1998, p. 2059-2106) para calcular a volatilidade de cada opção:

$$
\sigma\left(K_{T}, T-t\right)=\max \left\{0,01, a_{0}+a_{1} K_{T}+a_{2} K_{T}{ }^{2}+a_{3}(T-t)+a_{4}(T-t)^{2}+a_{5}(T-t) K_{T}\right\} .
$$

Esse modelo é teoricamente inconsistente, pois embora utilize ao final uma única volatilidade, parte de uma premissa de volatilidades diferentes para as opções e utiliza uma fórmula de cálculo de preço da opção para cálculo das volatilidades impícitas, e outra fórmula para cálculo de preços de opção e hedge. 


\subsubsection{Conclusões}

A conclusão do estudo é dada na tabela 4.3, ordenada do maior para o menor desempenho na amostra de estimação para opções de compra e venda, com reestimação semanal, e tendo como medida de desempenho o erro médio absoluto de hedge em numerário (mean absolute dollar error - MAE).

\begin{tabular}{|c|c|c|c|c|}
\hline \multicolumn{5}{|c|}{ HEDGE } \\
\hline \multirow{3}{*}{ MAE } & modelo 3 & modelo 2 & modelo 1 & modelo 4 \\
\cline { 2 - 5 } & 0,445 & 0,454 & 0,491 & 0,5 \\
\hline
\end{tabular}

Tabela 4.3 - Tabela de Desempenho de Hedge

\subsection{O trabalho de Heston e Nandi}

Notação:

$t$ : instante de observação.

$S_{t}$ : preço à vista do índice S\&P 500no instante $t$.

$F_{T}$ : preço forward do índice, i. e., corrigido pela taxa livre de risco para o instante $T$.

$C_{t}$ : preço da opção no instante $t$.

$D_{t}$ : valor dos dividendos pagos corrigidos pela taxa livre de risco para o instante $t$.

$K_{t}$ : preço de exercício da opção corrigido pela taxa livre de risco para o instante $t$.

$T$ : instante de expiração da opção.

$\sigma$ : volatilidade dos log-retornos da ação.

$N_{t}$ : quantidade de opções.

$e_{i, t}$ : diferença entre o preço de mercado e o preço de modelo da opção.

Heston e Nandi (2000, p. 585-625) desenvolve um modelo GARCH de precificação especificamente desenvolvido para a apresentação de uma solução fechada. Conforme ressalta Heston e Nandi (2000, p. 588), seu modelo é distinto do GARCH de Bollerslev 
(1986, p. 307-327), sendo similar aos modelos NGARCH e VGARCH de Engle e Ng (1993, p.1749-1778).

O termo fechada, conforme comenta Duan, Ritchken e Sun (2005, p.3), foi objeto de uma grande gama de interpretações na literatura, pois a solução não é efetivamente fechada como a fórmula de Black-Scholes, que permite o cálculo direto de preço e hedge. A solução não requer o uso de simulação de Monte Carlo para estimação do preço, como é o caso geral de modelos sem solução analítica, mas a solução final apresentada é uma integral no domínio complexo, que requer métodos numéricos de resolução.

Evidentemente o esforço computacional é significativamente reduzido, porém a solução não é propriamente fechada.

\subsubsection{Método}

- $\quad$ O estudo utiliza dados do mercado norte americano de opções do tipo européia sobre o índice S\&P 500, no período de de 1992 a 1994.

- $\quad$ A amostra é dividida em anos, sendo o primeiro semestre utilizado para estimação e comparação numa amostra de estimação e o segundo semestre para comparação numa amostra de validação.

- Todos os dados para estimação dos modelos são tomados num mesmo dia (quarta-feira), ou dia seguinte de negociação se não houver mercado.

- $\quad$ Os preços das opções são tomados em um intervalo de 45 minutos, pelo ponto médio observado entre oferta de compra e oferta de venda.

- Cada opção com respectivos preço de exercício e prazo de expiração é representada uma única vez na amostra, pela primeira cotação no intervalo de tempo de observação.

- $\quad$ Somente opções com mais de 6 dias e menos de 100 dias para expiração são incluídas na amostra.

- A taxa livre de risco é representada pela taxa contínua interpolada de $T$ bills com maturidades diferentes, cotados no ponto médio entre oferta de compra e oferta de venda.

- $\quad$ O preço do índice corrente é descontado pelo valor presente dos dividendos pagos durante a vigência da opção. 
- $\quad$ Somente opções com moneyness menor ou igual a $10 \%$ são incluídos na amostra.

$$
\left|\frac{K_{T}}{F_{T}}-1\right| \leq 0,1 .
$$

- $\quad$ Somente opções cujo preço satisfaz a condição de não arbitragem são incluídas na amostra.

$$
C\left(S_{t}, t\right) \geq S_{t}-D_{t}-K_{t}
$$

- $\quad$ Os modelos são reestimadas semanalmente e os preços e hedge calculados diariamente, a exceção da volatilidade, que segue um método particular para cada modelo.

- $\quad$ O desempenho foi avaliado na amostra de estimação pelo erro médio absoluto de hedge.

\subsubsection{Modelos}

\subsubsection{Modelo BS (Black-Scholes)}

É o modelo BSM com a volatilidade constante. É estimada uma única volatilidade para todas as opções, através de uma regressão não-linear de mínimos quadrados dos preços de mercado nos preços de modelo das opções, para uma dada volatilidade implícita obtida pela fórmula de Black-Scholes. É a minimização do erro quadrático médio entre o preço de mercado e o preço de modelo. A volatilidade é estimada diariamente e utiliza dados da últimas vinte e seis quartas-feiras.

$$
\hat{\sigma}^{2}=\min _{\sigma^{2}} \sum_{t=1}^{T} \sum_{i=1}^{N_{t}} e_{i, t}\left(\sigma^{2}\right) .
$$

\subsubsection{Modelo AHBS (Ad Hoc Black-Scholes)}

É o modelo BSM com a volatilidade constante, modificando a estimação da volatilidade. A volatilidade é estimada como uma única volatilidade para todas as opções, através de uma regressão das volatilidades implícitas, obtidas pela fórmula de Black-Scholes, nos dados de preço de exercício e prazo de expiração das opções sobre o índice S\&P 500. 
Utiliza a equação do modelo 3 de Dumas, Fleming e Whaley (1998, p. 2059-2106) para calcular a volatilidade de cada opção:

$$
\sigma\left(K_{T}, T-t\right)=a_{0}+a_{1} K_{T}+a_{2} K_{T}^{2}+a_{3}(T-t)+a_{4}(T-t)^{2}+a_{5}(T-t) K_{T} .
$$

A volatilidade é estimada semanalmente e utiliza dados da últimas vinte e seis quatasfeiras.

$$
\hat{\sigma}^{2}=\min _{\sigma^{2}} \sum_{t=1}^{T} \sum_{i=1}^{N_{t}} e_{i, t}\left(\sigma^{2}\right)
$$

\subsubsection{Modelo GARCH (Generalized Autoregressive Conditional Heteroskedasticity)}

O modelo GARCH foi arbitrariamente escolhido como $\operatorname{GARCH}(1,1)$.

Os parâmetros são estimados por mínimos quadrados não-lineares, minimizando o erro quadrático médio percentual medido pela diferença entre preço de modelo e preço de mercado em relação ao preço de mercado. O processo da volatilidade é inicializado pelo logaritmo do preço à vista. Foram utilizados dois modelos, um reestimado semanalmente, denominado atualizado e outro reestimado semestralmente, denominado não atualizado. A volatilidade é reestimada diariamente pelo modelo em ambos os casos.

\subsubsection{Conclusões}

A conclusão do estudo é dada na tabela 4.4, ordenada do maior para o menor desempenho na amostra de validação, com reestimação diária e tendo como medida de desempenho a raiz quadrada do erro quadrático médio de precificação em numerário (root mean squared dollar valuation error - RMSVE).

\begin{tabular}{|c|c|c|c|c|}
\hline \multicolumn{5}{|c|}{ PRECIFICAÇÃO } \\
\hline \multirow{2}{*}{ RMSVE } & $\begin{array}{c}\text { GARCH } \\
\text { atualizado }\end{array}$ & $\begin{array}{c}\text { GARCH não } \\
\text { atualizado }\end{array}$ & AHBS & BS \\
\cline { 2 - 5 } & 0.58 & 0.74 & 0.77 & 1.14 \\
\hline
\end{tabular}

Tabela 4.4 - Tabela de Desempenho de Precificação 


\subsection{O trabalho de Kim e Kim}

Notação:

$t$ : instante de observação.

$S_{t}$ : preço à vista do índice KOSPI 200 no instante $t$.

$C\left(S_{t}, t\right)$ : preço da opção no instante $t$.

$D_{t}$ : valor dos dividendos pagos corrigidos pela taxa livre de risco para o instante $t$.

$K_{t}$ : preço de exercício da opção corrigido pela taxa livre de risco para o instante $t$.

$T$ : instante de expiração da opção.

$\sigma$ : volatilidade dos log-retornos da ação.

$\omega$ : parâmetro do modelo $\mathrm{HN}$.

$\gamma$ : parâmetro do modelo $\mathrm{HN}$.

$\beta$ : parâmetro do modelo $\mathrm{HN}$.

$\alpha$ : parâmetro dos modelos $\mathrm{HN}$ e VG.

$v$ : volatilidade dos log-retornos nos modelos $\mathrm{SV}$ e VG.

$s$ : volatilidade da volatilidade nos modelos SV e VG.

$\rho$ : parâmetro do modelo SV.

$\kappa$ : parâmetro do modelo SV.

$\theta$ : parâmetro do modelo SV.

$\Phi(\bullet)$ : função acumulada de uma variável estocástica com distribuição normal padrão.

$\Gamma(\bullet)$ : função gama.

Kim e Kim (2004, p. 117-142) é um estudo comparativo de modelos de volatilidade estocástica. O estudo compara cinco modelos, sendo duas alternativas de implementação do modelo BSM e três modelos de volatilidade estocástica.

\subsubsection{Método}

- O estudo utiliza dados do mercado coreano de opções do tipo européia sobre o índice KOSPI 200, no período de janeiro de 1999 a dezembro de 2000.

- $\quad$ Os preços das opções são tomados em um intervalo de 30 minutos, pelo ponto médio observado entre oferta de compra e oferta de venda, com intervalo de cotação de um minuto. 
- Cada opção com respectivos preço de exercício e prazo de expiração é representada uma única vez na amostra, pela última cotação no intervalo de tempo de observação.

- $\quad$ Somente opções com mais de 6 dias e menos de 90 dias para expiração são incluídas na amostra.

- $\quad$ O preço do índice é ajustado pelo pagamento trimestral de dividendos.

- A taxa livre de risco é representada pelo rendimento trimestral de títulos do tesouro.

- $\quad$ Preços inferiores a 0,5 são excluídos.

- $\quad$ Somente opções cujo preço satisfaz a condição de não arbitragem são incluídas na amostra.

$$
C\left(S_{t}, t\right) \geq S_{t}-D_{t}-K_{t}
$$

- $\quad$ Todos os modelos foram reestimados diariamente.

- $\quad$ O desempenho foi avaliado na amostra de validação pelo erro quadrático médio de hedge e pelo erro quadrático médio de previsão de preço.

\subsubsection{Modelos}

\subsubsection{Modelo BS (Black-Scholes)}

É o modelo BSM implementado com volatilidade constante. É estimada uma única volatilidade para todas as opções, pela minimização do erro quadrático médio percentual entre preço de modelo e preço de mercado em relação ao preço de mercado.

\subsubsection{Modelo AHBS (Ad Hoc Black-Scholes)}

É o modelo S ad hoc de Dumas, Fleming e Whaley (1998, p. 2059-2106), que estima uma volatilidade para cada opção através de uma regressão das volatilidades implícitas obtidas pela fórmula de Black-Scholes, nos dados de preço de exercício e prazo de expiração das opções. Entretanto utiliza uma variante da função determinística de volatilidade.

$$
\sigma\left(S_{t}, K_{T}\right)=a_{0}+a_{1} \frac{S_{t}}{K_{T}}+a_{2}\left(\frac{S_{t}}{K_{T}}\right)^{2} .
$$


As volatilidades implícitas das opções são calculadas com dados do dia anterior e regredidas nos dados das opções no dia em questão. Em seguida as volatilidades para o cálculo de preço são obtidas do modelo estimado.

\subsubsection{Modelo GARCH (Generalized Autorregressive Conditional Heteroskedasticity)} É o modelo GARCH(1,1), desenvolvido em Heston e Nandi (2000, p. 585-625). Os parâmetros são estimados pela minimização do erro quadrático médio percentual entre preço de modelo e preço de mercado em relação ao preço de mercado, a exceção da volatilidade, que que é calculada pelo próprio modelo. O processo da volatilidade é inicializado com uma estimação de variância de log-retornos com dados de 1 ano para trás.

$$
C\left(S_{t}, t\right)=\frac{1}{2} S_{t}+\frac{1}{\pi} e^{-r(T-t)} \int_{0}^{\infty} \operatorname{Re}\left[\frac{K_{T}^{-i \phi} f^{*}(i \phi+1)}{i \phi}\right] d \phi-K_{T} e^{-r(T-t)}\left(\frac{1}{2}+\frac{1}{\pi} \int_{0}^{\infty} \operatorname{Re}\left[\frac{K_{T}^{-i \phi} f^{*}(i \phi)}{i \phi}\right]\right)
$$

Sendo que:

$$
\begin{gathered}
f(\varphi)=S_{t} \exp A(t, T, \varphi)+B_{1}(t, T, \varphi) h(t+2 \Delta t-i \Delta t) \\
A(t, T, \varphi)=A(t+\Delta t, T, \varphi)+\varphi r+B(t+\Delta t, T, \varphi) \omega-\frac{1}{2} \ln (1-2 \alpha B(t+\Delta t, T, \varphi)) \\
B(t, T, \varphi)=\varphi(\lambda+\gamma)-\frac{1}{2} \gamma^{2}+\beta B(t+\Delta t, T, \varphi)+\frac{1 / 2(\varphi-\gamma)^{2}}{1-2 \alpha B(t+\Delta t, T, \varphi)} \\
A(T, T, \varphi)=B(T, T, \varphi)=0 .
\end{gathered}
$$

\subsubsection{Modelo de SV (Stochastic Volatility)}

É o modelo em tempo contínuo, desenvolvido em Heston (1993 p. 327-343). Ele modela a variância por um processo estocástico com reversão à média.

$$
C_{t}=S_{t} P_{1}-K_{T} e^{-r(T-t)} P_{2}
$$


Sendo que:

$$
\begin{aligned}
& P_{j}=\left(\frac{1}{2}+\frac{1}{\pi} \int_{0}^{\infty} \operatorname{Re}\left(\frac{e^{i \phi \ln \left(K_{T}\right)} f_{j}\left(x, v_{t}, \tau, \phi\right)}{i \phi}\right) d \phi\right), \quad j=1,2 \\
& f_{j}\left(x, v_{t}, \tau, \phi\right)=\exp \left(C(\tau, \phi)+D(\tau, \phi) v_{t}+i \phi x\right) \\
& C(\tau, \phi)=r \phi i \tau+\frac{a}{s^{2}}\left(\left(b_{j}-\rho s \phi i+d\right) \tau-2 \ln \left(\frac{1-g e^{d \tau}}{1-g}\right)\right) \\
& D(\tau, \phi)=\frac{b_{j}-\rho s \phi i+d}{s^{2}}\left(\frac{1-g e^{d \tau}}{1-g}\right) \\
& g=\frac{b_{j}-\rho s \phi i+d}{b_{j}-\rho s \phi i-d}, \quad d=\sqrt{\left(\rho s \phi i-b_{j}\right)^{2}-s^{2}\left(2 \mu_{j} \phi i-\phi^{2}\right)} \\
& a=\kappa \theta, \quad b_{1}=\kappa-\rho \theta, \quad b_{2}=\kappa, \quad \mu_{1}=\frac{1}{2}, \quad \mu_{2}=-\frac{1}{2} \text {. }
\end{aligned}
$$

Os parâmetros são estimados pela minimização do erro quadrático médio percentual entre preço de modelo e preço de mercado em relação ao preço de mercado, a exceção da volatilidade, que que é calculada pelo próprio modelo.

\subsubsection{Modelo VG (Variance Gamma)}

É o modelo em tempo contínuo desenvolvido em Carr, Chang e Madan (1998, p. 79-105).

Modela os retornos como um processo estocástico com alta frequência de saltos de baixa magnitude. O processo avalia um movimento Browniano com tendência e volatilidade constantes, em tempos aleatórios dados por um processo com distribuição gama.

$$
C_{t}=S_{t} \Psi\left(d \sqrt{\frac{1-c_{1}}{v}},(\alpha+s) \sqrt{\frac{v}{1-c_{1}}}, \frac{t}{v}\right)-K_{T} e^{-r(T-t)} \Psi\left(d \sqrt{\frac{1-c_{2}}{v}}, \alpha \sqrt{\frac{v}{1-c_{2}}}, \frac{t}{v}\right)
$$


Sendo que:

$$
\begin{gathered}
d=\frac{1}{s} \ln \left(\frac{S_{t}}{K_{T}}\right)+r(T-t)+\frac{t}{v} \ln \left(\frac{1-c_{1}}{1-c_{2}}\right) \\
c_{1}=\frac{v(\alpha+s)^{2}}{2} \quad c_{2}=\frac{v \alpha^{2}}{2} \\
\Psi(a, b, \gamma)=\int_{0}^{\infty} \Phi\left(\frac{a}{\sqrt{g}}+b \sqrt{g}\right) \frac{g^{\gamma-1} e^{-g}}{\Gamma(\gamma)} d g .
\end{gathered}
$$

Os parâmetros são estimados pela minimização do erro quadrático médio percentual entre preço de modelo e preço de mercado em relação ao preço de mercado, inclusive a volatilidade.

\subsubsection{Conclusões}

A conclusão do estudo é dada nas tabelas 4.5 e 4.6, ordenada do maior para o menor desempenho na amostra de validação, para opções de compra, com reestimação diária e tendo como medida de desempenho o erro quadrático médio de hedge e precificação em numerário (mean squared dollar hedging error - MSHE e mean squared dollar valuation error - MSVE).

\begin{tabular}{|c|c|c|c|c|c|}
\hline \multicolumn{6}{|c|}{ HEDGE } \\
\hline \multirow{3}{*}{ MSHE } & VG & SV & BS & GARCH & AHBS \\
\cline { 2 - 6 } & 0,6764 & 0,6885 & 0,6775 & 1,0722 & 1,3067 \\
\hline
\end{tabular}

Tabela 4.5 - Tabela de Desempenho de Hedge

\begin{tabular}{|c|c|c|c|c|c|}
\hline \multicolumn{6}{|c|}{ PRECIFICAÇÃO } \\
\hline \multirow{3}{*}{ MSVE } & SV & BS & VG & AHBS & GARCH \\
\cline { 2 - 6 } & 0,5868 & 0,607 & 0,6076 & 0,7481 & 0,9382 \\
\hline
\end{tabular}

Tabela 4.6 - Tabela de Desempenho de Precificação 
Nesse estudo foi também surpreendente o desempenho do modelo BS. Kim e Kim (2004, p. 136) atribui esse fato à especificidade do mercado coreano, fortemente apoiado no modelo original BSM, que acaba refletindo a prática dos agentes no comportamento do mercado. 


\section{A ESTRATÉGIA BSM}

Neste capítulo analisamos o modelo BSM, abordando sua concepção e suas limitações.

Notação:

$t$ : instante de tempo contínuo, $t \in[0, T]$.

$T$ : instante de expiração da opção.

$S_{t}$ : preço à vista da ação.

$\mu$ : esperança dos log-retornos da ação.

$\sigma$ : volatilidade dos log-retornos da ação.

$C\left(S_{t}, t\right)$ : preço racional da opção.

$K_{T}$ : preço de exercício da opção.

$W_{t}$ : movimento browniano padrão.

$B_{t}:$ preço do ativo livre de risco.

$r$ : taxa contínua de retorno do ativo livre de risco.

$\Phi(w)$ : função acumulada de uma variável estocástica com distribuição normal padrão.

$\Pi(t)$ : carteira composta por uma opção e determinada quantidade de ação.

$\Delta \Pi(t)$ : variação no valor da carteira composta por uma opção e determinada quantidade de ação.

$\theta_{t}:$ quantidade da ação.

$\varepsilon$ : erro de hedge.

$z$ : variável estocástica com distribuição normal padrão.

$\Delta t:$ intervalo de tempo.

$\lambda$ : componente determinístico do erro de hedge.

$\eta$ : componente estocástico do erro de hedge. 


\subsection{O modelo BSM}

O modelo de precificação de opções BSM, que tem como marco de origem os trabalhos Black e Scholes (1973) e Merton (1973), é um modelo de precificação de opções européias em mercado completo e tempo contínuo.

Sua utilização como estratégia de hedge é decorrência direta de sua concepção a partir de um argumento de hedge. O argumento é de existência de uma carteira autofinanciável, composta por ação e opção sobre a ação, cujo retorno é a taxa livre de risco em um período de tempo suficientemente pequeno. O ajuste contínuo de quantidades adequadas de ativobase e ativo livre de risco replica o valor da opção, permitindo criar um hedge instantâneo sem risco, um hedge perfeito, ótimo ou com erro de hedge nulo. Essa carteira é denominada carteira de hedge, de onde é derivado o preço da opção.

Antes de analisar o modelo vamos elencar as premissas de sua concepção. As mesmas fontes que nos permitiram definir anteriormente mercado perfeito, também nos permitem listar as premissas que delimitam a validade do modelo BSM, Cox e Rubinstein (1985, p. 268), Cvitanic e Ma (1996, p. 370), Black e Scholes (1973, p. 640), Siqueira (1999, p. 111112), Smith (1990, p. 346) e Wilmott (1997, p. 41-42). As premissas do modelo BSM são:

- $\quad$ Mercado composto por uma ação, uma opção e um ativo livre de risco.

- $\quad$ Mercado perfeito.

- $\quad$ Tempo contínuo e transações contínuas no mercado.

- $\quad$ Preços sofrem mudanças contínuas, sem saltos.

- $\quad$ A dinâmica de preços segue um movimento Browniano geométrico, no qual a variação do preço da ação em qualquer período não depende do nível do preço da ação no início do período.

- $\quad$ Os preços dos ativos-base seguem um processo de Itô segundo um modelo de distribuição lognormal.

- $\quad$ A variância dos preços é constante ou determinística.

- $\quad$ A opção somente pode ser exercida na data de expiração.

- A taxa livre de risco é conhecida e constante.

- $\quad$ O preço da opção é resultante da interação entre os valores de cinco fatores: o preço à vista da ação $S_{t}$, a variância $\sigma^{2}$ dos log-retornos da ação até a expiração da 
opção, o preço de exercício da opção $K_{T}$, o tempo até a expiração da opção $T-t$ e a taxa de juros livre de risco $r$. Entre esses fatores, somente o preço da ação e o tempo até a expiração constituem variáveis do modelo propriamente dito, sendo que os demais são parâmetros com valores constantes. Também é importante observar que a variância, por constituir uma informação futura, é o único fator não observável do modelo e, portanto, deve ser estimado.

- $\quad$ O valor da opção tem sempre valor positivo $C\left(S_{t}, t\right) \geq 0$.

- $\quad$ O valor da opção nunca é maior do que o preço do ativo-base $C\left(S_{t}, t\right) \leq S_{t}$.

- $\quad$ O valor de uma opção com preço de exercício menor é sempre maior do que o valor de uma opção com preço de exercício maior sobre o mesmo ativo-base $C_{1}\left(S_{t}, t\right)>C_{2}\left(S_{t}, t\right), \quad K_{1}<K_{2}$.

- $\quad$ O preço da opção é sempre maior ou igual ao seu valor intrínseco $C\left(S_{t}, t\right) \geq \max \left\{S_{t}-K_{t} \exp -r(T-t), 0\right\}$.

- $\quad$ O preço do ativo-base corresponde a uma opção perpétua com preço de exercício igual a zero $S_{t}=C\left(S_{t}, \infty\right), \quad K_{\infty}=0$.

O modelo BSM deriva a dinâmica de preços da opção a partir da dinâmica de preços da ação e do ativo livre de risco, utilizando um argumento de hedge e um argumento de nãoarbitragem. Através das premissas do modelo e desses argumentos, deriva a equação conhecida como a equação diferencial parcial de Black-Scholes.

$$
\frac{\partial C\left(S_{t}, t\right)}{\partial t}+\frac{1}{2} \frac{\partial^{2} C\left(S_{t}, t\right)}{\partial S_{t}^{2}} S_{t}^{2} \sigma^{2}+\frac{\partial C\left(S_{t}, t\right)}{\partial S_{t}} r S_{t}-r C\left(S_{t}, t\right)=0
$$

A solução dessa equação diferencial parcial é que define a dinâmica de preços da opção. A demonstração detalhada do modelo BSM é dada no apêndice 1. Neste capítulo são apresentados somente os fundamentos do modelo e as equações que o representam. 


\subsection{Dinâmica de preços dos ativos no modelo BSM}

A dinâmica de preços dos ativos de risco é dada pelos processos estocásticos:

$$
\begin{aligned}
& d S_{t}=\left(v+\frac{\sigma^{2}}{2}\right) S_{t} d t+\sigma S_{t} d W_{t} \\
& d \ln \left(S_{t}\right)=v d t+\sigma d W_{t} .
\end{aligned}
$$

A solução da integração dos processos estocásticos resulta em:

$$
S_{t}=S_{0} e^{v t+\sigma W_{t}}
$$

A dinâmica de preços do ativo livre de risco é dada por:

$$
d B_{t}=r B_{t} d t
$$

A solução da integração do processos determinístico resulta em:

$$
B_{t}=B_{0} e^{-r t}
$$

O preço final da opção e a dinâmica de preços da opção são dados por:

$$
\begin{aligned}
& C\left(S_{T}, T\right)=\max \left\{S_{T}-K_{T}, 0\right\} \equiv\left(S_{T}-K_{T}\right)^{+} \\
& C\left(S_{t}, t\right)=S_{t} \Phi\left(\frac{\ln \frac{S_{t}}{K_{T}}+(T-t)\left(r+\frac{\sigma^{2}}{2}\right)}{\sigma \sqrt{T-t}}\right)-e^{(-r(T-t))} K_{T} \Phi\left(\frac{\ln \frac{S_{t}}{K_{T}}+(T-t)\left(r-\frac{\sigma^{2}}{2}\right)}{\sigma \sqrt{T-t}}\right) .
\end{aligned}
$$




\subsection{Estratégia de hedge no modelo BSM}

A carteira de hedge é dada por:

$$
\begin{aligned}
& \Pi(t)=C\left(S_{t}, t\right)+\theta_{t} S_{t} \\
& d \Pi(t)=d C\left(S_{t}, t\right)+\theta_{t} d S_{t} .
\end{aligned}
$$

A estratégia de hedge é dada por:

$$
\theta_{t}=-\frac{\partial C\left(S_{t}, t\right)}{\partial S_{t}}
$$

Sendo que o resultado da derivação é:

$$
\theta_{t}=-\Phi\left(\frac{\ln \frac{S_{t}}{K_{T}}+(T-t)\left(r+\frac{\sigma^{2}}{2}\right)}{\sigma \sqrt{T-t}}\right)
$$

\subsection{Características e limitações do modelo BSM}

As imperfeições do modelo BSM afetam tanto sua capacidade de precificação como sua capacidade de estabelecimento do hedge. A superação dessas deficiências passa por três caminhos: a introdução de pequenas alterações no modelo que não alterem sua estrutura, o emprego de artifícios de implementação e a criação de modelos alternativos que contemplem os aspectos não cobertos.

Excluindo a criação de modelos alternativos, os outros dois caminhos de implementação do modelo BSM são recorrentes em todos os estudos apresentados. No primeiro grupo, que consiste em pequenas alterações do modelo está a proposição de uma função determinística de volatilidade, conforme Dumas, Fleming e Whaley (1998, p. 2059-2106). 
Essa proposição, como o próprio trabalho conclui, é o limite entre uma alternativa de implementação do modelo BSM e a criação de um novo modelo com volatilidade estocástica. No segundo grupo, que consiste em somente utilizar artifícios de implementação que levem a um melhor desempenho, independente de sua coerência teórica, estão os métodos ad hoc ou não de estimação da volatilidade.

As imperfeições do modelo BSM na representação da realidade foram objeto de diversos estudos, inclusive dos próprios mentores do modelo. Duan (1995, p. 14-25) elenca seis trabalhos sobre o assunto e apresenta os principais vieses do modelo:

- Precificação a menor de opções out-of-the money.

- $\quad$ Precificação a menor de opção sobre ativos de baixa volatilidade.

- $\quad$ Precificação a menor de opções com pequeno prazo para expiração.

- Curva de volatilidade implícita em relação ao preço de exercício em forma de $\mathrm{U}$, que ficou conhecida como o sorriso de volatilidade.

- $\quad H e d g e$ pelo delta excessivo em situações de baixa variância e insuficiente em situações de alta variância.

Esses vieses estão relacionados à volatilidade, que é um dos aspectos mais importantes do modelo propriamente dito e, conforme vimos nos estudos comparativos, pode ser tratada por vários métodos. A volatilidade na teoria que envolve o modelo BMS, no entanto, não está vinculada ao problema econométrico do parâmetro que precisa ser estimado. É a volatilidade média dos preços do ativo-base no período à frente, até a expiração da opção. Dentro dessa interpretação, o problema real de implementação é que seu valor é desconhecido.

Outra característica intrínseca do modelo que resulta em problema econométrico de implementação é o ajuste discreto do hedge em lugar do ajuste contínuo, conforme prescrito pelo modelo, que resulta em erro de hedge. Wilmott (2005, p. 763-782) desvia do foco de estimação da variância para esse outro problema prático de implementação, sugerindo o emprego de uma correção na variância para compensar o erro. Esse estudo será analisado adiante em mais detalhe. 
A imposição de distribuição lognormal dos retornos também constitui uma fonte de imprecisão na representação da realidade, que levou ao desenvolvimento de modelos que incorporam assimetria e curtose.

Mas existem outros fatores não cobertos pelo modelo, mais relacionados ao ambiente e não propriamente ao modelo. Cox e Rubinstein (1985, p. 266-286) avalia especificamente a aplicação da fórmula de Black-Scholes, tratando alguns desses aspectos. São apresentadas soluções de contorno para tratamento de dividendos, exercício antecipado, requerimento de margens, taxas distintas de captação e aplicação, taxa livre de risco variável, volatilidade variável e diferença entre oferta de compra e oferta de venda.

Neste trabalho tratamos somente opções do tipo européia, portanto o exercício antecipado não é um fator a considerar. Não tratamos dividendos, margens, taxa livre de risco variável, taxa livre de risco diferente na captação e aplicação e diferença entre oferta de compra e oferta de venda. Somente a volatilidade variável e o ajuste discreto do hedge serão tratados na metodologia de implementação.

\subsection{Erro de hedge devido ao ajuste em tempo discreto da carteira replicante}

$\mathrm{O}$ argumento de hedge ou neutralização do risco no modelo BSM somente é válido infinitesimalmente. A replicação perfeita somente é possível de forma contínua, pois requer uma relação linear entre os preços do ativo-base e da opção, que é válida somente se as variações de preço forem contínuas em um intervalo de tempo tendendo a zero. Dentro da premissa de ajuste contínuo da carteira replicante, o BSM é um modelo de mercado completo. A violação dessa premissa torna o mercado incompleto e o hedge deixa de ser perfeito, com a consequência direta de erro de hedge.

Conforme Wilmott (2005, p. 765), Boyle e Emanuel (1980, p. 259-282) foi o primeiro estudo que tomou como objeto de análise somente o erro de hedge devido ao ajuste discreto da carteira replicante, excluindo outras considerações quanto à validade $\mathrm{e}$ aderência à realidade das premissas do modelo BSM. 
A análise conclui que o erro de hedge é proporcional ao intervalo de ajuste do hedge e tem um componente determinístico e um estocástico. O erro de hedge é dado pela multiplicação desses componentes pelo o intervalo de tempo de ajuste do hedge, conforme descrito na fórmula a seguir:

$$
\varepsilon=\lambda \eta \Delta t
$$

Sendo $\varepsilon$ o erro de hedge, $\lambda$ o componente determinístico, $\eta$ o componente estocástico e $\Delta t$ o intervalo de tempo.

O componente determinístico é dependente do preço da ação, da variância, do tempo para expiração, da taxa livre de risco e do preço de exercício.

$$
\lambda=\frac{\sigma S_{t}}{2 \sqrt{T-t}} \Phi\left(\frac{\ln \left(\frac{S_{t}}{K_{T}}\right)+(T-t)\left(r+\frac{\sigma^{2}}{2}\right)}{\sigma \sqrt{T-t}}\right)
$$

O componente estocástico é uma variável estocástica com distribuição qui-quadrado com um grau de liberdade.

$$
\begin{aligned}
& \eta=z^{2}-1 \\
& z \sim N(0,1) \\
& \eta \sim \chi_{1}^{2}(0,2) .
\end{aligned}
$$

Wilmott (2005, p. 763-782) estende o trabalho de Boyle e Emanuel (1980, p. 259-282) e não somente analisa o erro de hedge devido ao ajuste discreto, como também soluciona a otimização, minimizando a variância da carteira de hedge.

O estudo parte da definição de um processo estocástico discreto para os incrementos de preço da ação em lugar da equação diferencial estocástica em tempo contínuo. Wilmott 
(2005, p. 767) define um processo de incrementos de preço em tempo discreto, cujos retornos têm distribuição lognormal.

Processo em tempo contínuo:

$$
\begin{aligned}
& d \ln S_{t}=v d t+\sigma d W_{t} \\
& v=\mu-\frac{1}{2} \sigma^{2} .
\end{aligned}
$$

Processo em tempo discreto:

$$
\begin{aligned}
& \Delta \ln S_{t}=v \Delta t+\sigma z_{t} \sqrt{\Delta t} \\
& v=\mu-\frac{1}{2} \sigma^{2} .
\end{aligned}
$$

A carteira de hedge é dada por:

$$
\Pi(t)=C\left(t, S_{t}\right)-\theta_{t} S_{t}
$$

Na impossibilidade de uso do Lema de Itô, devido ao tratamento em tempo discreto, é utilizada uma expansão de Taylor:

$$
\Delta \Pi=\Delta t^{1 / 2} A_{1}\left(z, \theta_{t}\right)+\Delta t A_{2}\left(z, \theta_{t}\right)+\Delta t^{3 / 2} A_{3}\left(z, \theta_{t}\right)+\Delta t^{2} A_{4}\left(z, \theta_{t}\right)+\ldots
$$

Sendo que:

$$
\begin{aligned}
& A_{1}\left(z_{t}, \theta_{t}\right)=\sigma z_{t} S_{t}\left(\frac{\partial C\left(t, S_{t}\right)}{\partial S_{t}}-\theta_{t}\right) \\
& A_{2}\left(z_{t}, \theta_{t}\right)=\frac{\partial C\left(t, S_{t}\right)}{\partial t}+S_{t}\left(\frac{\partial C\left(t, S_{t}\right)}{\partial S_{t}}-\theta_{t}\right)\left(\mu+\frac{1}{2} \sigma^{2}\left(z_{t}^{2}-1\right)\right)+\frac{1}{2} \sigma^{2} z_{t}{ }^{2} S_{t}^{2} \frac{\partial^{2} C\left(t, S_{t}\right)}{\partial S_{t}^{2}}
\end{aligned}
$$


A expansão é truncada no segundo termo e o hedge é otimizado segundo os seguintes critérios:

- $\quad$ O hedge ótimo é o que minimiza a variância da carteira de hedge.

- $\quad$ O preço da opção é dado pelo valor que iguala o retorno esperado da carteira de hedge à taxa livre de risco.

A variância é minimizada através de:

$$
\begin{aligned}
& V[\Delta \Pi(t)]=E\left[(\Delta \Pi(t))^{2}\right]-(E[\Delta \Pi(t)])^{2} \\
& \frac{\partial V[\Delta \Pi(t)]}{\partial \theta}=0 .
\end{aligned}
$$

Resultando em:

$$
\begin{aligned}
& \theta_{t}=\frac{\partial C\left(t, S_{t}\right)}{\partial S_{t}}+\Delta t\left(\frac{1}{2} \sigma^{2} z^{2} S_{t}^{2} \frac{\partial^{2} C\left(t, S_{t}\right)}{\partial S_{t}^{2}}+\ldots\right) \\
& \theta_{t}=\frac{\partial C\left(t, S_{t}\right)}{\partial S_{t}}+\Delta t\left(\frac{1}{2} \sigma^{2} S_{t}^{2} \frac{\partial^{2} C\left(t, S_{t}\right)}{\partial S_{t}^{2}}+\frac{1}{2}\left(z^{2}-1\right) \sigma^{2} S_{t}^{2} \frac{\partial^{2} C\left(t, S_{t}\right)}{\partial S_{t}^{2}}+\ldots\right) .
\end{aligned}
$$

A expressão contém outros termos omitidos, mas o componente estocástico está expresso. Conforme Wilmott (2005, p. 769), pode-se observar na equação que o $\theta_{t}$ é o mesmo componente de replicação da fórmula de Black-Scholes acrescido de um fator de correção que consiste em um termo estocástico descrevendo o erro de hedge.

Aqui encontramos a convergência com o trabalho Boyle e Emanuel (1980, p. 263). A distribuição do erro de hedge é qui-quadrado com um grau de liberdade e esperança nula. Como a variável estocástica $z$ tem distribuição normal padrão, $z^{2}$ tem distribuição quiquadrado com um grau de liberdade. Consequentemente, o componente aleatório de correção do erro de hedge em um intervalo de tempo tem distribuição qui-quadrado com um grau de liberdade, esperança nula e desvio-padrão $\Delta t$. 
Devido à assimetria da distribuição dos erros de hedge, $68 \%$ dos valores são inferiores à esperança e $32 \%$ superiores. Isso significa que há muitos movimentos pequenos para baixo e poucos movimentos grandes para cima.

Um aspecto relevante da análise, entretanto, é que não havendo na prática uma replicação sem risco, o modelo de precificação BSM passa a ser dependente de preferências. Nessa abordagem o problema de preferências foi solucionado por minimização da variância da carteira de hedge.

Wilmott (2005, p. 772-773) verifica também o impacto do ajuste discreto do hedge na precificação da opção. Como a replicação perfeita não existe, o critério de precificação utilizado foi igualar o retorno esperado da carteira de hedge à taxa livre de risco, ao invés de igualar o valor da carteira de hedge à taxa livre de risco.

O resultado foi a seguinte equação diferencial parcial, onde os termos omitidos correspondem a derivadas parciais até as ordens $\frac{\partial^{2} C\left(t, S_{t}\right)}{\partial t^{2}}$ e $\frac{\partial^{4} C\left(t, S_{t}\right)}{\partial S_{t}^{4}}$ :

$$
\frac{\partial C\left(t, S_{t}\right)}{\partial t}+\frac{1}{2} \sigma^{2} S_{t}^{2} \frac{\partial^{2} C\left(t, S_{t}\right)}{\partial S_{t}^{2}}+r S_{t} \frac{\partial C\left(t, S_{t}\right)}{\partial S_{t}}-r C\left(t, S_{t}\right)+\Delta t(\ldots)=0
$$

Pode-se observar que a equação é a própria equação diferencial de Black-Scholes com um termo em $\Delta t$ agregado ao final. O valor da opção para o investidor passa a ser o preço dado pelo modelo BSM, somado a uma correção referente ao preço do risco de hedge.

Wilmott (2005, p. 773) não soluciona a equação, mas mostra uma solução aproximada dos termos omitidos. A solução aproximada foi obtida resolvendo as derivadas parciais omitidas como se o preço da opção fosse dado pela fórmula de Black-Scholes, ignorando o erro devido ao ajuste discreto do hedge, resultando em:

$$
\frac{\partial C\left(t, S_{t}\right)}{\partial t}+\frac{1}{2} \sigma^{2} S_{t}^{2} \frac{\partial^{2} C\left(t, S_{t}\right)}{\partial S_{t}^{2}}+r S_{t} \frac{\partial C\left(t, S_{t}\right)}{\partial S_{t}}-r C\left(t, S_{t}\right)+\frac{1}{2} \Delta t(\mu-r)\left(r-\mu-\sigma^{2}\right) S_{t}^{2} \frac{\partial^{2} C\left(t, S_{t}\right)}{\partial S_{t}^{2}}=0
$$


Se os termos adicionais forem agregados à variância, a equação torna-se então a equação diferencial de Black-Scholes com uma correção na variância.

$$
\begin{aligned}
& \frac{\partial C\left(t, S_{t}\right)}{\partial t}+\frac{1}{2}\left(\sigma^{2}+\Delta t(\mu-r)\left(r-\mu-\sigma^{2}\right)\right) S_{t}^{2} \frac{\partial^{2} C\left(t, S_{t}\right)}{\partial S_{t}^{2}}+r S_{t} \frac{\partial C\left(t, S_{t}\right)}{\partial S_{t}}-r C\left(t, S_{t}\right)=0 \\
& \frac{\partial C\left(t, S_{t}\right)}{\partial t}+\frac{1}{2} \sigma^{2}\left(1+\frac{\Delta t}{2 \sigma^{2}}(\mu-r)\left(r-\mu-\sigma^{2}\right)\right) S_{t}^{2} \frac{\partial^{2} C\left(t, S_{t}\right)}{\partial S_{t}^{2}}+r S_{t} \frac{\partial C\left(t, S_{t}\right)}{\partial S_{t}}-r C\left(t, S_{t}\right)=0
\end{aligned}
$$

A volatilidade corrigida e a razão de hedge passam a ser dados por:

$$
\begin{aligned}
& \sigma^{*}=\sigma\left(1+\frac{\Delta t}{2 \sigma^{2}}(\mu-r)\left(r-\mu-\sigma^{2}\right)\right)^{1 / 2} \\
& \theta_{t}=\frac{\partial C\left(t, S_{t}\right)}{\partial S_{t}}+\Delta t\left(\mu-r+\frac{1}{2} \sigma^{2}\right) S_{t} \frac{\partial^{2} C\left(t, S_{t}\right)}{\partial S_{t}^{2}} .
\end{aligned}
$$

Wilmott (2005, p. 772) sumariza as principais características do erro de hedge devido ao ajuste discreto do hedge:

- $\quad$ O erro esperado de hedge é zero.

- $\quad$ O erro de hedge é assimétrico, com distribuição qui-quadrado se os logretornos tiverem distribuição normal.

- $\quad$ O erro de hedge é proporcional à grega gama da opção.

- $\quad$ O erro de hedge é proporcional ao intervalo de ajuste do hedge.

- $\quad$ Para o delta hedge, somente a distribuição do quadrado dos log-retornos é relevante.

- $\quad$ O desvio padrão da distribuição objetiva do erro de hedge é maior na prática do que na teoria devido à leptocurtose.

- $\quad$ O erro total de hedge tem desvio padrão de ordem da raiz quadrada do intervalo de ajuste do hedge. 
A análise de Wilmott (2005, p. 773) conclui que na prática, em casos com valores de parâmetros típicos e ajuste de hedge diário, a utilização da correção da volatilidade no modelo BSM resulta em uma variação de $1 \%$ a $2 \%$ no preço da opção em relação à utilização do modelo sem correção. Entretanto em mercados com forte tendência a variação pode ser da ordem de 5\% a 10\%, casos que não podem ser ignorados.

Com relação ao hedge, conclui que em mercados com forte tendência a razão de hedge corrigida proporciona uma melhor redução do risco, minimizando a variância e desempenhando um papel de hedge antecipatório, pois a minimização é realizada sobre o intervalo de tempo até o próximo ajuste do hedge e a esperança dos log-retornos aparece na expressão da correção. O resultado é que a correção depende de expectativas. O efeito é importante quando o preço da ação está próximo do preço de exercício e a opção está próxima da data de expiração, momento em que a grega gama é muito grande (variação da taxa de variação do preço da opção).

Wilmott (2005 p. 767) sugere que o modelo apresentado pode ser utilizado com qualquer distribuição de log-retornos, não necessariamente normal, podendo ser inclusive uma distribuição obtida empiricamente. Quanto à volatilidade, sugere que no caso de utilização de uma volatilidade histórica como previsão da volatilidade implícita, esta deve ser calculada sobre um período correspondente ao período de ajuste do hedge. $\mathrm{O}$ inconveniente é a necessidade de estimação de uma esperança, que conforme destaca Luenberger (1998, p. 212-222), em geral tem um intervalo de confiança muito pouco preciso. A estimação dessa esperança pode resultar em um erro maior do que simplesmente ignorá-la.

\subsection{Resumo das características da estratégia de hedge BSM}

Podemos sumarizar o modelo BSM do ponto de vista da estratégia de hedge, pelas seguintes características:

- $\quad$ Hedge pelo delta.

- $\quad$ Hedge dinâmico uniperiódico.

- Distribuição lognormal de retornos do ativo-base. 
- $\quad$ Preços e retornos contínuos.

- $\quad$ Tempo contínuo.

- Volatilidade de retornos do ativo-base adequada conforme avaliação de implementação.

- $\quad$ Mercado completo, portanto hedge teoricamente perfeito, mas na prática imperfeito devido ao ajuste discreto.

- Não há otimização do hedge, uma vez que o modelo é de mercado completo e teoricamente não é esperado erro de hedge. Em lugar de otimização é calculada uma correção a ser aplicada para compensar o erro resultante do ajuste discreto do hedge. 


\section{A ESTRATÉGIA AC}

Neste capítulo descrevemos o desenvolvimento da estratégia AC desenvolvida por Ales Cerny.

\section{Notação:}

$t:$ instante de tempo discreto, $t \in\{0,1, \ldots, T\}$.

$T$ : instante de tempo de expiração da opção de compra européia.

$R f_{t}$ : processo-escalar retorno da taxa livre de risco.

$\beta_{t}$ : processo-escalar desconto cumulativo à taxa livre de risco.

$\mathbf{S}_{t}$ : processo-vetor preço dos ativos-base.

$\boldsymbol{\delta}_{t}$ : processo-vetor dividendo dos ativos-base.

$\mathbf{X}_{t}$ : processo-vetor valor descontado dos ativos-base (incluindo dividendos).

$\Delta \mathbf{X}_{t}$ : processo-vetor retorno descontado dos ativos-base (retorno em excesso à taxa livre de risco).

$\boldsymbol{\theta}_{t}$ : processo-vetor estratégia dinâmica autofinanciável (quantidades de ativos-base).

$x$ : investimento inicial.

$V_{t}^{x, \theta}$ : processo-escalar valor da estratégia autofinanciável com investimento inicial $x$ e $\boldsymbol{\theta}$ ativos-base.

$H_{t}$ : processo-escalar valor esperado do ativo-objeto (preço da opção e valor esperado de uma carteira replicante com erro esperado acumulado de hedge nulo).

$k_{t}$ : processo-escalar proporção de erro propagado.

$\varepsilon_{t}^{2}$ : processo-escalar erro quadrático esperado mínimo acumulado de replicação.

$\varepsilon_{0}^{2}$ : erro quadrático esperado mínimo acumulado de replicação no instante $t=0$.

$e_{t}$ : erro acumulado de hedge no instante $t$.

$\operatorname{ESRE}_{t}^{P}$ : processo-escalar erro quadrático esperado de replicação de um período na medida de probabilidade objetiva.

$E_{t}^{P}[\bullet]$ : esperança condicionada na medida de probabilidade objetiva, que assinala valores aos estados.

$\bullet^{\dagger}$ : vetor ou matriz transpostos. 


\subsection{O modelo AC}

Cerny (2004a, p. 267-312) e Cerny (2004b, p. 1-25) apresentam uma estratégia de hedge generalizada, que contempla a replicação do rendimento de um ativo-objeto descontado à taxa livre de risco, pela combinação linear de um conjunto de ativos-base. Utilizando uma solução de programação dinâmica estocástica, o estudo minimiza o erro quadrático esperado de hedge.

A generalidade da solução permite a incorporação de diversos fatos estilizados que tornam a implementação flexível, sendo o hedge de opção derivado como um caso particular.

A implementação utilizada neste trabalho restringe sua abrangência, tratando o hedge composto por uma ação e o o ativo livre de risco como ativos-base e uma opção como ativo-objeto. Os retornos são considerados independentes e identicamente distribuídos e a taxa livre de risco é considerada constante.

A distribuição dos retornos é não-paramétrica, obtida a partir do histórico de retornos discretizados. A partir da distribuição estimada dos retornos, os preços são dispostos em uma árvore de estados, utilizada para cálculo da estratégia de hedge.

\subsection{Dinâmica de preços dos ativos no modelo AC}

A dinâmica de preços dos ativos de risco parte de uma distribuição não-paramétrica de logretornos de $n$ níveis.

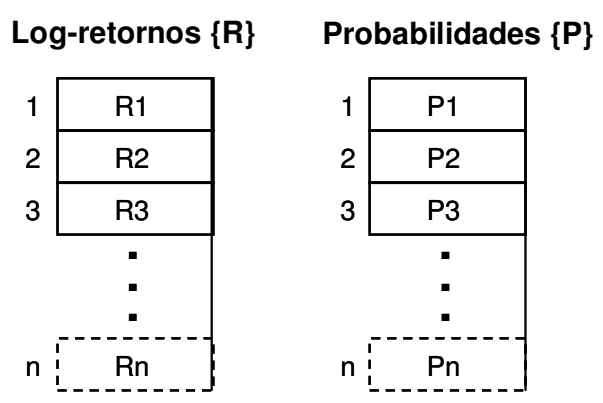


Figura 6.1 - Retornos e Probabilidades

Dado um preço inicial, os preços do ativo-base $S_{t}$ são expandidos em uma árvore de estados possíveis em instantes equidistantes de tempo.

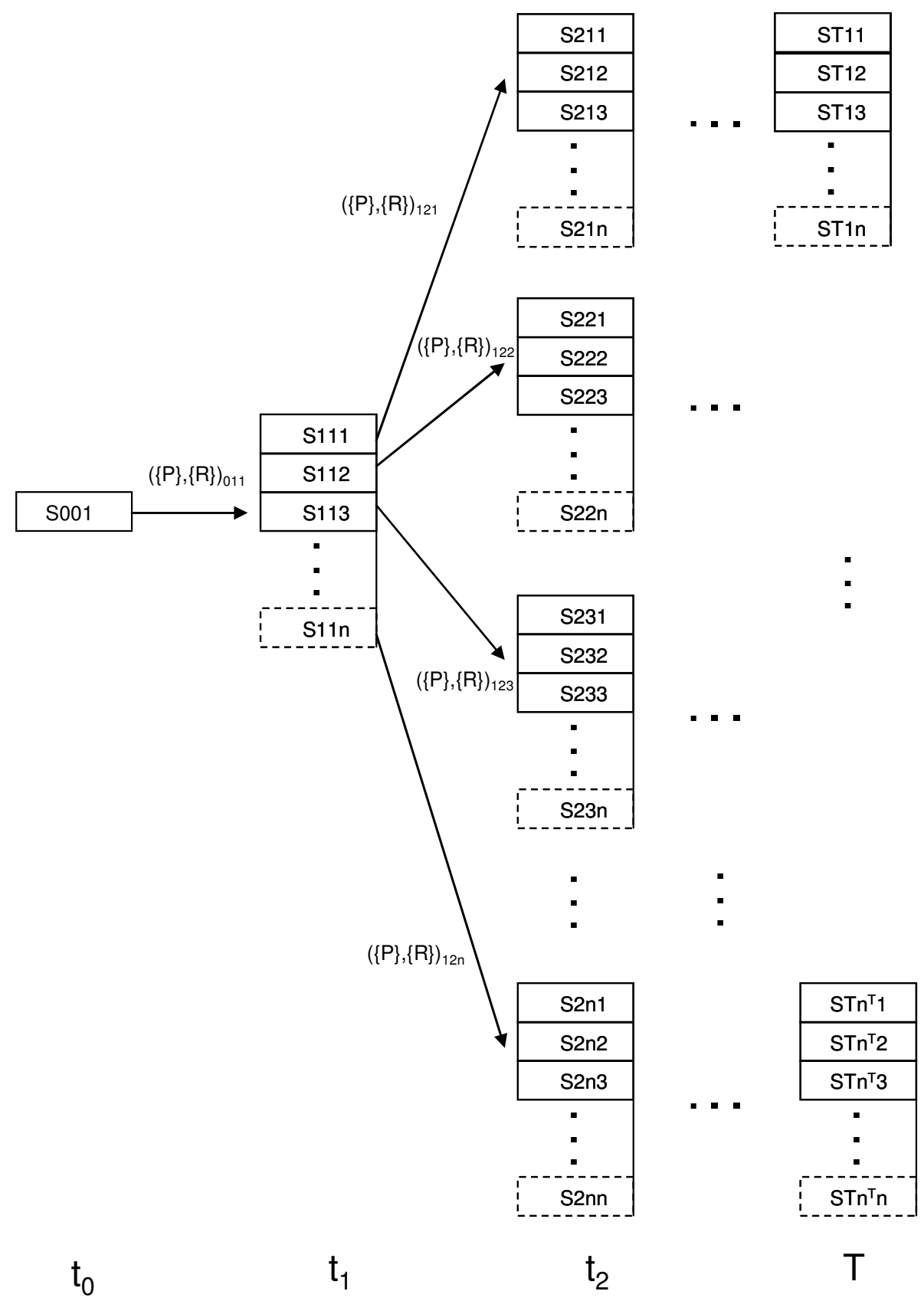

Figura 6.2 - Árvore de Estados de Preços 
$\mathrm{O}$ ativo livre de risco, tendo retorno constante $R f_{t}$, possui o mesmo valor em todos os instantes de tempo e sua dinâmica é descrita pelo processo $\beta_{t}$ de acumulação da taxa.

$$
\begin{aligned}
\beta_{t} & =R f_{0} R f_{1} \ldots R f_{T-1} \\
& =\prod_{i=0}^{T-1} R f_{i} \\
\beta_{0} & =1 .
\end{aligned}
$$

A partir da árvore de estados de preços e do processo de desconto é possível calcular os retornos descontados do ativo dados por:

$$
\Delta \mathbf{X}_{t} \equiv \mathbf{X}_{t}-\mathbf{X}_{t-1}=\frac{1}{\beta_{t-1}}\left(\frac{\mathbf{S}_{t}+\boldsymbol{\delta}_{t}}{R f_{t-1}}-\mathbf{S}_{t-1}\right)
$$

Dados o preço do ativo-base $S_{T}$ ao final de $T$ períodos e o preço de exercício da opção $K_{T}$, o rendimento da opção $H_{T}$ é dado por:

$$
H_{T}=\max \left\{S_{T}-K_{T}, 0\right\} \equiv\left(S_{T}-K_{T}\right)^{+} .
$$

\subsection{A solução de programação dinâmica da estratégia de hedge AC}

Por tratar-se de um modelo de mercado incompleto, pois existem mais estados da natureza do que ativos, a operação resulta em erro de replicação. A estratégia de hedge minimiza o erro quadrático esperado de replicação ao final de $T$ períodos.

O erro acumulado de hedge $e_{t}$ é a diferença entre o valor de uma carteira replicante $V_{t}^{x, \theta} \mathrm{e}$ o ativo-objeto $H_{t}$, todos esses valores associados a cada instante de tempo e a cada estado de preço do ativo-base, também dispostos em árvores de estado. O erro acumulado de hedge é dado por: 


$$
e_{t}=V_{t}^{x, \theta}-H_{t}
$$

O valor da carteira replicante descontado pela taxa livre de risco acumulada $\beta_{t}$, é o valor do investimento inicial $x=V_{0}^{x, \theta}$ somado aos rendimentos $\Delta \mathbf{X}_{t}$, em excesso à taxa livre de risco do ativo-base e descontados à taxa livre de risco. Os rendimentos são resultantes da adoção de uma estratégia $\boldsymbol{\theta}_{t}$ em cada instante de tempo e estado correspondente. Também é expandida uma árvore de estados para o valor da carteria replicante e para a estratégia, idênticas à árvore de estados de preços.

O valor descontado da carteira replicante é dado pelo valor inicial da carteira, somado aos rendimentos resultantes da aplicação da estratégia $\boldsymbol{\theta}_{t}$ em todos os períodos.

$$
V_{t}^{x, \theta} \beta_{t}^{-1}=V_{0}^{x, \theta}+\sum_{i=0}^{T} \boldsymbol{\theta}_{i-1}^{\dagger} \Delta \mathbf{X}_{i}
$$

O objetivo é obter o investimento inicial $x$ e a estratégia $\boldsymbol{\theta}$ que minimizam o erro quadrático esperado acumulado de hedge no instante final $T$ em relação ao instante inicial 0 , com a manutenção da carteira replicante $V_{t}^{x, \theta}$.

$$
\mathcal{E}_{0}^{2}=\min _{x, \theta_{0}, \ldots, \theta_{T-1}} E_{0}^{P}\left[\left(V_{T}^{x, \theta}-H_{T}\right)^{2}\right]
$$

A partir dessas premissas é desenvolvida a solução de programação dinâmica estocástica que fornece a estratégia ótima e a dinâmica de preços da opção.

A minimização do erro esperado acumulado de hedge é um problema de controle ótimo estocástico. Saridis (1995, p. 110) formula a solução de um problema de controle ótimo estocástico como a obtenção de uma função de controle determinística, que otimiza uma função de custo estocástica representativa do comportamento de um sistema. O sistema é descrito por estados estocásticos, parâmetros e momentos. A função controle utiliza toda a informação passada e otimiza a incerteza futura. 
O erro acumulado de hedge $e_{t}$ descreve uma trajetória que é função da variável estocástica que representa os retornos do ativo-base $\mathbf{X}$, à qual são aplicados controles $x$ e $\boldsymbol{\theta}, i . e ., o$ investimento inicial e a estratégia de hedge.

Pelo princípio da optimalidade de Bellman, a partir de qualquer ponto da trajetória ótima a otimização desse ponto em diante resulta na trajetória ótima.

Extraindo sucessivamente pela lei das esperanças iteradas a esperança do erro quadrático de um período e desmembrando o problema de minimização pelo princípio da optimalidade de Bellman:

$$
\begin{aligned}
\varepsilon_{0}^{2} & =\min _{x, \theta_{0}, \ldots, \theta_{T-1}} E_{0}^{P}\left[\left(V_{T}^{x, \theta}-H_{T}\right)^{2}\right] \\
& =\min _{x, \theta_{0}, \ldots, \theta_{T-1}} E_{0}^{P}\left[E _ { T - 1 } ^ { P } \left[\left(V_{T}^{x, \theta}-H_{T}\right)^{2} \rrbracket\right.\right. \\
& =\min _{x, \theta_{0}, \ldots, \theta_{T-2}} E_{0}^{P}\left[\min _{\theta_{T-1}} E_{T-1}^{P}\left[\left(V_{T}^{x, \theta}-H_{T}\right)^{2}\right]\right] \\
& =\min _{x, \theta_{0}, \ldots, \theta_{T-4}} E_{0}^{P}\left[\min _{\theta_{T-3}} E_{T-3}^{P}\left[\min _{\theta_{T-2}} E_{T-2}^{P}\left[\min _{\theta_{T-1}} E_{T-1}^{P}\left[\left(V_{T}^{x, \theta}-H_{T}\right)^{2}\right]\right]\right] .\right.
\end{aligned}
$$

A solução do problema de minimização gera um procedimento recursivo de cálculo do erro quadrático mínimo esperado acumulado de hedge na forma $J_{t}=k_{t}\left(V_{t}^{x, \theta}-H_{t}\right)^{2}+\varepsilon_{t}{ }^{2}$, sendo que $J_{0}=\varepsilon_{0}$. O processo recursivo parte de $H_{T}$ e $\Delta \mathbf{X}_{t}$ obtidos pela expansão da árvore de estados de preços. Aplicando recursivamente a solução de $t=T$ até $t=0$, obtém-se a solução do problema de minimização com os elementos descritos a seguir.

O processo erro quadrático mínimo esperado acumulado de hedge $\varepsilon_{t}{ }^{2}$, sendo $\varepsilon_{T}=0$, é dado por:

$$
\varepsilon_{t-1}{ }^{2}=E_{t-1}^{P}\left[\varepsilon_{t}{ }^{2}\right]+E_{t-1}^{P}\left[k_{t} H_{t}{ }^{2}\right]-k_{t-1} H_{t-1}{ }^{2}-E_{t-1}^{P}\left[k_{t} H_{t} \Delta \mathbf{X}_{t}\right]\left(E_{t-1}^{P}\left[k_{t} \Delta \mathbf{X}_{t} \Delta \mathbf{X}_{t}\right]\right)^{-1} E_{t}^{P}\left[k_{t} H_{t} \Delta \mathbf{X}_{t}\right]
$$


O processo proporção de erro propagado $k_{t}$, sendo $k_{T}=1$, é dado por:

$$
k_{t-1}=R f_{t-1}^{2}\left(E_{t-1}^{P}\left[k_{t}\right]-E_{t-1}^{P}\left[k_{t} \Delta \mathbf{X}_{t}\right]\left(E_{t-1}^{P}\left[k_{t} \Delta \mathbf{X}_{t} \Delta \mathbf{X}_{t}\right]\right)^{-1} E_{t-1}^{P}\left[k_{t} \Delta \mathbf{X}_{t}\right]\right) .
$$

O processo de valor médio $H_{t}$, que representa o preço da opção, sendo

$H_{T}=\max \left\{S_{T}-K_{T}, 0\right\}$ é dado por:

$$
H_{t-1}=E_{t-1}^{P}\left[\frac{R f_{t-1}^{2}}{k_{t-1}}\left(k_{t}-\left(E_{t-1}^{P}\left[k_{t} \Delta \mathbf{X}_{t}\right] E_{t-1}^{P}\left[k_{t} \Delta \mathbf{X}_{t} \Delta \mathbf{X}_{t}\right]\right)^{-1} k_{t} \Delta \mathbf{X}_{t}\right) \frac{H_{t}}{R f_{t-1}}\right] .
$$

Pode-se observar na expressão, se for extraído o termo

$m_{t t t-1}=\frac{R f_{t-1}^{2}}{k_{t-1}}\left(k_{t}-\left(E_{t-1}^{P}\left[k_{t} \Delta \mathbf{X}_{t}\right] E_{t-1}^{P}\left[k_{t} \Delta \mathbf{X}_{t} \Delta \mathbf{X}_{t}\right]\right)^{-1} k_{t} \Delta \mathbf{X}_{t}\right)$, que a expressão restante representa o preço da opção descontado à taxa livre de risco. O termo extraído pode ser interpretado como a mudança de medida de probabilidade da precificação pela teoria martingale, mas, por tatar-se de mercado incompleto, não existe uma mudança de medida de probabilidade equivalente e esse processo não representa de fato uma mudança de medida.

O processo-vetor estratégia ótima dinâmica autofinanciável é dado por:

$\boldsymbol{\theta}_{t}^{\mathrm{D}^{\dagger}}=-\left(\beta_{t+1}\right)^{-1} E_{t}^{P}\left[k_{t+1} \Delta \mathbf{X}_{t+1}\left(R f_{t} V_{t}^{x, \theta}-H_{t+1}\right)\right]\left(E_{t}^{P}\left[k_{t+1} \Delta \mathbf{X}_{t+1} \Delta \mathbf{X}_{t+1}^{\dagger}\right]\right)^{-1}$.

Com esses elementos tem-se que o investimento inicial ótimo é dado por $V_{0}^{x, \theta}=x=H_{0}$. Aplicando a estratégia à carteira replicante, agora de $t=0$ até $t=T$, obtém-se o resultado do hedge. O processo valor da carteira replicante é dado por:

$V_{t+1}^{x, \theta}=R f_{t} V_{t}^{x, \theta}+\beta_{t+1} \boldsymbol{\theta}_{t}^{D} \Delta \mathbf{X}_{t+1}$

A demonstração detalhada do modelo é apresentada no apêndice 2 . 


\subsection{Características e limitações da estratégia AC}

A estratégia AC apresenta uma restrição relacionada ao fato de ser uma estratégia multiperiódica. No caso de adaptação à opção do tipo européia, o hedge deve ser realizado sempre até a data de expiração. Somente na expiração pode ser determinado o rendimento da opção, dado o estado de preço do ativo-base. Além de que o erro quadrático esperado acumulado de hedge é minimizado em relação a esse instante de tempo, o que não implica otimização em relação a instantes anteriores. Otimizar o hedge em relação a um instante de tempo anterior à expiração implica determinar o rendimento teórico da opção nesse instante, dado o estado de preço do ativo-base. O aspecto negativo dessa abordagem é que esse rendimento é abstrato, pois a opção não pode ser exercida nesse instante, portanto não há rendimento definido, somente estimado. Já na data de expiração, o rendimento da opção é determinado de forma inequívoca pela diferença entre o preço do ativo-base e o preço de exercício.

Outra característica da estratégia AC é que somente é aplicável a processos de preço sem saltos. Cerny (2004b, p. 23) sugere a possibilidade de expandir o modelo para processos de preço descontínuos.

Pela sua própria concepção, o modelo restringe-se ao paradigma de média-variância, que equivale a maximizar a utilidade para um agente com função de utilidade quadrática. Sua extensão para incorporar a teoria de preferências requer a extensão do desenvolvimento, como também realça Cerny (2004a, p. 290).

Por fim, a principal limitação da estratégia AC, no caso de retornos não-IID, está relacionada a limitações computacionais, pela quantidade de estados a serem tratados. Uma implementação de $m$ níveis em $T$ períodos requer, somente no período final, o tratamento de $m^{T}$ estados, chegando-se facilmente aos limites computacionais. 


\subsection{Resumo das características da estratégia de hedge AC}

Podemos sumarizar a estratégia AC do ponto de vista da estratégia de hedge de opção, pelas seguintes características:

- $\quad$ Hedge pelo delta.

- Hedge dinâmico multiperiódico e autofinanciável.

- $\quad$ Conjunto de qualquer quantidade de ativos-base combinada com a taxa livre de risco.

- $\quad$ Hedge de um ativo objeto de qualquer natureza.

- Distribuição de retornos do ativo-base paramétrica ou não paramétrica, conforme método de implementação.

- Retornos não independentes e identicamente distribuídos ou a critério do método de implementação.

- $\quad$ Preços e retornos discretos.

- $\quad$ Tempo discreto.

- Taxa livre de risco estocástica ou determinística, conforme método de implementação.

- Volatilidade de retornos do ativo-base adequada conforme método de implementação.

- $\quad$ Mercado perfeito incompleto e consequentemente hedge imperfeito.

- $\quad$ Otimização do hedge por minimização do erro quadrático médio de hedge, solucionada por programação dinâmica.

- $\quad$ Solução recursiva adequada à implementação computacional. 


\section{ESTRATÉGIA HN}

Neste capítulo descrevemos o desenvolvimento do modelo GARCH de Heston e Nandi (2000, p. 585-625).

Notação:

$t:$ instante de tempo discreto, $t \in\{0,1, \ldots, T\}$.

$T$ : instante de expiração da opção.

$r$ : taxa contínua de retorno do ativo livre de risco.

$S_{t}$ : preço da ação.

$h_{t}$ : variância condicionada dos retornos da ação.

$\lambda$ : preço de mercado do risco.

$\omega$ : variância de longo prazo.

$\alpha_{i}$ : parâmetro de média móvel.

$\beta_{i}$ : parâmetro auto-regressivo.

$\lambda$ : parâmetro de assimetria.

$C\left(S_{t}, t\right)$ : preço de mercado da opção.

$C_{M}$ : preço racional da opção.

$Z_{t}$ : variável estocástica com distribuição normal padrão.

$\theta_{t}:$ quantidade da ação.

$\varepsilon$ : resíduo.

$e_{i, t}$ : diferença entre o preço de mercado e o preço de modelo da opção.

$f *(\bullet)$ : função geratriz de momentos ou função característica na medida neutralizadora do risco.

\section{1 modelo GARCH aplicado a opções}

Um dos trabalhos seminais na abordagem de precificação de opções utilizando modelos GARCH foi Duan (1995, p. 13-32). O objetivo do trabalho é a modelagem de um processo 
de preço de ativos financeiros, incorporando volatilidade estocástica em tempo discreto, para precificação de opções do tipo européia.

A volatilidade estocástica, assim como a função determinística de volatilidade é mais uma das formas de tentar suprir a deficiência do modelo BSM de volatilidade constante, porém, ao contrário da volatilidade determinística, ultrapassa o limite de aperfeiçoamento do modelo BSM para dar origem a uma nova gama de modelos. Apesar disso, Duan (1995, p. 13-32) procurou afastar-se o mínimo possível dos fundamentos do modelo BSM, que transforma-se em um caso particular do seu modelo quando os termos GARCH são anulados, resultando em um modelo de variância constante.

Entretanto o modelo não tem solução analítica, sendo necessário lançar mão de métodos de simulação para cálculo de preço e hedge. Duan (1995, p. 20-25) mostra testes do modelo, com os preços estimados por simulação de Monte Carlo. Não é apresentada uma comparação direta de desempenho com o modelo BSM. O trabalho limita-se a constatar que o modelo GARCH incorpora caracterísitcas que suprem satisfatoriamente as deficiências do modelo BSM relacionados à premissa de volatilidade constante, comparando cálculos de preço e hedge para opções com diferentes prazos de expiração e moneyness.

A precificação é dada pela teoria martingale, como sendo a esperança do preço da opção na medida neutralizadora do risco. Para solucionar o problema de incompletude do mercado, introduzido pela volatilidade estocástica, Duan (1995, p.14) recorreu ao conceito de LRNVR (Local Risk Neutral Valuation Relationship) e estabeleceu condições no modelo para sua validade. O conceito da LRNVR é de que é possível a precificação da opção pela teoria martingale, dado que a variância condicionada dos log-retornos um período à frente seja invariante com relação à mudança de medida de probabilidade para a medida neutralizadora do risco. A LRNVR também requer distribuição normal dos log-retornos na medida neutralizadora do risco. Essa condição assegura a precificação por mudança de medida de probabilidade independente de peferências e assegura a possibilidade de hedge contínuo perfeito. Essa independência de preferências tem sentido restrito, pois Duan (1995, p.16) enuncia um teorema segundo o qual a LRNVR é equivalente à maximização da utilidade para um agente com função utilidade da família CRRA. 
Duan (1995, p. 15) define a dinâmica de preços da ação como dada por um modelo $\operatorname{GARCH}(1,1)$.

A equação da dinâmica de preços é dada por:

$$
\begin{gathered}
\ln \left(\frac{S_{t}}{S_{t-1}}\right)=r+\lambda \sqrt{h_{t}}-\frac{1}{2} h_{t}+\varepsilon_{t} \\
\left\{\varepsilon_{t}\right\} \sim \operatorname{GARCH}(1,1) \Rightarrow \varepsilon_{t} \sim N\left(0, h_{t}\right) .
\end{gathered}
$$

A dinâmica da variância é dada por:

$$
h_{t}=\alpha_{0}+\alpha_{1} \varepsilon_{t-1}+\beta_{1} h_{t-1}
$$

Através de uma modificação na dinâmica de preços na medida de probabilidade objetiva, é obtido o processo na medida de probabilidade neutralizadora do risco, que tem como valor esperado o rendimento do ativo livre de risco. A dinâmica de preços na medida de probabilidade neutralizadora do risco é dada por:

$$
\begin{gathered}
\ln \left(\frac{S_{t}}{S_{t-1}}\right)=r-\frac{1}{2} h_{t}+\xi_{t} \\
\left\{\xi_{t}\right\} \sim \operatorname{GARCH}(1,1) \quad \Rightarrow \quad \xi_{t} \sim N\left(0, h_{t}\right) .
\end{gathered}
$$

A dinâmica da variância na medida de probabilidade neutralizadora do risco é, então, dada por:

$$
h_{t}=\alpha_{0}+\alpha_{1}\left(\xi_{t-1}-\lambda \sqrt{h_{t-1}}\right)^{2}+\beta_{1} h_{t-1} \text {. }
$$


A principal restrição desse modelo é a inexistência de solução fechada para precificação e hedge e, por consequência, requer métodos de simulação de Monte Carlo para cálculo. $\mathrm{O}$ preço racional da opção é calculado por simulação de Monte Carlo através da equação:

$$
C\left(S_{t}, t\right)=e^{-(T-t) r} E_{t}^{Q}\left[\max \left\{S_{T}-K_{T}, 0\right\}\right] .
$$

A razão de hedge é calculada por simulação de Monte Carlo através da equação:

$$
\theta_{t}=e^{-(T-t) r} E_{t}^{\mathrm{Q}}\left[\frac{S_{T}}{S_{t}} I_{\left(S_{T} \geq K_{T}\right)}\right] \text {. }
$$

\subsection{A dinâmica de preços do modelo GARCH HN}

O modelo GARCH de Heston e Nandi (2000, p. 585-625) é um modelo de precificação de opções similar ao modelo GARCH de Duan (1995, p. 13-32), que foi especificamente desenvolvido para obtenção de uma solução fechada, evitando recorrer aos métodos de simulação de Monte Carlo, que requerem um intenso trabalho computacional. O modelo foi desenvolvido sobre o conceito de LRNVR de Duan (1995, p. 14-17), mas as equações foram modificadas. A solução é apresentada para modelos GARCH com qualquer quantidade de defasagens, mas a estimação e os testes comparativos foram realizados somente para o modelo GARCH(1,1).

A equação da dinâmica de preços é dada por:

$$
\ln \left(S_{t}\right)=\ln \left(S_{t-\Delta t}\right)+r+\lambda h_{t}+\sqrt{h_{t}} Z_{t}
$$

A equação da dinâmica de preços é dada por:

$$
h_{t}=\omega+\alpha\left(Z_{t-\Delta t}-\gamma \sqrt{h_{t-\Delta t}}\right)^{2}+\beta h_{t-\Delta t} .
$$


Heston e Nandi (2000, p. 590-591) mostra que os processos neutralizadores do risco da dinâmica de preços e da variância tem aproximadamente a mesma forma dos processos na medida de probabilidade objetiva.

A dinâmica de preços na medida de probabilidade neutralizadora do risco é dada por:

$$
\ln \left(S_{t}\right)=\ln \left(S_{t-\Delta t}\right)+r-\frac{1}{2} h_{t}+\sqrt{h_{t}} Z_{t}
$$

A dinâmica da variância na medida de probabilidade neutralizadora do risco é dada por:

$$
h_{t}=\omega+\alpha\left(Z_{t-\Delta t}-\gamma \sqrt{h_{t-\Delta t}}\right)^{2}+\beta h_{t-\Delta t} .
$$

O preço da opção é calculado pela teoria martingale, da mesma forma que o modelo de Duan (1995, p. 13-32), porém ao invés de recorrer à solução por simulação, foi derivada uma solução analítica para a expressão de precificação.

$$
C\left(S_{t}, t\right)=e^{-(T-t) r} E_{t}^{Q}\left[\max \left\{S_{T}-K_{T}, 0\right\}\right] .
$$

A dinâmica de preços da opção é obtida na forma de uma integral que requer métodos numéricos de solução. Essa é a solução apresentada como fechada. 


$$
\begin{aligned}
& C\left(S_{t}, t\right)=\frac{1}{2} S_{t}+\frac{1}{\pi} e^{-r(T-t)} \int_{0}^{\infty} \operatorname{Re}\left[\frac{K_{T}^{-i \phi} f^{*}(i \phi+1)}{i \phi}\right] d \phi-K_{T} e^{-r(T-t)}\left(\frac{1}{2}+\frac{1}{\pi} \int_{0}^{\infty} \operatorname{Re}\left[\frac{K_{T}^{-i \phi} f^{*}(i \phi)}{i \phi}\right]\right) d \phi \\
& f^{*}(\varphi)=\left(S_{t}\right)^{\varphi} \exp \left(A(t, T, \varphi)+B(t, T, \varphi) h_{t+1}\right) \\
& A(t, T, \varphi)=A(t+1, T, \varphi)+\varphi r+B(t+1, T, \varphi) \omega-\frac{1}{2} \ln (1-2 \alpha B(t+1, T, \varphi)) \\
& B(t, T, \varphi)=\varphi(\lambda+\gamma)-\frac{1}{2} \gamma^{2}+\beta B(t+1, T, \varphi)+\frac{1 / 2(\varphi-\gamma)^{2}}{1-2 \alpha_{1} B_{1}(t+1, T, \varphi)} \\
& A(T, T, \varphi)=B(T, T, \varphi)=0 .
\end{aligned}
$$

O desenvolvimento do modelo é apresentado detalhadamente no apêndice 3.

\subsection{O modelo GARCH da estratégia de hedge HN}

Da mesma forma que no modelo BSM, a estratégia de hedge é dada pela derivada parcial do preço da opção em relação ao preço da ação. Como a fórmula do preço racional da opção tem o mesmo formato da fórmula de Black-Scholes, que é a multiplicação do preço do ativo-base por uma probabilidade neutralizadora do risco $P_{1}$, menos o preço de exercício descontado à taxa livre de risco multiplicado pela probabilidade neutralizadora do risco $P_{2}$, a estratégia de hedge é dada por $P_{1}$.

$$
\begin{aligned}
& \theta_{t}=-\frac{\partial C\left(S_{t}, t\right)}{\partial S_{t}} \\
& C\left(S_{t}, t\right)=S_{t} P_{1}-K_{T} e^{-r(T-t)} P_{2} \\
& \theta_{t}=-\frac{1}{2}-\frac{1}{\pi} \int_{0}^{\infty} \operatorname{Re}\left[\frac{K_{T}^{-i \phi} f^{*}(i \phi+1)}{i \phi f^{*}(1)}\right] d \phi .
\end{aligned}
$$




\subsection{Características e limitações da estratégia HN}

Por manter todas as premissas do modelo BSM, a exceção da volatilidade constante, o modelo GARCH apresenta praticamente as mesmas limitações do modelo BSM.

A premissa de mercado localmente completo, analogamente ao modelo BSM, requer um ajuste contínuo do hedge, inexistente na prática. Neste caso, porém, não encontramos referências que tratem o erro de hedge devido a esse ajuste discreto, como o trabalho de Wilmott (2005, p. 763-782) desenvolvido para o modelo BSM.

A estimação do modelo também abre possibilidades de estimação que conduzem a resultados diferentes.

A primeira questão de implementação é a periodicidade de reestimação do modelo. Heston e Nandi (2000, p. 596-601) apresenta dois estudos, um com reestimação semestral e outro com reestimação semanal do modelo, tento este último método apresentado melhores resultados, mas não há nenhuma justificativa para a periodicidade adotada.

A segunda questão de implementação é o método de estimação dos parâmetros. Modelos GARCH, em geral, são estimados pelo método de máxima verossimilhança, como apresentado em Bollerslev (1986, p. 307-327) ou Nelson (1991, p. 347-370). Heston e Nandi (2000, p. 596-601) utiliza máxima verossimilhança, mas também um método de mínimos quadrados não-lineares. O método é utilizado para minimizar o erro quadrático entre preço de mercado da opção e preço de modelo da opção calculado sobre a série histórica. O preço de mercado é regredido no preço de modelo com amostras semanais extraídas às quartas-feiras, de preços de opções com diversos exercícios e prazos de expiração.

$$
\begin{aligned}
& (\hat{\omega}, \hat{\alpha}, \hat{\beta}, \hat{\gamma}, \hat{\lambda})=\arg \min _{\alpha, \beta, \gamma, \lambda, \omega} \sum_{t=1}^{T} \sum_{i=1}^{n_{t}} e_{i, t}{ }^{2} \\
& C_{M}=C\left(S_{t}, t\right)+e_{i, t}{ }^{2}
\end{aligned}
$$


Esse método requer a integração entre o método de mínimos quadrados não-lineares e o método numérico de solução da integral de cálculo do preço da opção. Somente a implementação conjunta dos métodos permite que os parâmetros utilizados nas iterações de minimização do erro quadrático sejam utilizados para estimação da variância e, juntamente com essa estimação, transferidos ao método numérico de resolução da integral de cálculo de preço da opção. É interessante observar que embora os dados de opções sejam semanais, a previsão de variância condicionada um período à frente é computada diariamente pelo modelo estimado com os parâmetros intermediários para cálculo do preço da opção. Heston e Nandi (2000, p. 596-601) indica ter utilizado o método de LevenbergMarquardt para minimização do erro quadrático médio e o método de Romberg para solução da integral.

Modelos GARCH também apresentam sensibilidade à inicialização da variância. Heston e Nandi (2000, p. 596) argumenta que o processo de volatilidade com reversão à média torna o modelo menos sensível ao valor inicial atribuído à variância.

\subsection{Resumo das características da estratégia de hedge $\mathrm{HN}$}

Podemos sumarizar o modelo GARCH do ponto de vista da estratégia de hedge, pelas seguintes características:

- $\quad$ Hedge pelo delta.

- $\quad$ Hedge dinâmico uniperiódico.

- Distribuição de retornos do ativo-base descritos por um processo específico com média dependente da variância condicionada e variância condicionada seguindo um processo GARCH.

- $\quad$ Preços e retornos discretos.

- $\quad$ Tempo discreto.

- Volatilidade estocástica de retornos do ativo-base.

- $\quad$ Mercado localmente completo com hedge contínuo perfeito.

- Hedge em mercado localmente completo, portanto hedge teoricamente perfeito, mas na prática imperfeito devido ao ajuste discreto. 
- $\quad$ Não há otimização do hedge, uma vez que o modelo é de mercado completo e teoricamente não é esperado erro de hedge. Não há aplicação de correção para compensar o erro resultante. 


\section{AVALIAÇÃO COMPARATIVA}

\subsection{Discussão teórica}

Os modelos em Finanças buscam a representação do comportamento dos preços dos ativos financeiros por meio de formulações matemáticas. Podemos dizer que um modelo tem um melhor desempenho quanto melhor for capaz de mimetizar o mercado financeiro. Os modelos podem ser compostos por parâmetros constantes, variáveis determinísticas e variáveis estocásticas.

A complexidade dos modelos é diretamente afetada pela quantidade de variáveis e parâmetros que tratam. Outra característica que afeta a complexidade dos modelos é sua capacidade de incorporar fatos estilizados. Fatos estilizados são generalizações imprecisas de regularidades empíricas. Cont (2001, p. 223) define fatos estilizados como propriedades comuns a diversos instrumentos financeiros, mercados e períodos de tempo, observadas por estudos independentes. Hafner e Herwartz (2001, p. 1) elenca como fatos estilizados dos retornos de ações: a heteroscedasticidade condicionada, a leptocurtose condicionada e o efeito de alavancagem. Podemos acrescentar a esse conjunto, para prosseguirmos em nossa análise, a precificação do risco, que é a dependência do nível médio de retornos da volatilidade e a reversão à média, que é a tendência de volta do nível de preços ou volatilidade aos valores médios após desvios ocasionados por choques.

Uma vez definida a estrutura do modelo, incorporando as principais variáveis de influência e principais fatos estilizados, o modelo é completado pela estimação dos parâmetros. A partir do modelo pode-se analisar e e inferir conclusões a respeito do fenômeno que ele representa.

É importante observar que não há relação entre a complexidade e o desempenho dos modelos, haja vista a robustez do modelo BSM comprovada nos estudos apresentados na revisão da literatura. Tratando especificamente do problema de hedge, objeto deste trabalho, um argumento apresentado nos estudos como sendo um dos que mais explica o desempenho dos modelos é a estabilidade dos parâmetros do modelo ao longo do tempo, 
que se reflete na baixa variação dos parâmetros nas reestimações. Kim e Kim (2004, p. 129) avalia a estabilidade dos parâmetros ao longo do tempo e alerta para o fato de que uma maior quantidade de parâmetros leva a um ajuste excessivo do modelo aos dados utilizados para estimação, prejudicando o ajuste estrutural do modelo ao fenômeno e prejudicando seu desempenho.

Outro aspecto do desempenho, abordado por Nandi e Waggoner (2000, p. 39) é que, para um mesmo modelo, desempenho superior em precificação não implica desempenho superior em hedge. O estudo constatou uma diferença menor de desempenho entre modelos em hedge do que na precificação. A explicação dada é que os vieses de um modelo que levam a erros de precificação podem ser estáveis no tempo, consequentemente, não prejudicam o desempenho de hedge.

Observamos que, embora haja uma convergência quanto às razões pelo melhor desempenho dos modelos, os estudos são contraditórios quanto aos modelos que apresentam melhor desempenho. Ocorre de um estudo avaliar um modelo como tendo desempenho superior a outro e um outro estudo concluir o inverso, e. g., Heston e Nandi (2000, p. 585-625) e Kim e Kim (2004, p. 117-142) em relação ao modelo BSM e ao modelo HN. Uma das possíveis razões é que a estabilidade das estimações dos modelos depende de um padrão de mudança do comportamento dos preços dos ativos que não pode ser previsto, pois o verdadeiro PGD é desconhecido. Tanto que um dos métodos de implementação que gera os melhores resultados é a reestimação do modelo sempre com os dados mais recentes, capturando as últimas informações sobre o seu comportamento. A estimação da volatilidade implícita no modelo BSM utilizando os dados do dia anterior é o exemplo mais evidente. Essa variação de desempenho originada pela mudança no método de estimação dá indícios de que a forma de incorporação de novas informações ao modelo é tão importante quanto o próprio modelo. Esse é um aspecto que não é tratado diretamente na estrutura do modelo, ficando a cargo da estimação, que por sua vez não tem por finalidade a incorporação dinâmica de informações, mas a resolução de uma situação estática.

O modelo BSM é sem dúvida o modelo mais simples dentre os abordados neste estudo. Trata somente cinco componentes, entre parâmetros e variáveis. O preço da ação, o tempo para a expiração da opção e o preço de exercício, que são variáveis observáveis, a taxa 
livre de risco e a volatilidade dos log-retornos da ação, que são parâmetros, portanto constantes.

A robustez do modelo BSM reside na sua simplicidade e evidentemente na estabilidade relativa da volatilidade. Luenberger (1998, p. 212-222) mostra o problema de estimação de valor esperado e variância de log-retornos diários. Estimações de valor esperado em geral apresentam intervalos de confiança pouco precisos, o que praticamente invalida a utilidade de sua estimação. Já a variância, em geral apresenta um intervalo de confiança bem mais preciso. Consequentemente o fato do modelo BSM não depender da estimação do valor esperado dos log-retornos é por si só um fator de robustez. A taxa livre de risco, considerada no modelo BSM um parâmetro constante, é na realidade uma variável, mas o modelo perde pouco por essa simplificação. Mesmo constituindo uma estimação de valor esperado, em geral sofre mudanças contínuas e em pequena escala e seus processos de modelagem em geral incorporam reversão à média. O parâmetro mais crítico do modelo, a volatilidade, se por um lado constitui um parâmetro não tão estável, por outro lado tem como compensação uma estimação com um intervalo de confiança mais preciso, atenuando a falta de modelagem da heteroscedasticidade condicionada. Häfner e Herwartz (2001, p. 2) contesta a não presença do valor esperado dos log-retornos no modelo BSM, argumentando que a variância carrega implicitamente uma estimativa de valor esperado de retornos, que altera a estimação da variância. Sua argumentação tem por objetivo justificar a investigação de componentes auto-regressivos na modelagem da dinâmica de preços, para melhorar a estimação do valor esperado e por consequência da variância. Mas independente dessa presença indireta do valor esperado, é fato concreto que o intervalo de confiança de estimação da variância é mais preciso.

O modelo BSM carrega outras definições implícitas, que não aparecem na fórmula de Black-Scholes para cálculo do preço da opção e da estratégia de hedge. Entre elas está a premissa de distribuição normal dos log-retornos. Essa premissa exclui a incorporação da leptocurtose condicionada e do efeito de alavancagem. Entretanto a importância desses fatos estilizados, identificados mais simplesmente por assimetria e curtose da distribuição dos log-retornos, é ainda objeto de estudos na literatura, como em Cerny (2007, p. 1-37), que cita outros estudos que buscam identificar a incorporação desses fatos estilizados nos modelos. Os estudos tendem a comprovar que a contribuição de sua incorporação é baixa, o que reflete mais uma fonte de robustez do modelo BSM. 
O modelo GARCH de Heston e Nandi, embora praticamente difira do modelo BSM somente na concepção de um parâmetro, que é a volatilidade transformada em variável estocástica, ao modelar seu comportamento introduz uma série de fatos estilizados e cinco novos parâmetros, nenhum deles diretamente observável, como a própria volatilidade. Os componentes observáveis são o preço da ação, o tempo para a expiração da opção, o preço de exercício e a taxa livre de risco, que também é considerada constante. A volatilidade surge como variável estocástica e são introduzidos como parâmetros o preço de mercado do risco, a variância de longo prazo, a assimetria da variância e os parâmetros dos componentes auto-regressivo e de média móvel da variância.

A introdução da volatilidade estocástica altera também a premissa de distribuição normal dos log-retornos. A imposição de um processo gerador de dados específico para a dinâmica de log-retornos gera uma distribuição desconhecida, diferente da normal. A dinâmica de log-retornos da ação incorpora a precificação do risco e a volatilidade estocástica, mas não incorpora termos auto-regressivos. Essa limitação do modelo não é significativa, pois Häfner Herwartz (2001, p. 1-2,10) observa que diversos estudos corroboram a hipótese de autocorrelação dos log-retornos, porém, em comparação com o efeito de alavancagem é um fator de menor importância.

O modelo GARCH de Heston e Nandi, com diversos parâmetros, se por um lado tem a capacidade de capturar melhor os fatos estilizados, conforme Heston e Nandi (2000, p. 589), incorporando heteroscedasticidade condicionada dos log-retornos, leptocurtose condicionada dos log-retornos, efeito de alvancagem, reversão à média da volatilidade e precificação do risco, por outro lado, implica uma estimação mais complexa. Os fatos estilizados são representados por parâmetros que não são diretamente observáveis e não são necessariamente estáveis no tempo. Além disso, os modelos GARCH em geral requerem séries de dados mais longas para obtenção de significância dos parâmetros e são sensíveis à inicialização da variância.

A estimação da volatilidade no modelo BSM é muito mais flexível, pois o modelo não vincula nenhum método de estimação. Já o modelo GARCH oferece poucas possibilidades de uso de outras informações que não um conjunto de dados históricos para estimação. No caso específico do modelo GARCH analisado neste trabalho, Heston e Nandi (2000, p. 
596) afirma que o efeito de reversão à média da volatilidade no modelo o torna menos sensível ao valor de inicialização, mas não delimita essa sensibilidade. Em outros modelos GARCH esse é um problema adicional.

A leptocurtose condicionada é introduzida nos modelos GARCH pela estimação do modelo utilizando choques estocásticos com distribuição t de Student ou da família GED (Generalized Error Distribution) quando estimados por máxima verossimilhança. $\mathrm{Na}$ estimação de Heston e Nandi (2000, p. 585-625) por mínimos quadrados não-lineares da diferença entre preço de mercado e preço de modelo, a leptocurtose condicionada dos choques está implícita.

Uma das características mais importantes da introdução da volatilidade estocástica do modelo GARCH em relação ao modelo BSM, como observa Duan (1995, p.14) é a capacidade de representar o sorriso de volatilidade observado no cômputo de volatilidades implícitas no modelo BSM, que é o aumento da volatilidade implícita de opções out-of the-money e in-the-money. Entretanto, Härdle e Häfner (2000, p. 199) cita que estudos comprovam que o sorriso de volatilidade desaparece com o aumento do prazo para expiração da opção. Sem precisar a duração de tempo, o trabalho opta por definir como 30 dias o limiar a partir do qual o sorriso de volatilidade deixa de ser significativo para o estudo em questão. Härdle and Hafner (2000, p. 205) conclui que os modelos GARCH, com a introdução da volatilidade estocástica, são superiores ao modelo BSM em precificação de opções para prazos curtos de expiração. Por tratar-se de uma condição particular, esse fato também reforça a robustez do modelo BSM.

A estratégia AC difere das estratégias BSM e HN primeiramente porque foi concebida dentro de um paradigma multiperiódico, sem o objetivo precípuo de precificação de opções, mas sim de hedge de ativos financeiros. Sua adaptação ao hedge de opção apresenta a característica, desejável sob o prisma do investimento, de estabelecimento de uma estratégia autofinanciável sobre múltiplos períodos, mas impõe a restrição de manutenção da estratégia até a data da expiração da opção.

O modelo depende da distribução dos log-retornos que é não paramétrica, portanto não há parâmetros a serem estimados, somente probabilidades. Depende também das variáveis 
preço da ação, prazo até a expiração da opção e taxa livre de risco, sendo que a taxa livre de risco pode ser estocástica.

A expansão dos preços em árvore de estados a partir de uma distribuição não-paramétrica proporciona flexibilidade à dinâmica de preços e log-retornos. Por consequência, a distribuição pode incorporar quaisquer fatos estilizados e pode ser estimada por diversos métodos, seja a partir de dados históricos, critérios subjetivos, modelos matemáticos ou uma combinação de métodos. Como a árvore é expandida período a período, os logretornos não precisam ser necessariamente IID, podendo ser tratada uma distribuição diferente em cada período e em cada estado.

Embora o caráter não-paramétrico do modelo permita o tratamento flexível de diversos fatores, a viabilização do modelo requer a introdução de condições que limitem a quantidade de estados para tratamento computacional e exige a definição de critérios para a introdução de hipóteses e fatos estilizados. O tratamento de log-retornos não-IID vários períodos à frente demanda uma fundamentação teórica ou empírica sobre as distribuições, que não é parte integrante do modelo, mas afeta seu desempenho. Da mesma forma, a introdução de volatilidade estocástica também é possível, mas requer uma definição própria que também não é parte integrante do modelo. Neste trabalho as premissas foram simplificadas para log-retornos IID com distribuição não-paramétrica, estimada a partir de dados históricos e taxa livre de risco constante. Dessa forma o modelo incorpora assimetria e leptocurse aos log-retornos de acordo com os dados utilizados na estimação, mas é mantido com variância e taxa livre de risco constantes.

Podemos concluir que o modelo GARCH é o que melhor incorpora fatos estilizados, porém, é o mais sujeito a problemas de estimação. O modelo BSM é o que menos incorpora fatos estilizados, mas é menos susceptível a problemas de estimação. O modelo AC, embora possibilite maior amplitude na representação dos fatos estilizados, foi simplificado na implementação adotada perdendo a incorporação de alguns fatos, mas é o que menos impõe restrições à distribuição dos log-retornos. Tanto o modelo GARCH quanto o modelo BSM impõem os processos geradores de dados e buscam adaptá-los da melhor forma aos dados. 


\subsection{Avaliação por simulação}

\subsubsection{Método}

As avaliações comparativas de desempenho de estratégias de hedge nos estudos apresentados na revisão da literatura consistiam sempre na avaliação do erro de hedge período a período, como se constituíssem investimentos independentes, havendo interesse no resultado de cada período isoladamente.

Os testes calculam a estratégia de hedge para um período e no período seguinte avaliam o erro de hedge, representado pela diferença entre a quantidade de ação que foi calculada e a quantidade de ação que efetivamente geraria um hedge perfeito. O erro de hedge é avaliado pelo erro no cálculo do delta. Poderia ser avaliado pela diferença monetária, mas seria apenas uma mudança de escala. Ao final de determinada quantidade de períodos são avaliados os erros absoluto médio e quadrático médio de hedge, e as estratégias são comparadas sem considerar compensações entre os erros de hedge por excesso ou falta. Essa forma de avaliação, dentro do contexto diário utilizado nos trabalhos, tem pouco significado sob a óptica financeira, pois é improvável que um investidor faça hedge diariamente sem preocupar-se com o efeito acumulado das operações. Além disso, uma estratégia como a AC não é adequada à realização desse tipo de avaliação, pois é multiperiódica por concepção.

Neste trabalho propomos uma avaliação de desempenho por simulação. O teste realizado para comparação de desempenho entre as estratégias de hedge BSM, AC e HN consiste na replicação do valor de uma opção com o ativo livre de risco e uma proporção de ação. A estratégia é autofinanciável, cobrindo múltiplos períodos entre o estabelecimento da estratégia de hedge e a data de expiração da opção. Cada período de tempo corresponde a 1 semana e o hedge é mantido por 4 semanas até a expiração da opção. Ao final das 4 semanas é avaliado o erro absoluto médio e o erro quadrático médio de hedge, computado pela diferença entre o valor da carteira replicante e o rendimento da opção. Para evitar o problema de escala, o erro é normalizado pelo preço inicial da opção. 
O objetivo da simulação é reproduzir, na medida do possível, situações tais quais são encontradas no mercado financeiro. Para entendimento do contexto que queremos reproduzir, podemos conduzir a análise a seguir.

O mercado financeiro é composto por ativos, aos quais estão associados processos geradores de dados desconhecidos, que determinam o comportamento dos retornos e consequentemente dos preços. O objetivo de todos os modelos é definir um processo gerador de dados que reproduza a dinâmica dos retornos observados no mercado. Dada a complexidade do mercado, na construção e avaliação dos modelos são assumidas simplificações.

A primeira simplificação reside no objetivo de reprodução da dinâmica dos retornos do mercado. Esse objetivo é perseguido não pela identificação do processo gerador de dados do mercado, mas pela especificação de um processo gerador para representá-lo. O modelo especificado busca reproduzir a dinâmica dos retornos pela incorporação de alguns dos fatos estilizados observados no mercado. Qualquer especificação é, portanto, uma aproximação do processo gerador de dados do mercado, que evidentemente não corresponde ao verdadeiro processo gerador de dados que é desconhecido.

A segunda simplificação é de que o processo gerador de dados é o mesmo para todos os ativos. Os modelos de precificação e hedge são utilizados indiscriminadamente para quaisquer ações ou índices, como podemos observar nos trabalhos analisados na revisão da literatura.

A terceira simplificação é de que a dinâmica observada nos retornos é invariante no tempo, o que pode ser observado nos métodos apresentados nos estudos. Para isso foi utilizada uma parte da amostra de retornos, denominada amostra de estimação, para estimar os parâmetros dos modelos e outra parte subsequente da amostra, denominada amostra de validação, para comparação de desempenho entre os modelos.

O objetivo dessa análise apresentada foi identificar o contexto no qual será introduzida uma metodologia de simulação. A simulação, assim como os modelos, tem por objetivo criar um ambiente controlado, que reproduza o comportamento do mercado. 
A figura a seguir ilustra o método de simulação utilizado:

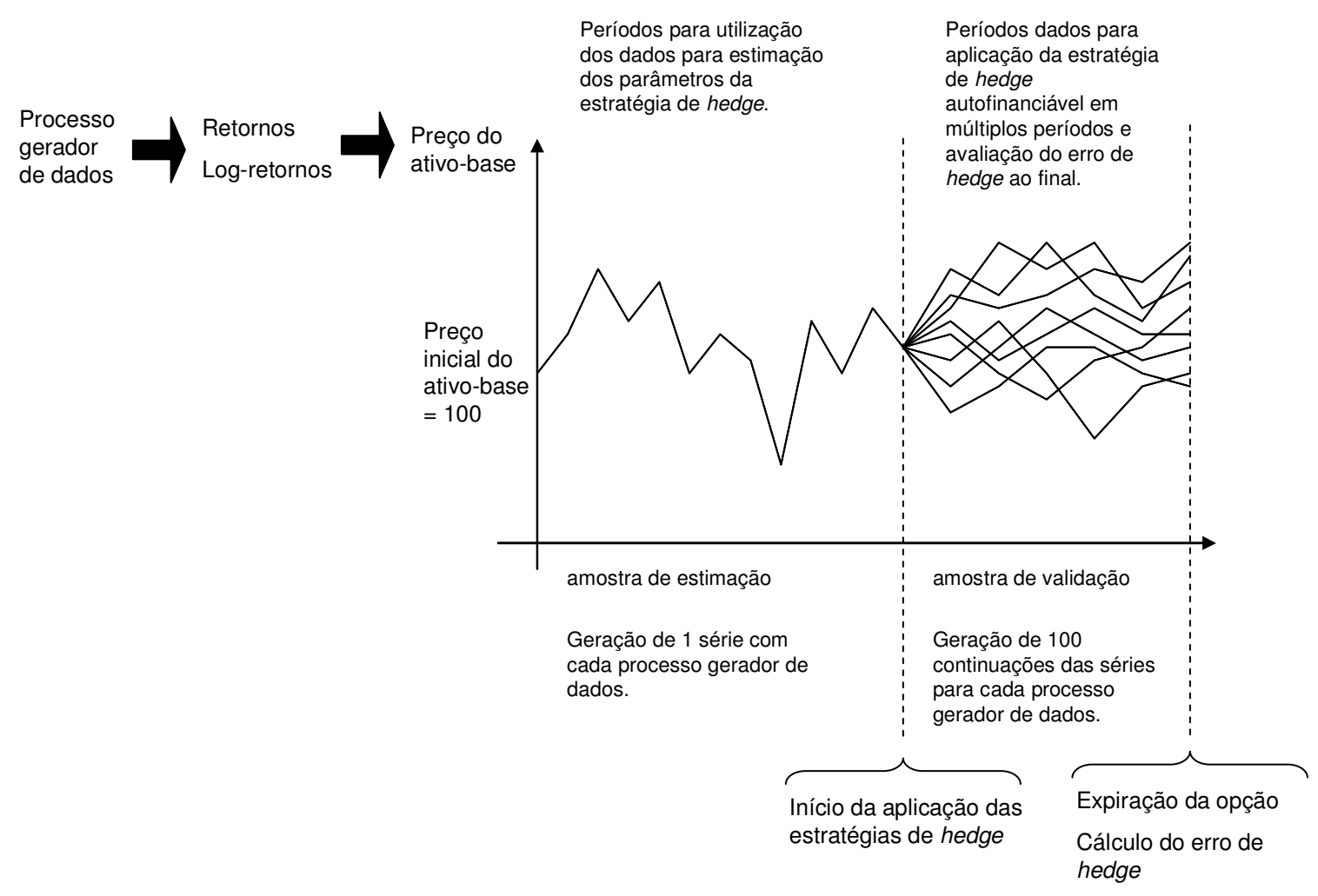

Figura 8.1 - Método de Simulação

Para geração de séries de log-retornos e preços diários de ativos foram utilizados quatro processos geradores de dados:

- Um processo gerador de log-retornos com distribuição normal, conforme apresentado em Cerny (2004a, p. 240-243).

- Um processo gerador de log-retornos com distribuição normal, com saltos com distribuição de Poisson na frequência e distribuição normal no tamanho, conforme apresentado em Cont e Tankov (2004, p 321-324).

- Um processo gerador de retornos representado por um modelo TGARCH, conforme apresentado em Hafner e Herwartz (2001, p. 17-20).

- Um processo gerador de log-retornos representado por um modelo GARCH, conforme apresentado em Heston e Nandi (2000, p. 588-591).

Todos os processos acompanhados dos respectivos equivalentes na medida de probabilidade neutralizadora do risco, para determinação dos preços de opção por simulação de Monte Carlo. O objetivo da utilização de diferentes processos geradores de dados é mimetizar o mercado, no sentido de que esses modelos incorporam fatos 
estilizados observados, e sua diversidade impõe a condição de processos geradores de dados desconhecidos. Assim, os modelos sob avaliação são testados quanto à sua capacidade de capturar informações de séries geradas por outros processos, como ocorre com as séries do mercado.

De forma análoga ao que ocorre no mercado, cada processo gerador de dados foi utilizado para gerar uma única série de retornos, a partir da qual foram estimados os parâmetros necessários a cada uma das estratégias de hedge sob avaliação. Essa série gerada para estimação do modelo é utilizada como amostra de estimação, conforme ilustrado na figura 8.1. A estimação dos modelos a serem utilizados em estratégias de hedge tem como perspectiva suportar qualquer possível trajetória futura do ativo-base. No mercado, porém, não é possível avaliar o desempenho das estratégias de hedge para diversas evoluções possíveis, pois somente uma pode ser observada. Como na simulação os processos geradores de dados são conhecidos, é possível gerar diversas continuações para a série da amostra de estimação, simulando as possíveis evoluções dos preços. Essas continuações da série utilizadas para cálculo dos erros de hedge e avaliação das estratégias de hedge são utilizadas como amostras de validação, conforme ilustrado na figura 8.1.

\subsubsection{Dados}

Foram utilizadas 4 séries de valores simulados como amostras de estimação de logretornos diários, geradas pelos 4 modelos geradores de dados descritos, a partir das quais foram geradas as séries de preços. O preço inicial utilizado foi 100 para os 4 processos geradores de dados. A taxa livre de risco foi definida arbitrariamente como $0,0378 \%$ ao dia e os parâmetros dos modelos foram ajustados para geração de retornos de tamanho comatível com essa escala. Esse ajuste de taxa e parâmetros teve por base valores observados no mercado brasileiro, para que os dados representem valores factíveis, mas sem a intenção de reprodução fiel de alguma situação. Cada uma das séries de log-retornos foi gerada com 520 log-retornos definidos como diários. Para cada série de estimação foram geradas 100 continuações como séries de validação com 20 log-retornos diários. Definindo uma semana como 5 dias, cada série de estimação de 520 preços diários foi transformada em uma série de 104 preços semanais e cada série de validação de 20 preços 
diários foi transformada em uma série de 4 preços semanais. Foram calculados os logretornos semanais para as séries de estimação, que foram utilizados para estimação dos parâmetros necessários aos modelos utilizados nas estratégias de hedge testadas. A cada série de validação foram agregados os últimos valores da ação das séries de estimação como valor inicial, compondo séries de 5 valores que delimitam 4 semanas. Em seguida foram calculados os preços de opção em cada semana utilizando os processos geradores na medida neutralizadora do risco, resultando em uma série de preços de opção para cada série de validação de preços de ação. O preço de exercício foi definido sempre como igual ao valor inicial da ação na série de validação.

\subsubsection{Teste das estratégias}

Tendo ao todo 400 séries de validação de preços de ação de 5 valores para 4 semanas e 400 séries de 5 preços de opção para 4 semanas, as estratégias foram computadas. O valor inicial da carteira replicante foi dado pelo valor da opção no período inicial. O hedge pelo delta foi calculado para cada estratégia, e a partir desses valores e do preço da ação, foi calculada a quantidade do ativo livre de risco a ser tomada. O processo foi repetido nos quatro períodos à frente e no período final foi computado o erro de hedge pela diferença entre o valor da carteira replicante e o rendimento da opção. O erro foi normalizado pelo preço inicial da opção para torná-lo comparável em magnitude, uma vez que os valores iniciais das opções e consequentemente do investimento nas carteiras replicantes difere para cada processo gerador de dados.

Notação:

$r f$ : taxa livre de risco.

$K_{4}$ : preço de exercício da opção no instante.

$V_{t}$ : valor da carteira replicante.

$S_{t}:$ preço da ação.

$C_{t}:$ preço racional da opção.

$B_{t}$ : valor em numerário tomado à taxa livre de risco..

$\theta_{t}:$ razão de hedge. 
$C_{M}$ : preço de mercado simulado da opção.

$e$ : erro absoluto acumulado de hedge.

\subsubsection{Estratégia BSM}

Para implementação da estratégia BSM a volatilidade foi estimada pela volatilidade implícita calculada com o preço da opção do dia, utilizando a fórmula de Black-Scholes pelo calculando as raízes da equação:

$$
C_{M}-S_{t} \Phi\left(\frac{\ln \frac{S_{t}}{K_{T}}+(T-t)\left(r f+\frac{\sigma^{2}}{2}\right)}{\sigma \sqrt{T-t}}\right)-e^{(-r f(T-t))} K_{T} \Phi\left(\frac{\ln \frac{S_{t}}{K_{T}}+(T-t)\left(r f-\frac{\sigma^{2}}{2}\right)}{\sigma \sqrt{T-t}}\right)=0
$$

Com a volatilidade implícita obtida, foi calculado o hedge pelo delta:

$$
\theta_{t}=-\Phi\left(\frac{\ln \frac{S_{t}}{K_{T}}+(T-t)\left(r f+\frac{\sigma^{2}}{2}\right)}{\sigma \sqrt{T-t}}\right)
$$

O processo de cálculo do hedge sobre a série de validação é descrito na figura 8.2 a seguir.

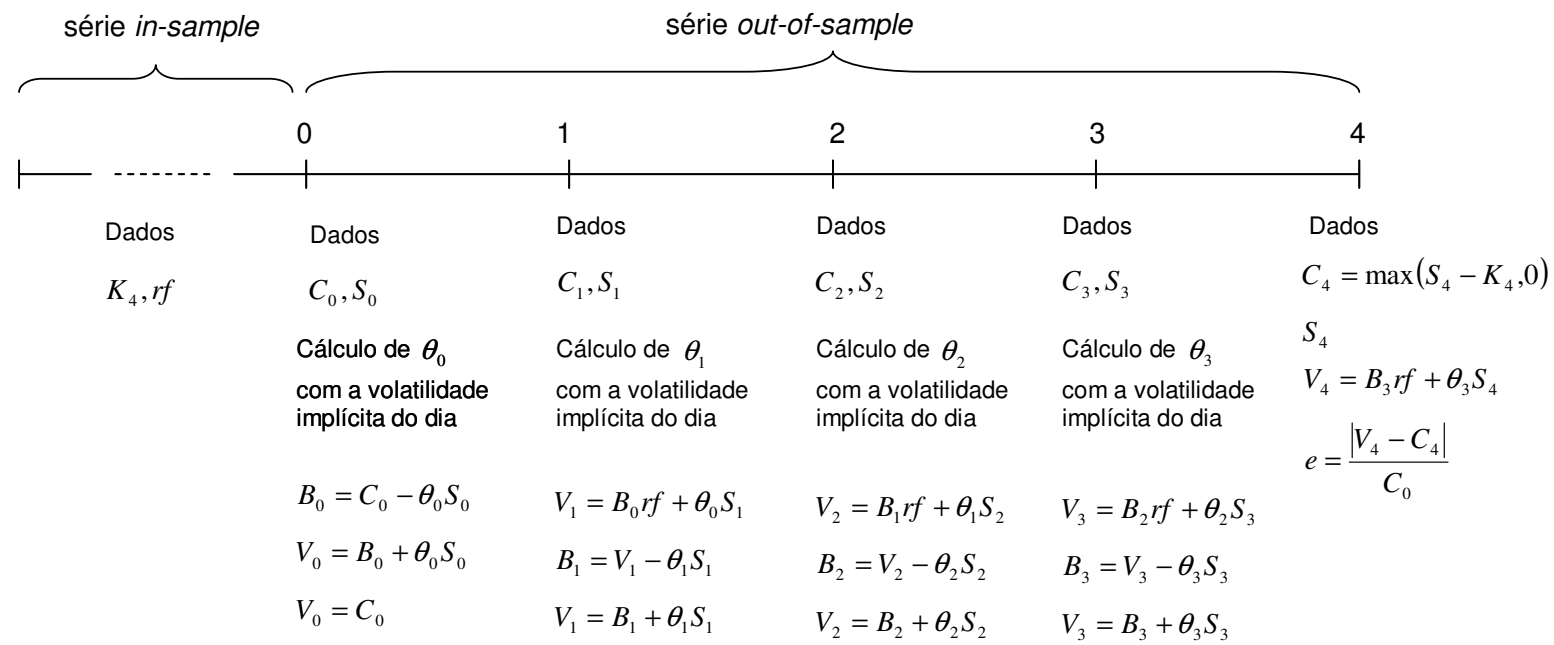

Figura 8.2 - Estratégia BSM 


\subsubsection{Estratégia AC}

O modelo AC foi definido com 7 níveis de log-retornos e os log-retornos e probabilidades foram estimados a partir da série de estimação de preços. A taxa livre de risco foi considerada constante. O modelo foi estimado uma única vez para todo o período de 4 semanas de hedge.

Com os níveis de log-retornos e as probabilidades foram calculadas as árvores de estado de preços e os valores ótimos de hedge pelo delta, correspondentes a cada estado de preço.

O processo de cálculo do hedge sobre a série de validação é descrito na figura 8.3 a seguir.

\begin{tabular}{|c|c|c|c|c|c|}
\hline & 0 & 1 & 2 & 3 & 4 \\
\hline \multirow{3}{*}{$\begin{array}{l}\text { Estimação dos níveis } \\
\text { de retorno e } \\
\text { respectivas } \\
\text { probabilidades sobre } \\
\text { a série in-sample }\end{array}$} & Dados & Dados & Dados & Dados & \multirow{5}{*}{$\begin{array}{l}\text { Dados } \\
C_{4}=\max \left(S_{4}-K_{4}, 0\right) \\
S_{4} \\
V_{4}=B_{3} r f+\theta_{3} S_{4} \\
e=\frac{\left|V_{4}-C_{4}\right|}{C_{0}}\end{array}$} \\
\hline & $C_{0}, S_{0}$ & $C_{1}, S_{1}$ & $C_{2}, S_{2}$ & $C_{3}, S_{3}$ & \\
\hline & $B_{0}=C_{0}-\theta_{0} S_{0}$ & $V_{1}=B_{0} r f+\theta_{0} S_{1}$ & $V_{2}=B_{1} r f+\theta_{1} S_{2}$ & $V_{3}=B_{2} r f+\theta_{2} S_{3}$ & \\
\hline Cálculo da árvore de $\theta_{i}$ & & $B_{1}=V_{1}-\theta_{1} S_{1}$ & $B_{2}=V_{2}-\theta_{2} S_{2}$ & $B_{3}=V_{3}-\theta_{3} S_{3}$ & \\
\hline $\begin{array}{l}\text { para os possiveis } S_{i} \\
i=0,1,2,3,4\end{array}$ & $V_{0}=C_{0}$ & $V_{1}=B_{1}+\theta_{1} S_{1}$ & $V_{2}=B_{2}+\theta_{2} S_{2}$ & $V_{3}=B_{3}+\theta_{3} S_{3}$ & \\
\hline Dados & & & & & \\
\hline$K_{4}, r f$ & & & & & \\
\hline
\end{tabular}

Figura 8.3 - Estratégia AC

\subsubsection{Estratégia $\mathrm{HN}$}

Para implementação da estratégia HN os parâmetros do modelo GARCH foram estimados a partir da série de estimação de log-retornos. O modelo foi estimado por máxima verossimilhança, utilizando a equação de verossimilhança dada por: 


$$
\begin{aligned}
& L(\Theta)=-\frac{1}{2} \sum_{t=1}^{T} \ln h_{t}-\frac{T}{2} \ln 2 \pi-\frac{1}{2} \sum_{t=1}^{T} \frac{\left(X_{t}-r-\lambda h_{t}\right)^{2}}{h_{t}} \\
& h_{t}=\omega+\beta h_{t-1}-\alpha \frac{\left(X_{t-1}-r-\lambda h_{t-1}-\gamma h_{t-1}\right)^{2}}{h_{t-1}} \\
& X_{t}=\ln S_{t}-\ln S_{t-1} \\
& \Theta=\left(\alpha, \beta, \gamma, \omega, \lambda, h_{0}\right) \quad t=\{0,1, \ldots, T\} .
\end{aligned}
$$

O modelo foi estimado uma única vez para todo o período de 4 semanas de hedge. A volatilidade condicionada foi inicializada com a volatilidade não condicionada da série de estimação e atualizada sobre uma janela deslizante, à medida que a estratégia evolui sobre a séride validação e mais valores de log-retornos tornam-se conhecidos.

Com os parâmetros estimados foram calculados os valores de hedge pelo delta, solucionando numéricamente a integral de cálculo de preço de opção do modelo GARCH de Heston e Nandi:

$$
\begin{aligned}
& \theta_{t}=-\frac{1}{2}-\frac{1}{\pi} \int_{0}^{\infty} \operatorname{Re}\left[\frac{K_{T}^{-i \phi} f^{*}(i \phi+1)}{i \phi f^{*}(1)}\right] d \phi \\
& f(\varphi)=\left(S_{t}\right)^{\varphi} \exp \left(A(t, T, \varphi)+B(t, T, \varphi) h_{t+1}\right) \\
& A(t, T, \varphi)=A(t+1, T, \varphi)+\varphi r+B(t+1, T, \varphi) \omega-\frac{1}{2} \ln (1-2 \alpha B(t+1, T, \varphi)) \\
& B(t, T, \varphi)=\varphi(\lambda+\gamma)-\frac{1}{2} \gamma^{2}+\beta B(t+1, T, \varphi)+\frac{1 / 2(\varphi-\gamma)^{2}}{1-2 \alpha_{1} B_{1}(t+1, T, \varphi)} \\
& A(T, T, \varphi)=B(T, T, \varphi)=0 .
\end{aligned}
$$


O processo de cálculo do hedge sobre a série de validação é descrito na figura 8.4 a seguir.

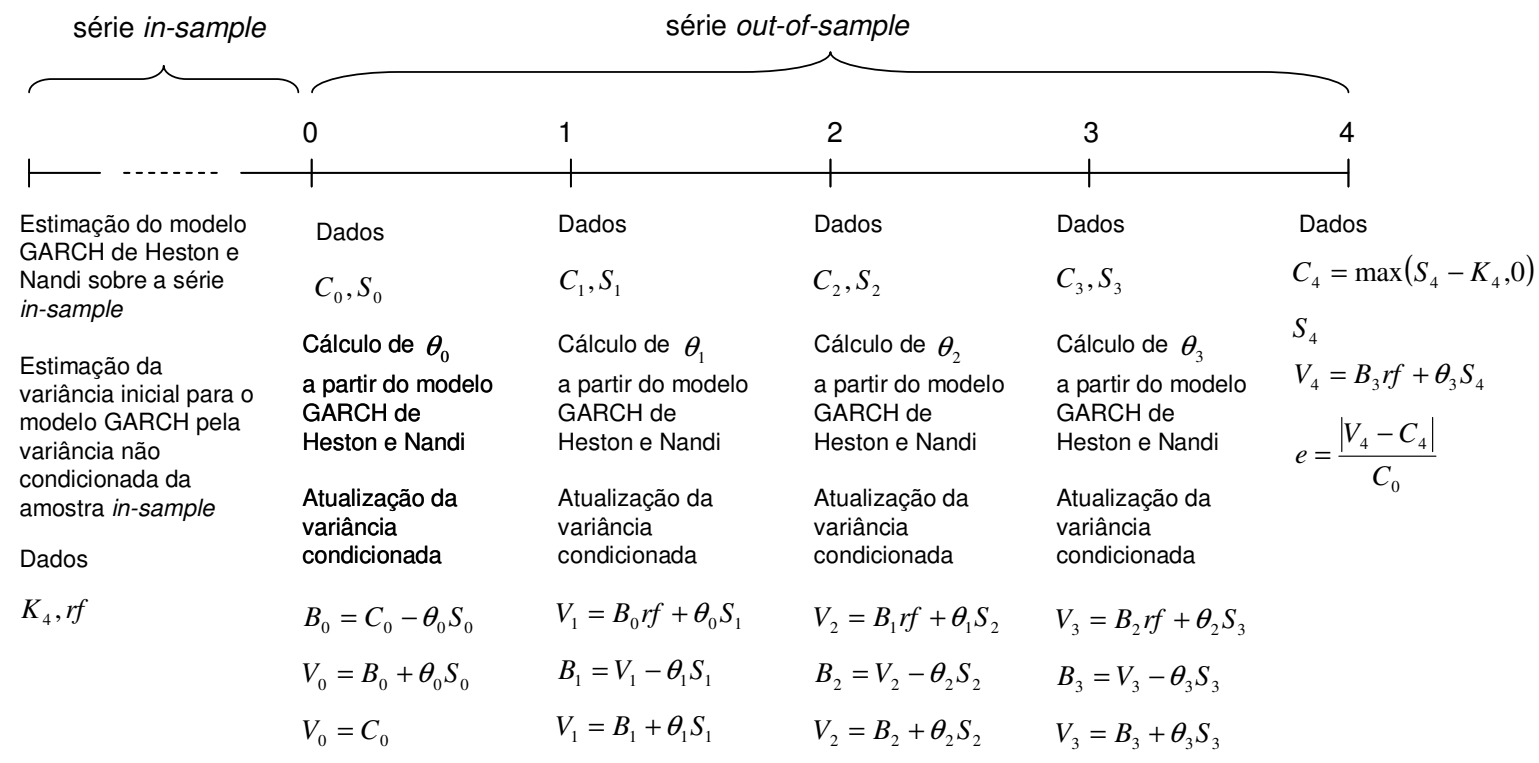

\section{Figura 8.4 - Estratégia HN}

\subsubsection{Processos Geradores de Dados}

Os processos geradores utilizados foram os seguintes:

Modelo 1 apresentado em Cerny (2004a, p. 240-243): série de log-retornos com distribuição normal.

Parâmetros:

$R_{t}$ : retorno diário.

$r f$ : taxa livre de risco discreta ao dia.

$\mu=0,00058914$.

$\sigma=0,014$.

$r f=0,00037829$.

$S_{0}=100$. 
Processo na medida objetiva:

$$
\begin{aligned}
& \ln R_{t}=\mu+\sigma z_{t} \\
& S_{t}=S_{t-1} R_{t} \\
& \left\{z_{t}\right\} \sim \operatorname{NID}(0,1) .
\end{aligned}
$$

Processo na medida neutralizadora do risco:

$$
\begin{aligned}
& \ln R_{t}=\ln (1+r f)-\frac{1}{2} \sigma^{2}+\sigma z_{t} \\
& S_{t}=S_{t-1} R_{t} \\
& \left\{z_{t}\right\} \sim N I D(0,1) .
\end{aligned}
$$

Modelo 2 apresentado em Cont e Tankov (2004, p. 321-323): série de log-retornos obtidos com o modelo de Merton, que combina log-retornos com distribuição normal e saltos com distribuição de Poisson e tamanho com distribuição normal.

Parâmetros:

$R_{t}$ : retorno diário.

$r f$ : taxa livre de risco discreta ao dia.

$\mu=0,00047131$.

$\sigma=0,012$

$m=0,00023566$.

$\delta=0,004$.

$\lambda=1,7$.

$r f=0,00037829$.

$S_{0}=100$.

Processo na medida objetiva:

$$
\begin{aligned}
& \ln R_{t}=\mu+\sigma z_{t}+\sum_{i=1}^{N_{t}} Y_{i} \\
& S_{t}=S_{t-1} R_{t} \\
& \left\{z_{t}\right\} \sim N I D(0,1) \\
& \left\{Y_{i}\right\} \sim N I D(m, \delta) \\
& \left\{N_{t}\right\} \sim \text { PoissonID }(\lambda) \\
& z_{t}, Y_{i}, N_{t} \text { mutuamente independentes. }
\end{aligned}
$$


Processo na medida neutralizadora do risco:

$$
\begin{aligned}
& \ln R_{t}=r f-\frac{1}{2} \sigma^{2}+\sigma z_{t}-\lambda \exp \left(m+\frac{1}{2} \delta^{2}-1\right)+\sum_{i=1}^{N_{t}} Y_{i} \\
& S_{t}=S_{t-1} R_{t} \\
& \left\{z_{t}\right\} \sim N I D(0,1) \\
& \left\{Y_{i}\right\} \sim N I D(m, \delta) \\
& \left\{N_{t}\right\} \sim \text { PoissonID }(\lambda) \\
& z_{t}, Y_{i}, N_{t} \text { mutuamente independentes. }
\end{aligned}
$$

Modelo 3 apresentado em Hafner e Herwartz (2000, p. 17-20): série de log-retornos obtidos com um modelo TGARCH.

Parâmetros:

$r_{t}:$ taxa de retorno diário.

$r f$ : taxa livre de risco discreta ao dia.

$v=0,00026$.

$\phi=0,062$.

$\alpha_{1}=0,03$.

$\alpha_{2}=0,26$.

$\beta=0,8$.

$\omega=0,0000026$.

$h_{0}=0,000000026$.

$r f=0,00037829$.

$S_{0}=100$. 
Processo na medida de probabilidade objetiva:

$$
\begin{aligned}
& r_{t}=v+\phi S_{t-1}+\sqrt{h_{t}} z_{t} \\
& h_{t}=\omega+\left(\left(\alpha_{1}+\alpha_{2} I_{z_{t-1}<0}\right) z_{t-1}{ }^{2}+\beta\right) h_{t-1} \\
& r_{t}=\frac{S_{t}}{S_{t-1}}-1 \\
& \left\{z_{t}\right\} \sim N I D(0,1) .
\end{aligned}
$$

Processo na medida de probabilidade neutralizadora do risco:

$$
\begin{aligned}
& r_{t}=r f+\sqrt{h_{t}} z_{t} \\
& h_{t}=\omega+\left(\left(\alpha_{1}+\alpha_{2} I_{z_{t-1}-\lambda_{t-1}<0}\right)\left(z_{t-1}-\lambda_{t-1}\right)^{2}+\beta\right) h_{t-1} \\
& \lambda_{t}=\frac{v+\phi r_{t-1}-r f}{\sqrt{h_{t}}} \\
& r_{t}=\frac{S_{t}}{S_{t-1}}-1 \\
& \left\{z_{t}\right\} \sim \operatorname{NID}(0,1) .
\end{aligned}
$$

Modelo 4 apresentado em Heston e Nandi (2000, p. 588-591): série de log-retornos obtidos com o modelo GARCH de Heston e Nandi.

Parâmetros:

$R_{t}$ : retorno diário.

$r f$ : taxa livre de risco discreta ao dia.

$\alpha=0,0000017$.

$\beta=0,17$.

$\lambda=1,7$.

$\omega=0,000028$.

$h_{0}=0,00008$.

$r f=0,00037829$.

$S_{0}=100$. 
Processo na medida de probabilidade objetiva:

$$
\begin{aligned}
& \ln R_{t}=\ln (1+r f)+\lambda h_{t}+\sqrt{h_{t}} z_{t} \\
& h_{t}=\omega+\beta h_{t-1}+\alpha\left(z_{t-1} \gamma \sqrt{h_{t-1}}\right)^{2} \\
& S_{t}=S_{t-1} R_{t} \\
& \left\{z_{t}\right\} \sim N I D(0,1) .
\end{aligned}
$$

Processo na medida de probabilidade neutralizadora do risco:

$$
\begin{aligned}
& \ln R_{t}=\ln (1+r f)-\frac{1}{2} h_{t}+\sqrt{h_{t}} z_{t} \\
& h_{t}=\omega+\beta h_{t-1}+\alpha\left(z_{t-1}+\left(\gamma+\lambda-\frac{1}{2}\right) \sqrt{h_{t-1}}\right)^{2} \\
& S_{t}=S_{t-1} R_{t} \\
& \left\{z_{t}\right\} \sim N I D(0,1) .
\end{aligned}
$$

\subsubsection{Simulação dos preços de opção}

Os preços de opção foram simulados utilizando os processos geradores de dados na medida neutralizadora do risco para cálculo dos preços por simulação de Monte Carlo.

$C_{t}:$ preço da opção.

$r f$ : taxa livre de risco discreta ao dia.

$S_{T}$ : preço da ação na data de expiração da opção.

$$
C_{t}=\frac{1}{(1+r f)^{T-t}} E_{t}^{Q}\left[S_{T}\right]
$$

O critério de interrupção das simulações de Monte Carlo foi a obtenção de uma precisão de $\pm 0,05$ em $95 \%$ dos valores, supondo distribuição normal dos erros de precificação. 


\subsection{Análise dos resultados}

\subsubsection{Comparação de desempenho}

\begin{tabular}{|l|cc|ccc|cc|}
\hline \multirow{4}{*}{$\begin{array}{c}\text { PROCESSO GERADOR } \\
\text { DE DADOS }\end{array}$} & \multicolumn{2}{|c|}{ BSM } & \multicolumn{2}{c|}{ AC } & \multicolumn{2}{c|}{ HN } \\
\cline { 2 - 8 } & $\begin{array}{c}\text { Erro } \\
\text { Normalizado } \\
\text { Absoluto } \\
\text { Médio }\end{array}$ & $\begin{array}{c}\text { Erro } \\
\text { Normalizado } \\
\text { Quadrático } \\
\text { Médio }\end{array}$ & $\begin{array}{c}\text { Erro } \\
\text { Normalizado } \\
\text { Absoluto } \\
\text { Médio }\end{array}$ & $\begin{array}{c}\text { Erro } \\
\text { Normalizado } \\
\text { Quadrático } \\
\text { Médio }\end{array}$ & $\begin{array}{c}\text { Erro } \\
\text { Normalizado } \\
\text { Absoluto } \\
\text { Médio }\end{array}$ & $\begin{array}{c}\text { Normalizado } \\
\text { Quadrático } \\
\text { Médio }\end{array}$ \\
\hline Normal & 0.20 & 0.46 & 0.13 & 0.53 & 0.18 & 0.47 \\
Normal com Jumps & 0.07 & 0.44 & 0.05 & 0.60 & 0.08 & 0.50 \\
TGARCH & 0.08 & 0.61 & 0.03 & 0.83 & 0.09 & 0.63 \\
GARCH Heston e Nandi & 0.02 & 0.22 & 0.04 & 0.38 & 0.02 & 0.23 \\
\hline Todos & 0.09 & 0.43 & 0.06 & 0.58 & 0.09 & 0.48 \\
\hline
\end{tabular}

Tabela 8.1 - Tabela Comparativa de Erros

Os resultados de simulação apresentados na tabela 8.1 não estabelecem uma dominância de desempenho entre as estratégias de hedge de opção. Pode-se observar que a estratégia AC resultou no menor erro médio absoluto enquanto que a estratégia BSM resultou no menor erro quadrático médio. A estratégia $\mathrm{HN}$ resultou em um desempenho igual à estratégia BSM em relação ao erro absoluto médio e ligeiramente inferior em relação ao erro quadrático médio, porém muito próximo.

Os resultados sugerem que a estratégia AC, apresentando erro médio absoluto inferior é mais exata, enquanto que a estratégia BSM, apresentando erro quadrático médio inferior, é mais precisa. A estratégia AC apresenta erros maiores que a estratégia BSM, mas com menor viés.

A dominância ocorreria se as hipóteses de um modelo fossem mais atendidas do que as hipóteses dos demais. Tratamos aqui das hipóteses assumidas na implementação dos modelos nos casos em que são necessárias decisões de implementação. As hipóteses das estratégias estão sumarizadas na tabela 8.2. 


\begin{tabular}{|l|l|l|}
\hline \multicolumn{3}{|c|}{ HIPÓTESES DAS ESTRATÉGIAS } \\
\hline \multicolumn{1}{|c|}{ BSM } & \multicolumn{1}{|c|}{ AC } & \multicolumn{1}{c|}{ HN } \\
\hline Log-retornos com distribuição NID. & $\begin{array}{l}\text { Log-retornos não-normais, com } \\
\text { distribuição igual à distribuição } \\
\text { histórica de um conjunto de períodos } \\
\text { anteriores ID. }\end{array}$ & $\begin{array}{l}\text { Log-retornos distribuidos segundo um } \\
\text { modelo GARCH específico ID. }\end{array}$ \\
\hline Taxa livre de risco constante. & Taxa livre de risco constante. & Taxa livre de risco constante. \\
\hline Volatilidade constante. & Volatilidade constante. & $\begin{array}{l}\text { Volatilidade estocástica com reversão à } \\
\text { média, dada por um modelo } \\
\text { GARCH(1,1) específico. }\end{array}$ \\
\hline $\begin{array}{l}\text { Volatilidade estimada pela última } \\
\text { volatilidade implícita calculada por } \\
\text { inversão do modelo. }\end{array}$ & $\begin{array}{l}\text { Volatilidade estimada pela volatilidade } \\
\text { histórica de um conjunto de períodos } \\
\text { anteriores. }\end{array}$ & $\begin{array}{l}\text { Parâmetros estimados por máxima } \\
\text { verossimilhança considerando } \\
\text { distribuição normal dos resíduos pelos } \\
\text { retornos históricos de um conjunto de } \\
\text { períodos anteriores. }\end{array}$ \\
\hline
\end{tabular}

Tabela 8.2 - Tabela de Hipóteses das Estratégias

Por terem sido utilizados 4 processos geradores de dados na simulação dos log-retornos (normal, normal com saltos, TGARCH e GARCH de Heston e Nandi), pelo menos em 3 dos 4 casos os dados não satisfazem as hipóteses das estratégias.

A estratégia $\mathrm{HN}$ teve o seu melhor desempenho com dados gerados pelo modelo GARCH de Heston e Nandi, que satisfaz suas hipóteses, tendo sido o desempenho mais próximo da estratégia BSM. Surpreendentemente, foi também com esse conjunto de dados que a estratégia BSM apresentou seu melhor desempenho e não com dados gerados pelo processo gerador de dados normal, que satisfaz suas hipóteses. Possivelmente o método de estimação da volatilidade implícita a cada período captura de forma satisfatória os efeitos da volatilidade estocástica, garantindo a robustez da estratégia BSM para tratar dados gerados por outros processos geradores.

O desempenho de todas as estratégias em erro absoluto médio foi pior com o processo gerador normal e pior em erro quadrático médio com o processo gerador TGARCH.

Verificando as características das estratégias na tabela 8.2, pode-se dizer que a estratégia BSM, ao estimar a volatilidade período a período, adapta-se à variação da volatilidade, assumindo que as variações são suaves a ponto de utilizar a última calculada como sendo a correta. As estratégias AC e HN, por utilizarem dados históricos na estimação da distribuição e dos parâmetros, embora capturem melhor os fatos estilizados da distribuição dos retornos e da volatilidade, pressupõem maior estabilidade no tempo da volatilidade e do comportamento dos retornos. 
Por fim, podemos concluir que os resultados reforçam a robustez da estratégia BSM, exaustivamente constatada na literatura, mas com ressalvas. O potencial de aperfeiçoamento da estratégia BSM praticamente esgota-se com um bom método de estimação da volatilidade implícita, conforme indicado em Dumas, Fleming e Whaley (1998, p. 2059-2106) e em Nandi e Waggoner (2000, p. 24-39), fato também constatado neste trabalho. Restaria apenas a possibilidade de introdução da correção proposta em Wilmott (2005, p. 763-782) para compensar o hedge em tempo discreto. O potencial de aperfeiçoamento das estratégias AC e HN, no entanto, ainda não está esgotado.

O modelo GARCH de Heston e Nandi foi estimado por máxima verossimilhança supondo resíduos com distribuição normal. Essa hipótese não é verdadeira para a maior parte das séries financeiras, nem para as séries simuladas. Um método alternativo de estimação pode ser utilizado, como o método dos momentos generalizado ou mesmo mínimos quadrados não-lineares conforme Heston e Nandi (2000, p. 585-625), mas minimizando erros de hedge em lugar de erros de precificação. Também é possível introduzir uma reestimação do modelo período a período, para compensar a instabilidade das estimações ao longo do tempo.

A estratégia AC permite incorporar o efeito de alavancagem sobre a volatilidade pela introdução de uma função de volatilidade dependente do nível de preços e até mesmo volatilidade estocástica. Também permite estimar uma distribuição de probabilidades de retornos variável de acordo com níveis de preço. Sua menor flexibilidade reside na concepção multiperiódica, que não permite reestimação dos parâmetros período a período durante a execução da estratégia, a exemplo das estratégias uniperiódicas. Essa limitação implica obrigatoriamente uma hipótese de estabilidade no tempo dos parâmetros, pelo menos no período de execução da estratégia.

Essas possibilidades de aperfeiçoamento da estimação das estratégias AC e HN podem torná-las mais robustas e competitivas em relação à estratégia BSM. O grande desafio continua sendo a superação da robustez do modelo BSM, que apesar de suas limitações teóricas, possibilita o uso de diversos artifícios para contornar as limitações e é insuperável no quesito simplicidade. 


\subsection{Considerações finais}

Encerramos aqui o trabalho tendo coberto os objetivos primários e secundários apresentados no capítulo 1, de discussão dos fundamentos e da evolução do conceito de hedge, realização de testes de estratégias, avaliação de especificidades de impelementação e compilação de características e demonstrações. Com os resultados obtidos podemos, então, rever o problema de pesquisa proposto e formular uma resposta.

\subsubsection{A escolha da estratégia de hedge faz diferença?}

Como resposta à pergunta de pesquisa sobre a importância da escolha da estratégia de hedge, podemos concluir que a escolha da estratégia de hedge por si só não faz diferença. Podemos sintetizar a otimização do desempenho em três aspectos:

- $\quad$ Os fatos estilizados presentes nos dados.

- Modelos que representem os principais fatos estilizados observados.

- $\quad$ Estimação satisfatória de parâmetros.

A incorporação de fatos estilizados deve ser constatada previamente nos dados, pois ativos distintos (small caps x blue chips), mercados distintos (taxa de juros em países diferentes) e períodos disitintos (aumento da correlação entre os retornos e da volatilidade em situações de crise) podem levar a comportamentos distintos dos valores. O incremento de complexidade do modelo com fatos estilizados deve estar vinculado à significância e necessidade de representação dos fatos, pois maior complexidade implica maior dificuldade de estimação. Portanto, o desempenho da estratégia está vinculado tanto à qualidade do modelo de representação dos fatos estilizados quanto à qualidade de estimação dos parâmetros. Uma mesma estratégia pode gerar resultados conflitantes em situações distintas, que apresentem fatos estilizados diferentes, e também pela utilização de metodologias de estimação. O aperfeiçoamento da estimação demanda a avaliação e escolha de métodos e uma análise mais aprofundada da qualidade da estimação, que por sua vez requer a avaliação das distribuições dos parâmetros e de sua significância dentro de intervalos de confiança. 
Outra questão não menos importante são os objetivos do investidor. O critério de identificação da melhor estratégia não é apenas uma questão matemática. A necessidade de realização de uma operação de hedge por um único período requer critérios de avaliação distintos da realização de uma sequência de operações. Neste caso uma estratégia menos viesada é melhor, mesmo que leve a erros absolutos maiores, pois o que interessa realmente é o efeito acumulado.

O uso de simulação foi determinante para permitir uma boa análise e implementação das estratégias, uma vez que permite total controle sobre as condições de teste, sem a inserção de vieses inevitáveis ao se tratar com dados reais. Dados reais apresentam complexidades adicionais como ausência de dados em determinados períodos, considerações sobre períodos mais prolongados de inatividade do mercado, utilização de média entre oferta de compra e oferta de venda como preço, tamanho insuficiente de amostras e falta de liquidez de determinados ativos. Essas características demandam decisões de modelagem e implementação mais complexas. Evidentemente estratégias de hedge somente tem sentido com o objetivo de aplicação em situações reais, mas a simulação é uma ferramenta fundamental para suportar uma etapa prévia de avaliação.

\subsection{Contribuições do trabalho}

Os estudos comparativos de desempenho de estratégias de hedge de opção apresentados no capítulo 4 tem diversas características em comum. Dumas, Fleming e Whaley (1998, p. 2059-2106) e Nandi e Waggoner (2000, p. 24-39) tratam somente alternativas para o modelo BSM. Heston e Nandi (2000, p. 585-625) trata somente o modelo GARCH proposto em comparação com o modelo BSM. Somente Kim e Kim (2004, p. 117-142) amplia a comparação entre modelos, avaliando o BSM, o HN e dois modelos de volatilidade estocástica em tempo contínuo de Heston e de Carr, Chang e Madan. Mas uma das características mais semelhantes foi o método de coleta de dados. Todos trabalharam sobre dados obtidos no mercado, utilizando métodos de coleta de dados muito similares quanto a dias, horários caracterísitcas das opções e utilização do ponto médio entre oferta de compra e oferta de venda como referência de preço das opções para 
compensar problemas de liquidez. Com relação aos métodos de estimação diferiram pouco nas implementações e um pouco mais nos prazos de reestimação dos parâmetros. Os métodos de avaliação de desempenho tiveram como pilar o erro quadrático médio do hedge pelo delta.

Este trabalho primeiramente procurou contrastar modelos mais diferentes entre si, com uma proposição mais próxima do trabalho de $\operatorname{Kim}$ e $\operatorname{Kim}(2004$, p. 117-142). Mas as maiores diferenças residem na proposição de análise teórica e interpretação dos fatos estilizados incorporados pelos modelos e no tratamento dos dados e avaliação de desempenho. Foram utilizados dados obtidos por simulação em lugar de dados de mercado e as estratégias foram comparadas sob uma abordagem multiperiódica e autofinanciável. A união dessas características procurou contribuir com a apresentação de uma nova perspectiva de análise.

Como outras contribuições do trabalho podemos identificar a compilação atualizada da evolução das visões do hedge ao longo do tempo e a apresentação de uma teoria geral do hedge, da qual o hedge de opção é um caso particular. Também apresenta demonstrações agregadas aos apêndices, de forma detalhada, expondo transformações importantes do ponto de vista acadêmico e didático, que na literatura não são apresentadas.

\subsection{Ampliação do estudo}

Os temas estudados para a elaboração deste trabalho abrem um leque de possibilidades de aplicação. Uma delas, diretamente relacionada às conclusões da pesquisa é o aprofundamento da análise da estimação para as estratégias AC e HN. Outra possibilidade relacionada à estratégia AC é sua utilização com diversos ativos-base, o que introduz a necessidade de estimação de distribuições conjuntas e pode ser aplicada a operações de hedge pelo delta-gama e pelo delta-vega. Outras características que podem ser exploradas nessa solução são a introdução de processos estocásticos na variância e na taxa livre de risco e a introdução de retornos não-IID. Também o método de estimação do modelo GARCH de Heston e Nandi pode ser melhorado com outras alternativas de estimação. 
Outro tema potencial é o estudo da aplicação dessas estratégias de hedge no gerenciamento de riscos.

O método de simulação desenvolvido também pode ser aprimorado para construção de uma metodologia de análise prévia de desempenho, ajustando os processos geradores de dados aos ativos reais, aos quais se desema aplicar uma estratégia.

Com relação especificamente à simulação realizada, o método poderia ser melhorado para tornar-se estatisticamente significativo, com a utilização não só de múltiplas sequências de validação, mas também com a utilização de múltiplas sequências de estimação e múltiplas estimações dos parâmetros. Também poderia ser ampliado o conjunto de processos geradores de dados e os processos podem ser utilizados com conjuntos distintos de parâmetros.

A vinculação entre o problema de definição e de estimação dos modelos nos mostra na literatura duas linhas paralelas de trabalho, o aprefeiçoamento dos modelos e a melhoria dos métodos econométricos de estimação e calibração, que oferecem inúmeras possibilidades de pesquisa.

Por fim, a exploração de dados reais complementaria a verificação da possibilidade de dominância de uma estratégia sobre outra, embora com a limitação de que nunca será possível uma afirmação definitiva, uma vez que os dados reais constituem sempre uma única amostra em um dado intervalo de tempo. Por maior e mais perfeita que possa ser a amostra, nunca é possível afirmar que contém todas as possíveis condições que o mercado financeiro pode apresentar. 


\section{REFERÊNCIAS}

AÏT-SAHALIA, Yacine. Financial engeneering: mathematical models of option pricing and their estimation. Chicago: University of Chicago 1998, notas de aula, 348 p.

ALMEIDA, Leonardo A.; SCHIRMER, Pedro P.; YOSHINO, Joe Akira. Derivativos de renda fixa no Brasil: modelo Hull White. Pesquisa e Planejamento Econômico, v. 33, n. 2, ago 2003, p. 299-333.

ANDREASEN, Jesper; BJARK, Jensen; POULSEN, Rolf. Eight valuation methods in mathematical finance: the Black and Scholes formula as an example. Working paper, 1999, p. 1-30.

ARAUJO, Gustavo Silva; BARBEDO, Claudio Henrique da Silveira; FIGUEIREDO, Antonio Carlos; LEMGRUBER, Eduardo Facó. Análise do modelo de precificação de Duan em opções de compra da Telebrás. Resenha BM\&F n. 160, abril-junho 2004, p. 43-57.

ASSOCIAÇÃO NACIONAL DAS CORRETORAS DE VALORES, CÂMBIO E MERCADORIAS - ANCOR. Preparatorio para exame de certificacao, 2008, 168 paginas, Volume 2.

AVELLANEDA, Marco. An introduction to option pricing and mathematical theory of risk. Proceedings of symposia in applied mathematics, v. 57, 1999, p. 32-56.

BASTOS, Edson; LAZIER, Iuri; SIQUEIRA, José de Oliveira. Dedução e análise da fórmula de Balck-Scholes. Trabalho em elaboração, 2008.

BAXTER, Martin W. RENNIE; Andrew J. O. Financial calculus. Cambridge: Cambridge University Press, 2000, 1. ed., 233 p.

BELLMAN, Richard. Dynamic Programming. New York: Dover Publications, 2003, 1. ed., 340 p.

BLACK , Fischer; SCHOLES, Myron. The pricing of corporate liabilities. The Journal of Political Economy, v. 81, n. 3, may-jun 1973, p. 637-654.

BLACKLEDGE, J.; EVANS, G.; YARDLEY, P. Analytic Methods for partial differential equations. London: Springer-Verlag, 2001, 1. ed., 298 p.

BRENNAN, M. J. The pricing of contingent claims in discrete time models. The Journal of Finance, v. 34, n. 1, mar 1979, p. 53-68.

BREEDEN, Douglas T; LITZENBERGER, Robert H. Prices of state contingent claims implicit in option prices. The Journal of Business, v. 51, n. 4, oct 1978, p. 621651.

BOLLERSLEV, Tim; Generalized autoregressive conditional heteroskedasticity. Journal of Econometrics, v. 31, 1986, p. 307-327. 
BOLLERSLEV, Tim. A conditionally heteroskedastic time series model for speculative prices and rates of return. The Review of Economics and Statistics, v. 69, n. 3, aug 1987 p. 542-547.

BOYLE, Phelim P.; EMANUEL, David. Discretely adjusted option hedges. Journal of Financial Economics, n. 8, 1980, p. 259-282.

BROOKS, Chris; CERNY, Ales; MIFFRE, Joelle. Optimal hedging with higher moments. Working paper, 2007, p. 1-36.

BUENO, Rodrigo de Losso da Silveira. GARCH multivariado e taxa ótima de hedge. São Paulo, 1999. Dissertação de Mestrado - Faculdade de Economia, Administração e Contabilidade da Universidade de São Paulo. 142 p.

CARR, Peter P.; CHANG, Eric C; MADAN, Dilip B. The variance gamma process and option pricing. European Finance Review, 1998, n. 2, p. 79-105.

CERNY, Ales. Mathematical techniques in finance: tools for incomplete markets. Princeton: Princeton University Press, 2004a, 1. ed., 378 p.

CERNY, Ales. Dynamic programming and mean variance hedging in discrete time. Applied Mathematical Finance, 2004b, v. 11, p. 1-25.

CERNY, Ales. Optimal hedging with higher moments. Working paper, 2007, p. 1-37.

CHRISTOFFERSEN, Peter; JACOBS, Kris. Which GARCH Model for Option Valuation. Management Science, v. 50, n. 9, sep 2004, p. 1204-1221.

CONT, Rama. Empirical properties of asset returns: stylized facts and statistical issues. Quantitative Finance, v. 1, 2001, p. 223-226.

CONT, Rama; TANKOV, Peter. Financial Modelling with Jump Processes. Boca Raton: Chapman \& Hall, 2004, 1. ed., 535p.

COSTA, Marcelo Nóbrega da; YOSHINO, Joe Akira. Calibração do modelo Heston para o mercado brasileiro de opções de câmbio (FX). Revista Brasileira de Finanças, v. 2, n. 1, 2004, p. 23-46.

COX, John C.; RUBINSTEIN, Mark. Options markets. Englewood Cliffs: Prentice Hall 1985, 1. ed., 498 p.

DERMAN, Emanuel; TALEB, Nassim Nicholas. The illusions of dynamic replication. Quantitative Finance, v. 5, n.4, aug 2005, p. 323-326.

DUAN, Jin-Chuan. The GARCH option pricing model. Mathematical Finance, v. 5, n.1, jan 1995, p. 13-32.

DUFFIE, Darrel. Future Markets. Englewood Cliffs: Prentice Hall, 1989, 1. ed., 415 p.

DUMAS, Bernard; FLEMING, Jeff; WHALEY, Robert E. Implied volatility functions: empirical tests. The Journal of Finanace, v. 53, n.6, dec 1998, p. 2059-2106. 
EDERINGTON, Louis $\mathrm{H}$. The hedging performance of the new futures markets. The Journal of finance, v. 34, n. 1, mar 1979, p. 157-170.

ENDERS, Walter. Applied Econometric Time Series. New York: Wiley 2004, 1. ed., 460 p.

ENGLE, Robert F. Autoregressive conditional heteroscedaticity with estimates of the variande of United Kingdom inflation. Econometrica, v. 50, n. 4, jul 1982, p. 987-1007.

ENGLE, Robert F.; ROSENBERG, Joshua. GARCH Gamma. Working paper, may 1995, p. $1-25$.

ENGLE, Robert F.; NG, Victor K. Measuring and testing the impacto of news on volatility. The journal of Finance, v. 48, n. 5, dec 1993, p. 1749-1778.

FARHI, Maryse. Derivativos financeiros, hedge, especulação e arbitragem. Campinas, Economia e Sociedade, v. 13 p. 93-114, dec 1999.

HAFNER, Christian M.; HERWARTZ, Helmut. Option pricing under linear autoregressive dynamics, heteroskedasticity, and conditional leptokurtosis. Journal of Empirical Finance, n. 8, 2001, p. 1-34.

HAMILTON, James D. Time series analysis. Princeton: Princeton University Press, 1994, 1. ed., 799 p.

HÄRDLE, W.; HAFNER, Christian M. Discrete time option pricing with flexible voltility estimation. Finance and Stochastics, n. 4, 2000, p. 189-207.

HARRISON, J. Michael; KREPS, David M. Martingales and arbitrage in multiperiod securities markets. Journal of Economic Theory, v. 20, 1979, p. 381-408.

HARRISON, J. Michael; PLISKA, Stanley R. Martingales and stochastic integrals in the theory of continuous trading. Stochastic Processes and their Applications, 11, 1981, p. 215-260.

HESTON, Steven L. A closed form solution for options with stochastic volatility with applications to bond and currency options. The Review of Financial Studies, v. 6 n. 2, 1993, p. 327-343.

HESTON, Steven L.; NANDI, Saikat. A closed form GARCH option valuation model. The Review of Financial Studies, v. 13, n. 3, 2000, p. 585-625.

HOUAISS, Antônio et al. Dicionário Eletrônico Houaiss da Língua Portuguesa, Versão 1.0. Rio de Janeiro: Ed.Objetiva, 2001.

HSIEH, K. C.; RITCHKEN, P. An empirical comparison of GARCH option pricing models. Rev. Deriv. Res., 2006, v. 8, p. 129-150.

HUANG, Chi-fu; LITZENBERGER, Robert H. Foundations for financial economics. New York : North-Holland. 1988, 1. ed., 365 p. 
HULL, John; WHITE, Alan. The pricing of options on assets with stochastic volatilities. The Journal of Finance, v. 42, n. 2, june 1987, p. 281-300.

JOHNSON, Leland L. The theory of hedging and speculation in commodity futures. The Review of Economic Studies, v. 27, n. 3, june 1960, p. 139-151.

JORION, Philippe; KHOURY, Sarkis Joseph. Financial risk management: domestic and international dimensions. Cambridge: Blackwell Publishers Inc. 1996, 1. ed., $368 \mathrm{p}$.

KENOURGIOS, Dimitris; PANAGIOTIS, Drosos; SAMITAS, Aristeidis. Hedge ratio estimation and hedging effectiveness: the case of the $S \& P 500$ stock index futures contract. Working paper 2005.

KARIYA, Takeaki; LIU, Regina Y. Asset pricing: discrete time approach. Boston: Kluwer Academic Publishers, 2003, 1. ed., 275 p.

KIM, Joon In; KIM, Sol. Empirical comparison of alternative stochastic volatility optio pricing models: evidence from Korean KOSPI 200 index options market. Pacific-Basin Finance Journal, 12, 2004, p. 117-142.

KLEBANER, Fima C. Introduction to stochastic calculus with applications. London: Imperial College Press, 2006, 2. ed., 416 p.

KOZIOL, Joseph D. Hedging: principles, practices, and strategies for the financial markets. New York: Wiley, 1990, 1. ed., 422 p.

LAKATOS, Eva Maria; MARCONI, Marina de Andrade. Fundamentos de metodologia científica. São Paulo: Atlas, 6. ed., 2007, 315 p.

LUENBERGER, David G. Investment Science. Oxford: Oxford University Press, 1998, 1. ed., $494 \mathrm{p}$.

MADAN, Dilip B.; SENETA, Eugene. The Variance Gamma VG model for share market returns. The journal of Business, v. 63, n. 4, oct 1990, p. 511-524.

MAGILL, Michael; QUINZII, Martine. Theory of incomplete markets. Cambridge: MIT Press, 2002, 1. ed., 540 p.

MAGNUS, Jan R.; NEUDECKER, Heinz. Matrix differential calculus: with applications in statistics and econometrics. New York: Wiley, 2002, 2. ed., 395 p.

MERRIAM-WEBSTER. The Merriam-Websters Dictionary. Springfield Massachussets: Pocket Books, 2006, 1232 p.

MERTON, Robert C. Theory of rational option pricing. The Bell Journal of Economics and Management Science, v. 4, n. 1, 1973, p. 141-183.

MITTELHAMMER, Ron C. Mathematical statistics for economics and business. New York: Springer-Verlag, 1999, 1. ed., 723 p. 
NANDI, Saikat; WAGGONER, Daniel. Issues in hedging option positions. Economic Review, first quarter 2000, p. 24-29.

NEFTCI, Salih N. An introduction to the mathematics of financial derivatives. San Diego: Academic Press, 2000, 2. ed., 527 p.

NELSON, Daniel B. Conditional heteroskedasticity in asset returns: A new approach. Econometrica, v. 59, n. 2, mar, 1991, p. 347-370.

PISKOUNOV, N. Cálculo diferencial e integral, v. 1. Porto: Edições Lopes da Silva, 1979, 1. ed., 457 p.

PISKOUNOV, N. Cálculo diferencial e integral, v. 2. Porto: Edições Lopes da Silva, 1979, 1. ed., 516 p.

PLISKA, Stanley R. Introduction to mathematical finance: discrete time models. Massachusetts: Blackwell Publishers, 1998, 1. ed., 262 p.

ROSS, Sheldom M. Simulation. San Diego: Academic Press, 2002, 3. ed., 274 p.

SARIDIS, George N. Stochastic processes, estimation and control: the entropy approach. New York: Wiley, 1995, 1. ed., 230 p.

SCHÄL, Manfred. On quadratic cost criteria for option hedging. Mathematics of operations research, v. 19, n. 1, feb 1994, p. 121-131.

SCHWEIZER, Martin. Variance-optimal hedging in discrete time. Discussion papaer, 1995, p. 1-35.

SECURATO, José Roberto. Cálculo financeiro das tesourarias. São Paulo: Saint Paul Editora Ltda 2007, 3. ed., 424 p.

SHIRYAEV, Albert N. Essentials of stochastic finance: facts, models, theory. Singapore: World Scientific 2003, 1. ed., 834 p.

SIQUEIRA, José O. Determinação entrópica do preço racional da opção européia simples ordinária sobre ação e bond: uma aplicação da teoria da informação em finanças em condição de incerteza. São Paulo, 1999. Tese de Doutorado Faculdade de Economia, Administração e Contabilidade da Universidade de São Paulo.

SMITH JR., Clifford W. Option pricing: a review. Journal of Financial Economics, 3, 1976, p. 3-51.

SMITH JR., Clifford W. The modern theory of corporate finance. New York: Mc GrawHill, 1990, 2. ed. 695 p.

SPIEGEL, Murray R. Análise de Fourier. São Paulo: Mc Graw-Hill, 1976, 1. ed. 250 p.

STEELE, J. Michael. Stochastic Calculus and financial applications. New York: Springer-Verlag 2001, 1. ed., 300 p. 
TOFT, Klaus Bjerre. On the mean-variance tradeoff in option replication with transaction costs. The Journal of Financial and Quantitative Analysis, v. 31, n. 2, jun 1996, p. 233-263.

WEINGERGER H. F. A first course in partial differential equations: with complex variables and transform methods. New York: Dover, 1995, 1. ed., 446 p.

WHALLEY Elizabeth; WILMOTT Paul. The best hedging strategy. Working paper 1999.

WILMOTT, Paul. The mathematics of financial derivatives. New York: Cambridge University Press. 1997, 1. ed. 317 p.

WILMOTT, Paul. Paul Wilmot introduces quantitative finance. West Sussex: Wiley, 2001, 1. ed., 521 p.

WILMOTT, Paul. Paul Wilmott on quantitative finance. New York: Wiley, 2005, 2. ed., $1379 \mathrm{p}$.

WORKING, Holbrook. Futures trading and hedging. The American Economic Review, v.43, n.3, jun 1953a, p. 314-343.

WORKING, Holbrook. Hedging reconsidered. Journal of Farm Economics, v. 35, n. 4, nov 1953b, p. 544-561. 


\section{APÊNDICES}

APÊNDICE 1 - DEMONSTRAÇÕES - ESTRATÉGIA BSM APÊNDICE 2 - DEMONSTRAÇÕES ESTRATÉGIA AC APÊNDICE 3 - DEMONSTRAÇÕES - ESTRATÉGIA HN APÊNDICE 4 - PROGRAMAS 


\section{APÊNDICE 1 - DEMONSTRAÇÕES - ESTRATÉGIA BSM}

Notação:

$t$ : instante de tempo contínuo.

$T$ : instante de tempo de expiração da opção.

$S_{t}$ : preço da ação.

$\mu$ : esperança dos log-retornos da ação.

$\sigma$ : desvio-padrão dos log-retornos da ação.

$C\left(S_{t}, t\right)$ : preço da opção.

$K_{T}$ : preço de exercício da opção.

$W_{t}$ : movimento browniano padrão.

$B_{t}:$ preço do ativo livre de risco.

$r$ : taxa de retorno do ativo livre de risco.

$\Phi(w)$ : função acumulada de uma variável estocástica com distribuição normal padrão.

$\Pi(t)$ : carteira composta por uma opção e determinada quantidade de ação.

$\Delta_{t}:$ quantidade da ação.

\subsection{Premissas do Modelo}

- $\quad$ O preço da ação seguem um processo de Itô e os log-retornos têm distribuição NID.

- A esperança dos log-retornos é constante.

- A variância dos log-retornos é constante.

- $\quad$ A taxa livre de risco é constante.

\subsection{Definição 1}

A dinâmica de preços dos ativos de risco é dada por:

$$
d S_{t}=\mu S_{t} d t+\sigma S_{t} d W_{t}
$$


ou

$d \ln \left(S_{t}\right)=\left(\mu-\frac{1}{2} \sigma^{2}\right) d t+\sigma d W_{t}$

$S_{t}=S_{0} e^{\mu t+\sigma W_{t}}$.

Fim da definição 1

\subsection{Definição 2}

A dinâmica de preços do ativo livre de risco é dada por:

$d B_{t}=r B_{t} d t$

$B_{t}=B_{0} e^{-r t}$

$B_{0}=1$.

Fim da definição 2

\subsection{Proposição 1}

O preço racional da opção e a dinâmica de preços da opção são dados por:

$C_{T}=\max \left\{S_{T}-K_{T}, 0\right\} \equiv\left(S_{T}-K_{T}\right)^{+}$

$C\left(S_{t}, t\right)=S_{t} \Phi\left(\frac{\ln \frac{S_{t}}{K_{T}}+(T-t)\left(r+\frac{\sigma^{2}}{2}\right)}{\sigma \sqrt{T-t}}\right)-e^{-r(T-t)} K_{T} \Phi\left(\frac{\ln \frac{S_{t}}{K_{T}}+(T-t)\left(r-\frac{\sigma^{2}}{2}\right)}{\sigma \sqrt{T-t}}\right)$.

Fim da proposição 1

Demonstração da proposição 1

Lema de Itô 
Conforme Smith (1990, p. 375), o lema de Itô é uma regra de diferenciação aplicável a funções de determinadas variáveis aleatórias, especificamente, as que seguem um processo de Itô.

Um processo de Itô é um processo estocástico de Markov em tempo contínuo e é representado por:

$d S_{t}=\mu\left(S_{t}, t\right) d t+\sigma\left(S_{t}, t\right) d W_{t}$.

$d W_{t}$ - processo padrão Gauss-Wiener $d W_{t} \sim N(0, d t)$.

O problema tratado pelo Lema de Itô tem a seguinte forma:

Dada uma variável aleatória $S_{t}$, que segue um processo de Itô $S_{t}=f(t)$, tal que $d S_{t}=\mu\left(S_{t}, t\right) d t+\sigma\left(S_{t}, t\right) d W_{t}$ e uma dada função $C\left(S_{t}, t\right)$, qual é o diferencial $d C\left(S_{t}, t\right)$ ?

Pelo Lema de Itô

$$
\begin{aligned}
& d C\left(S_{t}, t\right)=\left(\frac{\partial C\left(S_{t}, t\right)}{\partial t}+\frac{\partial C\left(S_{t}, t\right)}{\partial S_{t}} S_{t} \mu\left(S_{t}, t\right)+\frac{1}{2} \frac{\partial^{2} C\left(S_{t}, t\right)}{\partial S_{t}{ }^{2}} S_{t}{ }^{2} \sigma^{2}\left(S_{t}, t\right)\right) d t \\
& +\frac{\partial C\left(S_{t}, t\right)}{\partial S_{t}} S_{t} \sigma\left(S_{t}, t\right) d W_{t} .
\end{aligned}
$$

Essa é precisamente a situação que define o problema de precificação de derivativos do qual é derivada a fórmula de Black-Scholes.

A demonstração apresentada a seguir foi elaborada com base em Willmot (1997, p. 33-89) e Bastos, Lazier e Siqueira (2008).

Sejam os preços de uma ação representados por um processo estocástico composta por um movimento browniano padrão em um espaço de probabilidades $(\Omega, \mathcal{F}, \mathbb{P})$.

$$
d S_{t}=\mu S_{t} d t+\sigma S_{t} d W_{t}
$$

ou 
$d \ln \left(S_{t}\right)=\left(\mu-\frac{1}{2} \sigma^{2}\right) d t+\sigma d W_{t}$

A solução para as equação (3) e (4) é:

$S_{t}=S_{0} e^{\mu t+\sigma W_{t}}$

Sejam os preços do ativo livre de risco representados por um processo determinístico.

$d B_{t}=r B_{t} d t$

$B_{t}=B_{0} e^{-r t}$.

Conforme Wilmott (1997, p. 41-44), seja uma carteira $\Pi(t)$ composta por 1 opção e $\Delta_{t}$ ações.

$\Pi(t)=C\left(S_{t}, t\right)+\Delta_{t} S_{t}$

As variações instantâneas da carteira são dadas por:

$d \Pi(t)=d C\left(S_{t}, t\right)+\Delta_{t} d S_{t}$.

A quantidade de ações $\Delta_{t}$ é mantida fixa no intervalo de tempo, por essa razão o diferencial $d \Pi_{t}$ não apresenta termos diferencias em $\Delta_{t}$.

Considerando que $C\left(S_{t}, t\right)$ é função de $S_{t}$, que é uma função de uma variável estocástica dada em (4), cujo diferencial é dado em (3), aplicando o Lema de Itô para obtenção do diferencial da função da opção resulta:

$d C\left(S_{t}, t\right)=\left(\frac{\partial C\left(S_{t}, t\right)}{\partial t}+\frac{\partial C_{t}\left(S_{t}, t\right)}{\partial S_{t}} S_{t} \mu+\frac{1}{2} \frac{\partial^{2} C\left(S_{t}, t\right)}{\partial S_{t}{ }^{2}} S_{t}^{2} \sigma^{2}\right) d t+\frac{\partial C\left(S_{t}, t\right)}{\partial S_{t}} S_{t} \sigma d W_{t}$. 
Substituindo (10) e (3) em (9) resulta:

$$
\begin{aligned}
d \Pi(t) & =d C\left(S_{t}, t\right)+\Delta_{t} d S_{t} \\
& =\left(\frac{\partial C\left(S_{t}, t\right)}{\partial t}+\frac{\partial C\left(S_{t}, t\right)}{\partial S_{t}} S_{t} \mu+\frac{1}{2} \frac{\partial^{2} C\left(S_{t}, t\right)}{\partial S_{t}^{2}} S_{t}{ }^{2} \sigma^{2}\right) d t+\frac{\partial C\left(S_{t}, t\right)}{\partial S_{t}} S_{t} \sigma d W_{t}+\Delta_{t} \mu S_{t} d t+\Delta_{t} \sigma S_{t} d W_{t} \\
& =\left(\frac{\partial C\left(S_{t}, t\right)}{\partial t}+\frac{\partial C\left(S_{t}, t\right)}{\partial S_{t}} S_{t} \mu+\frac{1}{2} \frac{\partial^{2} C\left(S_{t}, t\right)}{\partial S_{t}{ }^{2}} S_{t}{ }^{2} \sigma^{2}+\Delta_{t} \mu S_{t}\right) d t+\sigma S_{t}\left(\frac{\partial C\left(S_{t}, t\right)}{\partial S_{t}}+\Delta_{t}\right) d W_{t} .
\end{aligned}
$$

Na expressão (13) entra o argumento de hedge do modelo que conduz à sua solução, conforme descrito em Wilmott (1997, p. 43) e Wilmott (1997, p. 83). É possível construir uma carteira que replique perfeitamente o preço da opção em qualquer instante de tempo $t$, através da escolha conveniente da quantidade de ações $\Delta_{t}$ da carteira. A replicação somente é possível porque no limite de um intervalo de tempo infinitesimal, a relação entre o preço da ação e o preço da opção é linear. Dado que a carteira replica perfeitamente o preço da opção em qualquer instante de tempo $t$, isso significa eliminar o componente de risco da carteira, de tal forma que as variações no valor dessa carteira sejam completamente isentas de risco. A neutralização do componente de risco implica:

$$
\frac{\partial C\left(S_{t}, t\right)}{\partial S_{t}}+\Delta_{t}=0
$$

$$
\Delta_{t}=-\frac{\partial C\left(S_{t}, t\right)}{\partial S_{t}} .
$$


Portanto substituindo (15) em (13):

$$
\begin{aligned}
d \Pi(t) & =\left(\frac{\partial C\left(S_{t}, t\right)}{\partial t}+\frac{\partial C\left(S_{t}, t\right)}{\partial S_{t}} S_{t} \mu+\frac{1}{2} \frac{\partial^{2} C\left(S_{t}, t\right)}{\partial S_{t}{ }^{2}} S_{t}{ }^{2} \sigma^{2}+\Delta_{t} \mu S_{t}\right) d t \\
& =\left(\frac{\partial C\left(S_{t}, t\right)}{\partial t}+\frac{\partial C\left(S_{t}, t\right)}{\partial S_{t}} S_{t} \mu+\frac{1}{2} \frac{\partial^{2} C\left(S_{t}, t\right)}{\partial S_{t}{ }^{2}} S_{t}{ }^{2} \sigma^{2}-\frac{\partial C\left(S_{t}, t\right)}{\partial S_{t}} \mu S_{t}\right) d t \\
& =\left(\frac{\partial C\left(S_{t}, t\right)}{\partial t}+\frac{1}{2} \frac{\partial^{2} C\left(S_{t}, t\right)}{\partial S_{t}{ }^{2}} S_{t}{ }^{2} \sigma^{2}\right) d t .
\end{aligned}
$$

Agora em (18) entra o argumento de não-arbitragem, descrito em Wilmott (1997, p. 43) e Wilmott (1997, p. 83). Dado que a variação do valor na carteira é isenta de risco, para que não exista arbitragem o valor investido na carteira sem risco deve ter como rendimento a taxa livre de risco. Se a carteira tiver valor maior do que essa quantia, é possível uma operação de arbitragem que gera lucro sem risco, tomando emprestado o valor da carteira à taxa livre de risco e comprando a carteira. Se a carteira tiver valor menor do que essa quantia, é possível uma operação de arbitragem que gera lucro sem risco, vendendo a carteira e investindo à taxa livre de risco.

Logo, de (16):

$$
d \Pi(t)=\Pi(t) r d t
$$

Como trata-se de um hedge perfeito, a estratégia autofinanciável, que define a carteira replicante é dada a partir de (18) e (19) por:

$$
r \Pi(t) d t=\left(\frac{\partial C\left(S_{t}, t\right)}{\partial t}+\frac{1}{2} \frac{\partial^{2} C\left(S_{t}, t\right)}{\partial S_{t}^{2}} S_{t}^{2} \sigma^{2}\right) d t .
$$


Como:

$\Pi(t)=C\left(S_{t}, t\right)+\Delta_{t} S_{t}$

$\Delta_{t}=-\frac{\partial C\left(S_{t}, t\right)}{\partial S_{t}}$

$\Pi(t)=C\left(S_{t}, t\right)-\frac{\partial C\left(S_{t}, t\right)}{\partial S_{t}} S_{t}$.

Substituindo (23) em (20) resulta:

$$
\begin{aligned}
& r\left(C\left(S_{t}, t\right)-\frac{\partial C\left(S_{t}, t\right)}{\partial S_{t}} S_{t}\right) d t=\left(\frac{\partial C\left(S_{t}, t\right)}{\partial t}+\frac{1}{2} \frac{\partial^{2} C_{t}\left(S_{t}, t\right)}{\partial S_{t}{ }^{2}} S_{t}{ }^{2} \sigma^{2}\right) d t \\
& \frac{\partial C\left(S_{t}, t\right)}{\partial t}+\frac{1}{2} \frac{\partial^{2} C\left(S_{t}, t\right)}{\partial S_{t}{ }^{2}} S_{t}{ }^{2} \sigma^{2}+\frac{\partial C\left(S_{t}, t\right)}{\partial S_{t}} r S_{t}-r C\left(S_{t}, t\right)=0 .
\end{aligned}
$$

Sujeita às condições de contorno:

$$
t \geq 0
$$

$C\left(S_{t}, t\right) \geq 0, \quad C(0, t)=0$,

$S_{t} \geq 0, \quad S_{t} \rightarrow \infty \quad \Rightarrow \quad C\left(S_{t}, t\right) \rightarrow S_{t} \rightarrow \infty$

$C\left(S_{T}, T\right)=\max \left\{S_{T}-K_{T} ; 0\right\} \geq 0$.

A equação (25) é a equação diferencial parcial de Black-Scholes. Conforme observa Aït Sahalia (1998. p. 56), qualquer derivativo cujo ativo subjacente siga um processo 
estocástico de Itô, conforme descrito pelo modelo de movimento browniano geométrico, deve satisfazer essa equação, não somente opções.

Essa equação é definida como uma equação diferencial parcial parabólica, que pode ser reduzida por transformação à forma da equação de difusão do calor, que é uma equação bem conhecida na Física.

A equação de difusão do calor é da forma:

$\frac{\partial u(x, \tau)}{\partial \tau}=\frac{\partial^{2} u(x, \tau)}{\partial x^{2}}$

É necessário transformar a equação diferencial parcial de Black-Scholes (25), para obtermos uma equação no mesmo formato de (30). O primeiro passo, conforme Wilmott (1997, p. 77), é converter a equação com coeficientes variáveis em uma equação com coeficientes constantes, eliminando os multiplicadores $S_{t}{ }^{2}$ e $S_{t} \operatorname{dos}$ termos $\frac{\partial^{2} C\left(S_{t}, t\right)}{\partial S_{t}{ }^{2}}$ e $\frac{\partial C\left(S_{t}, t\right)}{\partial S_{t}}$. A mesma transformação deixa a equação com termos adimensionais e a transforma de backward para forward, eliminando o inconveniente de tratamento de condições de contorno das equações diferenciais backward. As alterações não impactam informacionalmente a equação, somente sua forma. Fazendo as transformações de variáveis:

$$
\begin{aligned}
& S_{t} \equiv K_{T} e^{x} \\
& C\left(S_{t}, t\right) \equiv K_{T} v(x, \tau) \\
& t \equiv T-\frac{\tau}{1 / 2 \sigma^{2}} .
\end{aligned}
$$


Sendo que:

$x=\ln S_{t}-\ln K_{T}, \quad x \in \mathrm{R}, \quad S_{t}>0, \quad K_{T}>0$

$\frac{\partial x}{\partial S_{t}}=\frac{1}{S_{t}}$

$\tau=\frac{\sigma^{2}(T-t)}{2}, t \geq 0, T>0$

$\frac{\partial \tau}{\partial t}=-\frac{\sigma^{2}}{2}$

$\frac{\partial C\left(S_{t}, t\right)}{\partial t}=\frac{\partial C\left(S_{t}, t\right)}{\partial \tau} \frac{\partial \tau}{\partial t}$

$$
=K_{T} \frac{\partial v(x, \tau)}{\partial \tau}\left(-\frac{\sigma^{2}}{2}\right)
$$

$=-\frac{K_{T} \sigma^{2}}{2} \frac{\partial v(x, \tau)}{\partial \tau}$

$$
\begin{aligned}
\frac{\partial C\left(S_{t}, t\right)}{\partial S_{t}} & =\frac{\partial C\left(S_{t}, t\right)}{\partial x} \frac{\partial x}{\partial S_{t}} \\
& =K_{T} \frac{\partial v(x, \tau)}{\partial x} \frac{1}{S_{t}} \\
& =\frac{K_{T}}{S_{t}} \frac{\partial v(x, \tau)}{\partial x}
\end{aligned}
$$




$$
\begin{aligned}
\frac{\partial^{2} C\left(S_{t}, t\right)}{\partial S_{t}{ }^{2}} & =\frac{\partial}{\partial S_{t}}\left(\frac{K_{T}}{S_{t}} \frac{\partial v(x, \tau)}{\partial x}\right) \\
& =\frac{\partial v(x, \tau)}{\partial x} \frac{\partial}{\partial S_{t}}\left(\frac{K_{T}}{S_{t}}\right)+\frac{K_{T}}{S_{t}} \frac{\partial}{\partial S_{t}}\left(\frac{\partial v(x, \tau)}{\partial x}\right) \\
& =\frac{\partial v(x, \tau)}{\partial x}\left(-\frac{K_{T}}{S_{t}{ }^{2}}\right)+\frac{K_{T}}{S_{t}}\left(\frac{\partial v(x, \tau)}{\partial x} \frac{\partial x}{\partial S_{t}}\right) \\
& =-\frac{K_{T}}{S_{t}{ }^{2}} \frac{\partial v(x, \tau)}{\partial x}+\frac{K_{T}}{S_{t}{ }^{2}} \frac{\partial^{2} v(x, \tau)}{\partial x^{2}}
\end{aligned}
$$

Com essas transformações, a equação (25) resulta em: 


$$
\begin{aligned}
& -\frac{K_{T} \sigma^{2}}{2} \frac{\partial v(x, \tau)}{\partial \tau}+\frac{1}{2}\left(-\frac{K_{T}}{S_{t}{ }^{2}} \frac{\partial v(x, \tau)}{\partial x}+\frac{K_{T}}{S_{t}{ }^{2}} \frac{\partial^{2} v(x, \tau)}{\partial x^{2}}\right) S_{t}^{2} \sigma^{2}+\frac{K_{T}}{S_{t}} \frac{\partial v(x, \tau)}{\partial x} r S_{t}-r K_{T} v(x, \tau)=0 \\
& -\frac{K_{T} \sigma^{2}}{2} \frac{\partial v(x, \tau)}{\partial \tau}-\frac{K_{T} \sigma^{2}}{2} \frac{\partial v(x, \tau)}{\partial x}+\frac{K_{T} \sigma^{2}}{2} \frac{\partial^{2} v(x, \tau)}{\partial x^{2}}+r K_{T} \frac{\partial v(x, \tau)}{\partial x}-r K_{T} v(x, \tau)=0 \\
& -\frac{\sigma^{2}}{2} \frac{\partial v(x, \tau)}{\partial \tau}+\left(-\frac{\sigma^{2}}{2}+r\right) \frac{\partial v(x, \tau)}{\partial x}+\frac{\sigma^{2}}{2} \frac{\partial^{2} v(x, \tau)}{\partial x^{2}}-r v(x, \tau)=0 \\
& -\frac{\partial v(x, \tau)}{\partial \tau}+\left(\frac{r}{1 / 2 \sigma^{2}}-1\right) \frac{\partial v(x, \tau)}{\partial x}+\frac{\partial^{2} v(x, \tau)}{\partial x^{2}}-\frac{r}{1 / 2 \sigma^{2}} v(x, \tau)=0 .
\end{aligned}
$$

A partir de (26), (27), (28), (29), (31), (32) e (33), as condições de contorno de (41) tornam-se:

$$
\begin{aligned}
& S_{t}=K_{T} e^{x} \\
& S_{t} \rightarrow 0 \quad \Rightarrow \quad x \rightarrow-\infty \\
& C\left(S_{t}, t\right)=K_{T} v(x, \tau) \mid \begin{array}{lll}
S_{t} \rightarrow 0 & \Rightarrow & x \rightarrow-\infty \\
C(0, t)=0 & \Rightarrow & v(-\infty, \tau)=0
\end{array} \\
& \begin{array}{l}
S_{t} \rightarrow \infty \\
C\left(S_{t}, t\right) \rightarrow S_{t} \rightarrow \infty
\end{array} \mid \quad \Rightarrow \quad v(\infty, \tau) \rightarrow \infty \\
& C\left(S_{T}, T\right)=\max \left\{S_{T}-K_{T} ; 0\right\} \quad \Rightarrow \quad v(x, \tau)=\max \left\{e^{x}-1 ; 0\right\} .
\end{aligned}
$$

O passo seguinte na conversão do formato da equação (41) para o formato da equação de difusão do calor é a eliminação dos termos em $\frac{\partial v(x, \tau)}{\partial x}$ e $v(x, \tau)$. Isso pode ser obtido por meio de uma substituição de variável, que consiste na multiplicação de todos os termos da 
equação por uma exponencial diferente de zero, sem alterar informacionalmente o conteúdo da equação:

$v(x, \tau)=u(x, \tau) e^{\alpha x+\beta \tau}$.

Sendo que:

$\frac{\partial v}{\partial \tau}=\frac{\partial}{\partial \tau}\left(e^{\alpha x+\beta \pi u(x, \tau)}\right)=u(x, \tau) \beta e^{\alpha x+\beta \tau}+\frac{\partial u}{\partial \tau} e^{\alpha x+\beta \tau}$

$\frac{\partial v}{\partial x}=\frac{\partial}{\partial x}\left(e^{\alpha x+\beta u(x, \tau)}\right)=u(x, \tau) \alpha e^{\alpha x+\beta \tau}+\frac{\partial u}{\partial x} e^{\alpha x+\beta \tau}$

$\frac{\partial^{2} v}{\partial x^{2}}=\frac{\partial}{\partial x}\left(u(x, \tau) \alpha e^{\alpha x+\beta \tau}+\frac{\partial u}{\partial x} e^{\alpha x+\beta \tau}\right)$

$=\frac{\partial}{\partial x}\left(u(x, \tau) \alpha e^{\alpha x+\beta \tau}+\frac{\partial u}{\partial x} e^{\alpha x+\beta \tau}\right)$

$=\left(u(x, \tau) \alpha^{2} e^{\alpha x+\beta \tau}+\frac{\partial u}{\partial x} \alpha e^{\alpha x+\beta \tau}\right)+\left(\frac{\partial u}{\partial x} \alpha e^{\alpha x+\beta \tau}+e^{\alpha x+\beta \tau} \frac{\partial^{2} u}{\partial x^{2}}\right)$

$=u(x, \tau) \alpha^{2} e^{\alpha x+\beta \tau}+2 \frac{\partial u}{\partial x} \alpha e^{\alpha x+\beta \tau}+e^{\alpha x+\beta \tau} \frac{\partial^{2} u}{\partial x^{2}}$.

Substituindo (46), (47), (48) e (49) em (41) resulta: 


$$
\begin{gathered}
-u(x, \tau) \beta e^{\alpha x+\beta \tau}+\frac{\partial u}{\partial \tau} e^{\alpha x+\beta \tau}+\left(\frac{r}{1 / 2 \sigma^{2}}-1\right)\left(u(x, \tau) \alpha e^{\alpha x+\beta \tau}+\frac{\partial u}{\partial x} e^{\alpha x+\beta \tau}\right) \\
+u(x, \tau) \alpha^{2} e^{\alpha x+\beta \tau}+2 \frac{\partial u}{\partial x} \alpha e^{\alpha x+\beta \tau}+e^{\alpha x+\beta \tau} \frac{\partial^{2} u}{\partial x^{2}}-\frac{r}{1 / 2 \sigma^{2}} u(x, \tau) e^{\alpha x+\beta \tau}=0 \\
u(x, \tau)\left(\alpha^{2}+\alpha\left(\frac{r}{1 / 2 \sigma^{2}}-1\right)-\frac{r}{1 / 2 \sigma^{2}}-\beta\right)+\frac{\partial u}{\partial \tau}+\left(\frac{r}{1 / 2 \sigma^{2}}-1+2 \alpha\right) \frac{\partial u}{\partial x}+\frac{\partial^{2} u}{\partial x^{2}}=0
\end{gathered}
$$

Como $\alpha$ e $\beta$ são constantes arbitrárias da exponencial introduzida em (46), podemos definí-las com qualquer valor, sem alterar informacionalmente a equação. Definindo convenientemente para eliminação dos termos $u(x, \tau)$ e $\frac{\partial u}{\partial x}$ de (51):

$$
\begin{aligned}
& \beta \equiv \alpha^{2}+\alpha\left(\frac{r}{1 / 2 \sigma^{2}}-1\right)-\frac{r}{1 / 2 \sigma^{2}} \\
& 2 \alpha \equiv-\left(\frac{r}{1 / 2 \sigma^{2}}-1\right) .
\end{aligned}
$$

Finalmente a equação (50) resulta na forma da equação de difusão do calor que se buscava, conforme definido em (30):

$$
\frac{\partial u(x, \tau)}{\partial \tau}=\frac{\partial^{2} u(x, \tau)}{\partial x^{2}}
$$


Solucionando o sistema de equações formado por (52) e (53) para colocar a equação (46) em termos dos parâmetros $\alpha$ e $\beta$ anteriormente definidos:

$$
\begin{aligned}
\alpha & =-\frac{1}{2}\left(\frac{r}{1 / 2 \sigma^{2}}-1\right) \\
\beta & =\frac{1}{4}\left(\frac{r}{1 / 2 \sigma^{2}}-1\right)^{2}-\frac{1}{2}\left(\frac{r}{1 / 2 \sigma^{2}}-1\right)^{2}-\frac{r}{1 / 2 \sigma^{2}} \\
& =-\frac{1}{4}\left(\frac{r}{1 / 2 \sigma^{2}}-1\right)^{2}-\frac{r}{1 / 2 \sigma^{2}} \\
& =-\frac{1}{4}\left(\left(\frac{r}{1 / 2 \sigma^{2}}\right)^{2}-2 \frac{r}{1 / 2 \sigma^{2}}+1\right)-\frac{r}{1 / 2 \sigma^{2}} \\
& \left.=-\frac{1}{4}\left(\frac{r}{1 / 2 \sigma^{2}}+1\right)^{2} \cdot\left(\frac{r}{1 / 2 \sigma^{2}}\right)^{2}+2 \frac{r}{1 / 2 \sigma^{2}}+1\right) \\
& \left.=-\frac{r}{2}\right) \\
& \left.=-\frac{r}{2}\right)^{2} \\
& =1
\end{aligned}
$$

Substituindo (55) e (56) em (46) chegamos a uma equação em função dos parâmetros iniciais do problema:

$$
v(x, \tau)=u(x, \tau) e^{-\frac{1}{2}\left(\frac{r}{1 / 2 \sigma^{2}}-1\right) x-\frac{1}{4}\left(\frac{r}{1 / 2 \sigma^{2}}+1\right)^{2} \tau} .
$$


A partir de (44), (45), (46) e (57), as condições de contorno de (54) tornam-se:

$$
\begin{array}{lll}
v(-\infty, \tau)=0 & \Rightarrow & u(-\infty, \tau)=0 \\
v(\infty, \tau)=\infty & \Rightarrow & u(\infty, \tau)=\infty
\end{array}
$$

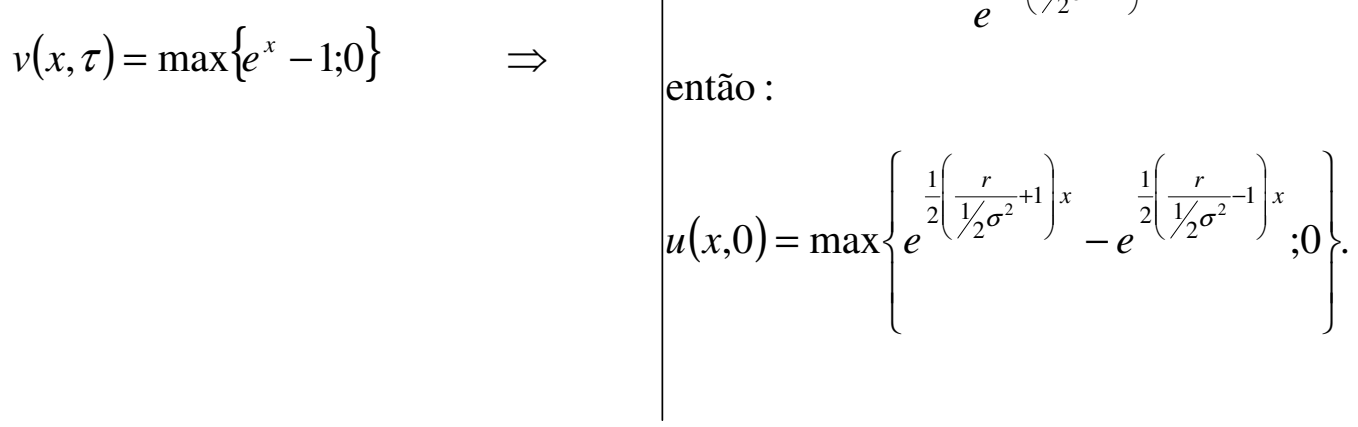

A equação de difusão do calor dada por (54), pode ser solucionada de diversas formas. Optamos por desenvolver a solução utilizando a transformada de Fourier.

Definem-se a transformada de Fourier em relação a $x$ e sua inversa da seguinte forma:

$$
\begin{aligned}
& \mathcal{F}_{x}\{u(x, \tau)\} \equiv \frac{1}{\sqrt{2 \pi}} \int_{-\infty}^{\infty} u(x, \tau) e^{-i \omega x} d x \\
& u(x, \tau)=\mathcal{F}_{x}{ }^{-1}\left\{\mathcal{F}_{x}\{u(x, \tau)\}\right\} \equiv \frac{1}{\sqrt{2 \pi}} \int_{-\infty}^{\infty} \mathcal{F}_{x}\{u(x, \tau)\} e^{i \omega x} d \omega .
\end{aligned}
$$

Aplicando a transformada de Fourier em relação a $x$ aos membros da equação (54): 
$\mathcal{F}_{x}\left\{\frac{\partial u(x, \tau)}{\partial \tau}\right\}=\mathcal{F}_{x}\left\{\frac{\partial^{2} u(x, \tau)}{\partial x^{2}}\right\}$.

Dadas as propriedades de diferenciação da transformada de Fourier tem-se que:

$\mathcal{F}_{x}\left\{\frac{\partial^{2} u(x, \tau)}{\partial x^{2}}\right\}=-\omega^{2} \mathcal{F}_{x}\{u(x, \tau)\}$

$\mathcal{F}_{x}\left\{\frac{\partial u(x, \tau)}{\partial \tau}\right\}=\frac{\partial \mathcal{F}_{x}\{u(x, \tau)\}}{\partial \tau}$

Aplicando as propriedades (66) e (67) em (65) resulta:

$\frac{\partial \mathcal{F}_{x}\{u(x, \tau)\}}{\partial \tau}=-\omega^{2} \mathcal{F}_{x}\{u(x, \tau)\}$

Como $\mathcal{F}_{x}\{u(x, \tau)\}$ é uma função somente de $\tau$, a equação (68) torna-se uma equação diferencial ordinária linear homogênea de primeira ordem com coeficientes constantes em $\mathcal{F}_{x}$, que é uma equação diferencial da forma:

$\frac{d y}{d t}-a^{2} y=0$

A solução geral de equações na forma (69) é uma equação na forma:

$$
y=C e^{-a^{2} t} .
$$

A solução geral de (68) é, portanto:

$$
\mathcal{F}_{x}\{u(x, \tau)\}=C e^{-\omega^{2} \tau} .
$$


Logo, $\mathcal{F}_{x}\{u(x, 0)\}=C$, mas:

$u(x, 0)=f(x)$.

Portanto qualquer que seja $f(x)$, tem-se que:

$\mathcal{F}_{x}\{u(x, 0)\}=f(x)$

Consequentemente:

$\mathcal{F}_{x}\{u(x, \tau)\}=\mathcal{F}_{x}\{f(x)\} e^{-\omega^{2} \tau}$

Aplicando a transformada inversa de Fourier ao termo $e^{-\omega^{2} \tau}$ em (74), obtém-se, conforme Spiegel (1976, p. 126):

$$
\begin{aligned}
g(x, \tau) & =\mathcal{F}_{x}{ }^{-1}\left\{e^{-\omega^{2} \tau}\right\} \\
& =\frac{1}{\sqrt{2 \pi}} \int_{-\infty}^{\infty} e^{-\omega^{2} \tau} e^{i \omega x} d \omega \\
& =\sqrt{\frac{1}{4 \pi \tau}} e^{-\frac{x^{2}}{4 \tau}} .
\end{aligned}
$$

Assim, $\mathcal{F}_{x}\{g(x, \tau)\}=e^{-\omega^{2} \tau}$ e a equação (74) pode ser representada por:

$$
\begin{aligned}
& \mathcal{F}_{x}\{u(x, \tau)\}=\mathcal{F}_{x}\{f(x)\} \mathcal{F}_{x}\{g(x, \tau)\} \\
& u(x, \tau)=\mathcal{F}_{x}{ }^{-1}\left\{\mathcal{F}_{x}\{f(x)\} \mathcal{F}_{x}\{g(x, \tau)\}\right\} .
\end{aligned}
$$


Dada a propriedade da convolução da transformada de Fourier, sendo “*” o operador convolução, tem-se que:

$$
\begin{aligned}
\mathcal{F}_{x}{ }^{-1}\left\{\mathcal{F}_{x}\{f(x)\} \mathcal{F}_{x}\{g(x, \tau)\}\right\} & =f(x) * g(x, \tau) \\
& =\int_{-\infty}^{\infty} f(\xi) g(x-\xi, \tau) d \xi .
\end{aligned}
$$

Substituindo (73), (75) e (77) em (78), obtém-se:

$$
u(x, \tau)=\int_{-\infty}^{\infty} u(\xi, 0) \sqrt{\frac{1}{4 \pi \tau}} e^{-\frac{(x-\xi)^{2}}{4 \tau}} d \xi
$$

Inserindo a condição inicial (62) em (81) resulta:

$$
u(x, \tau)=\int_{-\infty}^{\infty}\left(\max \left\{e^{\frac{1}{2}\left(\frac{r}{1 / 2 \sigma^{2}}+1\right) \xi}-e^{\frac{1}{2}\left(\frac{r}{1 / 2 \sigma^{2}}-1\right) \xi} ; 0\right\}\right) \sqrt{\frac{1}{4 \pi \tau}} e^{-\frac{(x-\xi)^{2}}{4 \tau}} d \xi
$$

Como os termos multiplicativos da função a ser integrada são não-negativos, dados pelo operador $\max \{\}$, pela raiz e pela exponencial, o limite inferior de integração passa a ser 0 .

Com os novos limites de integração, $\xi$ assume somente valores não negativos, e como a função $e^{\frac{1}{2}\left(\frac{r}{1 / 2 \sigma^{2}}+1\right) \xi}-e^{\frac{1}{2}\left(\frac{r}{1 / 2 \sigma^{2}}-1\right) \xi}$ é nula para $\xi=0$ e positiva para valores positivos de $\xi, \mathrm{o}$ operador $\max \{\}$ pode ser suprimido.

Podemos demonstrar que a função $e^{\frac{1}{2}\left(\frac{r}{1 / 2 \sigma^{2}}+1\right) \xi}-e^{\frac{1}{2}\left(\frac{r}{1 / 2 \sigma^{2}}-1\right) \xi}$ é positiva para valores positivos de $\xi$ supondo: 
171

$$
\begin{aligned}
& e^{\frac{1}{2\left(\frac{r}{1 / 2 \sigma^{2}}+1\right) \xi}}-e^{\frac{1}{2}\left(\frac{r}{1 / 2 \sigma^{2}}-1\right) \xi}>0 \\
& e^{\frac{1}{2\left(\frac{r}{1 / 2 \sigma^{2}}+1\right) \xi}>e^{\frac{1}{2}\left(\frac{r}{1 / 2 \sigma^{2}}-1\right) \xi}} \\
& \frac{1}{2}\left(\frac{r}{1 / 2 \sigma^{2}}+1\right) \xi>\frac{1}{2}\left(\frac{r}{1 / 2 \sigma^{2}}-1\right) \xi \\
& \frac{r}{1 / 2 \sigma^{2}} \xi+\xi>\frac{r}{1 / 2 \sigma^{2}} \xi-\xi \\
& \frac{r}{1 / 2 \sigma^{2}} \xi+\xi>\frac{r}{1 / 2 \sigma^{2}} \xi-\xi \\
& \xi>-\xi
\end{aligned}
$$

A condição $\xi>-\xi$ somente é válida se $\xi>0$.

Fazendo em (80) as seguintes substituições de variáveis:

$$
\zeta \equiv \frac{(\xi-x)}{\sqrt{2 \tau}} \Rightarrow \mid \begin{aligned}
& \xi=x+\zeta \sqrt{2 \tau} \\
& d \xi=\sqrt{2 \tau} d \zeta
\end{aligned}
$$

$$
\xi=0 \quad \Rightarrow \quad \zeta=-\frac{x}{\sqrt{2 \tau}}
$$


A equação (80) torna-se:

$$
\begin{aligned}
u(x, \tau) & =\int_{-\frac{x}{\sqrt{2 \tau}}}^{\infty}\left(e^{\frac{1}{2}\left(\frac{r}{1 / 2 \sigma^{2}}+1\right)(x+\zeta \sqrt{2 \tau})}-e^{\frac{1}{2}\left(\frac{r}{1 / 2 \sigma^{2}}-1\right)(x+\zeta \sqrt{2 \tau})}\right) \sqrt{\frac{1}{4 \pi \tau}} e^{-\frac{\zeta^{2}}{2}} \sqrt{2 \tau} d \zeta \\
& =\frac{1}{\sqrt{2 \pi}} \int_{-\frac{x}{\sqrt{2 \tau}}}^{\infty} e^{\frac{1}{2\left(\frac{r}{1 / 2 \sigma^{2}}+1\right)(x+\zeta \sqrt{2 \tau})-\frac{\zeta^{2}}{2}} d \zeta-\frac{1}{\sqrt{2 \pi}} \int_{-\frac{x}{\sqrt{2 \tau}}}^{\infty} e^{\frac{1}{2}\left(\frac{r}{1 / 2 \sigma^{2}}-1\right)(x+\zeta \sqrt{2 \tau})-\frac{\zeta^{2}}{2}} d \zeta} \\
& =\frac{1}{\sqrt{2 \pi}} e^{\frac{1}{2}\left(\frac{r}{1 / 2 \sigma^{2}}+1\right) x} \int_{-\frac{x}{\sqrt{2 \tau}}}^{\infty} e^{-\frac{1}{2}\left(\zeta^{2}-\zeta \sqrt{2 \tau}\left(\frac{r}{1 / 2 \sigma^{2}}+1\right)\right)} d \zeta-\frac{1}{\sqrt{2 \pi}} e^{\frac{1}{2\left(\frac{r}{1 / 2 \sigma^{2}}-1\right) x} \int_{-\frac{x}{\sqrt{2 \tau}}}^{\infty} e^{-\frac{1}{2}\left(\zeta^{2}-\zeta \sqrt{2 \tau}\left(\frac{r}{1 / 2 \sigma^{2}}-1\right)\right)} d \zeta}
\end{aligned}
$$

Completando os quadrados nos expoentes em (84):

$$
\begin{aligned}
& u(x, \tau)=\frac{1}{\sqrt{2 \pi}} e^{\frac{1}{2}\left(\frac{r}{1 / 2 \sigma^{2}}+1\right) x} \int_{-\frac{x}{\sqrt{2 \tau}}}^{\infty} e^{-\frac{1}{2}\left(\zeta^{2}-\zeta \sqrt{2 \tau}\left(\frac{r}{1 / 2 \sigma^{2}}+1\right)-\frac{\tau}{2}\left(\frac{r}{1 / 2 \sigma^{2}}+1\right)^{2}+\frac{\tau}{2}\left(\frac{r}{1 / 2 \sigma^{2}}+1\right)^{2}\right)} d \zeta \\
& -\frac{1}{\sqrt{2 \pi}} e^{\frac{1}{2}\left(\frac{r}{1 / 2 \sigma^{2}}-1\right) x} \int_{-\frac{x}{\sqrt{2 \tau}}}^{\infty} e^{-\frac{1}{2}\left(\zeta^{2}-\zeta \sqrt{2 \tau}\left(\frac{r}{1 / 2 \sigma^{2}}-1\right)--\frac{\tau}{2}\left(\frac{r}{1 / 2 \sigma^{2}}-1\right)^{2}+\frac{\tau}{2}\left(\frac{r}{1 / 2 \sigma^{2}}-1\right)^{2}\right)} d \zeta \\
& =\frac{1}{\sqrt{2 \pi}} e^{\frac{1}{2}\left(\frac{r}{1 / 2 \sigma^{2}}+1\right) x} e^{\frac{\tau}{4}\left(\frac{r}{1 / 2 \sigma^{2}}+1\right)^{2}} \int_{-\frac{x}{\sqrt{2 \tau}}}^{\infty} e^{-\frac{1}{2}\left(\zeta^{2}-2 \zeta \frac{1}{2} \sqrt{2 \tau}\left(\frac{r}{1 / 2 \sigma^{2}}+1\right)+\frac{\tau}{2}\left(\frac{r}{1 / 2 \sigma^{2}}+1\right)\right.} d \zeta \\
& -\frac{1}{\sqrt{2 \pi}} e^{\frac{1}{2}\left(\frac{r}{1 / 2 \sigma^{2}}-1\right) x} e^{\frac{\tau}{4}\left(\frac{r}{1 / 2 \sigma^{2}}+1\right)^{2}} \int_{-\frac{x}{\sqrt{2 \tau}}}^{\infty} e^{-\frac{1}{2}\left(\zeta^{2}-2 \zeta \frac{1}{2} \sqrt{2 \tau}\left(\frac{r}{1 / 2 \sigma^{2}}-1\right)+\frac{\tau}{2}\left(\frac{r}{1 / 2 \sigma^{2}}-1\right)^{2}\right)} d \zeta \\
& =\frac{1}{\sqrt{2 \pi}} e^{\frac{1}{2}\left(\frac{r}{1 / 2 \sigma^{2}}+1\right) x+\frac{\tau}{4}\left(\frac{r}{1 / 2 \sigma^{2}}+1\right)^{2}} \int_{-\frac{x}{\sqrt{2 \tau}}}^{\infty} e^{-\frac{1}{2}\left(\zeta-\frac{1}{2} \sqrt{2 \tau}\left(\frac{r}{1 / 2 \sigma^{2}}+1\right)\right)^{2}} d \zeta \\
& -\frac{1}{\sqrt{2 \pi}} e^{\frac{1}{2}\left(\frac{r}{1 / 2 \sigma^{2}}-1\right) x+\frac{\tau}{4}\left(\frac{r}{1 / 2 \sigma^{2}}-1\right)^{2}} \int_{-\frac{x}{\sqrt{2 \tau}}}^{\infty} e^{-\frac{1}{2}\left(\zeta-\frac{1}{2} \sqrt{2 \tau}\left(\frac{r}{1 / 2 \sigma^{2}}-1\right)\right)^{2}} d \zeta
\end{aligned}
$$


173

Fazendo as substituições de variáveis:

$$
\begin{aligned}
& z_{1}=\zeta-\frac{1}{2} \sqrt{2 \tau}\left(\frac{r}{1 / 2 \sigma^{2}}+1\right) \\
& d \zeta=d z_{1}
\end{aligned}
$$

$$
\zeta \in\left[-\frac{x}{\sqrt{2 \tau}}, \infty\right) \Rightarrow z_{1} \in\left[-\frac{x}{\sqrt{2 \tau}}-\frac{1}{2} \sqrt{2 \tau}\left(\frac{r}{1 / 2 \sigma^{2}}+1\right), \infty\right)
$$

$$
z_{2}=\zeta-\frac{1}{2} \sqrt{2 \tau}\left(\frac{r}{1 / 2 \sigma^{2}}-1\right)
$$

$d \zeta=d z_{2}$

$$
\zeta \in\left[-\frac{x}{\sqrt{2 \tau}}, \infty\right) \Rightarrow z_{2} \in\left[-\frac{x}{\sqrt{2 \tau}}-\frac{1}{2} \sqrt{2 \tau}\left(\frac{r}{1 / 2 \sigma^{2}}-1\right), \infty\right)
$$

A equação (85) torna-se:

$$
\begin{aligned}
u(x, \tau)= & \frac{1}{\sqrt{2 \pi}} e^{\frac{1}{2}\left(\frac{r}{1 / 2 \sigma^{2}}+1\right) x+\frac{\tau}{4}\left(\frac{r}{1 / 2 \sigma^{2}}+1\right)^{2}} \int_{-\frac{x}{\sqrt{2 \tau}}-\frac{1}{2} \sqrt{2 \tau}\left(\frac{r}{1 / 2 \sigma^{2}}+1\right)}^{\infty}\left(e^{-\frac{1}{2} z_{1}^{2}}\right) d z_{1} \\
& \left.-\frac{1}{\sqrt{2 \pi}} e^{\frac{\tau}{4}\left(\frac{r}{1 / 2 \sigma^{2}}-1\right)^{2}} \int_{-\frac{x}{\sqrt{2 \tau}}-\frac{1}{2} \sqrt{2 \tau}\left(\frac{r}{1 / 2 \sigma^{2}}\right)\left(e^{-\frac{1}{2} z_{2}^{2}}\right) d z_{2}}^{\frac{1}{2}\left(\frac{r}{1 / 2 \sigma^{2}}+1\right) x+\frac{\tau}{4}\left(\frac{r}{1 / 2 \sigma^{2}}+1\right)^{2}} \frac{1}{\sqrt{2 \pi}} \int_{-\infty}^{\frac{x}{\sqrt{2 \tau}}+\frac{1}{2} \sqrt{2 \tau}\left(\frac{r}{1 / 2 \sigma^{2}}+1\right)}\right)\left(e^{-\frac{1}{2} z_{1}^{2}}\right) d z_{1} \\
= & -e^{\frac{1}{2}\left(\frac{r}{1 / 2 \sigma^{2}}-1\right) x+\frac{\tau}{4}\left(\frac{r}{1 / 2 \sigma^{2}}-1\right)} \frac{1}{\sqrt{2 \pi}} \int_{-\infty}^{\frac{x}{\sqrt{2 \tau}}+\frac{1}{2} \sqrt{2 \tau}\left(\frac{r}{1 / 2 \sigma^{2}}-1\right)}\left(e^{-\frac{1}{2} z_{2}^{2}}\right) d z_{2} .
\end{aligned}
$$


Assim, $u(x, \tau)$ em (88) é a solução da equação do calor em função dos termo do problema. É necessário, então, retornar às equações originais. Retornando à equação (57):

$v(x, \tau)=u(x, \tau) e^{-\frac{1}{2}\left(\frac{r}{1 / 2 \sigma^{2}}-1\right) x-\frac{1}{4}\left(\frac{r}{1 / 2 \sigma^{2}}+1\right)^{2} \tau}$.

Substituindo (88) em (57):

$$
\begin{aligned}
v(x, \tau)= & e^{\frac{1}{2}\left(\frac{r}{1 / 2 \sigma^{2}}+1\right) x} e^{\frac{\tau}{4}\left(\frac{r}{1 / 2 \sigma^{2}}+1\right)^{2}} e^{-\frac{1}{2}\left(\frac{r}{1 / 2 \sigma^{2}}-1\right) x-\frac{1}{4}\left(\frac{r}{1 / 2 \sigma^{2}}+1\right)^{2} \tau} \frac{1}{\sqrt{2 \pi}} \int_{-\infty}^{\frac{x}{\sqrt{2 \tau}}+\frac{1}{2} \sqrt{2 \tau}\left(\frac{r}{1 / 2 \sigma^{2}}+1\right)}\left(e^{-\frac{1}{2} z_{1}^{2}}\right) d z_{1} \\
& \left.-e^{\frac{1}{2}\left(\frac{r}{1 / 2 \sigma^{2}}-1\right) \times+\frac{\tau}{4}\left(\frac{r}{1 / 2 \sigma^{2}}-1\right)} e^{2} e^{-\frac{1}{2}\left(\frac{r}{1 / 2 \sigma^{2}}-1\right) x-\frac{1}{4}\left(\frac{r}{1 / 2 \sigma^{2}}+1\right)^{2} \tau} \frac{1}{\sqrt{2 \pi}} \int_{-\infty}^{\frac{x}{\sqrt{2 \tau}}+\frac{1}{2} \sqrt{2 \tau}\left(\frac{r}{1 / 2 \sigma^{2}}-1\right)}\right)\left(e^{-\frac{1}{2} z_{2}^{2}}\right) d z_{2} \\
= & e^{x} \frac{1}{\sqrt{2 \pi}} \int_{-\infty}^{\frac{x}{\sqrt{2 \tau}}+\frac{1}{2} \sqrt{2 \tau}\left(\frac{r}{1 / 2 \sigma^{2}}+1\right)}\left(e^{-\frac{1}{2} z_{1}^{2}}\right) d z_{1}-e^{\frac{r}{1 / 2 \sigma^{2}} \tau} \frac{1}{\sqrt{2 \pi}} \int_{-\infty}^{\frac{x}{\sqrt{2 \tau}}+\frac{1}{2} \sqrt{2 \tau}\left(\frac{r}{1 / 2 \sigma^{2}}-1\right)}\left(e^{-\frac{1}{2} z_{2}^{2}}\right) d z_{2} .
\end{aligned}
$$

Retornando à equação (32):

$C\left(S_{t}, t\right)=K_{T} v(x, \tau)$

Substituindo (91) em (32):

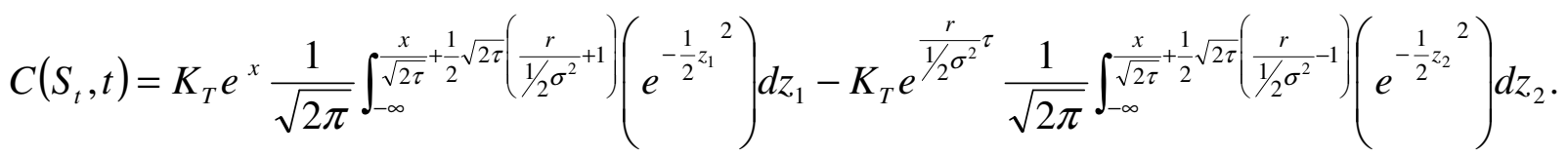


Retornando às equações (34) e (36):

$x=\ln S_{t}-\ln K_{T}, \quad x \in \mathbb{R}, \quad S_{t}>0, \quad K_{T}>0$

$\tau=\frac{\sigma^{2}(T-t)}{2}, t \geq 0, T>0$

Substituindo (34) e (36) em (90):

$$
\begin{aligned}
& C\left(S_{t}, t\right)=K_{T} e^{\ln \frac{S_{t}}{K_{T}}} \frac{1}{\sqrt{2 \pi}} \int_{-\infty} \frac{\ln \frac{S_{t}}{K_{T}}}{2 \frac{\sigma^{2}(T-t)}{2}}+\frac{1}{2} \sqrt{2 \frac{\sigma^{2}(T-t)}{2}}\left(\frac{r}{1 / 2 \sigma^{2}}+1\right)\left(e^{-\frac{1}{2} z_{1}^{2}}\right) d z_{1} \\
& -K_{T} e^{\frac{r}{1 / 2 \sigma^{2}} \tau} \frac{1}{\sqrt{2 \pi}} \int_{-\infty}^{\frac{\ln \frac{S_{t}}{K_{T}}}{2 \frac{\sigma^{2}(T-t)}{2}}}+\frac{1}{2} \sqrt{2 \frac{\sigma^{2}(T-t)}{2}}\left(\frac{r}{1 / 2 \sigma^{2}}-1\right)\left(e^{-\frac{1}{2} z_{2}^{2}}\right) d z_{2} \\
& =K_{T} e^{\ln \frac{S_{t}}{K_{T}}} \frac{1}{\sqrt{2 \pi}} \int_{-\infty}^{\frac{\ln \frac{S_{t}}{K_{T}}}{\sigma \sqrt{(T-t)}}+\frac{\sigma}{2} \sqrt{(T-t)}\left(\frac{r}{1 / 2 \sigma^{2}}+1\right)}\left(e^{-\frac{1}{2}^{2} z_{1}}\right) d z_{1} \\
& \left.-K_{T} e^{\frac{r}{1 / 2 \sigma^{2}} \tau} \frac{1}{\sqrt{2 \pi}} \int_{-\infty}^{\frac{\ln \frac{S_{t}}{K_{T}}}{\sigma \sqrt{(T-t)}}+\frac{\sigma}{2} \sqrt{(T-t)}\left(\frac{r}{1 / 2 \sigma^{2}}-1\right)}\right)\left(e^{-\frac{1}{2} z_{2}^{2}}\right) d z_{2} \\
& =K_{T} e^{\ln \frac{S_{t}}{K_{T}}} \frac{1}{\sqrt{2 \pi}} \int_{-\infty}^{\frac{\ln \frac{S_{t}}{K_{T}}}{\sigma \sqrt{(T-t)}}+\frac{r}{\sigma} \sqrt{(T-t)}+\frac{\sigma}{2} \sqrt{(T-t)}}\left(e^{-\frac{1}{2} z^{2}}\right) d z_{1} \\
& -K_{T} e^{\frac{r}{1 / 2 \sigma^{2}} \tau} \frac{1}{\sqrt{2 \pi}} \int_{-\infty}^{\frac{\ln \frac{S_{t}}{K_{T}}}{\sigma \sqrt{(T-t)}}+\frac{r}{\sigma} \sqrt{(T-t)}-\frac{\sigma}{2} \sqrt{(T-t)}}\left(e^{-\frac{1}{2} z_{2}^{2}}\right) d z_{2} \\
& =K_{T} e^{\ln \frac{S_{t}}{K_{T}}} \frac{1}{\sqrt{2 \pi}} \int_{-\infty}^{\frac{\ln \frac{S_{t}}{K_{T}}\left(r+1 / 2 \sigma^{2}\right)(T-t)}{\sigma \sqrt{(T-t)}}}\left(e^{-\frac{1}{2} z_{1}^{2}}\right) d z_{1}-K_{T} e^{\frac{r}{1 / 2 \sigma^{2}} \tau} \frac{1}{\sqrt{2 \pi}} \int_{-\infty}^{\frac{\ln \frac{S_{t}}{K_{T}}\left(r-1 / 2 \sigma^{2}\right)(T-t)}{\sigma \sqrt{(T-t)}}}\left(e^{-\frac{1}{2} z_{2}^{2}}\right) d z_{2} .
\end{aligned}
$$


Como a função distribuição acumulada de uma variável estocástica normal padão é dada por:

$\Phi(w)=\frac{1}{\sqrt{2 \pi}} \int_{-\infty}^{w} e^{-\frac{1}{2} z^{2}} d z$.

A dinâmica do preço da opção é dada por:

$$
C\left(S_{t}, t\right)=S_{t} \Phi\left(\frac{\ln \frac{S_{t}}{K_{T}}+(T-t)\left(r+\frac{\sigma^{2}}{2}\right)}{\sigma \sqrt{T-t}}\right)-e^{(-r(T-t))} K_{T} \Phi\left(\frac{\ln \frac{S_{t}}{K_{T}}+(T-t)\left(r-\frac{\sigma^{2}}{2}\right)}{\sigma \sqrt{T-t}}\right)
$$

q. e. $d$. proposição 1 .

É importante observar que a distribuição acumulada $\Phi$ é uma distribuição acumulada da normal padrão neutralizadora do risco, como pode ser interpretado de Breeden e Litzenberger (1978, p. 621-651). Embora o conceito de precificação de derivativos pela teoria martingale não existisse quando demonstrada a fórmula de Black-Scholes, o processo na medida neutralizadora do risco foi introduzido com o conceito de nãoarbitragem nas equações (19) e (20), quando foi definido que a carteira de hedge deve ter o rendimento do ativo livre de risco.

Outras formas alternativas da demonstração da fórmula de Black-Scholes são indicadas em Andreasen, Bjark e Poulsen (1999, p. 1-30). 


\section{APÊNDICE 2 - DEMONSTRAÇÕES ESTRATÉGIA AC}

Notação:

$t:$ instante de tempo discreto, $t \in\{0,1, \ldots, T\}$.

$T$ : instante de tempo de expiração da opção de compra européia.

$R f_{t}$ : processo-escalar retorno da taxa livre de risco.

$\beta_{t}$ : processo-escalar desconto cumulativo à taxa livre de risco.

$\mathbf{S}_{t}$ : processo-vetor preço dos ativos-base.

$\boldsymbol{\delta}_{t}:$ processo-vetor dividendo dos ativos-base.

$\mathbf{X}_{t}$ : processo-vetor valor descontado dos ativos-base (incluindo dividendos).

$\Delta \mathbf{X}_{t}$ : processo-vetor retorno descontado dos ativos-base (retorno em excesso à taxa livre de risco).

$\boldsymbol{\theta}_{t}$ : processo-vetor estratégia dinâmica autofinanciável (quantidades de ativos-base).

$x$ : investimento inicial.

$V_{t}^{x, \theta}$ : processo-escalar valor da estratégia autofinanciável com investimento inicial $x$ e $\boldsymbol{\theta}$ ativos-base.

$H_{t}$ : processo-escalar valor esperado do ativo-objeto (preço da opção e valor esperado de uma carteira replicante com erro esperado acumulado de hedge nulo).

$k_{t}$ : processo-escalar proporção de erro propagado.

$\varepsilon_{t}^{2}$ : processo-escalar erro quadrático esperado mínimo acumulado de replicação.

$\varepsilon_{0}^{2}$ : erro quadrático esperado mínimo acumulado de replicação no instante $t=0$.

$e_{t}$ : erro acumulado de hedge no instante $t$.

$\operatorname{ESRE}_{t}^{P}$ : processo-escalar erro quadrático esperado de replicação de um período na medida de probabilidade objetiva.

$E_{t}^{P}[\bullet]$ : esperança condicionada na medida de probabilidade objetiva, que assinala valores aos estados.

$\bullet^{\dagger}$ : vetor ou matriz transpostos. 


\subsection{Premissas do modelo}

- $\quad$ O espaço de probabilidades filtrado é finito.

- Todos os processos são adaptados (conhecidos somente em $t$ ), exceto o processo de desconto à taxa livre de risco que é previsível (conhecido em $t-1$ ).

- $\quad$ Exogeneidade: uma variável estocástica $\mathbf{W}: \Omega \rightarrow \mathrm{R}$ é exógena se para cada evento $\omega \in \Omega, \mathbf{W}(\omega)$ é independente das escolhas de $V_{0}^{x, \theta}(\omega), \boldsymbol{\theta}_{0}(\omega), \ldots \boldsymbol{\theta}_{T-1}(\omega)$.

- $\quad \mathbf{X}_{t}$ e $\beta_{t}$ são exógenos.

- $\quad k_{t}$ e $H_{t}$ são exógenos.

- $\quad$ Retornos $\Delta \mathbf{X}_{t}$ são linearmente independentes.

$-\quad k_{t}>0$.

\subsection{Definição 1}

O processo-desconto $\beta_{t}$ é o desconto cumulativo que, em qualquer instante, leva qualquer valor a valor presente do instante inicial do investimento, à taxa livre de risco. É um processo previsível, pois $\beta_{t}$ é conhecido em $t-1$.

O processo-desconto é dado diretamente por:

$$
\begin{aligned}
\beta_{t} & =R f_{0} R f_{1} \ldots R f_{t-1} \\
& =\prod_{i=0}^{T-1} R f_{i} \\
\beta_{0} & =1 .
\end{aligned}
$$

\subsection{Definição 2}

O processo valor do ativo subjacente incluindo dividendos $\mathbf{X}_{t}$ é o valor do ativo em qualquer instante, levado a valor presente do instante inicial do investimento à taxa livre de risco. É um processo estocástico, pois $\mathbf{X}_{t}$ não é conhecido em $t-1$. 
O processo valor do ativo subjacente descontado é dado diretamente por:

$\mathbf{X}_{t} \equiv \frac{\mathbf{S}_{t}}{\beta_{t}}+\sum_{i=1}^{t} \frac{\boldsymbol{\delta}_{i}}{\beta_{i}}$

\subsection{Proposição 1}

O processo retorno descontado do ativo subjacente incluindo dividendos é o retorno descontado de um período do ativo subjacente incluindo dividendos, em valor monetário, levado a valor presente do instante inicial do investimento, à taxa livre de risco.

O processo retorno descontado do ativo subjacente é dado por:

$$
\Delta \mathbf{X}_{t}=\mathbf{X}_{t}-\mathbf{X}_{t-1}=\frac{1}{\beta_{t-1}}\left(\frac{\mathbf{S}_{t}+\boldsymbol{\delta}_{t}}{R f_{t-1}}-\mathbf{S}_{t-1}\right)
$$

Fim da proposição 1 .

Demonstração da proposição 1:

$$
\begin{aligned}
\Delta \mathbf{X}_{t}= & \frac{\mathbf{S}_{t}}{\beta_{t}}+\sum_{i=1}^{t} \frac{\boldsymbol{\delta}_{i}}{\beta_{i}}-\frac{\mathbf{S}_{t-1}}{\beta_{t-1}}-\sum_{i=1}^{t-1} \frac{\boldsymbol{\delta}_{i}}{\beta_{i}} \\
& =\frac{\mathbf{S}_{t}}{\beta_{t}}+\frac{\boldsymbol{\delta}_{t}}{\beta_{t}}-\frac{\mathbf{S}_{t-1}}{\beta_{t-1}}+\sum_{i=1}^{t-1} \frac{\boldsymbol{\delta}_{i}}{\beta_{i}}-\sum_{i=1}^{t-1} \frac{\boldsymbol{\delta}_{i}}{\beta_{i}} \\
& =\frac{\mathbf{S}_{t}+\boldsymbol{\delta}_{t}}{R f_{t} \beta_{t-1}}-\frac{\mathbf{S}_{t-1}}{\beta_{t-1}} \\
& =\frac{1}{\beta_{t-1}}\left(\frac{\mathbf{S}_{t}+\boldsymbol{\delta}_{t}}{R f_{t-1}}-\mathbf{S}_{t-1}\right)
\end{aligned}
$$

q. e. d. proposição 1 . 


\subsection{Proposição 2}

O processo-valor da carteira replicante do ativo-objeto é dado por:

$V_{t}=R f_{t-1} V_{t-1}+\beta_{t} \boldsymbol{\theta}_{t-1}^{\dagger} \Delta \mathbf{X}_{t}$.

Fim da proposição 2.

Demonstração da proposição 2:

O investimento inicial é definido como a soma entre um valor em ativo livre de risco $B_{0} \mathrm{e}$ quantidades $\boldsymbol{\theta}_{0}$ de ativos de risco $\mathbf{X}_{0}$.

$x \equiv B_{0}+\boldsymbol{\theta}_{0}^{\dagger} \mathbf{X}_{0}$.

O valor inicial do processo-valor da carteira replicante do ativo-objeto é igual ao investimento inicial.

$V_{0}^{x, \theta} \equiv x$.

A evolução do processo-valor da estratégia autofinanciável em $t=1$ é dado por:

$$
\begin{aligned}
V_{1}^{x, \theta} & =B_{0} R f_{0}+\boldsymbol{\theta}_{0}^{\dagger} \mathbf{X}_{1} R f_{0} \\
& =B_{0} R f_{0}+\boldsymbol{\theta}_{0}^{\dagger}\left(\mathbf{X}_{0}+\Delta \mathbf{X}_{1}\right) R f_{0} \\
& =\left(B_{0}+\boldsymbol{\theta}_{0}^{\dagger} \mathbf{X}_{0}+\boldsymbol{\theta}_{0}^{\dagger} \Delta \mathbf{X}_{1}\right) R f_{0} \\
& =V_{0}^{x, \theta} R f_{0}+\boldsymbol{\theta}_{0}^{\dagger} \Delta \mathbf{X}_{1} R f_{0} .
\end{aligned}
$$

A aplicação de uma nova estratégia ao valor resultante corresponde a um novo investimento em ativo livre de risco $B_{1}$ e um somado a uma nova quantidade $\boldsymbol{\theta}_{1}$ de ativos de risco $\mathbf{X}_{1}$ que sendo um valor descontado deve ser corrigido à taxa livre de risco. 
$V_{1}^{x, \theta}=B_{1}+\boldsymbol{\theta}_{1}^{\dagger} \mathbf{X}_{1} R f_{0}$.

A evolução do processo-valor da estratégia autofinanciável em $t=2$ é dado por:

$$
\begin{aligned}
V_{2}^{x, \theta} & =B_{1} R f_{1}+\boldsymbol{\theta}_{1}^{\dagger} \mathbf{X}_{2} R f_{0} R f_{1} \\
& =B_{1} R f_{1}+\boldsymbol{\theta}_{1}^{\dagger}\left(\mathbf{X}_{1}+\Delta \mathbf{X}_{2}\right) R f_{0} R f_{1} \\
& =\left(B_{1}+\boldsymbol{\theta}_{1}^{\dagger} \mathbf{X}_{1}+\boldsymbol{\theta}_{1}^{\dagger} \Delta \mathbf{X}_{2}\right) R f_{0} R f_{1} \\
& =V_{1}^{x, \theta} R f_{1}+\boldsymbol{\theta}_{1}^{\dagger} \Delta \mathbf{X}_{2} R f_{0} R f_{1} .
\end{aligned}
$$

Por indução finita tem-se que:

$V_{t}^{x, \theta}=V_{t-1}^{x, \theta} R f_{t-1}+\boldsymbol{\theta}_{t-1}^{\dagger} \Delta \mathbf{X}_{t} \beta_{t}$.

q. e. d. proposição 2 .

\subsection{Proposição 3}

O processo de valor descontado da estratégia autofinanciável é o valor em qualquer instante, da carteira replicante do ativo-objeto, levado a valor presente do instante inicial do investimento, à taxa livre de risco.

O processo de valor descontado da estratégia autofinanciável é dado por:

$\frac{V_{t}^{x, \theta}}{\beta_{t}}=V_{0}^{x, \theta}+\sum_{i=0}^{t} \boldsymbol{\theta}_{i-1}^{\dagger} \Delta \mathbf{X}_{i}$

Fim da proposição 3 .

Demonstração da proposição 3: 


$$
\begin{aligned}
V_{t}^{x, \theta} & =R f_{t-1} V_{t-1}^{x, \theta}+\beta_{t} \boldsymbol{\theta}_{t-1}^{\dagger} \Delta \mathbf{X}_{t} \\
& =R f_{t-1}\left(R f_{t-2} V_{t-2}^{x, \theta}+\beta_{t-1} \boldsymbol{\theta}_{t-2}^{\dagger} \Delta \mathbf{X}_{t-1}\right)+\beta_{t} \boldsymbol{\theta}_{t-1}^{\dagger} \Delta \mathbf{X}_{t} \\
& =R f_{t-1} R f_{t-2} V_{t-2}^{x, \theta}+R f_{t-1} \beta_{t-1} \boldsymbol{\theta}_{t-2}^{\dagger} \Delta \mathbf{X}_{t-1}+\beta_{t} \boldsymbol{\theta}_{t-1}^{\dagger} \Delta \mathbf{X}_{t} \\
& =R f_{t-1} R f_{t-2} V_{t-2}^{x, \theta}+\beta_{t} \boldsymbol{\theta}_{t-2}{ }^{\dagger} \Delta \mathbf{X}_{t-1}+\beta_{t} \boldsymbol{\theta}_{t-1}{ }^{\dagger} \Delta \mathbf{X}_{t} \\
& =R f_{t-1} R f_{t-2}\left(R f_{t-3} V_{t-3}^{x, \theta}+\beta_{t-2} \boldsymbol{\theta}_{t-3}^{\dagger} \Delta \mathbf{X}_{t-2}{ }^{\dagger}+\beta_{t} \boldsymbol{\theta}_{t-2}^{\dagger} \Delta \mathbf{X}_{t-1}+\beta_{t} \boldsymbol{\theta}_{t-1}^{\dagger} \Delta \mathbf{X}_{t}\right. \\
& =R f_{t-1} R f_{t-2} R f_{t-3} V_{t-3}^{x, \theta}+R f_{t-1} R f_{t-2} \beta_{t-2} \boldsymbol{\theta}_{t-3}^{\dagger} \Delta \mathbf{X}_{t-2}+\beta_{t} \boldsymbol{\theta}_{t-2}^{\dagger} \Delta \mathbf{X}_{t-1}+\beta_{t} \boldsymbol{\theta}_{t-1}^{\dagger} \Delta \mathbf{X}_{t} \\
& =R f_{t-1} R f_{t-2} R f_{t-3} V_{t-3}^{x, \theta}+\beta_{t} \boldsymbol{\theta}_{t-3}^{\dagger} \Delta \mathbf{X}_{t-2}+\beta_{t} \boldsymbol{\theta}_{t-2}^{\dagger} \Delta \mathbf{X}_{t-1}+\beta_{t} \boldsymbol{\theta}_{t-1}^{\dagger} \Delta \mathbf{X}_{t} .
\end{aligned}
$$

Por indução finita tem-se que:

$$
\begin{aligned}
& V_{t}^{x, \theta}=R f_{t-1} R f_{t-2} R f_{t-3} \ldots R f_{0} V_{0}^{x, \theta}+\beta_{t} \boldsymbol{\theta}_{0}^{\dagger} \Delta \mathbf{X}_{1}+\beta_{t} \boldsymbol{\theta}_{1}^{\dagger} \Delta \mathbf{X}_{2}+\ldots+\beta_{t} \boldsymbol{\theta}_{t-1}^{\dagger} \Delta \mathbf{X}_{t} \\
& \frac{V_{t}^{x, \theta}}{\beta_{t}}=V_{0}^{x, \theta}+\boldsymbol{\theta}_{0}^{\dagger} \Delta \mathbf{X}_{1}+\boldsymbol{\theta}_{1}^{\dagger} \Delta \mathbf{X}_{2}+\ldots+\boldsymbol{\theta}_{t-1}^{\dagger} \Delta \mathbf{X}_{t} \\
& \frac{V_{t}^{x, \theta}}{\beta_{t}}=V_{0}^{x, \theta}+\sum_{i=1}^{t} \boldsymbol{\theta}_{i-1}^{\dagger} \Delta \mathbf{X}_{i} .
\end{aligned}
$$$$
\text { q. e. d. proposição } 3 \text {. }
$$ 


\subsection{Proposição 4}

A a estratégia autofinanciável da ótima de hedge da equação (5) é dada por:

$\boldsymbol{\theta}_{t-1}^{D^{\dagger}}=-\left(\beta_{t}\right)^{-1} E_{t-1}^{P}\left[k_{t} \Delta \mathbf{X}_{t}\left(R f_{t-1} V_{t-1}^{x, \theta}-H_{t}\right)\right]\left(E_{t-1}^{P}\left[k_{t} \Delta \mathbf{X}_{t} \Delta \mathbf{X}_{t}^{\dagger}\right]\right)^{-1}$.

$k_{t}$ é o processo proporção de erro propagado

$k_{t}=\left(R f_{t}\right)^{2}\left(E_{t}^{P}\left[k_{t+1}\right]-E_{t}^{P}\left[k_{t+1} \Delta \mathbf{X}_{t+1}^{\dagger}\right]\left(E_{t}^{P}\left[k_{t+1} \Delta \mathbf{X}_{t+1} \Delta \mathbf{X}_{t+1}^{\dagger}\right]\right)^{-1} E_{t}^{P}\left[k_{t+1} \Delta \mathbf{X}_{t+1}\right]\right)$.

O erro quadrático esperado mínimo acumulado de hedge, que é o erro quadrático esperado mínimo acumulado de replicação é definido como:

$\mathcal{\varepsilon}_{0}^{2} \equiv \min _{x, \theta_{0}, \ldots, \theta_{T-1}} E_{0}^{P}\left[\left(V_{T}^{x, \theta}-H_{T}\right)^{2}\right]$

$\varepsilon_{0}^{2}=\min _{x, \theta_{0}, \ldots, \theta_{T-1}} E_{0}^{P}\left[\left(\beta_{T}\left(V_{0}^{x, \theta}+\sum_{i=0}^{T-1} \boldsymbol{\theta}_{i}^{\dagger} \Delta \mathbf{X}_{i+1}\right)-H_{T}\right)^{2}\right]$.

É dado também por:

$\varepsilon_{0}^{2}=E_{0}^{P}\left[\sum_{t=0}^{T-1} \operatorname{ESRE}_{t}^{P}\right]$

$\operatorname{ESRE}_{t}^{P}$ é o erro quadrático esperado mínimo de hedge de um período, dado por:

$$
\begin{aligned}
\operatorname{ESRE}_{t}^{P}= & E_{t}^{P}\left[k_{t+1}\left(H_{t+1}\right)^{2}\right]-k_{t}\left(H_{t}\right)^{2} \\
& -E_{t}^{P}\left[k_{t+1} H_{t+1} \Delta \mathbf{X}_{t+1}^{\dagger}\right]\left(E_{t}^{P}\left[k_{t+1} \Delta \mathbf{X}_{t+1} \Delta \mathbf{X}_{t+1}^{\dagger}\right]\right)^{-1}\left(E_{t}^{P}\left[k_{t+1} H_{t+1} \Delta \mathbf{X}_{t+1}\right]\right) .
\end{aligned}
$$


$H_{t}$ é o processo de valor médio do ativo-objeto:

$H_{t}=\frac{\left(R f_{t}\right)^{2}}{k_{t}} E_{t}^{P}\left[\left(k_{t+1}-\left(E_{t}^{P}\left[k_{t+1} \Delta \mathbf{X}_{t+1}^{\dagger}\right] E_{t}^{P}\left[k_{t+1} \Delta \mathbf{X}_{t+1} \Delta \mathbf{X}_{t+1}^{\dagger}\right]\right)^{-1} k_{t+1} \Delta \mathbf{X}_{t+1}\right) \frac{H_{t+1}}{R f_{t}}\right]$.

Fim da proposição 4 .

Demonstração da proposição 4:

Seja o erro quadrático esperado mínimo acumulado de hedge no instante $t=0$ dado por:

$\varepsilon_{0}^{2}=\min _{x, \theta_{0}, \ldots, \theta_{T-1}} E_{0}^{P}\left[\left(V_{T}^{x, \theta}-H_{T}\right)^{2}\right]$

Pelo princípio da optimalidade de Bellman, a partir de qualquer ponto da trajetória ótima, a otimização desse ponto em diante resulta na trajetória ótima.

Extraindo sucessivamente pela lei das esperanças iteradas a esperança do erro quadrático de um período e desmembrando o problema de minimização pelo princípio da optimalidade de Bellman temos:

$$
\begin{aligned}
\mathcal{E}_{0}{ }^{2}= & \min _{x, \theta_{0}, \ldots, \theta_{T-1}} E_{0}^{P}\left[\left(V_{T}^{x, \theta}-H_{T}\right)^{2}\right] \\
& =\min _{x, \theta_{0}, \ldots, \theta_{T-1}} E_{0}^{P}\left[E _ { T - 1 } ^ { P } \left[\left(V_{T}^{x, \theta}-H_{T}\right)^{2} \rrbracket\right.\right. \\
& =\min _{x, \theta_{0}, \ldots, \theta_{T-2}} E_{0}^{P}\left[\min _{\theta_{T-1}} E_{T-1}^{P}\left[\left(V_{T}^{x, \theta}-H_{T}\right)^{2}\right]\right] \\
& =\min _{x, \theta_{0}, \ldots, \theta_{T-4}} E_{0}^{P}\left[\min _{\theta_{T-3}} E_{T-3}^{P}\left[\min _{\theta_{T-2}} E_{T-2}^{P}\left[\min _{\theta_{T-1}} E_{T-1}^{P}\left[\left(V_{T}^{x, \theta}-H_{T}\right)^{2}\right]\right]\right] .\right.
\end{aligned}
$$


Fazendo:

$$
\begin{aligned}
J_{T}= & \left(V_{T}^{x, \theta}-H_{T}\right)^{2} \\
J_{T-1}= & \min _{\theta_{T-1}} E_{T-1}^{P}\left[J_{T}\right] \\
= & \min _{\theta_{T-1}} E_{T-1}^{P}\left[\left(V_{T}^{x, \theta}-H_{T}\right)^{2}\right] \\
J_{T-2}= & \min _{\theta_{T-2}} E_{T-2}^{P}\left[J_{T-1}\right] \\
= & \min _{\theta_{T-2}} E_{T-2}^{P}\left[\left(V_{T-1}^{x, \theta}-H_{T-1}\right)^{2}\right] \\
& \vdots \\
J_{T-n}= & \min _{\theta_{T-n}} E_{T-n}^{P}\left[J_{T-n+1}\right] \\
= & \min _{\theta_{T-n}} E_{T-n}^{P}\left[\left(V_{T-n+1}^{x, \theta}-H_{T-n+1}\right)^{2}\right] .
\end{aligned}
$$

Supondo que a solução de minimização do erro quadrático esperado de hedge no instante $t=T-1$ para um dado $\theta_{T-1}$ da equação (20) seja da forma:

$$
J_{T-1}=k_{T-1}\left(V_{T-1}^{x, \theta}-H_{T-1}\right)^{2}+\left(\varepsilon_{T-1}\right)^{2} .
$$

sendo que $k_{T-1}, H_{T-1}$ e $\varepsilon_{T-1}$ dependem somente do preço do ativo e do tempo (não dependem de $\left.\theta_{T-1}\right)$.

Com essa suposição, solucionada a minimização em $T-1$ da equação (20), é necessário solucionar a minimização em $T-2$ da equação (21). Substituindo a solução suposta em (24) na equação (21): 


$$
\begin{aligned}
J_{T-2} & =\min _{\theta_{T-2}} E_{T-2}^{P}\left[J_{T-1}\right] \\
& =\min _{\theta_{T-2}} E_{T-2}^{P}\left[k_{T-1}\left(V_{T-1}^{x, \theta}-H_{T-1}\right)^{2}+\left(\varepsilon_{T-1}\right)^{2}\right] .
\end{aligned}
$$

Substituindo o valor da estratégia autofinanciável de (5) em (25) temos:

$$
\begin{aligned}
J_{T-2} & =\min _{\theta_{T-2}} E_{T-2}^{P}\left[k_{T-1}\left(R f_{T-2} V_{T-2}^{x, \theta}+\beta_{T-1} \boldsymbol{\theta}_{T-2}^{\dagger} \Delta \mathbf{X}_{T-1}-H_{T-1}\right)^{2}+\left(\varepsilon_{T-1}\right)^{2}\right] \\
& =\min _{\theta_{T-2}} E_{T-2}^{P}\left[\begin{array}{l}
k_{T-1}\left(\begin{array}{l}
\left(R f_{T-2} V_{T-2}^{x, \theta}-H_{T-1}\right)^{2}+2\left(R f_{T-2} V_{T-2}^{x, \theta}-H_{T-1}\right) \beta_{T-1} \boldsymbol{\theta}_{T-2}^{\dagger} \Delta \mathbf{X}_{T-1} \\
+\left(\beta_{T-1} \boldsymbol{\theta}_{T-2}^{\dagger} \Delta \mathbf{X}_{T-1}\right)^{2}
\end{array}\right)+\left(\varepsilon_{T-1}\right)^{2}
\end{array}\right] .
\end{aligned}
$$

Aplicando a (27) a condição de primeira ordem com a premissa de que a derivada da esperança é a esperança da derivada resulta:

$$
\begin{aligned}
\frac{d J_{T-2}}{d \boldsymbol{\theta}_{T-2}} & =\frac{d}{d \theta_{T-2}}\left(\min _{\theta_{T-2}} E_{T-2}^{P}\left[k_{T-1}\left(\begin{array}{l}
\left(R f_{T-2} V_{T-2}^{x, \theta}-H_{T-1}\right)^{2}+2\left(R f_{T-2} V_{T-2}^{x, \theta}-H_{T-1}\right) \beta_{T-1} \boldsymbol{\theta}_{T-2}{ }^{\dagger} \Delta \mathbf{X}_{T-1} \\
+\left(\beta_{T-1} \boldsymbol{\theta}_{T-2}^{\dagger} \Delta \mathbf{X}_{T-1}\right)^{2}
\end{array}\right)+\left(\varepsilon_{T-1}\right)^{2}\right]\right) \\
& =\min _{\theta_{T-2}} E_{T-2}^{P}\left[\frac{d}{d \boldsymbol{\theta}_{T-2}}\left(k_{T-1}\left(\begin{array}{l}
\left(R f_{T-2} V_{T-2}^{x, \theta}-H_{T-1}\right)^{2}+2\left(R f_{T-2} V_{T-2}^{x, \theta}-H_{T-1}\right) \beta_{T-1} \boldsymbol{\theta}_{T-2}^{\dagger} \Delta \mathbf{X}_{T-1} \\
+\left(\beta_{T-1} \boldsymbol{\theta}_{T-2}^{\dagger} \Delta \mathbf{X}_{T-1}\right)^{2}
\end{array}\right)+\left(\varepsilon_{T-1}\right)^{2}\right)\right] .
\end{aligned}
$$


Supondo a condição de primeira ordem:

$$
\begin{aligned}
& \frac{d J_{T-2}}{d \boldsymbol{\theta}_{T-2}}=0 \\
& E_{T-2}^{P}\left[2 k_{T-1}\left(R f_{T-2} V_{T-2}^{x, \boldsymbol{\theta}}-H_{T-1}\right) \beta_{T-1} \Delta \mathbf{X}_{T-1}^{\dagger}+2 k_{T-1}^{\dagger} \beta_{T-1} \beta_{T-1} \boldsymbol{\theta}_{T-2}^{\dagger} \Delta \mathbf{X}_{T-1} \Delta \mathbf{X}_{T-1}^{\dagger}\right]=0 \\
& E_{T-2}^{P}\left[2 k_{T-1}\left(R f_{T-2} V_{T-2}^{x, \boldsymbol{\theta}}-H_{T-1}\right) \beta_{T-1} \Delta \mathbf{X}_{T-1}^{\dagger}\right]+E_{T-2}^{P}\left[2 k_{T-1} \beta_{T-1} \beta_{T-1} \boldsymbol{\theta}_{T-2}^{\dagger} \Delta \mathbf{X}_{T-1} \Delta \mathbf{X}_{T-1}^{\dagger}\right]=0 \\
& E_{T-2}^{P}\left[2 k_{T-1}\left(R f_{T-2} V_{T-2}^{x, \theta}-H_{T-1}\right) \beta_{T-1} \Delta \mathbf{X}_{T-1}^{\dagger}\right]+\boldsymbol{\theta}_{T-2}^{\dagger} E_{T-2}^{P}\left[2 k_{T-1} \beta_{T-1} \beta_{T-1} \Delta \mathbf{X}_{T-1} \Delta \mathbf{X}_{T-1}^{\dagger}\right]=0 \\
& \mathbf{\theta}_{T-2}^{D}{ }^{\dagger}=-E_{T-2}^{P}\left[k_{T-1}\left(R f_{T-2} V_{T-2}^{x, \theta}-H_{T-1}\right) \beta_{T-1} \Delta \mathbf{X}_{T-1}^{\dagger}{ }^{\dagger}\right]\left(E_{T-2}^{P}\left[k_{T-1} \beta_{T-1} \beta_{T-1} \Delta \mathbf{X}_{T-1} \Delta \mathbf{X}_{T-1}^{\dagger}\right)^{-1}\right. \\
& \quad=-\left(\beta_{T-1}\right)^{-1} E_{T-2}^{P}\left[k_{T-1} \Delta \mathbf{X}_{T-1}^{\dagger}\left(R f_{T-2} V_{T-2}^{x, \theta}-H_{T-1}\right)\right]\left(E_{T-2}^{P}\left[k_{T-1} \Delta \mathbf{X}_{T-1} \Delta \mathbf{X}_{T-1}^{\dagger}{ }^{\dagger}\right]\right)^{-1} .
\end{aligned}
$$

Retornando o ponto mínimo ${\theta_{T-2}^{D}}^{\dagger}$ de (28) na equação (20) de $J_{T-2}$ :

$$
\begin{aligned}
& J_{T-2}=E_{T-2}^{P}\left[k_{T-1}\left(\left(R f_{T-2} V_{T-2}^{x, \theta}-H_{T-1}\right)^{2}+2\left(R f_{T-2} V_{T-2}^{x, \theta}-H_{T-1}\right) \beta_{T-1} \boldsymbol{\theta}_{T-2}^{\dagger} \Delta \mathbf{X}_{T-1}+\left(\beta_{T-1} \boldsymbol{\theta}_{T-2}^{\dagger} \Delta \mathbf{X}_{T-1}\right)^{2}\right)+\left(\varepsilon_{T-1}\right)^{2}\right] \\
& \begin{array}{l}
E_{T-2}^{P}\left[\begin{array}{l}
k_{T-1}\left(\begin{array}{l}
\left(R f_{T-2} V_{T-2}^{x, \theta}-H_{T-1}\right)^{2} \\
-2\left(R f_{T-2} V_{T-2}^{x, \theta}-H_{T-1}\right) \beta_{T-1}\left(\beta_{T-1}\right)^{-1} E_{T-2}^{P}\left[k_{T-1} \Delta \mathbf{X}_{T-1}^{\dagger}\left(R f_{T-2} V_{T-2}^{x, \theta}-H_{T-1}\right)\right]\left(E_{T-2}^{P}\left[k_{T-1} \Delta \mathbf{X}_{T-1} \Delta \mathbf{X}_{T-1}^{\dagger}\right]\right)^{-1} \Delta \mathbf{X}_{T-1} \\
+\left(\beta_{T-1}\left(\beta_{T-1}\right)^{-1} E_{T-2}^{P}\left[k_{T-1} \Delta \mathbf{X}_{T-1}^{\dagger}\left(R f_{T-2} V_{T-2}^{x, \theta}-H_{T-1}\right)\right]\left(E_{T-2}^{P}\left[k_{T-1} \Delta \mathbf{X}_{T-1} \Delta \mathbf{X}_{T-1}^{\dagger}\right]\right)^{-1} \Delta \mathbf{X}_{T-1}\right)^{2}
\end{array}\right. \\
+\left(\varepsilon_{T-1}\right)^{2}
\end{array}\right]
\end{array} \\
& =E_{T-2}^{P}\left\lfloor k_{T-1}\left(R f_{T-2} V_{T-2}^{x, \theta}-H_{T-1}\right)^{2}\right\rfloor \\
& -2 E_{T-2}^{P}\left[\left(R f_{T-2} V_{T-2}^{x, \theta}-H_{T-1}\right) E_{T-2}^{P}\left[k_{T-1} \Delta \mathbf{X}_{T-1}^{\dagger}\left(R f_{T-2} V_{T-2}^{x, \theta}-H_{T-1}\right)\right]\left(E_{T-2}^{P}\left[k_{T-1} \Delta \mathbf{X}_{T-1} \Delta \mathbf{X}_{T-1}^{\dagger}\right)^{-1} k_{T-1} \Delta \mathbf{X}_{T-1}\right]\right. \\
& +E_{T-2}^{P}\left[k_{T-1}\left(E_{T-2}^{P}\left[k_{T-1} \Delta \mathbf{X}_{T-1}^{\dagger}\left(R f_{T-2} V_{T-2}^{x, \theta}-H_{T-1}\right)\right]\left(E_{T-2}^{P}\left[k_{T-1} \Delta \mathbf{X}_{T-1} \Delta \mathbf{X}_{T-1}^{\dagger}\right]^{-1} \Delta \mathbf{X}_{T-1}\right)^{2}\right]+E_{T-2}^{P}\left[\left(\varepsilon_{T-1}\right)^{2}\right]\right. \text {. }
\end{aligned}
$$


A equação (29) precisa ser rearranjada para formar um quadrado em forma de binômio de Newton ("straightforward but tedious" - Cerny (2004a, p. 301).

Expandindo em (29) o binômio quadrático no primeiro termo e distribuindo as multiplicações no segundo e terceiro termos:

$$
\begin{aligned}
& J_{T-2}=E_{T-2}^{P}\left[k_{T-1}\left(R f_{T-2}\right)^{2}\left(V_{T-2}^{x, \theta}\right)^{2}\right]-2 E_{T-2}^{P}\left[k_{T-1} R f_{T-2} V_{T-2}^{x, \theta} H_{T-1}\right]+E_{T-2}^{P}\left[k_{T-1}\left(H_{T-1}\right)^{2}\right] \\
& -2 E_{T-2}^{P}\left[R f_{T-2} V_{T-2}^{x, \theta} E_{T-2}^{P}\left[k_{T-1} \Delta \mathbf{X}_{T-1}^{\dagger}\left(R f_{T-2} V_{T-2}^{x, \theta}-H_{T-1}\right)\right]\left(E_{T-2}^{P}\left[k_{T-1} \Delta \mathbf{X}_{T-1} \Delta \mathbf{X}_{T-1}^{\dagger}\right]\right)^{-1} k_{T-1} \Delta \mathbf{X}_{T-1}\right] \\
& +2 E_{T-2}^{P}\left[H_{T-1} E_{T-2}^{P}\left[k_{T-1} \Delta \mathbf{X}_{T-1}^{\dagger}\left(R f_{T-2} V_{T-2}^{x, \theta}-H_{T-1}\right)\right]\left(E_{T-2}^{P}\left[k_{T-1} \Delta \mathbf{X}_{T-1} \Delta \mathbf{X}_{T-1}^{\dagger}\right]\right)^{-1} k_{T-1} \Delta \mathbf{X}_{T-1}\right] \\
& +E_{T-2}^{P}\left[k_{T-1}\left(\begin{array}{l}
E_{T-2}^{P}\left[k_{T-1} \Delta \mathbf{X}_{T-1}^{\dagger} R f_{T-2} V_{T-2}^{x, \theta}\right]\left(E_{T-2}^{P}\left[k_{T-1} \Delta \mathbf{X}_{T-1} \Delta \mathbf{X}_{T-1}^{\dagger}\right]\right)^{-1} \Delta \mathbf{X}_{T-1} \\
-E_{T-2}^{P}\left[k_{T-1} \Delta \mathbf{X}_{T-1}{ }^{\dagger} H_{T-1}\right]\left(E_{T-2}^{P}\left[k_{T-1} \Delta \mathbf{X}_{T-1} \Delta \mathbf{X}_{T-1}{ }^{\dagger}\right)^{-1} \Delta \mathbf{X}_{T-1}\right.
\end{array}\right)^{2}\right] \\
& +E_{T-2}^{P}\left[\left(\varepsilon_{T-1}\right)^{2}\right]
\end{aligned}
$$

Agrupando em (30) o terceiro termo ao sétimo termo ao final da expressão e distribuindo as multiplicações do quarto, quinto e sexto termos: 


$$
\begin{aligned}
& J_{T-2}=E_{T-2}^{P}\left[k_{T-1}\left(R f_{T-2}\right)^{2}\left(V_{T-2}^{x, \theta}\right)^{2}\right]-2 E_{T-2}^{P}\left[k_{T-1} R f_{T-2} V_{T-2}^{x, \theta} H_{T-1}\right] \\
& -2 E_{T-2}^{P}\left[R f_{T-2} V_{T-2}^{x, \theta} E_{T-2}^{P}\left[k_{T-1} \Delta \mathbf{X}_{T-1}^{\dagger} R f_{T-2} V_{T-2}^{x, \theta}\right]\left(E_{T-2}^{P}\left[k_{T-1} \Delta \mathbf{X}_{T-1} \Delta \mathbf{X}_{T-1}^{\dagger}\right]\right)^{-1} k_{T-1} \Delta \mathbf{X}_{T-1}\right] \\
& +2 E_{T-2}^{P}\left[R f_{T-2} V_{T-2}^{x, \theta} E_{T-2}^{P}\left[k_{T-1} \Delta \mathbf{X}_{T-1}^{\dagger} H_{T-1}\right]\left(E_{T-2}^{P}\left[k_{T-1} \Delta \mathbf{X}_{T-1} \Delta \mathbf{X}_{T-1}^{\dagger}\right)^{\dagger} k_{T-1} \Delta \mathbf{X}_{T-1}\right]\right. \\
& +2 E_{T-2}^{P}\left[H_{T-1} E_{T-2}^{P}\left[k_{T-1} \Delta \mathbf{X}_{T-1}^{\dagger} R f_{T-2} V_{T-2}^{x, \theta}\right]\left(E_{T-2}^{P}\left[k_{T-1} \Delta \mathbf{X}_{T-1} \Delta \mathbf{X}_{T-1}^{\dagger}\right)^{\dagger} k_{T-1}^{-1} \Delta \mathbf{X}_{T-1}\right]\right. \\
& -2 E_{T-2}^{P}\left[H_{T-1} E_{T-2}^{P}\left[k_{T-1} \Delta \mathbf{X}_{T-1}^{\dagger} H_{T-1}\right]\left(E_{T-2}^{P}\left[k_{T-1} \Delta \mathbf{X}_{T-1} \Delta \mathbf{X}_{T-1}^{\dagger}\right]\right)^{-1} k_{T-1} \Delta \mathbf{X}_{T-1}\right] \\
& +E_{T-2}^{P}\left[k_{T-1}\left(\begin{array}{l}
E_{T-2}^{P}\left[k_{T-1} \Delta \mathbf{X}_{T-1}^{\dagger} R f_{T-2} V_{T-2}^{x, \theta}\right]\left(E_{T-2}^{P}\left[k_{T-1} \Delta \mathbf{X}_{T-1} \Delta \mathbf{X}_{T-1}^{\dagger}\right]^{\dagger} \Delta \mathbf{X}_{T-1}\right. \\
-E_{T-2}^{P}\left[k_{T-1} \Delta \mathbf{X}_{T-1}^{\dagger} H_{T-1}\right]\left(E_{T-2}^{P}\left[k_{T-1} \Delta \mathbf{X}_{T-1} \Delta \mathbf{X}_{T-1}^{\dagger}{ }^{\dagger}\right)^{-1} \Delta \mathbf{X}_{T-1}\right.
\end{array}\right)^{2}\right] \\
& +E_{T-2}^{P}\left[\left(\varepsilon_{T-1}\right)^{2}\right]+E_{T-2}^{P}\left[k_{T-1}\left(H_{T-1}\right)^{2}\right] .
\end{aligned}
$$

Extraindo as constantes das esperanças em (31): 


$$
\begin{aligned}
& J_{T-2}=\left(R f_{T-2}\right)^{2}\left(V_{T-2}^{x, \theta}\right)^{2} E_{T-2}^{P}\left[k_{T-1}\right]-2 R f_{T-2} V_{T-2}^{x, \theta} E_{T-2}^{P}\left[k_{T-1} H_{T-1}\right] \\
& -2\left(R f_{T-2}\right)^{2}\left(V_{T-2}^{x, \theta}\right)^{2} E_{T-2}^{P}\left[E_{T-2}^{P}\left[k_{T-1} \Delta \mathbf{X}_{T-1}\right]\left(E_{T-2}^{P}\left[k_{T-1} \Delta \mathbf{X}_{T-1} \Delta \mathbf{X}_{T-1}^{\dagger}\right]\right)^{-1} k_{T-1} \Delta \mathbf{X}_{T-1}\right] \\
& +2 R f_{T-2} V_{T-2}^{x, \theta} E_{T-2}^{P}\left[H_{T-1} E_{T-2}^{P}\left[k_{T-1} \Delta \mathbf{X}_{T-1}^{\dagger}\right]\left(E_{T-2}^{P}\left[k_{T-1} \Delta \mathbf{X}_{T-1} \Delta \mathbf{X}_{T-1}^{\dagger}\right)^{-1} k_{T-1} \Delta \mathbf{X}_{T-1}\right]\right. \\
& +2 R f_{T-2} V_{T-2}^{x, \theta} E_{T-2}^{P}\left[H_{T-1} E_{T-2}^{P}\left[k_{T-1} \Delta \mathbf{X}_{T-1}^{\dagger}\right]\left(E_{T-2}^{P}\left[k_{T-1} \Delta \mathbf{X}_{T-1} \Delta \mathbf{X}_{T-1}^{\dagger}\right]\right)^{-1} k_{T-1} \Delta \mathbf{X}_{T-1}\right] \\
& -2 E_{T-2}^{P}\left[H_{T-1} E_{T-2}^{P}\left[k_{T-1} \Delta \mathbf{X}_{T-1}^{\dagger} H_{T-1}\right]\left(E_{T-2}^{P}\left[k_{T-1} \Delta \mathbf{X}_{T-1} \Delta \mathbf{X}_{T-1}^{\dagger}\right]\right)^{-1} k_{T-1} \Delta \mathbf{X}_{T-1}\right] \\
& +E_{T-2}^{P}\left[k_{T-1}\left(\begin{array}{l}
R f_{T-2} V_{T-2}^{x, \theta} E_{T-2}^{P}\left[k_{T-1} \Delta \mathbf{X}_{T-1}^{\dagger}\right]\left(E_{T-2}^{P}\left[k_{T-1} \Delta \mathbf{X}_{T-1} \Delta \mathbf{X}_{T-1}^{\dagger}{ }^{\dagger}\right)^{-1} \Delta \mathbf{X}_{T-1}\right. \\
-E_{T-2}^{P}\left[k_{T-1} \Delta \mathbf{X}_{T-1}^{\dagger} H_{T-1}\right]\left(E_{T-2}^{P}\left[k_{T-1} \Delta \mathbf{X}_{T-1} \Delta \mathbf{X}_{T-1}{ }^{\dagger}\right]\right)^{-1} \Delta \mathbf{X}_{T-1}
\end{array}\right)^{2}\right] \\
& +E_{T-2}^{P}\left[\left(\varepsilon_{T-1}\right)^{2}\right]+E_{T-2}^{P}\left[k_{T-1}\left(H_{T-1}\right)^{2}\right]
\end{aligned}
$$

Desmembrando em (32) o terceiro termo e agrupando uma parcela ao primeiro, agrupando o quinto termo ao segundo para formar um binômio quadrático em $V_{T-2}^{x, \theta}$, desmembrando o sexto termo e agrupando uma parcela ao final da expressão e expandindo o quadrado do sétimo termo: 


$$
\begin{aligned}
J_{T-2}= & \left(V_{T-2}^{x, \theta}\right)^{2}\left(R f_{T-2}\right)^{2}\left(E_{T-2}^{P}\left[k_{T-1}\right]-E_{T-2}^{P}\left[E_{T-2}^{P}\left[k_{T-1} \Delta \mathbf{X}_{T-1}^{\dagger}\right]\left(E_{T-2}^{P}\left[k_{T-1} \Delta \mathbf{X}_{T-1} \Delta \mathbf{X}_{T-1}^{\dagger}\right]\right)^{-1} k_{T-1} \Delta \mathbf{X}_{T-1}\right]\right. \\
& -2 R f_{T-2} V_{T-2}^{x, \theta} E_{T-2}^{P}\left[k_{T-1} H_{T-1}-H_{T-1} E_{T-2}^{P}\left[k_{T-1} \Delta \mathbf{X}_{T-1}^{\dagger}\right]\left(E_{T-2}^{P}\left[k_{T-1} \Delta \mathbf{X}_{T-1} \Delta \mathbf{X}_{T-1}^{\dagger}\right)^{-1} k_{T-1} \Delta \mathbf{X}_{T-1}\right]\right. \\
& -\left(R f_{T-2}\right)^{2}\left(V_{T-2}^{x, \theta}\right)^{2} E_{T-2}^{P}\left[E_{T-2}^{P}\left[k_{T-1} \Delta \mathbf{X}_{T-1}^{\dagger}\right]\left(E_{T-2}^{P}\left[k_{T-1} \Delta \mathbf{X}_{T-1}^{\Delta} \Delta \mathbf{X}_{T-1}^{\dagger}\right]\right)^{-1} k_{T-1} \Delta \mathbf{X}_{T-1}\right] \\
& +2 R f_{T-2} V_{T-2}^{x, \theta} E_{T-2}^{P}\left[E_{T-2}^{P}\left[k_{T-1} \Delta \mathbf{X}_{T-1}^{\dagger} H_{T-1}\right]\left(E_{T-2}^{P}\left[k_{T-1} \Delta \mathbf{X}_{T-1} \Delta \mathbf{X}_{T-1}^{\dagger}\right)^{-1} k_{T-1} \Delta \mathbf{X}_{T-1}\right]\right. \\
& -E_{T-2}^{P}\left[H_{T-1} E_{T-2}^{P}\left[k_{T-1} \Delta \mathbf{X}_{T-1}^{\dagger} H_{T-1}\right]\left(E_{T-2}^{P}\left[k_{T-1} \Delta \mathbf{X}_{T-1} \Delta \mathbf{X}_{T-1}^{\dagger}\right]\right)^{-1} k_{T-1} \Delta \mathbf{X}_{T-1}\right]
\end{aligned}
$$$$
+\left(R f_{T-2}\right)^{2}\left(V_{T-2}^{x, \theta}\right)^{2} E_{T-2}^{P}\left[\begin{array}{l}
k_{T-1} E_{T-2}^{P}\left[k_{T-1} \Delta \mathbf{X}_{T-1}^{\dagger}\right]\left(E_{T-2}^{P}\left[k_{T-1} \Delta \mathbf{X}_{T-1} \Delta \mathbf{X}_{T-1}^{\dagger}\right)^{\dagger} \Delta \mathbf{X}_{T-1}\right. \\
E_{T-2}^{P}\left[k_{T-1} \Delta \mathbf{X}_{T-1}^{\dagger}\right]\left(E_{T-2}^{P}\left[k_{T-1} \Delta \mathbf{X}_{T-1} \Delta \mathbf{X}_{T-1}^{\dagger}\right]\right)^{-1} \Delta \mathbf{X}_{T-1}
\end{array}\right]
$$$$
-2 R f_{T-2} V_{T-2}^{x, \theta} E_{T-2}^{P}\left[\begin{array}{l}
k_{T-1} E_{T-2}^{P}\left[k_{T-1} \Delta \mathbf{X}_{T-1}^{\dagger}\right]\left(E_{T-2}^{P}\left[k_{T-1} \Delta \mathbf{X}_{T-1} \Delta \mathbf{X}_{T-1}^{\dagger}\right)^{\dagger} \Delta \mathbf{X}_{T-1}\right. \\
E_{T-2}^{P}\left[k_{T-1} \Delta \mathbf{X}_{T-1}^{\dagger} H_{T-1}\right]\left(E_{T-2}^{P}\left[k_{T-1} \Delta \mathbf{X}_{T-1} \Delta \mathbf{X}_{T-1}^{\dagger}\right)^{\dagger} \Delta \mathbf{X}_{T-1}\right.
\end{array}\right]
$$$$
+E_{T-2}^{P}\left[\begin{array}{l}
k_{T-1} E_{T-2}^{P}\left[k_{T-1} \Delta \mathbf{X}_{T-1}^{\dagger} H_{T-1}\right]\left(E_{T-2}^{P}\left[k_{T-1} \Delta \mathbf{X}_{T-1} \Delta \mathbf{X}_{T-1}^{\dagger}{ }^{\dagger}\right]\right)^{-1} \Delta \mathbf{X}_{T-1} \\
E_{T-2}^{P}\left[k_{T-1} \Delta \mathbf{X}_{T-1}^{\dagger} H_{T-1}\right]\left(E_{T-2}^{P}\left[k_{T-1} \Delta \mathbf{X}_{T-1} \Delta \mathbf{X}_{T-1}^{\dagger}\right]\right)^{-1} \Delta \mathbf{X}_{T-1}
\end{array}\right]
$$$$
+E_{T-2}^{P}\left[\left(\varepsilon_{T-1}\right)^{2}\right]+E_{T-2}^{P}\left[k_{T-1}\left(H_{T-1}\right)^{2}\right]-E_{T-2}^{P}\left[H_{T-1} E_{T-2}^{P}\left[k_{T-1} \Delta \mathbf{X}_{T-1} H_{T-1}\right]\left(E_{T-2}^{P}\left[k_{T-1} \Delta \mathbf{X}_{T-1} \Delta \mathbf{X}_{T-1}^{\dagger}\right)^{\dagger-1} k_{T-1} \Delta \mathbf{X}_{T-1}\right] .\right.
$$

Aplicando a (33) a lei das esperanças iteradas ao terceiro, quarto e quinto termos e a propriedade vetorial $a^{\dagger} b=b^{\dagger} a$ ao sexto, sétimo e oitavo termos: 


$$
\begin{aligned}
& J_{T-2}=\left(V_{T-2}^{x, \theta}\right)^{2}\left(R f_{T-2}\right)^{2}\left(E_{T-2}^{P}\left[k_{T-1}\right]-E_{T-2}^{P}\left[E_{T-2}^{P}\left[k_{T-1} \Delta \mathbf{X}_{T-1}^{\dagger}\right]\left(E_{T-2}^{P}\left[k_{T-1} \Delta \mathbf{X}_{T-1} \Delta \mathbf{X}_{T-1}^{\dagger}\right)^{\dagger} k_{T-1} \Delta \mathbf{X}_{T-1}\right)\right.\right. \\
& -2 R f_{T-2} V_{T-2}^{x, \theta} E_{T-2}^{P}\left[k_{T-1} H_{T-1}-H_{T-1} E_{T-2}^{P}\left[k_{T-1} \Delta \mathbf{X}_{T-1}^{\dagger}\right]\left(E_{T-2}^{P}\left[k_{T-1} \Delta \mathbf{X}_{T-1} \Delta \mathbf{X}_{T-1}^{\dagger}\right]\right)^{-1} k_{T-1} \Delta \mathbf{X}_{T-1}\right] \\
& -\left(R f_{T-2}\right)^{2}\left(V_{T-2}^{x, \theta}\right)^{2}\left(E_{T-2}^{P}\left[k_{T-1} \Delta \mathbf{X}_{T-1}^{\dagger}\right]\left(E_{T-2}^{P}\left[k_{T-1} \Delta \mathbf{X}_{T-1} \Delta \mathbf{X}_{T-1}^{\dagger}\right]\right)^{-1} E_{T-2}^{P}\left[k_{T-1} \Delta \mathbf{X}_{T-1}\right]\right) \\
& +2 R f_{T-2} V_{T-2}^{x, \theta}\left(E_{T-2}^{P}\left[k_{T-1} \Delta \mathbf{X}_{T-1}^{\dagger} H_{T-1}\right]\left(E_{T-2}^{P}\left[k_{T-1} \Delta \mathbf{X}_{T-1} \Delta \mathbf{X}_{T-1}^{\dagger}\right]\right)^{-1} E_{T-2}^{P}\left[k_{T-1} \Delta \mathbf{X}_{T-1}\right]\right) \\
& -E_{T-2}^{P}\left[k_{T-1} \Delta \mathbf{X}_{T-1}^{\dagger} H_{T-1}\right]\left(E_{T-2}^{P}\left[k_{T-1} \Delta \mathbf{X}_{T-1} \Delta \mathbf{X}_{T-1}^{\dagger}\right]^{-1} E_{T-2}^{P}\left[k_{T-1} \Delta \mathbf{X}_{T-1} H_{T-1}\right]\right. \\
& +\left(R f_{T-2}\right)^{2}\left(V_{T-2}^{x, \theta}\right)^{2} E_{T-2}^{P}\left[\begin{array}{l}
E_{T-2}^{P}\left[k_{T-1} \Delta \mathbf{X}_{T-1}^{\dagger}\right]\left(E_{T-2}^{P}\left[k_{T-1} \Delta \mathbf{X}_{T-1} \Delta \mathbf{X}_{T-1}^{\dagger}\right]\right)^{-1} k_{T-1} \Delta \mathbf{X}_{T-1} \Delta \mathbf{X}_{T-1}^{\dagger} \\
\left(E_{T-2}^{P}\left[k_{T-1} \Delta \mathbf{X}_{T-1}\right]\left(E_{T-2}^{P}\left[k_{T-1} \Delta \mathbf{X}_{T-1} \Delta \mathbf{X}_{T-1}^{\dagger}\right]\right)^{-1}\right)^{\dagger}
\end{array}\right] \\
& -2 R f_{T-2} V_{T-2}^{x, \theta} E_{T-2}^{P}\left[\begin{array}{l}
E_{T-2}^{P}\left[k_{T-1} \Delta \mathbf{X}_{T-1}^{\dagger}\right]\left(E_{T-2}^{P}\left[k_{T-1} \Delta \mathbf{X}_{T-1} \Delta \mathbf{X}_{T-1}^{\dagger}\right]\right)^{-1} k_{T-1} \Delta \mathbf{X}_{T-1} \Delta \mathbf{X}_{T-1}^{\dagger} \\
\left(E_{T-2}^{P}\left[k_{T-1} \Delta \mathbf{X}_{T-1}^{\dagger} H_{T-1}\right]\left(E_{T-2}^{P}\left[k_{T-1} \Delta \mathbf{X}_{T-1} \Delta \mathbf{X}_{T-1}^{\dagger}\right)^{\dagger-1}\right)^{\dagger}\right.
\end{array}\right] \\
& +E_{T-2}^{P}\left[\begin{array}{l}
E_{T-2}^{P}\left[k_{T-1} \Delta \mathbf{X}_{T-1}^{\dagger} H_{T-1}\right]\left(E_{T-2}^{P}\left[k_{T-1} \Delta \mathbf{X}_{T-1} \Delta \mathbf{X}_{T-1}^{\dagger}\right]\right)^{-1} k_{T-1} \Delta \mathbf{X}_{T-1} \Delta \mathbf{X}_{T-1}^{\dagger} \\
\left(E_{T-2}^{P}\left[k_{T-1} \Delta \mathbf{X}_{T-1}^{\dagger} H_{T-1}\right]\left(E_{T-2}^{P}\left[k_{T-1} \Delta \mathbf{X}_{T-1} \Delta \mathbf{X}_{T-1}^{\dagger}\right]\right)^{-1}\right)^{\dagger}
\end{array}\right] \\
& +E_{T-2}^{P}\left[\left(\varepsilon_{T-1}\right)^{2}\right]+E_{T-2}^{P}\left[k_{T-1}\left(H_{T-1}\right)^{2}\right]-E_{T-2}^{P}\left[H_{T-1} E_{T-2}^{P}\left[k_{T-1} \Delta \mathbf{X}_{T-1} H_{T-1}\right]\left(E_{T-2}^{P}\left[k_{T-1} \Delta \mathbf{X}_{T-1} \Delta \mathbf{X}_{T-1}^{\dagger}\right)^{-1} k_{T-1} \Delta \mathbf{X}_{T-1}\right] .\right.
\end{aligned}
$$

Aplicando a (34) a lei das esperanças iteradas ao sexto, sétimo e oitavo termos: 


$$
\begin{aligned}
& J_{T-2}=\left(V_{T-2}^{x, \theta}\right)^{2}\left(R f_{T-2}\right)^{2}\left(E_{T-2}^{P}\left[k_{T-1}\right]-E_{T-2}^{P}\left[E_{T-2}^{P}\left[k_{T-1} \Delta \mathbf{X}_{T-1}^{\dagger}\right]\left(E_{T-2}^{P}\left[k_{T-1} \Delta \mathbf{X}_{T-1} \Delta \mathbf{X}_{T-1}^{\dagger}\right]\right)^{-1} k_{T-1} \Delta \mathbf{X}_{T-1}\right]\right) \\
& -2 R f_{T-2} V_{T-2}^{x, \theta} E_{T-2}^{P}\left[k_{T-1} H_{T-1}-H_{T-1} E_{T-2}^{P}\left[k_{T-1} \Delta \mathbf{X}_{T-1}^{\dagger}\right]\left(E_{T-2}^{P}\left[k_{T-1} \Delta \mathbf{X}_{T-1} \Delta \mathbf{X}_{T-1}^{\dagger}\right]\right)^{-1} k_{T-1} \Delta \mathbf{X}_{T-1}\right] \\
& -\left(R f_{T-2}\right)^{2}\left(V_{T-2}^{x, \theta}\right)^{2}\left(E_{T-2}^{P}\left[k_{T-1} \Delta \mathbf{X}_{T-1}^{\dagger}\right]\left(E_{T-2}^{P}\left[k_{T-1} \Delta \mathbf{X}_{T-1} \Delta \mathbf{X}_{T-1}^{\dagger}\right]\right)^{-1} E_{T-2}^{P}\left[k_{T-1} \Delta \mathbf{X}_{T-1}\right]\right) \\
& +2 R f_{T-2} V_{T-2}^{x, \theta}\left(E_{T-2}^{P}\left[k_{T-1} \Delta \mathbf{X}_{T-1}^{\dagger} H_{T-1}\right]\left(E_{T-2}^{P}\left[k_{T-1} \Delta \mathbf{X}_{T-1} \Delta \mathbf{X}_{T-1}^{\dagger}\right]\right)^{-1} E_{T-2}^{P}\left[k_{T-1} \Delta \mathbf{X}_{T-1}\right]\right) \\
& -E_{T-2}^{P}\left[k_{T-1} \Delta \mathbf{X}_{T-1}^{\dagger} H_{T-1}\right]\left(E_{T-2}^{P}\left[k_{T-1} \Delta \mathbf{X}_{T-1} \Delta \mathbf{X}_{T-1}^{\dagger}\right]\right)^{-1} E_{T-2}^{P}\left[k_{T-1} \Delta \mathbf{X}_{T-1} H_{T-1}\right] \\
& +\left(R f_{T-2}\right)^{2}\left(V_{T-2}^{x, \theta}\right)^{2} E_{T-2}^{P}\left[k_{T-1} \Delta \mathbf{X}_{T-1}^{\dagger}\right]\left(E_{T-2}^{P}\left[k_{T-1} \Delta \mathbf{X}_{T-1} \Delta \mathbf{X}_{T-1}^{\dagger}\right]\right)^{-1} E_{T-2}^{P}\left[k_{T-1} \Delta \mathbf{X}_{T-1} \Delta \mathbf{X}_{T-1}^{\dagger}\right] \\
& \left(E_{T-2}^{P}\left[k_{T-1} \Delta \mathbf{X}_{T-1}\right]\left(E_{T-2}^{P}\left[k_{T-1} \Delta \mathbf{X}_{T-1} \Delta \mathbf{X}_{T-1}^{\dagger}\right]\right)^{-1}\right)^{\dagger} \\
& -2 R f_{T-2} V_{T-2}^{x, \theta} E_{T-2}^{P}\left[k_{T-1} \Delta \mathbf{X}_{T-1}^{\dagger}\right]\left(E_{T-2}^{P}\left[k_{T-1} \Delta \mathbf{X}_{T-1} \Delta \mathbf{X}_{T-1}^{\dagger}\right)^{\dagger} E_{T-2}^{P}\left[k_{T-1} \Delta \mathbf{X}_{T-1} \Delta \mathbf{X}_{T-1}^{\dagger}\right]\right. \\
& \left(E_{T-2}^{P}\left[k_{T-1} \Delta \mathbf{X}_{T-1}^{\dagger} H_{T-1}\right]\left(E_{T-2}^{P}\left[k_{T-1} \Delta \mathbf{X}_{T-1} \Delta \mathbf{X}_{T-1}^{\dagger}\right]\right)^{-1}\right)^{\dagger} \\
& +E_{T-2}^{P}\left[k_{T-1} \Delta \mathbf{X}_{T-1}^{\dagger} H_{T-1}\right]\left(E_{T-2}^{P}\left[k_{T-1} \Delta \mathbf{X}_{T-1} \Delta \mathbf{X}_{T-1}^{\dagger}\right]\right)^{-1} E_{T-2}^{P}\left[k_{T-1} \Delta \mathbf{X}_{T-1} \Delta \mathbf{X}_{T-1}^{\dagger}\right] \\
& \left(E_{T-2}^{P}\left[k_{T-1} \Delta \mathbf{X}_{T-1}^{\dagger} H_{T-1}\right]\left(E_{T-2}^{P}\left[k_{T-1} \Delta \mathbf{X}_{T-1} \Delta \mathbf{X}_{T-1}^{\dagger}\right]^{-1}\right)^{\dagger}\right. \\
& +E_{T-2}^{P}\left[\left(\varepsilon_{T-1}\right)^{2}\right]+E_{T-2}^{P}\left[k_{T-1}\left(H_{T-1}\right)^{2}\right] \\
& -E_{T-2}^{P}\left[H_{T-1} E_{T-2}^{P}\left[k_{T-1} \Delta \mathbf{X}_{T-1} H_{T-1}\right]\left(E_{T-2}^{P}\left[k_{T-1} \Delta \mathbf{X}_{T-1} \Delta \mathbf{X}_{T-1}^{\dagger}\right]\right)^{-1} k_{T-1} \Delta \mathbf{X}_{T-1}\right] .
\end{aligned}
$$

Eliminando em (35) as multiplicações pelo inverso no sexto, sétimo e oitavo termos: 


$$
\begin{aligned}
& J_{T-2}=\left(V_{T-2}^{x, \theta}\right)^{2}\left(R f_{T-2}\right)^{2}\left(E_{T-2}^{P}\left[k_{T-1}\right]-E_{T-2}^{P}\left[E_{T-2}^{P}\left[k_{T-1} \Delta \mathbf{X}_{T-1}^{\dagger}\right]\left(E_{T-2}^{P}\left[k_{T-1} \Delta \mathbf{X}_{T-1} \Delta \mathbf{X}_{T-1}^{\dagger}\right)^{-1} k_{T-1} \Delta \mathbf{X}_{T-1}\right)\right.\right. \\
& -2 R f_{T-2} V_{T-2}^{x, \theta} E_{T-2}^{P}\left[k_{T-1} H_{T-1}-H_{T-1} E_{T-2}^{P}\left[k_{T-1} \Delta \mathbf{X}_{T-1}^{\dagger}\right]\left(E_{T-2}^{P}\left[k_{T-1} \Delta \mathbf{X}_{T-1} \Delta \mathbf{X}_{T-1}^{\dagger}\right]\right)^{-1} k_{T-1} \Delta \mathbf{X}_{T-1}\right] \\
& -\left(R f_{T-2}\right)^{2}\left(V_{T-2}^{x, \theta}\right)^{2}\left(E_{T-2}^{P}\left[k_{T-1} \Delta \mathbf{X}_{T-1}^{\dagger}\right]\left(E_{T-2}^{P}\left[k_{T-1} \Delta \mathbf{X}_{T-1} \Delta \mathbf{X}_{T-1}^{\dagger}\right)^{-1} E_{T-2}^{P}\left[k_{T-1} \Delta \mathbf{X}_{T-1}\right]\right)\right. \\
& +2 R f_{T-2} V_{T-2}^{x, \theta}\left(E_{T-2}^{P}\left[k_{T-1} \Delta \mathbf{X}_{T-1}^{\dagger} H_{T-1}\right]\left(E_{T-2}^{P}\left[k_{T-1} \Delta \mathbf{X}_{T-1} \Delta \mathbf{X}_{T-1}^{\dagger}\right]\right)^{-1} E_{T-2}^{P}\left[k_{T-1} \Delta \mathbf{X}_{T-1}\right]\right) \\
& -E_{T-2}^{P}\left[k_{T-1} \Delta \mathbf{X}_{T-1}^{\dagger} H_{T-1}\right]\left(E_{T-2}^{P}\left[k_{T-1} \Delta \mathbf{X}_{T-1} \Delta \mathbf{X}_{T-1}^{\dagger}\right]^{\dagger} E_{T-2}^{P}\left[k_{T-1} \Delta \mathbf{X}_{T-1} H_{T-1}\right]\right. \\
& +\left(R f_{T-2}\right)^{2}\left(V_{T-2}^{x, \boldsymbol{\theta}}\right)^{2} E_{T-2}^{P}\left[k_{T-1} \Delta \mathbf{X}_{T-1}^{\dagger}\right]\left(E_{T-2}^{P}\left[k_{T-1} \Delta \mathbf{X}_{T-1}\right]\left(E_{T-2}^{P}\left[k_{T-1} \Delta \mathbf{X}_{T-1} \Delta \mathbf{X}_{T-1}^{\dagger}\right]\right)^{-1}\right)^{\dagger} \\
& -2 R f_{T-2} V_{T-2}^{x, \theta} E_{T-2}^{P}\left[k_{T-1} \Delta \mathbf{X}_{T-1}^{\dagger}\right]\left(E_{T-2}^{P}\left[k_{T-1} \Delta \mathbf{X}_{T-1}^{\dagger} H_{T-1}\right]\left(E_{T-2}^{P}\left[k_{T-1} \Delta \mathbf{X}_{T-1} \Delta \mathbf{X}_{T-1}^{\dagger}\right]\right)^{-1}\right)^{\dagger} \\
& +E_{T-2}^{P}\left[k_{T-1} \Delta \mathbf{X}_{T-1}^{\dagger} H_{T-1}\right]\left(E_{T-2}^{P}\left[k_{T-1} \Delta \mathbf{X}_{T-1}^{\dagger} H_{T-1}\right]\left(E_{T-2}^{P}\left[k_{T-1} \Delta \mathbf{X}_{T-1} \Delta \mathbf{X}_{T-1}^{\dagger}\right)^{-1}\right)^{\dagger}\right. \\
& +E_{T-2}^{P}\left[\left(\varepsilon_{T-1}\right)^{2}\right]+E_{T-2}^{P}\left[k_{T-1}\left(H_{T-1}\right)^{2}\right] \\
& -E_{T-2}^{P}\left[H_{T-1} E_{T-2}^{P}\left[k_{T-1} \Delta \mathbf{X}_{T-1} H_{T-1}\right]\left(E_{T-2}^{P}\left[k_{T-1} \Delta \mathbf{X}_{T-1} \Delta \mathbf{X}_{T-1}^{\dagger}\right]\right)^{-1} k_{T-1} \Delta \mathbf{X}_{T-1}\right] .
\end{aligned}
$$

Aplicando a (36) a propriedade vetorial $\left(\mathrm{a}^{\dagger} \mathrm{b}\right)=\left(\mathrm{b}^{\dagger} \mathrm{a}\right)$ ao sexto, sétimo e oitavo termos: 


$$
\begin{aligned}
& J_{T-2}=\left(V_{T-2}^{x, \theta}\right)^{2}\left(R f_{T-2}\right)^{2}\left(E_{T-2}^{P}\left[k_{T-1}\right]-E_{T-2}^{P}\left[E_{T-2}^{P}\left[k_{T-1} \Delta \mathbf{X}_{T-1}^{\dagger}\right]\left(E_{T-2}^{P}\left[k_{T-1} \Delta \mathbf{X}_{T-1} \Delta \mathbf{X}_{T-1}^{\dagger}\right]\right)^{-1} k_{T-1} \Delta \mathbf{X}_{T-1}\right]\right) \\
& -2 R f_{T-2} V_{T-2}^{x, \theta} E_{T-2}^{P}\left[k_{T-1} H_{T-1}-H_{T-1} E_{T-2}^{P}\left[k_{T-1} \Delta \mathbf{X}_{T-1}^{\dagger}\right]\left(E_{T-2}^{P}\left[k_{T-1} \Delta \mathbf{X}_{T-1} \Delta \mathbf{X}_{T-1}^{\dagger}\right]\right)^{-1} k_{T-1} \Delta \mathbf{X}_{T-1}\right] \\
& -\left(R f_{T-2}\right)^{2}\left(V_{T-2}^{x, \theta}\right)^{2}\left(E_{T-2}^{P}\left[k_{T-1} \Delta \mathbf{X}_{T-1}^{\dagger}\right]\left(E_{T-2}^{P}\left[k_{T-1} \Delta \mathbf{X}_{T-1} \Delta \mathbf{X}_{T-1}^{\dagger}\right]\right)^{-1} E_{T-2}^{P}\left[k_{T-1} \Delta \mathbf{X}_{T-1}\right]\right) \\
& +2 R f_{T-2} V_{T-2}^{x, \theta}\left(E_{T-2}^{P}\left[k_{T-1} \Delta \mathbf{X}_{T-1}^{\dagger} H_{T-1}\right]\left(E_{T-2}^{P}\left[k_{T-1} \Delta \mathbf{X}_{T-1} \Delta \mathbf{X}_{T-1}^{\dagger}\right]\right)^{-1} E_{T-2}^{P}\left[k_{T-1} \Delta \mathbf{X}_{T-1}\right]\right) \\
& -E_{T-2}^{P}\left[k_{T-1} \Delta \mathbf{X}_{T-1}^{\dagger} H_{T-1}\right]\left(E_{T-2}^{P}\left[k_{T-1} \Delta \mathbf{X}_{T-1} \Delta \mathbf{X}_{T-1}^{\dagger}\right]\right)^{-1} E_{T-2}^{P}\left[k_{T-1} \Delta \mathbf{X}_{T-1} H_{T-1}\right] \\
& +\left(R f_{T-2}\right)^{2}\left(V_{T-2}^{x, \theta}\right)^{2} E_{T-2}^{P}\left[k_{T-1} \Delta \mathbf{X}_{T-1}\right]\left(E_{T-2}^{P}\left[k_{T-1} \Delta \mathbf{X}_{T-1} \Delta \mathbf{X}_{T-1}^{\dagger}\right]\right)^{-1} E_{T-2}^{P}\left[k_{T-1} \Delta \mathbf{X}_{T-1}\right] \\
& -2 R f_{T-2} V_{T-2}^{x, \theta} E_{T-2}^{P}\left[k_{T-1} \Delta \mathbf{X}_{T-1}^{\dagger} H_{T-1}\right]\left(E_{T-2}^{P}\left[k_{T-1} \Delta \mathbf{X}_{T-1} \Delta \mathbf{X}_{T-1}^{\dagger}\right]\right)^{-1} E_{T-2}^{P}\left[k_{T-1} \Delta \mathbf{X}_{T-1}\right] \\
& +E_{T-2}^{P}\left[k_{T-1} \Delta \mathbf{X}_{T-1}^{\dagger} H_{T-1}\right]\left(E_{T-2}^{P}\left[k_{T-1} \Delta \mathbf{X}_{T-1} \Delta \mathbf{X}_{T-1}^{\dagger}{ }^{\dagger}\right]\right)^{-1} E_{T-2}^{P}\left[k_{T-1} \Delta \mathbf{X}_{T-1} H_{T-1}\right] \\
& +E_{T-2}^{P}\left[\left(\varepsilon_{T-1}\right)^{2}\right]+E_{T-2}^{P}\left[k_{T-1}\left(H_{T-1}\right)^{2}\right] \\
& -E_{T-2}^{P}\left[H_{T-1} E_{T-2}^{P}\left[k_{T-1} \Delta \mathbf{X}_{T-1} H_{T-1}\right]\left(E_{T-2}^{P}\left[k_{T-1} \Delta \mathbf{X}_{T-1} \Delta \mathbf{X}_{T-1}^{\dagger}\right)^{-1} k_{T-1} \Delta \mathbf{X}_{T-1}\right] .\right.
\end{aligned}
$$

Eliminando em (37) o terceiro e sexto, quarto e sétimo e quinto e oitavo termos que se anulam: 


$$
\begin{aligned}
J_{T-2}= & \left(V_{T-2}^{x, \theta}\right)^{2}\left(R f_{T-2}\right)^{2}\left(E_{T-2}^{P}\left[k_{T-1}\right]-E_{T-2}^{P}\left[E_{T-2}^{P}\left[k_{T-1} \Delta \mathbf{X}_{T-1}^{\dagger}\right]\left(E_{T-2}^{P}\left[k_{T-1} \Delta \mathbf{X}_{T-1} \Delta \mathbf{X}_{T-1}^{\dagger}\right]\right)^{-1} k_{T-1} \Delta \mathbf{X}_{T-1}\right]\right) \\
& -2 R f_{T-2} V_{T-2}^{x, \theta} E_{T-2}^{P}\left[k_{T-1} H_{T-1}-H_{T-1} E_{T-2}^{P}\left[k_{T-1} \Delta \mathbf{X}_{T-1}^{\dagger}\right]\left(E_{T-2}^{P}\left[k_{T-1} \Delta \mathbf{X}_{T-1} \Delta \mathbf{X}_{T-1}^{\dagger}\right]\right)^{-1} k_{T-1} \Delta \mathbf{X}_{T-1}\right] \\
& +E_{T-2}^{P}\left[\left(\varepsilon_{T-1}\right)^{2}\right]+E_{T-2}^{P}\left[k_{T-1}\left(H_{T-1}\right)^{2}\right] \\
& -E_{T-2}^{P}\left[H_{T-1} E_{T-2}^{P}\left[k_{T-1} \Delta \mathbf{X}_{T-1} H_{T-1}\right]\left(E_{T-2}^{P}\left[k_{T-1} \Delta \mathbf{X}_{T-1} \Delta \mathbf{X}_{T-1}^{\dagger}\right]^{-1} k_{T-1} \Delta \mathbf{X}_{T-1}\right]\right.
\end{aligned}
$$

Somando e subtraindo $k_{T-2}\left(H_{T-2}\right)^{2}$ em (38), multiplicando e dividindo o segundo termo por $R f_{T-2} k_{T-2}$, colocando $H_{T-1}$ em evidência e definindo:

$$
k_{T-2} \equiv\left(R f_{T-2}\right)^{2}\left(E_{T-2}^{P}\left[k_{T-1}\right]-E_{T-2}^{P}\left[k_{T-1} \Delta \mathbf{X}_{T-1}^{\dagger}\right]\left(E_{T-2}^{P}\left[k_{T-1} \Delta \mathbf{X}_{T-1} \Delta \mathbf{X}_{T-1}^{\dagger}\right]\right)^{-1} E_{T-2}^{P}\left[k_{T-1} \Delta \mathbf{X}_{T-1}\right]\right) .
$$

A equação (38) torna-se:

$$
\begin{aligned}
J_{T-2}= & \left(V_{T-2}^{x, \theta}\right)^{2} k_{T-2} \\
& -2\left(V_{T-2}^{x, \theta}\right) R f_{T-2} E_{T-2}^{P}\left[\left(k_{T-1}-E_{T-2}^{P}\left[k_{T-1} \Delta \mathbf{X}_{T-1}\right]\left[E_{T-2}^{P}\left[k_{T-1} \Delta \mathbf{X}_{T-1} \Delta \mathbf{X}_{T-1}^{\dagger}\right)^{-1} k_{T-1} \Delta \mathbf{X}_{T-1}\right) H_{T-1}\right] \frac{R f_{T-2} k_{T-2}}{R f_{T-2} k_{T-2}}\right. \\
& +k_{T-2}\left(H_{T-2}\right)^{2}-k_{T-2}\left(H_{T-2}\right)^{2} \\
& +E_{T-2}^{P}\left[\left(\varepsilon_{T-1}\right)^{2}\right]+E_{T-2}^{P}\left[k_{T-1}\left(H_{T-1}\right)^{2}\right] \\
& -E_{T-2}^{P}\left[k_{T-1} H_{T-1} \Delta \mathbf{X}_{T-1}\right]\left(E_{T-2}^{P}\left[k_{T-1} \Delta \mathbf{X}_{T-1} \Delta \mathbf{X}_{T-1}^{\dagger}\right)^{-1} E_{T-2}^{P}\left[k_{T-1} H_{T-1} \Delta \mathbf{X}_{T-1}\right] .\right.
\end{aligned}
$$


Definindo em (40):

$$
H_{T-2} \equiv E_{T-2}^{P}\left[\left(k_{T-1}-E_{T-2}^{P}\left[k_{T-1} \Delta \mathbf{X}_{T-1}\right]\left(E_{T-2}^{P}\left[k_{T-1} \Delta \mathbf{X}_{T-1} \Delta \mathbf{X}_{T-1}^{\dagger}\right]\right)^{-1} k_{T-1} \Delta \mathbf{X}_{T-1}\right) \frac{H_{T-1}}{R f_{T-2}}\right] \frac{\left(R f_{T-2}\right)^{2}}{k_{T-2}}
$$

A equação (40) torna-se:

$$
\begin{aligned}
J_{T-2}= & \left(V_{T-2}^{x, \theta}\right)^{2} k_{T-1}-2\left(V_{T-2}^{x, \theta}\right) k_{T-2} H_{T-2}+k_{T-1}\left(H_{T-2}\right)^{2} \\
& +E_{T-2}^{P}\left[\left(\varepsilon_{T-1}\right)^{2}\right]+E_{T-2}^{P}\left[k_{T-1}\left(H_{T-1}\right)^{2}\right]-k_{T-1}\left(H_{T-2}\right)^{2} \\
& -E_{T-2}^{P}\left[k_{T-1} H_{T-1} \Delta \mathbf{X}_{T-1}\right]\left(E_{T-2}^{P}\left[k_{T-1} \Delta \mathbf{X}_{T-1} \Delta \mathbf{X}_{T-1}^{\dagger}\right]\right)^{-1} E_{T-2}^{P}\left[k_{T-1} H_{T-1} \Delta \mathbf{X}_{T-1}\right] .
\end{aligned}
$$

Definindo em (42):

$$
\begin{aligned}
\mathcal{E}_{T-2}^{2} & \equiv E_{T-2}^{P}\left[\left(\varepsilon_{T-1}\right)^{2}\right]+E_{T-2}^{P}\left[k_{T-1}\left(H_{T-1}\right)^{2}\right]-k_{T-1}\left(H_{T-1}\right)^{2} \\
& -E_{T-2}^{P}\left[k_{T-1} H_{T-1} \Delta \mathbf{X}_{T-1}\right] E_{T-2}^{P}\left[k_{T-1} \Delta \mathbf{X}_{T-1} \Delta \mathbf{X}_{T-1}^{\dagger}\right]^{\dagger} E_{T-2}^{P}\left[k_{T-1} H_{T-1} \Delta \mathbf{X}_{T-1}\right] .
\end{aligned}
$$

A equação (41) torna-se:

$$
J_{T-2}=k_{T-2}\left(V_{T-2}^{x, \theta}-H_{T-2}\right)^{2}+\varepsilon_{T-2}^{2} .
$$

onde $k_{T-2}, H_{T-2}$ e $\varepsilon_{T-2}^{2}$ são dados pelas equações (39), (41) e (43) respectivamente. 
A equação (44) é a solução do problema de minimização apresentado em (25).

$$
\begin{aligned}
J_{T-2} & =\min _{\theta_{T-2}} E_{T-2}\left[J_{T-1}\right] \\
& =\min _{\theta_{T-2}} E_{T-2}\left[k_{T-1}\left(V_{T-1}^{x, \theta}-H_{T-1}\right)^{2}+\left(\varepsilon_{T-1}\right)^{2}\right] .
\end{aligned}
$$

Mas a equação (24) foi a solução suposta para o problema de minimização da equação (20):

$$
\begin{aligned}
J_{T-1} & =\min _{\theta_{T-1}} E_{T-1}\left[J_{T}\right] \\
& =\min _{\theta_{T-1}} E_{T-1}\left[\left(V_{T}^{x, \theta}-H_{T}\right)^{2}\right] \\
J_{T-1} & =k_{T-1}\left(V_{T-1}^{x, \theta}-H_{T-1}\right)^{2}+\varepsilon_{T-1}{ }^{2} .
\end{aligned}
$$

Podemos observar, comparando a solução obtida na equação (44) para o problema de minimização da equação (25), com a solução suposta na equação (24) para a o problema de minimização da equação (20), que obtivemos assim uma solução recursiva na forma:

$$
J_{t}=k_{t}\left(V_{t}^{x, \theta}-H_{t}\right)^{2}+\varepsilon_{t}{ }^{2}
$$

em que:

$$
\begin{aligned}
& J_{t}=\min _{\theta_{t}} E_{t}^{P}\left[\left(V_{t+1}^{x, \theta}-H_{t+1}\right)^{2}\right] \\
& k_{t}=\left(R f_{t}\right)^{2}\left(E_{t}^{P}\left[k_{t+1}\right]-E_{t}^{P}\left[k_{t+1} \Delta \mathbf{X}_{t+1}^{\dagger}\right]\left(E_{t}^{\mathrm{P}}\left[k_{t+1} \Delta \mathbf{X}_{t+1} \Delta \mathbf{X}_{t+1}^{\dagger}\right]^{-1} E_{t}^{P}\left[k_{t+1} \Delta \mathbf{X}_{t+1}\right]\right)\right. \\
& H_{t}=E_{t}^{P}\left[\frac{\left(R f_{t}\right)^{2}}{k_{t}}\left(k_{t+1}-\left(E_{t}^{P}\left[k_{t+1} \Delta \mathbf{X}_{t+1}^{\dagger}\right] E_{t}^{P}\left[k_{t+1} \Delta \mathbf{X}_{t+1} \Delta \mathbf{X}_{t+1}^{\dagger}\right]\right)^{-1} k_{t+1} \Delta \mathbf{X}_{t+1}\right) \frac{H_{t+1}}{R f_{t}}\right]
\end{aligned}
$$




$$
\begin{aligned}
\varepsilon_{t}^{2}= & E_{t}^{\mathrm{P}}\left[\varepsilon_{t+1}^{2}\right]+E_{t}^{P}\left[k_{t+1}\left(H_{t+1}\right)^{2}\right]-k_{t}\left(H_{t}\right)^{2} \\
& -E_{t}^{\mathrm{P}}\left[k_{t+1} H_{t+1} \Delta \mathbf{X}_{t-1}^{\dagger}\right]\left(E_{t}^{P}\left[k_{t+1} \Delta \mathbf{X}_{t+1} \Delta \mathbf{X}_{t+1}^{\dagger}\right]\right)^{-1} E_{t}^{P}\left[k_{t+1} H_{t+1} \Delta \mathbf{X}_{t+1}\right] .
\end{aligned}
$$

Para completar a verificação da solução é então necessário retornar à solução do problema de otimização inicial da equação (20), cuja solução foi suposta ser dada na forma da equação (24). Retomando as equações (20) e (24):

$$
\begin{aligned}
J_{T-1} & =\min _{\theta_{T-1}} E_{T-1}^{P}\left[J_{T}\right] \\
& =\min _{\theta_{T-1}} E_{T-1}^{P}\left[\left(V_{T}^{x, \theta}-H_{T}\right)^{2}\right] \\
J_{T-1} & =k_{T-1}\left(V_{T-1}^{x, \theta}-H_{T-1}\right)^{2}+\varepsilon_{T-1}{ }^{2} .
\end{aligned}
$$

Para que a solução recursiva seja válida, $J_{T}$ deve ser expresso na forma:

$$
J_{T}=\left(V_{T}^{x, \theta}-H_{T}\right)^{2}=k_{T}\left(V_{T}^{x, \theta}-H_{T}\right)^{2}+\varepsilon_{T}^{2} .
$$

Essa forma é válida com a condição inicial de que $\varepsilon_{T}=0$ e $k_{T}=1$.

Assim, aplicando recursivamente a solução de $t=T$ até $t=0$, obtém-se a solução do problema de minimização:

$$
J_{0}=\varepsilon_{0}^{2}
$$


Como o cálculo recursivo do erro quadrático esperado mínimo de replicação é dado por (49):

$$
\begin{aligned}
\varepsilon_{t}^{2}= & E_{t}^{\mathrm{P}}\left[\left(\varepsilon_{t+1}\right)^{2}\right]+E_{t}^{\mathrm{P}}\left[k_{t+1}\left(H_{t+1}\right)^{2}\right]-k_{t}\left(H_{t}\right)^{2} \\
& -E_{t}^{\mathrm{P}}\left[k_{t+1} H_{t+1} \Delta \mathbf{X}_{t-1}^{\dagger}\right]\left(E_{t}^{\mathrm{P}}\left[k_{t+1} \Delta \mathbf{X}_{t+1} \Delta \mathbf{X}_{t+1}^{\dagger}\right)^{-1} E_{t}\left[k_{t+1} H_{t+1} \Delta \mathbf{X}_{t+1}\right],\right.
\end{aligned}
$$

podemos definir em (49) o erro quadrático esperado mínimo de replicação de um período como sendo:

$$
\begin{aligned}
\operatorname{ESRE}_{t}^{P} \equiv & E_{t}^{P}\left[k_{t+1}\left(H_{t+1}\right)^{2}\right]-k_{t} H_{t}^{2} \\
& -\left(E_{t}^{P}\left[k_{t+1} H_{t+1} \Delta \mathbf{X}_{t+1}^{\dagger}\right]\right)\left(E_{t}^{P}\left[k_{t+1} \Delta \mathbf{X}_{t+1} \Delta \mathbf{X}_{t+1}^{\dagger}\right]\right)^{-1}\left(E_{t}^{P}\left[k_{t+1} H_{t+1} \Delta \mathbf{X}_{t+1}\right]\right) .
\end{aligned}
$$

A equação (49) torna-se:

$$
\varepsilon_{t}^{2}=E_{t}\left[\varepsilon_{t+1}^{2}\right]+\operatorname{ESRE}_{t}^{P}
$$

O erro quadrático esperado mínimo acumulado de replicação no período atual, calculado recursivamente, é a soma do erro quadrático esperado mínimo acumulado de replicação entre o período seguinte e o período final, com o erro esperado mínimo de replicação de um período (entre o período atual e o período seguinte).

Logo:

$\varepsilon_{T-1}^{2}=E_{T-1}^{P}\left[\varepsilon_{T}^{2}\right]+E S R E_{T-1}^{P}$, sendo que $\varepsilon_{T}=0$, então :

$\varepsilon_{T-1}^{2}=\operatorname{ESRE}_{T-1}^{P}$ 


$$
\begin{aligned}
\mathcal{E}_{T-2}{ }^{2}= & E_{T-2}^{P}\left[\varepsilon_{T-1}{ }^{2}\right]+\operatorname{ESRE}_{T-2}^{P} \\
& =E_{T-2}^{P}\left[\operatorname{ESRE}_{T-1}^{P}\right]+\operatorname{ESRE}_{T-2}^{P} \\
\mathcal{E}_{T-3}{ }^{2}= & E_{T-3}^{P}\left[\varepsilon_{T-2}{ }^{2}\right]+\operatorname{ESRE}_{T-3}^{P} \\
& =E_{T-3}^{P}\left[E_{T-2}^{P}\left[E S R E_{T-1}^{P}\right]+\operatorname{ESRE}_{T-2}^{P}\right]+\operatorname{ESRE}_{T-3}^{P} \\
& =E_{T-3}^{P}\left[\operatorname{ESRE}_{T-1}^{P}+\operatorname{ESRE}_{T-2}^{P}\right]+\operatorname{ESRE}_{T-3}^{P}
\end{aligned}
$$

Por indução finita tem-se que:

$$
\begin{aligned}
\mathcal{E}_{0}^{2} & =E_{0}^{P}\left[\sum_{t=1}^{T-1} \operatorname{ESRE}_{t}^{P}\right]+\operatorname{ESRE}_{0}^{P} \\
& =E_{0}^{P}\left[\sum_{t=0}^{T-1} \operatorname{ESRE}_{t}^{P}\right] .
\end{aligned}
$$

O erro quadrático esperado mínimo acumulado de replicação no instante $t=0$ é esperança da soma dos erros quadráticos esperados mínimos de replicação de um período.

Podemos observar nas equações (20) e (45), que o erro quadrático esperado mínimo acumulado em um instante intermediário qualquer é a soma do erro quadrático mínimo esperado acumulado calculado recursivamente até o instante intermediário, com uma proporção da diferença existente entre o valor da carteira replicante e o valor do ativoobjeto naquele instante. 


$$
\begin{aligned}
J_{t}=\min _{\theta_{t}} E_{t}^{P}\left[J_{t+1}\right] \\
=k_{t}\left(V_{t}^{x, \theta}-H_{t}\right)^{2}+\varepsilon_{t}{ }^{2} .
\end{aligned}
$$

No período inicial essa diferença é nula, pois o hedge é iniciado com a carteira replicante tendo o mesmo valor do ativo-objeto, portanto somente no instante $t=0, J_{t}=\varepsilon_{t}{ }^{2}$.

O erro quadrático esperado mínimo acumulado de replicação no instante $t=0$ é então dado por (9), (10) e (11):

$$
\begin{aligned}
\varepsilon_{0}^{2} & =\min _{x, \theta_{0}, \ldots, \theta_{T-1}} E_{0}^{P}\left[\left(V_{T}^{x, \theta}-H_{T}\right)^{2}\right] \\
& =\min _{x, \theta_{0}, \ldots, \theta_{T-1}} E_{0}^{P}\left[\left(\beta_{T}\left(V_{0}^{x, \theta}+\sum_{i=0}^{T-1} \boldsymbol{\theta}_{i-1}^{\dagger} \Delta \mathbf{X}_{i+1}\right)-H_{T}\right)^{2}\right] \\
& =E_{0}^{P}\left[\sum_{t=0}^{T-1} E S R E_{t}^{P}\right] .
\end{aligned}
$$

Por fim, retornando à equação (28), a estratégia dinâmica autofinanciável ótima é dada por:

$$
\boldsymbol{\theta}_{t-1}^{D^{\dagger}}=-\left(\beta_{t}\right)^{-1} E_{t-1}^{P}\left[k_{t} \Delta \mathbf{X}_{t}\left(R f_{t-1} V_{t-1}^{x, \theta}-H_{t}\right)\right]\left(E_{t-1}^{P}\left[k_{t} \Delta \mathbf{X}_{t} \Delta \mathbf{X}_{t}^{\dagger}\right]\right)^{-1} .
$$

q.e. $d$. proposição 4 . 


\section{APÊNDICE 3 - DEMONSTRAÇÕES - ESTRATÉGIA HN}

Notação:

$t:$ instante de tempo contínuo $t \in[0, T]$.

$T$ : instante de expiração da opção de compra européia.

$r$ : taxa contínua de retorno do ativo livre de risco.

$S_{t}$ : preço à vista da ação sem dividendos.

$h_{t}$ : variância condicionada dos log-retornos da ação.

$\lambda$ : preço de mercado do risco.

$\omega$ : variância de longo prazo.

$\alpha_{i}$ : parâmetro de média móvel.

$\beta_{i}$ : parâmetro auto-regressivo.

$\lambda$ : parâmetro de assimetria.

$C\left(S_{t}, t\right)$ : preço racional da opção de compra européia.

$Z_{t}$ : variável estocástica com distribuição normal padrão.

$\theta_{t}:$ quantidade da ação.

\subsection{Premissas do modelo}

- $\quad$ O preço da ação segue um processo específico em tempo discreto e os logretornos têm distribuição lognormal.

- A esperança dos log-retornos é constante.

- $\quad$ A variância condicionada dos log-retornos segue um modelo GARCH específico.

A taxa livre de risco é constante. 


\subsection{Definição 1}

A equação da dinâmica de preços é dada por:

$\ln \left(S_{t}\right)=\ln \left(S_{t-\Delta t}\right)+r+\lambda h_{t}+\sqrt{h_{t}} Z_{t}$

A equação da dinâmica da variância é dada por:

$h_{t}=\omega+\sum_{i=1}^{p} \beta_{i} h_{t-i \Delta t}+\sum_{i=1}^{q} \alpha_{i}\left(Z_{t-i \Delta t}-\gamma_{i} \sqrt{h_{t-i \Delta t}}\right)^{2}$.

Fim da definição 1

\subsection{Definição 2}

Duan (1995, p. 14) define a LRNVR (Locally Risk Neutral Valuation Relationship), que possibilita a precificação de opções, utilizando modelos GARCH, por meio da mudança de medida de probabilidade. A LNVR estipula que a variância condicionada um período à frente é invariante com relação à mudança para a medida neutralizadora do risco.

Duan (1995, p.15) define que uma medida de probabilidade Q satisfaz à LRNVR se é mutuamente absolutamente contínua com relação à medida $\mathrm{P}$ e $\frac{S_{t}}{S_{t-1}} \mid \mathcal{F}_{t-1}$ tem distribuição lognormal na medida $Q$ e $E_{t-1}^{\mathrm{Q}}\left[\frac{S_{t}}{S_{t-1}}\right]=e^{r}$.

Fim da definição 2 . 


\subsection{Teorema 1}

Este teorema está demonstrado em Duan (1995, p.25-31).

Seja uma variável estocástica $y_{t}=v+h Z_{t}$, sendo $v$ a esperança contante e $Z_{t} \sim N(0,1)$ na medida objetiva $\mathbb{P}$, então $y_{t} \sim N(0, h)$.

Seja a medida martingale $\mathrm{Q}$ definida por $d \mathrm{Q}=e^{(r-\rho) T+\sum_{s=1}^{T} y_{s i}} d \mathbb{P}$ mutuamente absolutamente contínua em relação à medida $\mathbb{P}$.

Então se $S_{t-1}=E_{t-1}^{\mathrm{P}}\left[e^{-\rho+y_{t}} S_{t}\right]$ :

Q é uma medida de probabilidade e, para qualquer variável estocástica $W_{t}, \mathfrak{F}_{t}$ mensurável:

$$
\begin{aligned}
& E_{t-1}^{\mathrm{Q}}\left[W_{t}\right]=E_{t-1}^{\mathrm{P}}\left[W_{t} e^{(r-\rho)+y_{t}}\right] . \\
& \frac{S_{t}}{S_{t-1}} \mid \mathcal{F}_{t-1} \text { tem distribuição lognormal na medida } Q . \\
& E_{t-1}^{\mathrm{Q}}\left[\frac{S_{t}}{S_{t-1}}\right]=E_{t-1}^{\mathrm{P}}\left[e^{-\rho+y_{t}}\right]=e^{-r} . \\
& V_{t-1}^{\mathrm{Q}}\left[\frac{S_{t}}{S_{t-1}}\right]=V_{t-1}^{\mathrm{P}}\left[\frac{S_{t}}{S_{t-1}}\right] \text { quase certamente com relação à medida } \mathbb{P} .
\end{aligned}
$$

Fim do teorema 1.

\subsection{Proposição 1}

A dinâmica de preços na medida de probabilidade neutralizadora do risco para o modelo (1) é dada por:

$$
\ln \left(S_{t}\right)=\ln \left(S_{t-\Delta t}\right)+r-\frac{1}{2} h_{t}+\sqrt{h_{t}} Z_{t} .
$$


A dinâmica da variância na medida de probabilidade neutralizadora do risco é dada por:

$h_{t}=\omega+\sum_{i=1}^{p} \beta_{i} h_{t-i \Delta t}+\sum_{i=1}^{q} \alpha_{i}\left(Z_{t-i \Delta t}-\gamma_{i} \sqrt{h_{t-i \Delta t}}\right)^{2}$.

Fim da proposição 1.

Demonstração da proposição 1:

Rearranjando os termos na equação (1)

$$
\begin{aligned}
\ln \left(S_{t}\right) & =\ln \left(S_{t-\Delta t}\right)+r-\frac{1}{2} h_{t}+\sqrt{h_{t}} Z_{t} \\
& =\ln \left(S_{t-\Delta t}\right)+r+\lambda \sqrt{h_{t}} \sqrt{h_{t}}+\sqrt{h_{t}} Z_{t}-\frac{1}{2} h_{t}+\frac{1}{2} \sqrt{h_{t}} \sqrt{h_{t}} \\
& =\ln \left(S_{t-\Delta t}\right)+r-\frac{1}{2} h_{t}+\sqrt{h_{t}}\left(Z_{t}+\lambda \sqrt{h_{t}}+\frac{1}{2} \sqrt{h_{t}}\right) \\
& =\ln \left(S_{t-\Delta t}\right)+r-\frac{1}{2} h_{t}+\sqrt{h_{t}}\left(Z_{t}+\left(\lambda+\frac{1}{2}\right) \sqrt{h_{t}}\right) .
\end{aligned}
$$

Fazendo:

$Z_{t}^{*}=Z_{t}+\left(\lambda+\frac{1}{2}\right) \sqrt{h_{t}}$.

A equação (5) torna-se:

$\ln \left(S_{t}\right)=\ln \left(S_{t-\Delta t}\right)+r-\frac{1}{2} h_{t}+\sqrt{h_{t}} Z_{t}^{*}$. 
Eliminando os logaritmos em (7):

$$
\frac{S_{t}}{S_{t-1}}=e^{r-\frac{1}{2} h_{t}+\sqrt{h_{t}} Z_{t}^{*}}
$$

A determinação de $\lambda=-\frac{1}{2}$ transforma a variável $Z_{t}^{*}$ em (6) em uma variável com distribuição normal padrão $Z_{t}^{*} \sim N(0,1)$.

Se o processo em (8) representa um processo na medida neutralizadora de risco, então pelo teorema 1 , se $E_{t-1}^{Q}\left[\frac{S_{t}}{S_{t-1}}\right]=e^{r}$, a distribuição é lognormal na medida $Q$ e a condição LRNVR é satisfeita.

$$
\begin{aligned}
E_{t-1}^{\mathrm{Q}}\left[\frac{S_{t}}{S_{t-1}}\right] & =E_{t-1}^{\mathrm{Q}}\left[e^{r-\frac{1}{2} h_{t}+\sqrt{h_{t}} Z_{t}}\right] \\
& =e^{r-\frac{1}{2} h_{t}+\frac{1}{2} h_{t}} \\
& =e^{r} .
\end{aligned}
$$


Rearranjando os termos na equação (4)

$$
\begin{aligned}
h_{t} & =\omega+\sum_{i=1}^{p} \beta_{i} h_{t-i \Delta t}+\sum_{i=1}^{q} \alpha_{i}\left(Z_{t-i \Delta t}-\gamma_{i} \sqrt{h_{t-i \Delta t}}\right)^{2} \\
& =\omega+\sum_{i=1}^{p} \beta_{i} h_{t-i \Delta t}+\sum_{i=2}^{q} \alpha_{i}\left(Z_{t-i \Delta t}-\gamma_{i} \sqrt{h_{t-i \Delta t}}\right)^{2}+\alpha_{1}\left(Z_{t-\Delta t}-\gamma_{1} \sqrt{h_{t-\Delta t}}\right)^{2} \\
& =\omega+\sum_{i=1}^{p} \beta_{i} h_{t-i \Delta t}+\sum_{i=2}^{q} \alpha_{i}\left(Z_{t-i \Delta t}-\gamma_{i} \sqrt{h_{t-i \Delta t}}\right)^{2}+\alpha_{1}\left(Z_{t-\Delta t}+\left(\lambda+\frac{1}{2}\right) \sqrt{h_{t-\Delta t}}-\left(\lambda+\frac{1}{2}\right) \sqrt{h_{t-\Delta t}}-\gamma_{1} \sqrt{h_{t-\Delta t}}\right)^{2} \\
& =\omega+\sum_{i=1}^{p} \beta_{i} h_{t-i \Delta t}+\sum_{i=2}^{q} \alpha_{i}\left(Z_{t-i \Delta t}-\gamma_{i} \sqrt{h_{t-i \Delta t}}\right)^{2}+\alpha_{1}\left(Z_{t-\Delta t}+\left(\lambda+\frac{1}{2}\right) \sqrt{h_{t-\Delta t}}-\left(\lambda+\frac{1}{2}+\gamma_{1}\right) \sqrt{h_{t-\Delta t}}\right)^{2} .
\end{aligned}
$$

Substituindo (6) em (9) e fazendo:

$\gamma_{1}^{*}=\lambda+\frac{1}{2}+\gamma_{1}$

A equação (9) torna-se:

$$
h_{t}=\omega+\sum_{i=1}^{p} \beta_{i} h_{t-i \Delta t}+\sum_{i=2}^{q} \alpha_{i}\left(Z_{t-i \Delta t}-\gamma_{i} \sqrt{h_{t-i \Delta t}}\right)^{2}+\alpha_{1}\left(Z_{t-\Delta t}^{*}-\gamma_{1}^{*} \sqrt{h_{t-\Delta t}}\right)^{2} .
$$

Como a condição $\lambda=-\frac{1}{2}$ foi estabelecida para a obtenção do processo da equação (1) na medida neutralizadora do risco, a equação (11) torna-se: 


$$
\begin{aligned}
& h_{t}=\omega+\sum_{i=1}^{p} \beta_{i} h_{t-i \Delta t}+\sum_{i=2}^{q} \alpha_{i}\left(Z_{t-i \Delta t}-\gamma_{i} \sqrt{h_{t-i \Delta t}}\right)^{2}+\alpha_{1}\left(Z_{t-\Delta t}-\gamma_{1} \sqrt{h_{t-\Delta t}}\right)^{2} \\
& h_{t}=\omega+\sum_{i=1}^{p} \beta_{i} h_{t-i \Delta t}+\sum_{i=1}^{q} \alpha_{i}\left(Z_{t-i \Delta t}-\gamma_{i} \sqrt{h_{t-i \Delta t}}\right)^{2} .
\end{aligned}
$$

q.e. $d$. proposição 1 .

\subsection{Definição 3}

A dinâmica de preços do ativo livre de risco é dada por:

$d B_{t} \equiv r B_{t} d t$

$B_{t}=B_{0} e^{-r t}$

Fim da definição 3.

\subsection{Definição 4}

O preço racional da opção de compra européia é dado por:

$C\left(S_{t}, t\right) \equiv e^{-r(T-t)} E_{t}^{\mathrm{Q}}\left[\max \left\{S_{T}-K_{T}, 0\right\}\right]$.

Fim da definição 4 


\subsection{Proposição 2}

O preço racional da opção de compra européia dado por:

$C\left(S_{t}, t\right)=\frac{1}{2} S_{t}+\frac{1}{\pi} e^{-r(T-t)} \int_{0}^{\infty} \operatorname{Re}\left[\frac{K_{T}^{-i \phi} f^{*}(i \phi+1)}{i \phi}\right] d \phi-K_{T} e^{-r(T-t)}\left(\frac{1}{2}+\frac{1}{\pi} \int_{0}^{\infty} \operatorname{Re}\left[\frac{K_{T}^{-i \phi} f^{*}(i \phi)}{i \phi}\right]\right) d \phi$.

Sendo que $f^{*}$ é a função característica de $\ln S_{T}$ na medida de probabilidade neutralizadora do risco.

Fim da proposição 2.

Demonstração da proposição 2:

Seja $f^{*}(t, T, \phi)$ a função geratriz de momentos de ordem $\phi$ de $\ln S_{T}$ na medida neutralizadora do risco dada por:

$$
f^{*}(t, T, \phi)=E_{t}^{\mathrm{Q}}\left[e^{\phi \ln S_{T}}\right]
$$

sendo que:

$$
\begin{aligned}
f^{*}(t, T, 1) & =E_{t}^{\mathrm{Q}}\left[e^{\ln S_{T}}\right] \\
& =E_{t}^{\mathrm{Q}}\left[S_{T}\right]
\end{aligned}
$$

Seja $p\left(\ln S_{T}\right)$ a função densidade de probabilidade de $\ln S_{T}$ na medida neutralizadora do risco. 
Seja $p^{A}\left(\ln S_{T}\right)$ uma densidade de probabilidade ajustada de $\ln S_{T}$ na medida neutralizadora do risco, tal que:

$$
p^{A}\left(\ln S_{T}\right)=\frac{e^{\ln S_{T}} p\left(\ln S_{T}\right)}{f^{*}(t, T, 1)} .
$$

Seja $g^{*}(t, T, \phi)$ a função geratriz de momentos de ordem $\phi$ de $\ln S_{T}$ na medida neutralizadora do risco, para a densidade de probabilidade ajustada $p^{A}\left(\ln S_{T}\right)$ na medida neutralizadora do risco, dada por:

$$
\begin{aligned}
g^{*}(t, T, \phi) & =\int_{-\infty}^{\infty} e^{\phi \ln S_{T}} p^{A}\left(\ln S_{T}\right) d\left(\ln S_{T}\right) \\
& =\int_{-\infty}^{\infty} e^{\phi \ln S_{T}} \frac{e^{\ln S_{T}} p\left(\ln S_{T}\right)}{f^{*}(t, T, 1)} d\left(\ln S_{T}\right) \\
& =\frac{1}{f^{*}(t, T, 1)} \int_{-\infty}^{\infty} e^{(\phi+1) \ln S_{T}} p\left(\ln S_{T}\right) d\left(\ln S_{T}\right) \\
& =\frac{f^{*}(t, T, \phi+1)}{f^{*}(t, T, 1)} .
\end{aligned}
$$

O preço racional da opção de compra européia dado por (14), passa a ser então:

$$
\begin{aligned}
C\left(S_{t}, t\right) & =e^{-r(T-t)} E_{t}^{\mathrm{Q}}\left[\max \left\{e^{\ln S_{T}}-K_{T}, 0\right\}\right] \\
& =e^{-r(T-t)}\left(\int_{\ln K_{T}}^{\infty} e^{\ln S_{T}} p\left(\ln S_{T}\right) d\left(\ln S_{T}\right)-K_{T} \int_{\ln K_{T}}^{\infty} p\left(\ln S_{T}\right) d\left(\ln S_{T}\right)\right) .
\end{aligned}
$$

Inserindo (16) em substituição da densidade de probabilidade da primeira integral em (20):

$$
C\left(S_{t}, t\right)=e^{-r(T-t)}\left(f(t, T, 1) \int_{\ln K_{T}}^{\infty} p^{A}\left(\ln S_{T}\right) d\left(\ln S_{T}\right)-K_{T} \int_{\ln K_{T}}^{\infty} p\left(\ln S_{T}\right) d\left(\ln S_{T}\right)\right) .
$$


Se $f^{*}(t, T, \phi)$ é a função geratriz de momentos de $\ln S_{T}$ para a densidade de probabilidades $p\left(\ln S_{T}\right)$ dada em (17) e $\frac{f^{*}(t, T, \phi+1)}{f^{*}(t, T, 1)}$ é a função geratriz de momentos de $\ln S_{T}$ para a densidade de probabilidades ajustada $p^{A}\left(\ln S_{T}\right)$ dada em (18), então $f^{*}(t, T, i \phi)$ e $\frac{f^{*}(t, T, i \phi+1)}{f^{*}(t, T, 1)}$ são as funções características de $\ln S_{T}$ para as densidades de probabilidade $p\left(S_{T}\right)$ e $p^{A}\left(S_{T}\right)$ respectivamente.

Como a função densidade de probabilidade pode ser obtida a partir da função característica:

$f(x)=\int_{-\infty}^{\infty} \frac{1}{2 \pi} e^{-x i t} M_{x}(i t) d t$.

As densidades de probabilidade em (21), conforme indicado em Heston e Nandi (2000, p. 620) são dadas por:

$$
\begin{aligned}
& \int_{\ln K_{T}}^{\infty} p\left(\ln S_{T}\right) d\left(\ln S_{T}\right)=\frac{1}{2}+\frac{1}{\pi} \int_{0}^{\infty} \operatorname{Re}\left[\frac{e^{-i \phi \ln K_{T}} f^{*}(i \phi)}{i \phi}\right] d \phi \\
& \int_{\ln K_{T}}^{\infty} p^{A}\left(\ln S_{T}\right) d\left(\ln S_{T}\right)=\frac{1}{2}+\frac{1}{\pi} \int_{0}^{\infty} \operatorname{Re}\left[\frac{e^{-i \phi \ln K_{T}} f^{*}(i \phi+1)}{i \phi}\right] d \phi .
\end{aligned}
$$

Substituindo (18), (23) e (24) em (21):

$$
C\left(S_{t}, t\right)=e^{-r(T-t)}\left(E_{t}^{Q}\left[S_{T}\right]\left(\frac{1}{2}+\frac{1}{\pi} \int_{0}^{\infty} \operatorname{Re}\left[\frac{e^{-i \phi \ln K_{T}} f^{*}(i \phi+1)}{i \phi}\right] d \phi\right)-K_{T}\left(\frac{1}{2}+\frac{1}{\pi} \int_{0}^{\infty} \operatorname{Re}\left[\frac{e^{-i \phi \ln K_{T}} f^{*}(i \phi)}{i \phi}\right] d \phi\right)\right) .
$$


Como $e^{-r(T-t)} E_{t}^{\mathrm{Q}}\left[S_{T}\right]=S_{t}$, a equação (21) torna-se:

$$
\begin{aligned}
C\left(S_{t}, t\right) & =e^{-r(T-t)}\left(E_{t}^{\mathrm{Q}}\left[e^{\ln S_{T}}-\left(\frac{1}{2}+\frac{1}{\pi} \int_{0}^{\infty} \operatorname{Re}\left[\frac{e^{-i \phi \ln K_{T}} f^{*}(i \phi+1)}{i \phi}\right] d \phi\right)-K_{T}\left(\frac{1}{2}+\frac{1}{\pi} \int_{0}^{\infty} \operatorname{Re}\left[\frac{e^{-i \phi \ln K_{T}} f^{*}(i \phi)}{i \phi}\right] d \phi\right)\right)\right. \\
& =\frac{1}{2} S_{t}+\frac{e^{-r(T-t)}}{\pi} \int_{0}^{\infty} \operatorname{Re}\left[\frac{e^{-i \phi \ln K_{T}} f^{*}(i \phi+1)}{i \phi}\right] d \phi-e^{-r(T-t)} K_{T}\left(\frac{1}{2}+\frac{1}{\pi} \int_{0}^{\infty} \operatorname{Re}\left[\frac{e^{-i \phi \ln K_{T}} f^{*}(i \phi)}{i \phi}\right] d \phi\right) .
\end{aligned}
$$

q. e. d. proposição 2 .

\subsection{Proposição 3}

A função geratriz de momentos condicionada de $\ln S_{T}$ na medida neutralizadora do risco é dada por:

$f^{*}(t, T, \varphi)=E_{t}^{\mathrm{Q}}\left[e^{\varphi \ln S_{T}}\right]$.

Sendo que $\varphi=\phi$ para a função geratriz de momentos e $\varphi=i \phi$ para a função característica e têm a forma:

$f^{*}(t, T, \varphi)=S_{t}^{\varphi} \exp \left(A(t, T, \varphi)+\sum_{i=1}^{p} B_{i}(t, T, \varphi) h_{t-\Delta t(i-2)}+\sum_{i=1}^{q-1} C_{i}(t, T, \varphi)\left(Z_{t-\Delta t(i-1)}-\gamma_{i} \sqrt{h_{t-\Delta t(i-1)}}\right)^{2}\right)$.

Sendo que:

$$
A(t, T, \varphi)=A(t+\Delta t, T, \varphi)+\varphi r+B_{1}(t+\Delta t, T, \varphi) \omega-\frac{1}{2} \ln \left(1-2 \alpha_{1} B_{1}(t+\Delta t, T, \varphi)\right)-2 C_{1}(t+\Delta t, T, \varphi)
$$




$$
\begin{aligned}
B_{1}(t, T, \varphi)= & \varphi\left(\lambda+\gamma_{1}\right)-\frac{1}{2} \gamma_{1}^{2}+\beta_{1} B_{1}(t+\Delta t, T, \varphi)+B_{2}(t+\Delta t, T, \varphi) \\
& +\frac{1 / 2\left(\varphi-\gamma_{1}\right)^{2}}{1-2 \alpha_{1} B_{1}(t+\Delta t, T, \varphi)-2 C_{1}(t+\Delta t, T, \varphi)} \\
B_{i}(t, T, \varphi)= & \beta_{i} B_{1}(t+\Delta t, T, \varphi)+B_{i+1}(t+\Delta t, T, \varphi), \quad 1<i \leq p \\
C_{i}(t, T, \varphi)= & \alpha_{i+1} B_{1}(t+\Delta t, T, \varphi)+C_{i+1}(t+\Delta t, T, \varphi), \quad 1<i \leq q-1 \\
A(T, T, \varphi)= & B_{i}(T, T, \varphi)=C_{i}(T, T, \varphi)=0 .
\end{aligned}
$$

Fim da proposição 3 .

Demonstração da proposição 3:

Seja a função geratriz de momentos condicionada de $\ln S_{T}$ na medida neutralizadora do risco dada por (23):

$$
f^{*}(t, T, \varphi)=E_{t}^{Q}\left[e^{\varphi\left(\ln S_{T}\right)}\right] .
$$

Assumindo que a função geratriz de momentos toma a seguinte forma log-linear:

$$
f^{*}(t, T, \varphi)=\exp \left(\varphi\left(\ln S_{T}\right)+A(t, T, \varphi)+\sum_{i=1}^{p} B_{i}(t, T, \varphi) h_{t-\Delta t(i-2)}+\sum_{i=1}^{q-1} C_{i}(t, T, \varphi)\left(Z_{t-\Delta t(i-1)}-\gamma_{i} \sqrt{h_{t-\Delta t}(i-1)}\right)^{2}\right) .
$$

Como $\ln S_{T}$ é conhecido em $t=T$, a equação (23) torna-se $f^{*}(T, T, \varphi)=e^{\varphi \ln S_{T}}$. Logo, a condição terminal dos coeficientes $A, B_{i}$ e $C_{i}$ é dada por:

$$
A(T, T, \varphi)=B_{i}(T, T, \varphi)=C_{i}(T, T, \varphi)=0 .
$$


Aplicando a lei das esperanças iteradas a (23) resulta:

$$
\begin{aligned}
f^{*}(t, T, \varphi) & =E_{t}^{Q}\left[f^{*}(t+\Delta t, T, \varphi)\right] \\
& =E_{t}^{Q}\left[\exp \left(\begin{array}{l}
\varphi\left(\ln S_{T}\right)+A(t, T, \varphi)+\sum_{i=1}^{p} B_{i}(t, T, \varphi) h_{t-\Delta t(i-2)} \\
+\sum_{i=1}^{q-1} C_{i}(t, T, \varphi)\left(Z_{t-\Delta t(i-1)}-\gamma_{i} \sqrt{h_{t-\Delta t}(i-1)}\right)^{2}
\end{array}\right)\right] .
\end{aligned}
$$

Substituindo a dinâmica de $\ln S_{T}$ dada por (1) e (2) a equação (28) torna-se:

$$
f^{*}(t, T, \varphi)=E_{t}^{\mathrm{Q}}\left[\exp \left(\begin{array}{l}
\varphi\left(\ln S_{T}+r+\lambda h_{t+\Delta t}+\sqrt{h_{t+\Delta t}} Z_{t+\Delta t}\right) \\
+A(t+\Delta t, T, \varphi) \\
+B_{1}(t+\Delta t, T, \varphi)\left(\beta_{1} h_{t+\Delta t}+\alpha_{1}\left(Z_{t+\Delta t}-\gamma_{1} \sqrt{h_{t+\Delta t}}\right)^{2}\right) \\
+B_{1}(t+\Delta t, T, \varphi)\left(\omega+\sum_{i=1}^{p-1} \beta_{i+1} h_{t-\Delta t}(i-2)+\sum_{i=1}^{q-1} \alpha_{i+1}\left(Z_{t-\Delta t(i-2)}-\gamma_{i+1} \sqrt{h_{t-\Delta t(i-2)}}\right)^{2}\right.
\end{array}\right)\right) .
$$

Rearranjando os termos e completando quadrados em (29): 
$f^{*}(t, T, \varphi)=E_{t}^{Q}\left(\begin{array}{l}\left.\ln S_{T}+r\right) \\ +A(t+\Delta t, T, \varphi) \\ +B_{1}(t+\Delta t, T, \varphi) \omega \\ +B_{1}(t+\Delta t, T, \varphi) \alpha_{1}\left(Z_{t+\Delta t}-\left(\gamma_{1}-\frac{\varphi}{2 B_{1}(t+\Delta t, T, \varphi) \alpha_{1}+C_{1}(t+\Delta t, T, \varphi)}\right) \sqrt{h_{t+\Delta t}}\right)^{2} \\ +C_{1}(t+\Delta t, T, \varphi)\left(Z_{t+\Delta t}-\left(\gamma_{1}-\frac{\varphi}{2 B_{1}(t+\Delta t, T, \varphi) \alpha_{1}+C_{1}(t+\Delta t, T, \varphi)}\right) \sqrt{h_{t+\Delta t}}\right)^{2} \\ +\varphi \lambda+B_{1}(t+\Delta t, T, \varphi) \beta_{1} \\ +\left(\varphi \gamma_{1}-\frac{\varphi^{2}}{4 B_{1}(t+\Delta t, T, \varphi) \alpha_{1}+C_{1}(t+\Delta t, T, \varphi)}\right) h_{t+\Delta t} \\ +B_{1}(t+\Delta t, T, \varphi)_{i=1}^{p-1} \beta_{i+1} h_{t+2 \Delta t-i \Delta t} \\ +\sum_{i=1}^{p-1} B_{i+1}(t+\Delta t, T, \varphi) h_{t+2 \Delta t-i \Delta t} \\ +B_{1}(t+\Delta t, T, \varphi)_{i=1}^{q-1} \alpha_{i+1}\left(Z_{t+2 \Delta t-i \Delta t}-\gamma_{i+1} \sqrt{h_{t+2 \Delta t-i \Delta t}}\right)^{2} \\ +\sum_{i=1}^{q-2} C_{i+1}(t+\Delta t, T, \varphi)\left(Z_{t+\Delta t-i \Delta t}-\gamma_{i+1} \sqrt{h_{t+\Delta t-i \Delta t}}\right)^{2}\end{array}\right)$.

Utilizando o resultado de que para uma variável normal padrão $Z$ :

$E\left[\exp \left(a(z+b)^{2}\right)\right]=\exp \left(-\frac{1}{2} \ln (1-2 a)+\frac{a b^{2}}{1-2 a}\right)$

$1-2 a>0$

$a<1 / 2$.

Substituindo (31) em (30) e igualando termos em (30) resulta: 


$$
\begin{aligned}
& A(t, T, \varphi)=A(t+\Delta t, T, \varphi)+\varphi r+B_{1}(t+\Delta t, T, \varphi) \omega-\frac{1}{2} \ln \left(1-2 \alpha_{1} B_{1}(t+\Delta t, T, \varphi)\right)-2 C_{1}(t+\Delta t, T, \varphi) \\
& B_{1}(t, T, \varphi)=\varphi(\lambda+\gamma)-\frac{1}{2} \gamma_{1}^{2}+\beta_{1} B_{1}(t+\Delta t, T, \varphi)+B_{2}(t+\Delta t, T, \varphi)+\frac{1 / 2\left(\varphi-\gamma_{1}\right)^{2}}{1-2 \alpha_{1} B_{1}(t+\Delta t, T, \varphi)-2 C_{1}(t+\Delta t, T, \varphi)} \\
& B_{i}(t, T, \varphi)=\beta_{i} B_{1}(t+\Delta t, T, \varphi)+B_{i+1}(t+\Delta t, T, \varphi), \quad 1<i \leq p \\
& C_{i}(t, T, \varphi)=\alpha_{i+1} B_{1}(t+\Delta t, T, \varphi)+C_{i+1}(t+\Delta t, T, \varphi), \quad 1<i \leq q-1 \\
& A(T, T, \varphi)=B_{i}(T, T, \varphi)=C_{i}(T, T, \varphi)=0 .
\end{aligned}
$$

As equações (32) podem ser utilizadas para calcular recursivamente os coeficientes $A, B_{i}$ e $C_{i}$, iniciando com as condições finais $A(T, T, \varphi)=B_{i}(T, T, \varphi)=C_{i}(T, T, \varphi)=0$.

q. e. d. proposição 3 . 


\section{APÊNDICE 4 - PROGRAMAS UTILIZADOS}

Os programas utilizados foram elaborados utilizando os softwares Matlab 7.0.1 e

Mathematica 6.0.

\subsection{Programa para geração das séries de estimação e validação}

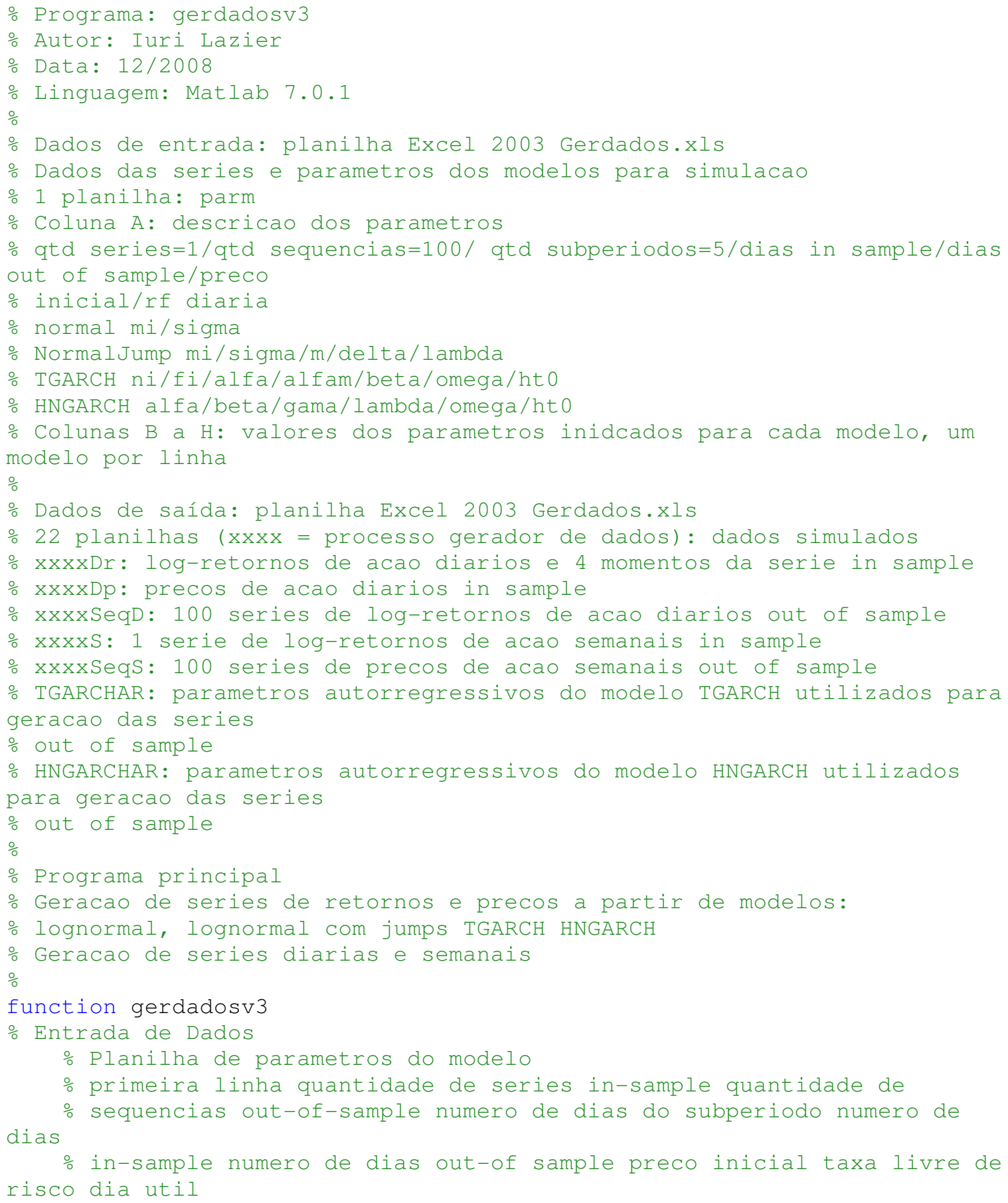


\% em seguida uma linha para cada serie de cada modelo

$\mathrm{t} 1=\mathrm{clock}$;

parm=xlsread ('Gerdados.xls', 'Parm' );

ser $=\operatorname{parm}(1,1)$; seq=parm (1,2); $\operatorname{p=parm}(1,3)$; tt=parm $(1,4)$; tc=parm $(1,5)$;

s0 0 parm $(1,6) ; \operatorname{rfd}=\operatorname{parm}(1,7)$;

- Dados do modelo normal

for $i=1$ : ser

$\operatorname{mil}(i)=\operatorname{parm}(i+1,1) ; \operatorname{sigma1}(i)=\operatorname{parm}(i+1,2)$;

end

\% Dados do modelo normal com jumps

for $i=1$ : ser

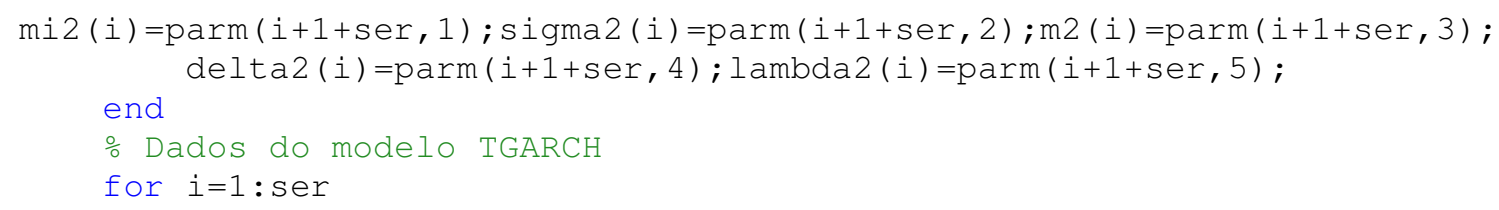




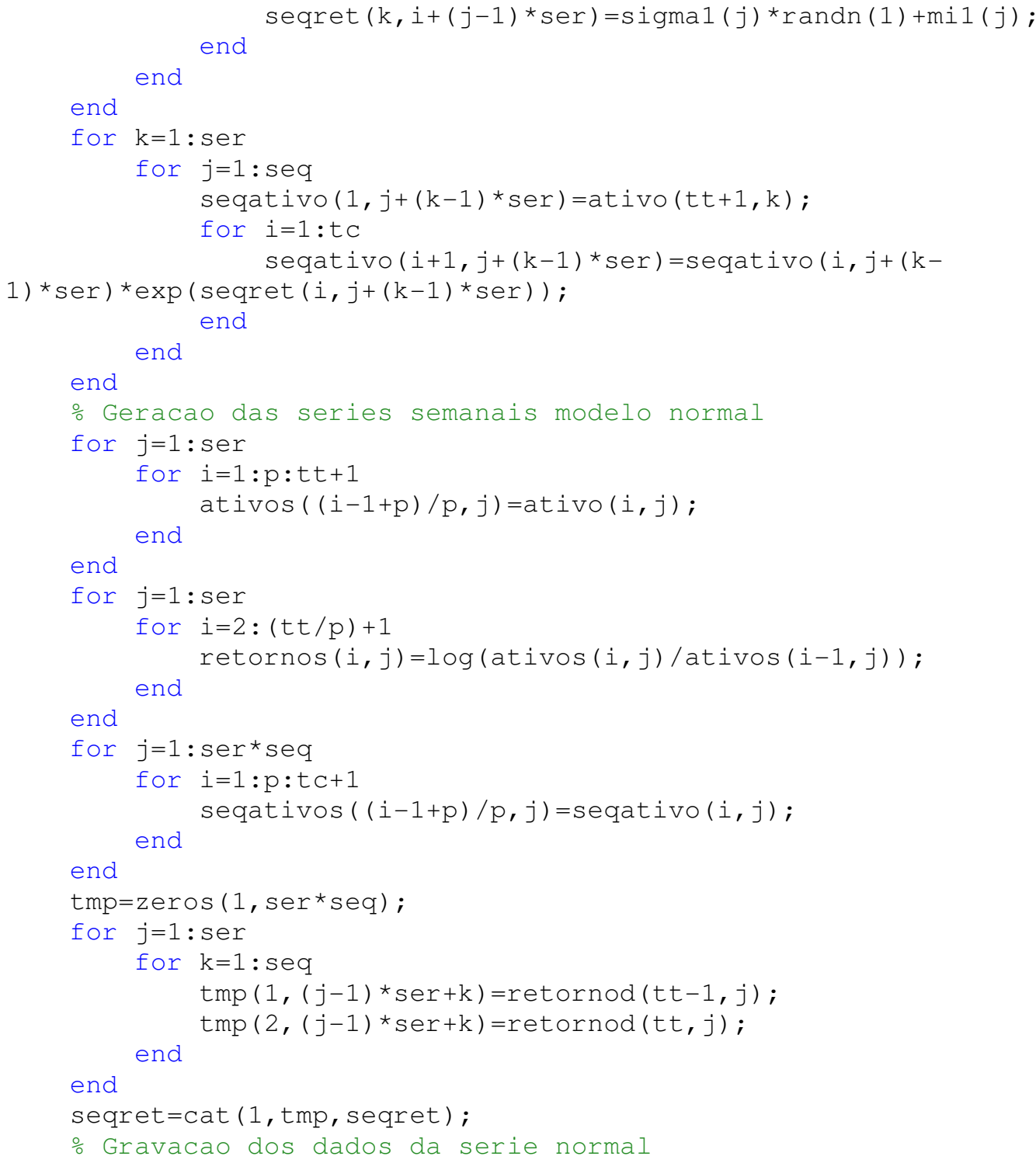




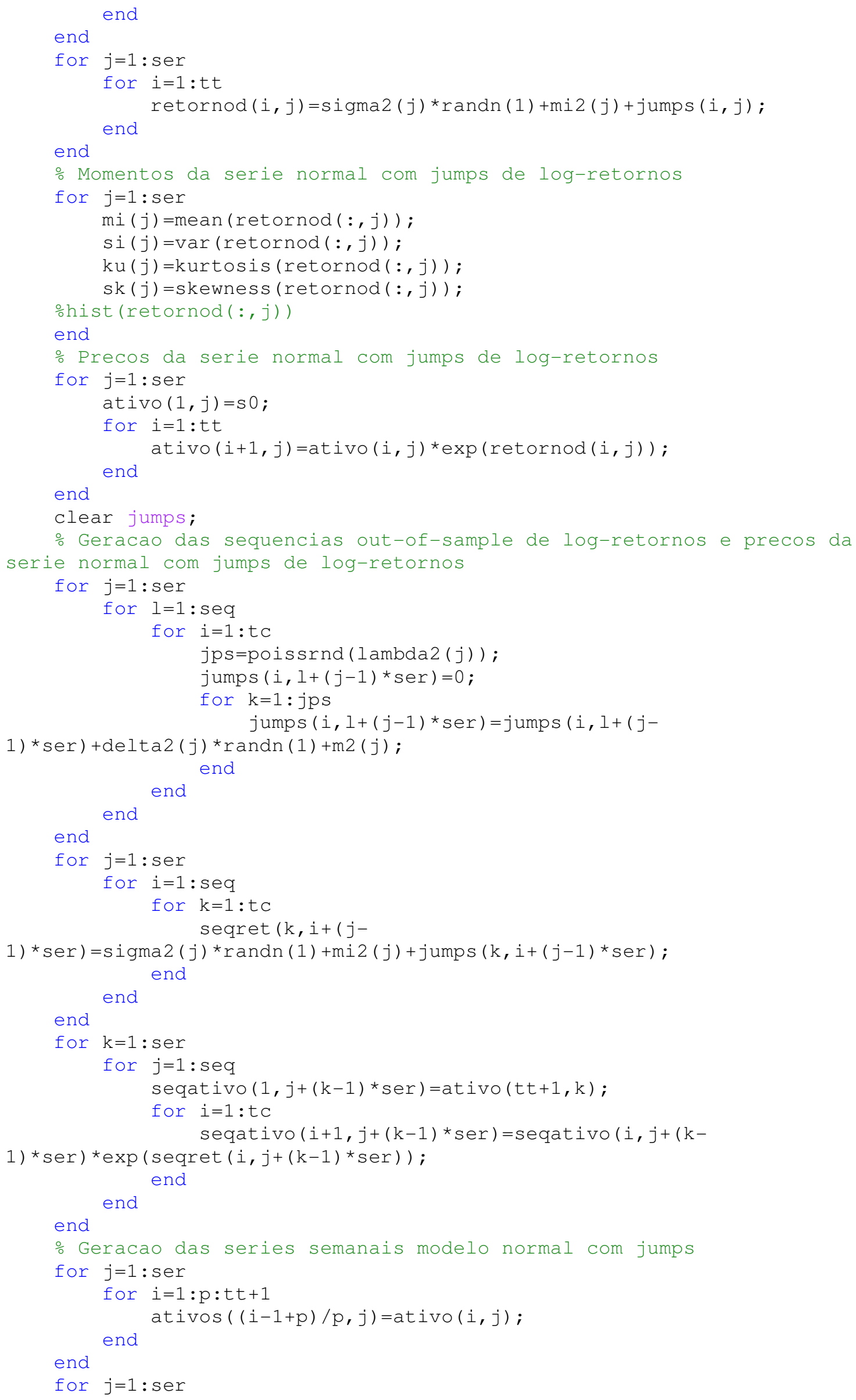




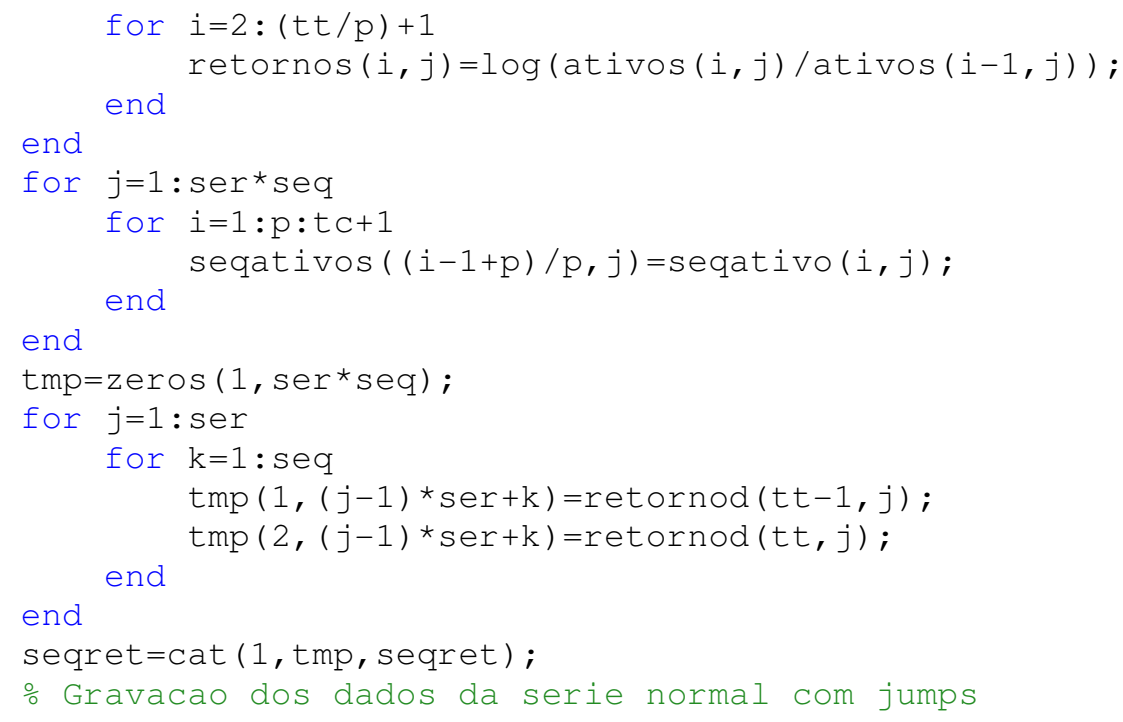

xlswrite('Gerdados.xls', mi, 'NormalJumpDr', 'A3') ; xlswrite('Gerdados.xls', s i, 'Normal JumpDr', 'A4');

xlswrite('Gerdados.xls', sk, 'NormalJumpDr', 'A5' ) ; xlswrite('Gerdados.xls', k u, 'Normal JumpDr', 'A6');

xlswrite('Gerdados.xls', retornod, 'NormalJumpDr', 'A9' ) ;

xlswrite ('Gerdados.xls', ativo, 'NormalJumpDp', 'A8' ) ;

xlswrite ('Gerdados.xls', retornos, 'NormalJumps', 'A1' );

xlswrite('Gerdados.xls', seqret, 'NormalJumpSeqD', 'Al' ) ;

xlswrite ('Gerdados.xls', seqativos, 'Normal JumpseqS ', 'Al') ;

clear retornod;clear ativo; clear seqret;clear seqativo; clear

retornos;clear ativos;

clear mi;clear si;clear ku; clear sk;

- Serie TGARCH de log-retornos e precos

\% Log-retornos e precos da serie TGARCH

for $j=1$ :ser

ativo $(1, j)=s 0 ;$ retornod $(1, j)=0 ;$ qsi=randn $(1) ;$ ht $=$ ht $03(j)$;

for $i=1$ : tt

if qsi<0

ind $=1$;

else

ind $=0$;

end

$h t=\operatorname{omega} 3(j)+\left((\operatorname{alfa} 3(j)+\operatorname{alfam} 3(j) * i n d) * \operatorname{qsi}{ }^{\wedge} 2+\operatorname{beta} 3(j)\right) * h t$; qsi=randn $(1)$; retornod $(i+1, j)=\operatorname{ni} 3(j)+f i 3(j)$ *retornod $(i, j)+\left(h t^{\wedge}(1 / 2)\right)$ *asi; $\operatorname{ativo}(i+1, j)=\operatorname{ativo}(i, j) *(1+\operatorname{retornod}(i+1, j))$;

end

seqht $(j)=h t ; \operatorname{seqqsi}(j)=q s i$; ultretseq $(j)=\operatorname{retornod}(t t+1, j)$;

ohist (retornod $(:, j)$ )

end

․ Momentos da serie TGARCH de log-retornos

$\operatorname{retornod}(1,:)=[]$;

for $j=1:$ ser

$\operatorname{mi}(j)=$ mean $(r e t o r n o d(:, j))$;

si $(j)=\operatorname{var}($ retornod $(:, j))$;

$\mathrm{ku}(j)=\operatorname{kurtosis}($ retornod $(:, j))$;

end

$\operatorname{sk}(j)=\operatorname{skewness}($ retornod $(:, j))$;

\% Geracao das sequencias out-of-sample de log-retornos e precos da serie TGARCH de log-retornos

for $k=1$ : ser 


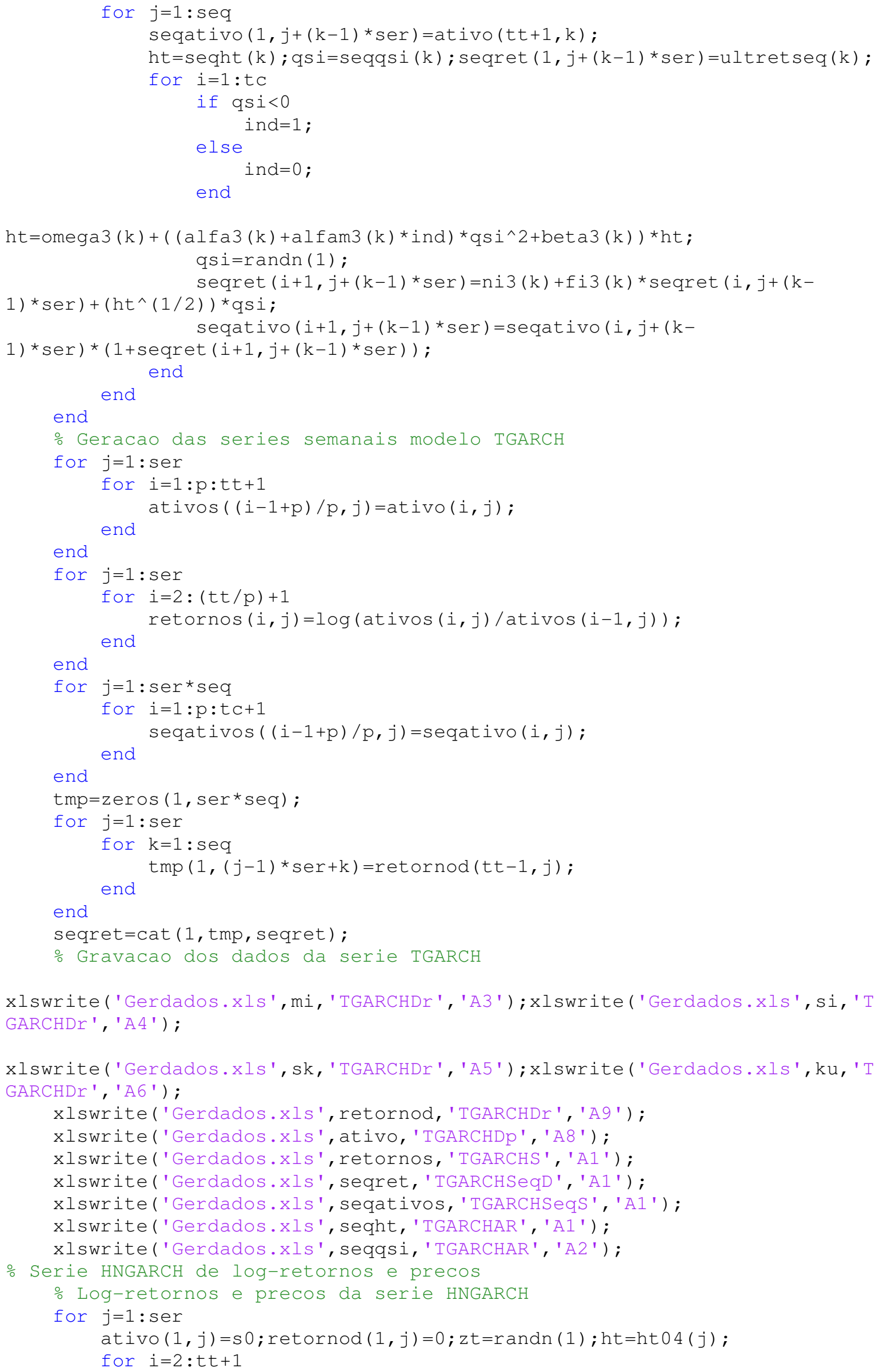




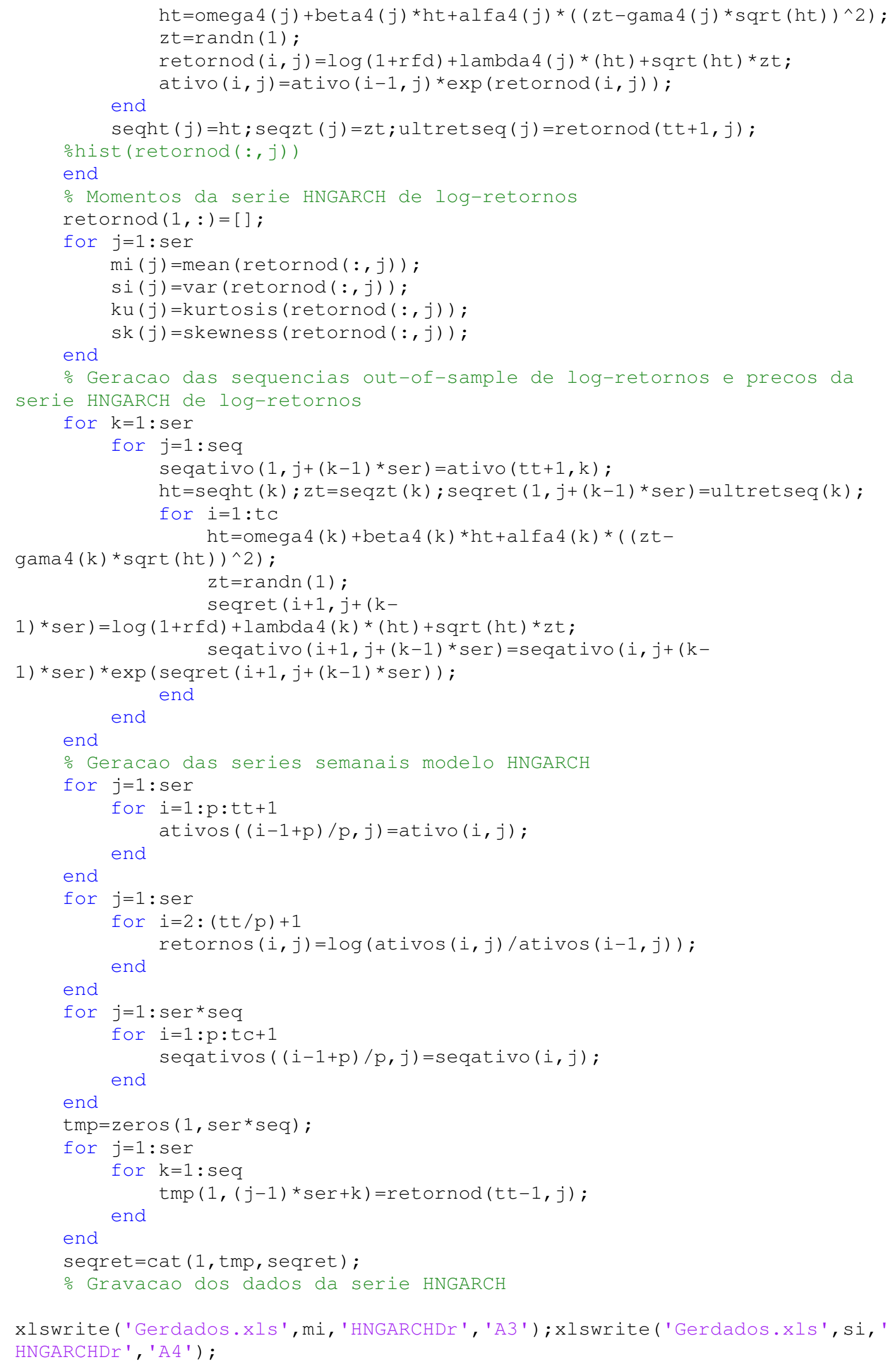




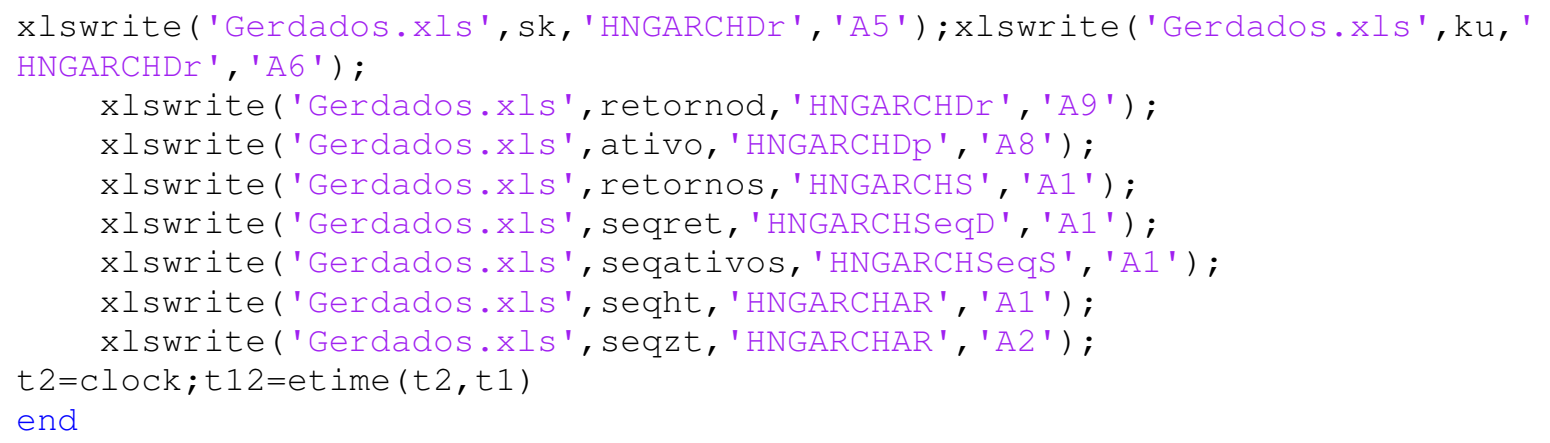

\subsection{Programa para cálculo de preços de opção}

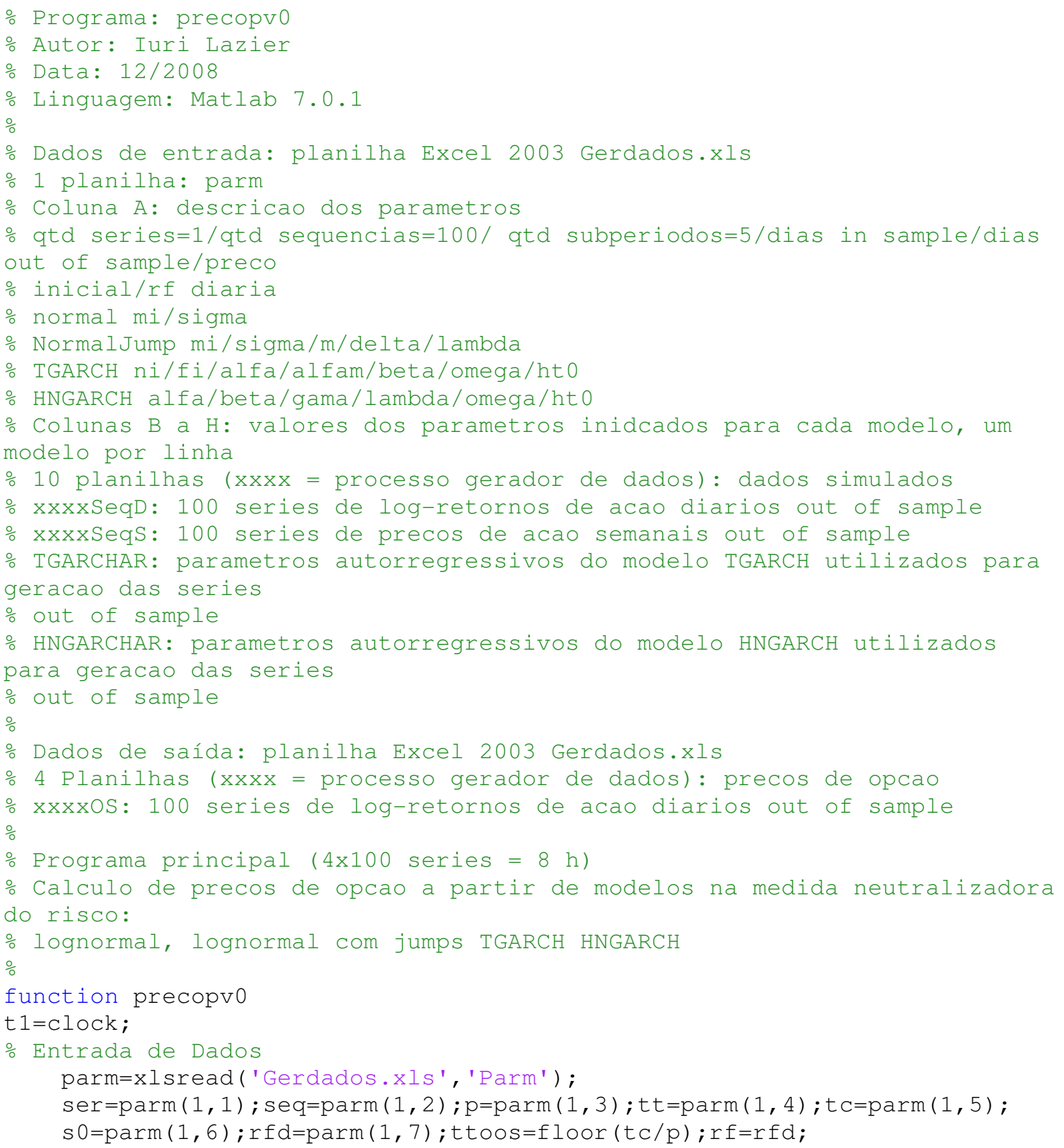




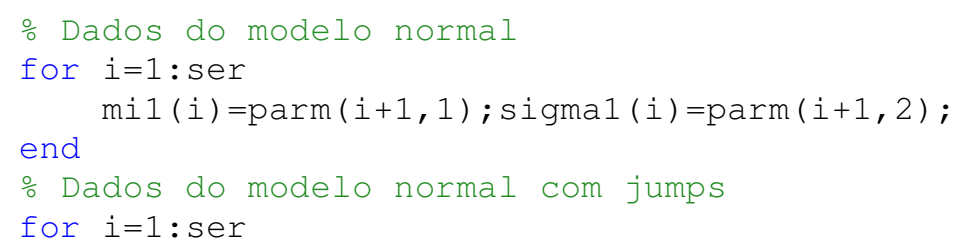

opcao

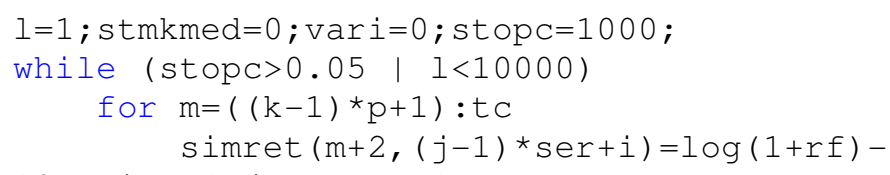




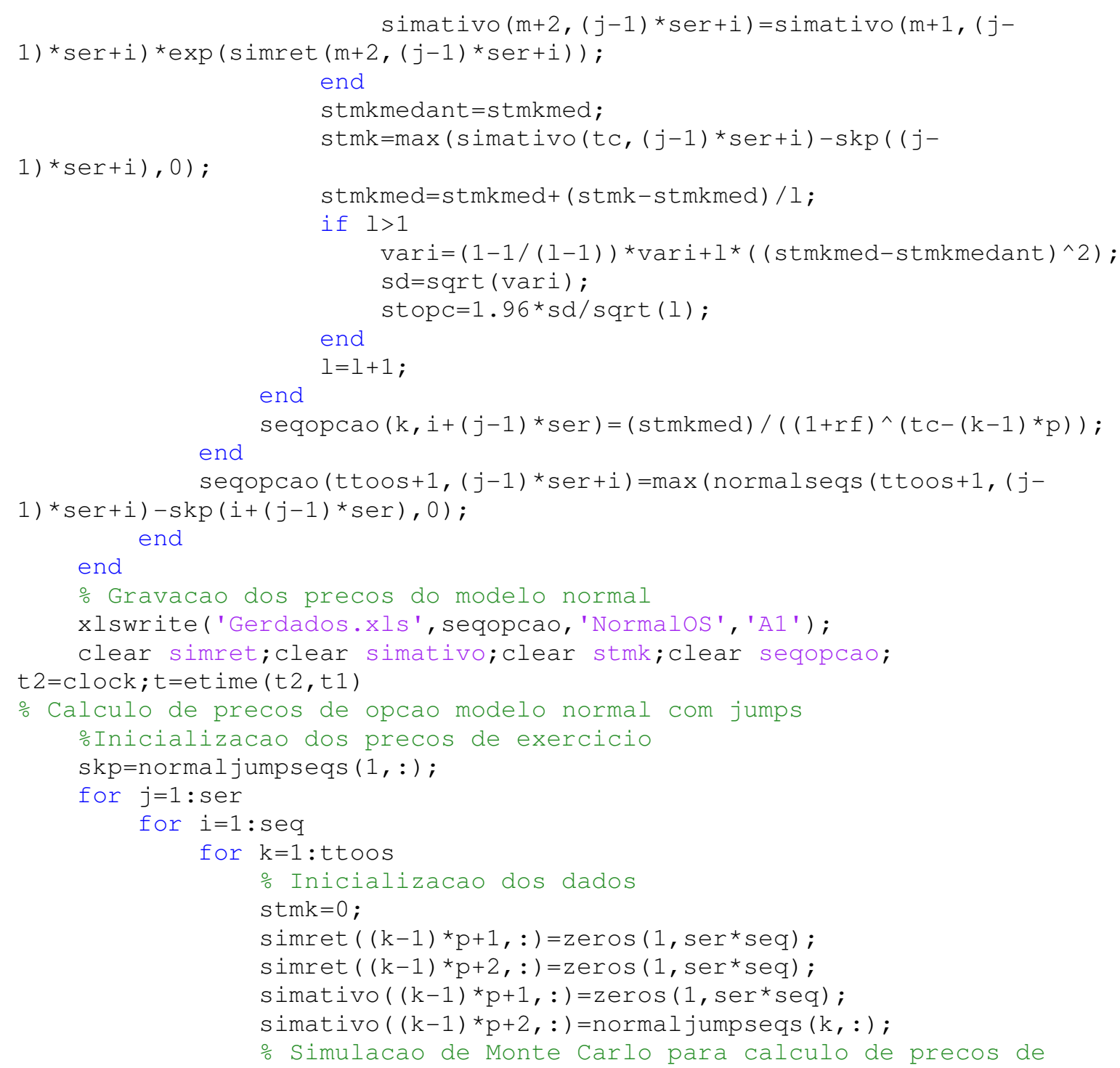

opcao

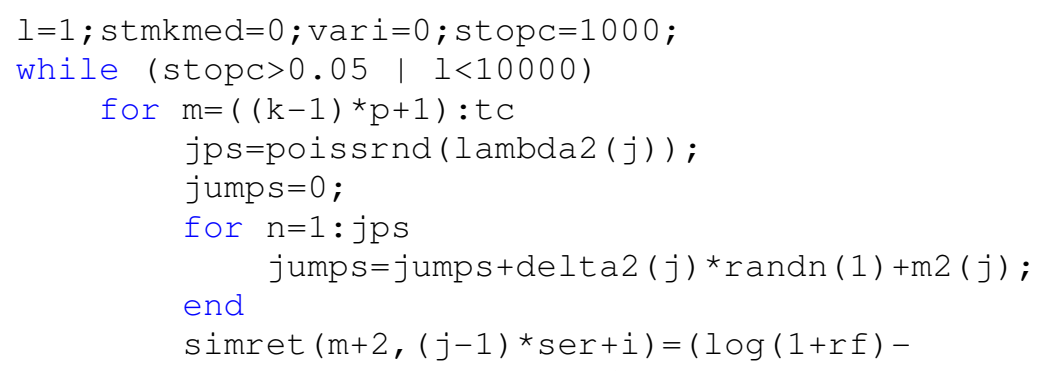

$(1 / 2) *\left(\operatorname{sigma} 2(j)^{\wedge} 2\right)-\operatorname{lambda} 2(j) *(\exp (\operatorname{m2}(j)+(1 / 2) *(\operatorname{delta} 2(j) \wedge 2))-$

1)) +sigma $2(j)$ *randn (1) + jumps ; simativo $(m+2,(j-1) *$ ser $+i)=\operatorname{simativo}(m+1,(j-$

$1) * \operatorname{ser}+i) * \exp (\operatorname{simret}(m+2,(j-1) * \operatorname{ser}+i))$; end stmkmedant $=$ stmkmed;

$1) \star \operatorname{ser}+i), 0)$; stmk $=\max (\operatorname{simativo}(t c,(j-1) * \operatorname{ser}+i)-\operatorname{skp}((j-$

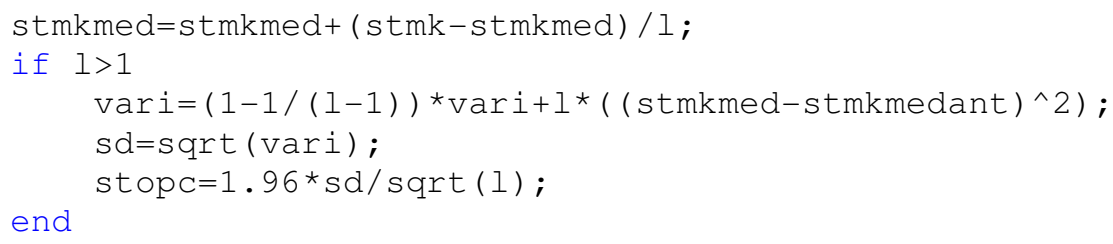




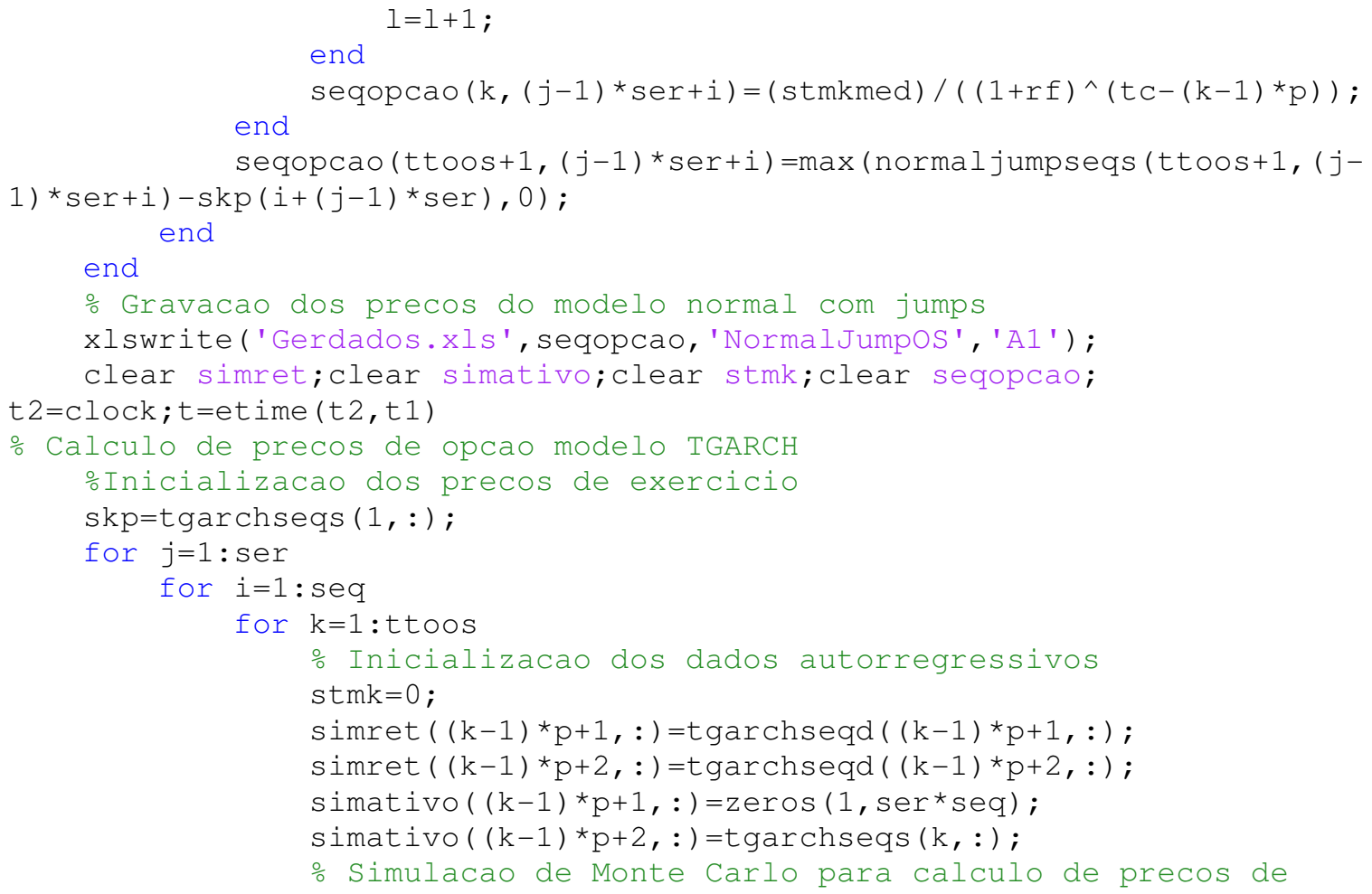




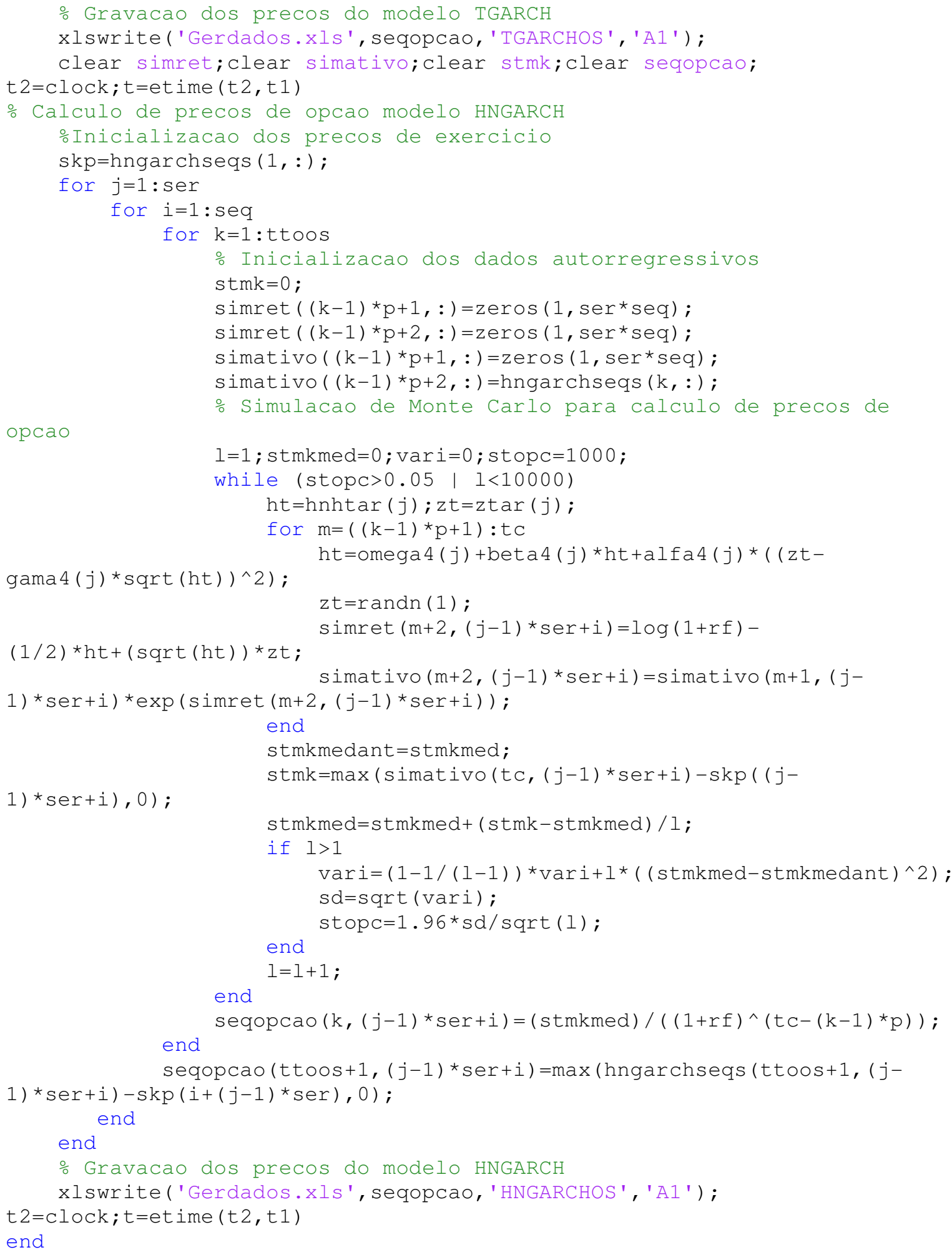

\subsection{Programa para estimação e teste da estratégia BSM}

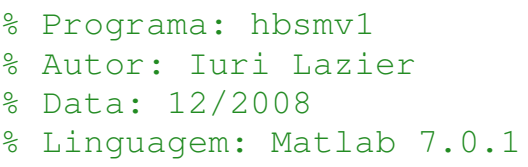




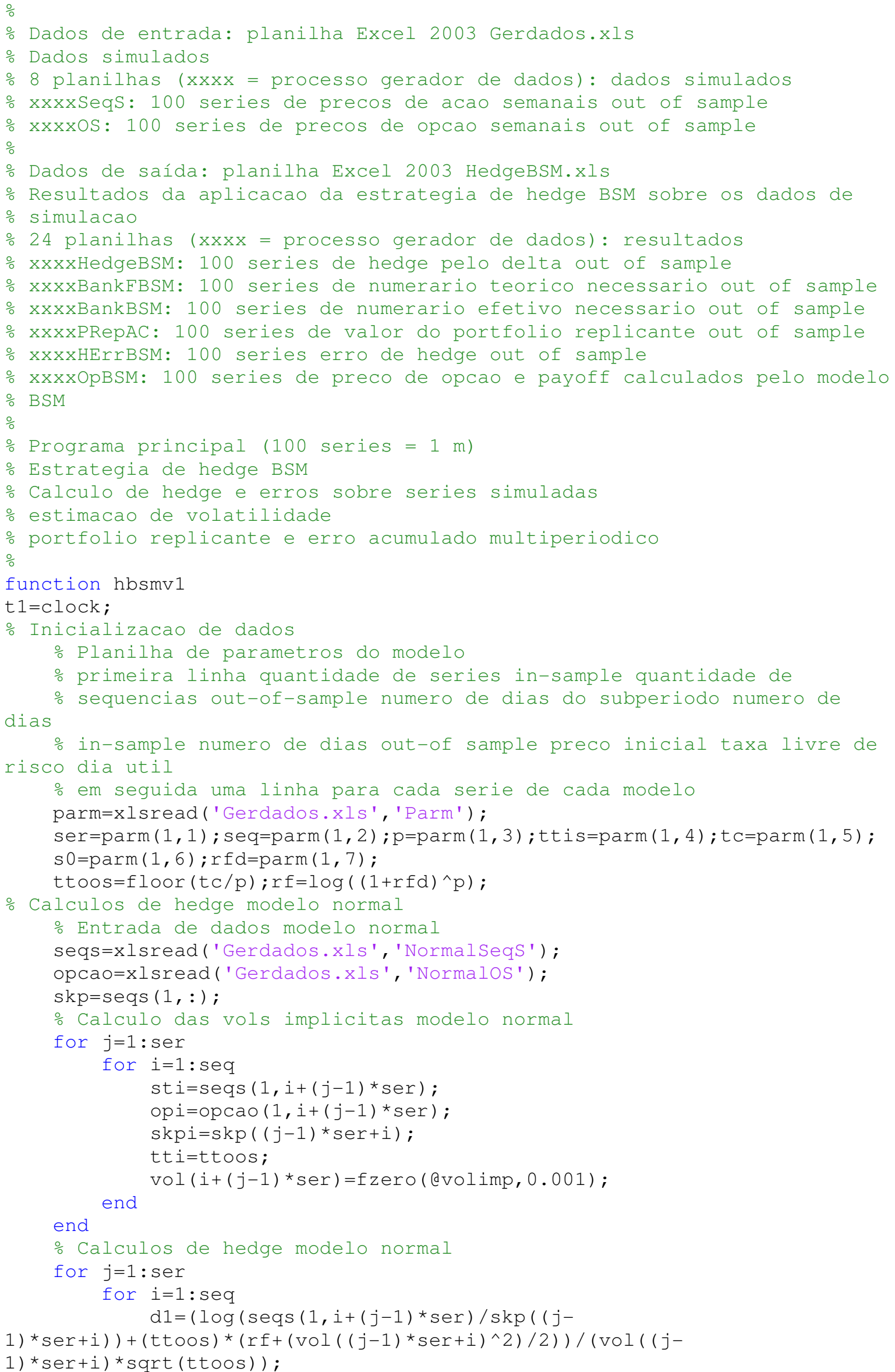




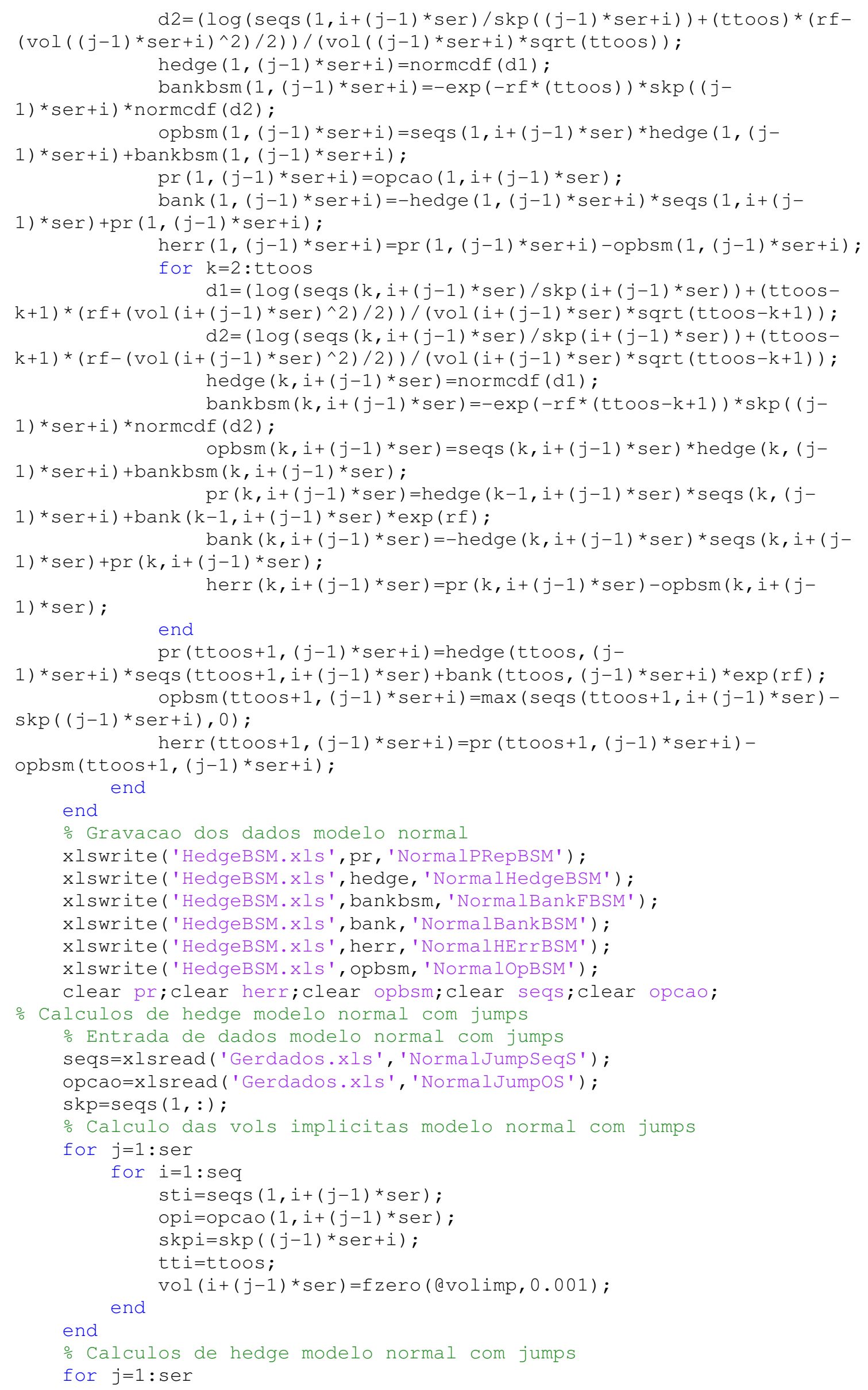




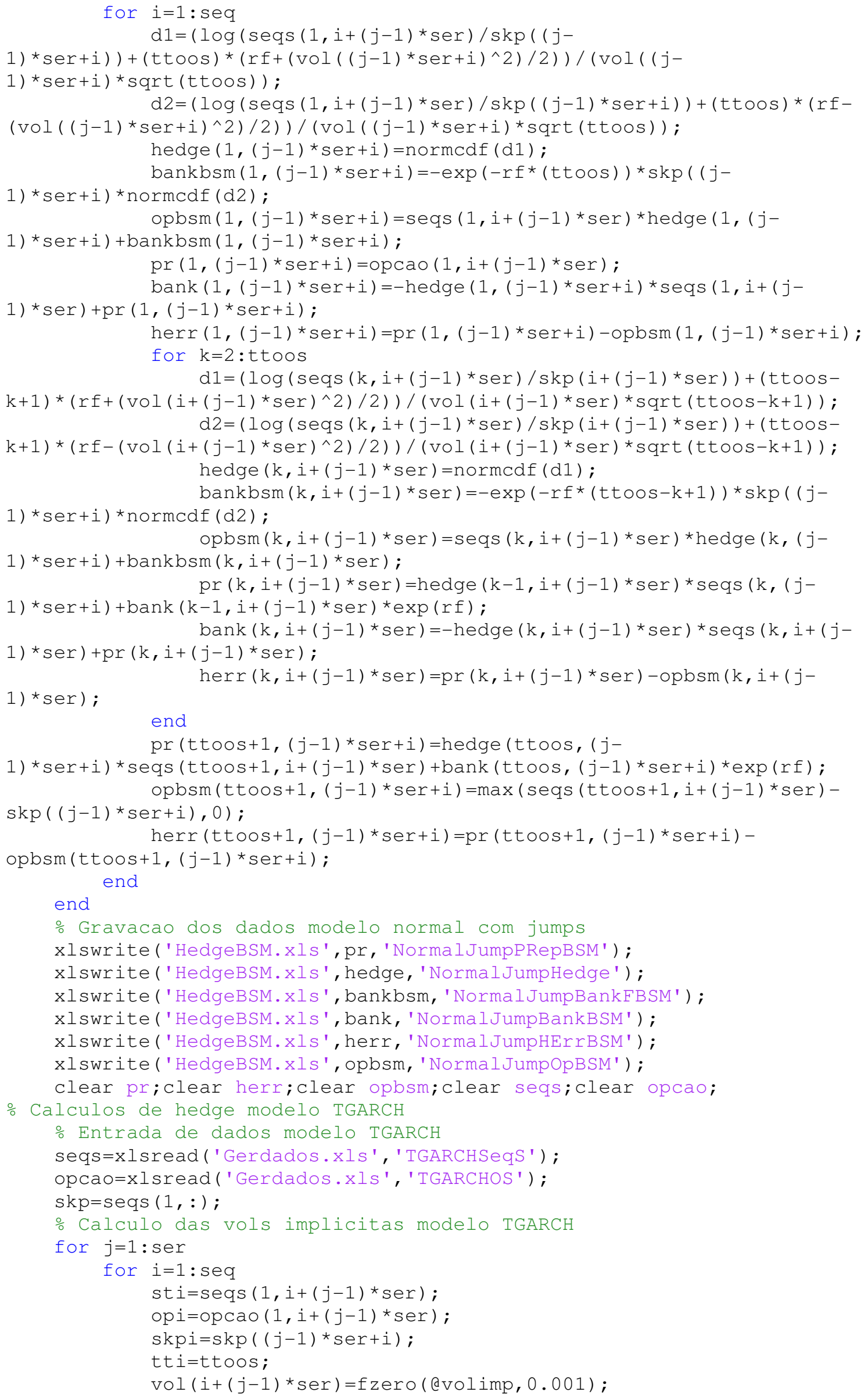




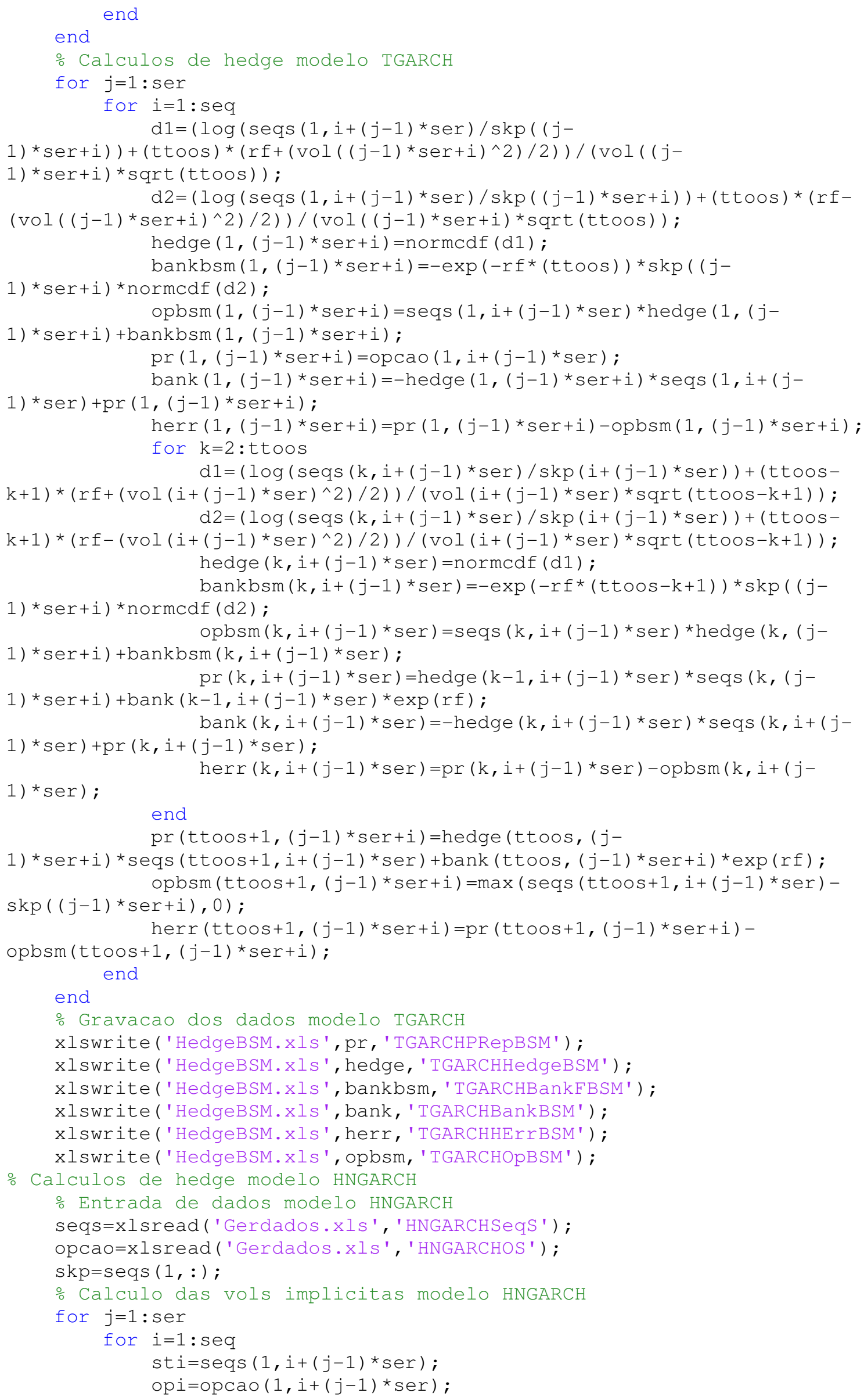




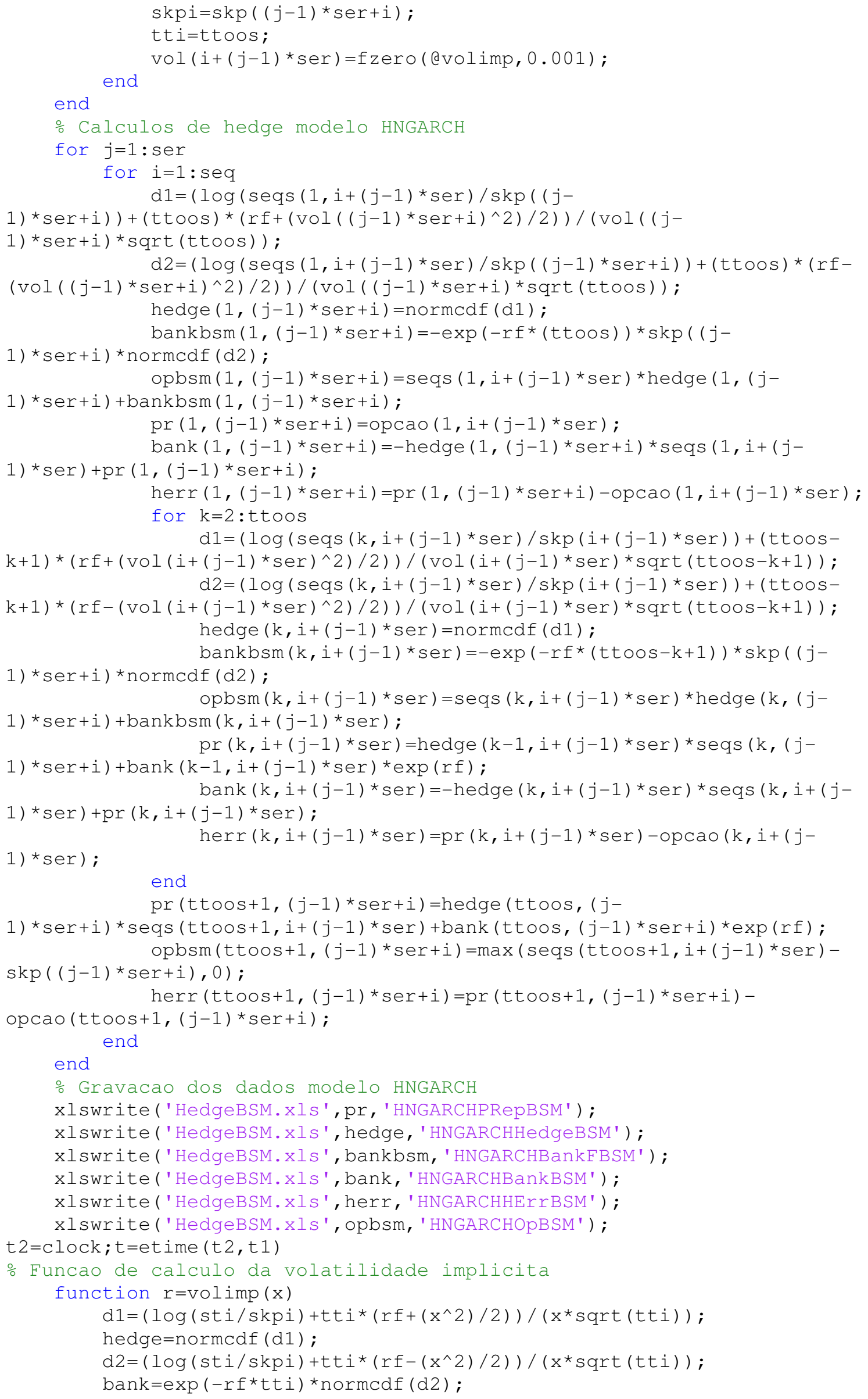




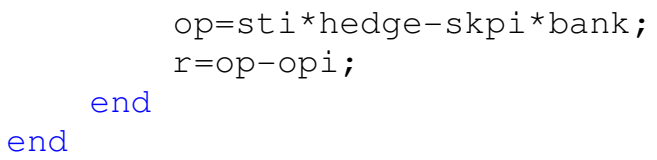

\subsection{Programa para estimação e teste da estratégia AC}

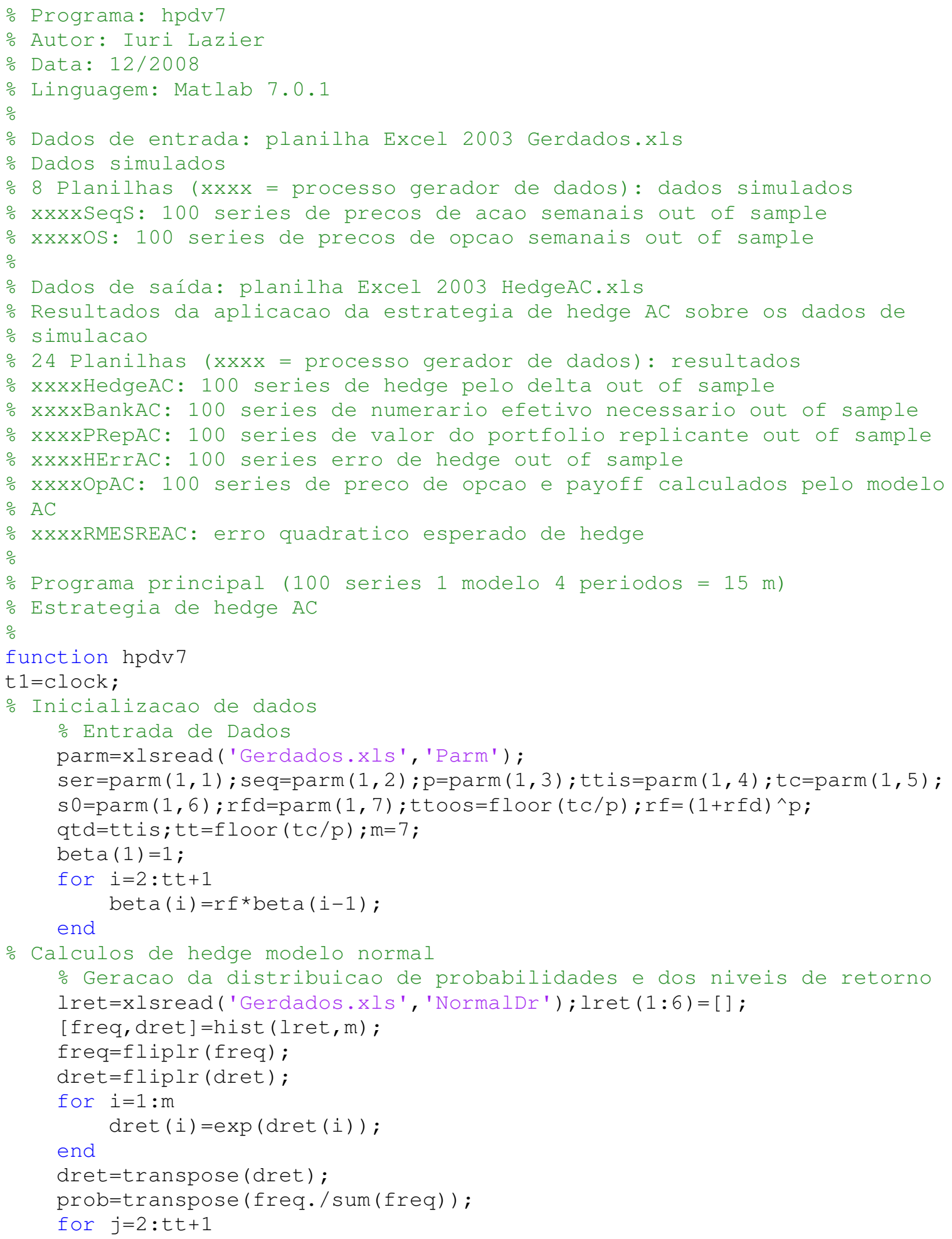



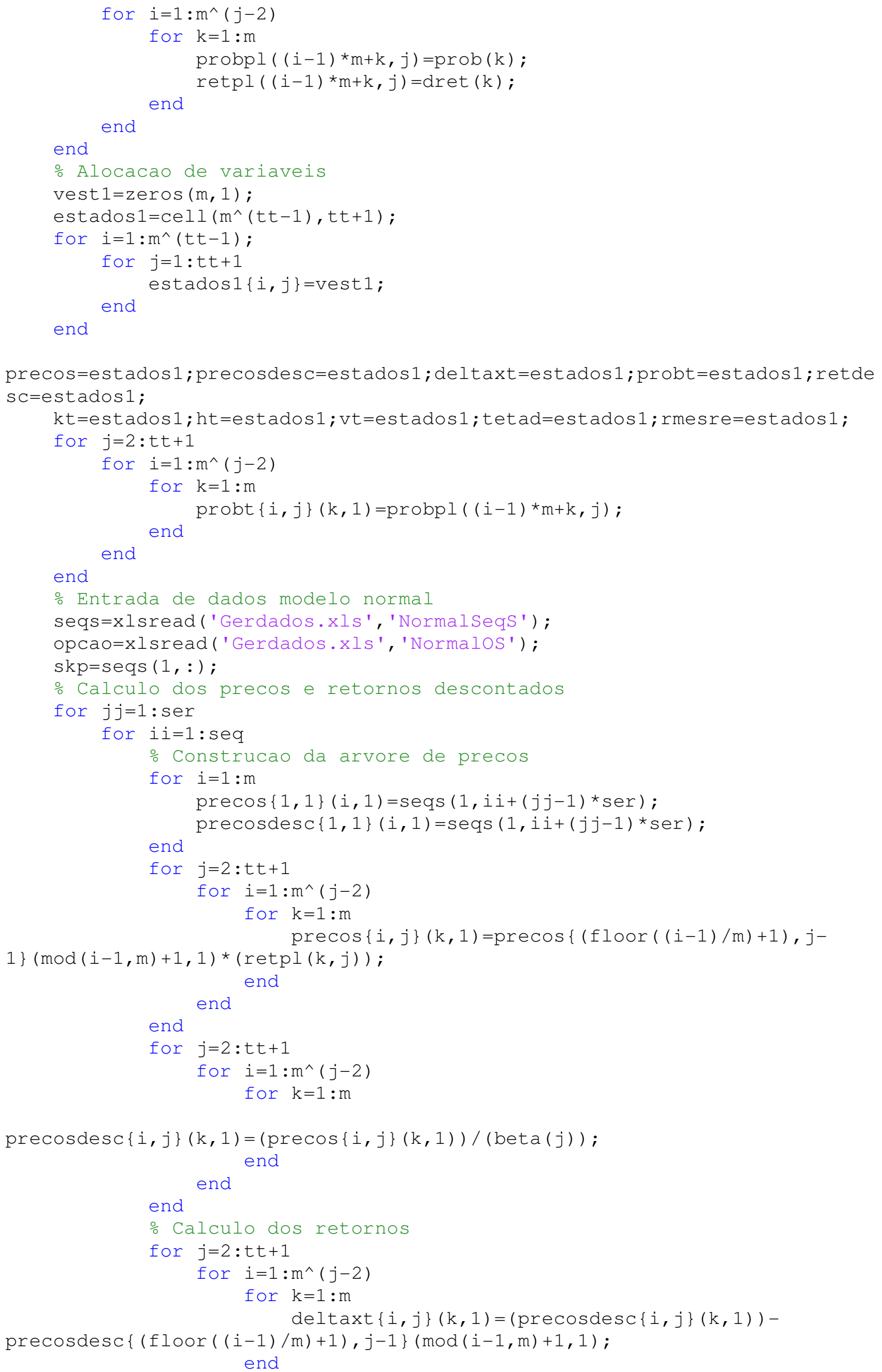


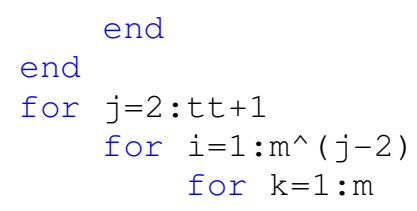

retdesc $\{i, j\}(k, 1)=(\operatorname{deltaxt}\{i, j\}(k, 1)) /(\operatorname{precosdesc}\{(f \operatorname{loor}((i-1) / m)+1), j-$ $1\}(\bmod (i-1, m)+1,1))$; end

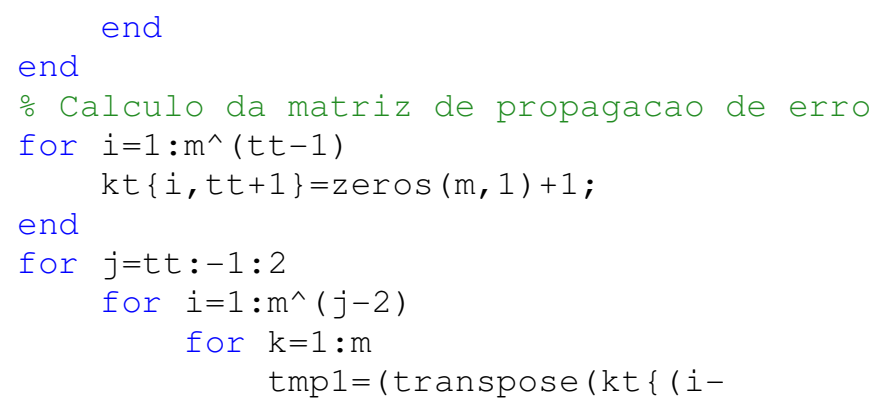




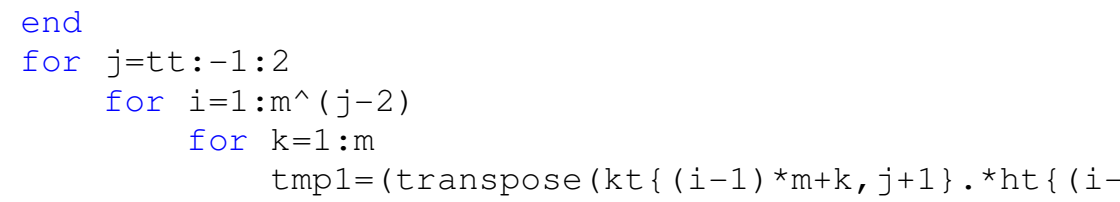

$1) \star m+k, j+1\} . * h t\{(i-1) * m+k, j+1\})) * \operatorname{probt}\{(i-1) * m+k, j+1\} ;$ tmp2 $=($ transpose $(k t\{(i-1) * m+k, j+1\} . * h t\{(i-$

$\left.\left.1) \star m+k, j+1\} \cdot{ }^{*} \operatorname{deltaxt}\{(i-1) \star m+k, j+1\}\right) * \operatorname{probt}\{(i-1) * m+k, j+1\}\right)^{\wedge} 2 ;$ tmp3 $=$ transpose $(k t\{(i-1) * m+k, j+1\} . * \operatorname{deltaxt}\{(i-$

$1) \star m+k, j+1\} . * \operatorname{deltaxt}\{(i-1) * m+k, j+1\}) * \operatorname{probt}\{(i-1) * m+k, j+1\}$; rmesre $\{i, j\}(k, 1)=$ transpose $(r \operatorname{mesre}\{(i-$

$1) \star m+k, j+1\}) * \operatorname{probt}\{(i-1) \star m+k, j+1\}+\operatorname{tmp} 1-k t\{i, j\}(k, 1) *\left((h t\{i, j\}(k, 1))^{\wedge} 2\right)-$ tmp2/tmp3;

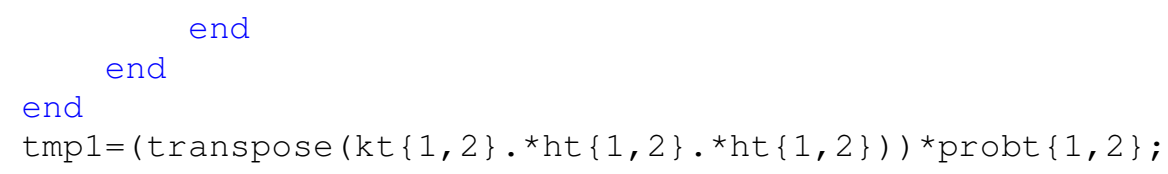

$\operatorname{tmp} 2=\left(\operatorname{transpose}\left(\operatorname{kt}\{1,2\} \cdot{ }^{\star} \operatorname{ht}\{1,2\} \cdot{ }^{\star} \operatorname{deltaxt}\{1,2\}\right) \star \operatorname{probt}\{1,2\}\right) \wedge 2 ;$

$\operatorname{tmp} 3=\operatorname{transpose}(\operatorname{kt}\{1,2\} . * \operatorname{deltaxt}\{1,2\} . * \operatorname{deltaxt}\{1,2\}) * \operatorname{probt}\{1,2\}$; rmesre $\{1,1\}(1,1)=\operatorname{transpose}(\operatorname{rmesre}\{1,2\}) * \operatorname{probt}\{1,2\}+\operatorname{tmp} 1-$

$\operatorname{kt}\{1,1\}(1,1) *\left((\operatorname{ht}\{1,1\}(1,1))^{\wedge} 2\right)-\operatorname{tmp} 2 / \operatorname{tmp} 3$;

o Cálculo do hedge otimo dinamico e do portfolio replicante $\operatorname{vt}\{1,1\}=\operatorname{ht}\{1,1\}$;

$\operatorname{tmp} 1=\operatorname{transpose}\left(\operatorname{kt}\{1,2\} \cdot * \operatorname{deltaxt}\{1,2\} \cdot{ }^{*} \operatorname{deltaxt}\{1,2\}\right) * \operatorname{probt}\{1,2\}$;

$\operatorname{tmp} 2=\operatorname{transpose}\left(\operatorname{kt}\{1,2\} .{ }^{\star} \operatorname{deltaxt}\{1,2\} . *\left(\operatorname{rf}{ }^{\star} \operatorname{vt}\{1,1\}(1,1)\right)\right){ }^{*} \operatorname{probt}\{1,2\}$; tmp3 $=\operatorname{transpose}\left(\operatorname{kt}\{1,2\} .{ }^{*} \operatorname{deltaxt}\{1,2\} .{ }^{\star} \operatorname{ht}\{1,2\}\right){ }^{\star} \operatorname{probt}\{1,2\}$; for $i=1: m$ end tetad $\{1,1\}(i, 1)=-(\operatorname{tmp} 2-\operatorname{tmp} 3) /(\operatorname{beta}(2) * \operatorname{tmp} 1)$;

for $j=2: t t$

for $i=1: m^{\wedge}(j-2)$

for $k=1: m$

$\operatorname{vt}\{i, j\}(k, 1)=r f * v t\{(f \operatorname{loor}((i-1) / m)+1), j-1\}(\bmod (i-$

$1, m)+1,1)+\operatorname{beta}(j) * \operatorname{tetad}\{(f \operatorname{loor}((i-1) / m)+1), j-1\}(\bmod (i-$

$1, m)+1,1) * \operatorname{deltaxt}\{i, j\}(k, 1)$;

tmpl $=$ transpose $\left(k t\{(i-1) * m+k, j+1\} \cdot{ }^{*} \operatorname{deltaxt}\{(i-\right.$

$\left.\left.1){ }^{*}+k, j+1\right\} . * \operatorname{deltaxt}\{(i-1) * m+k, j+1\}\right) * \operatorname{probt}\left\{(i-1){ }^{*} m+k, j+1\right\}$; tmp2 $=$ transpose $(k t\{(i-1) * m+k, j+1\} . * \operatorname{deltaxt}\{(i-$

$1) * m+k, j+1\} . *(r f * v t\{i, j\}(k, 1))) * \operatorname{probt}\{(i-1) * m+k, j+1\}$; tmp3 $=$ transpose $(k t\{(i-1) * m+k, j+1\} . * \operatorname{deltaxt}\{(i-$

$1) \star m+k, j+1\} . * h t\{(i-1) * m+k, j+1\}) * \operatorname{probt}\{(i-1) * m+k, j+1\}$; tetad $\{i, j\}(k, 1)=-(\operatorname{tmp} 2-\operatorname{tmp} 3) /(\operatorname{beta}(j+1) * \operatorname{tmp} 1)$; end end

end

for $i=1: m^{\wedge}(t t-1)$

for $k=1: m$

$\mathrm{vt}\{i, t t+1\}(k, 1)=r f * v t\{(f \operatorname{loor}((i-1) / m)+1), t t\}(\bmod (i-$

$1, m)+1,1)+\operatorname{beta}(t t+1) * \operatorname{tetad}\{(\operatorname{floor}((i-1) / m)+1), t t\}(\bmod (i-$

$1, m)+1,1) * \operatorname{deltaxt}\{i, t t+1\}(k, 1)$;

end

end

- Execucao da estrategia

o Cálculo do hedge otimo dinamico e do portfolio replicante atop $(:, 1)=\operatorname{seqs}(:, i i+(j j-1)$ *ser $)$;

atop $(:, 2)=\operatorname{opcao}(:, i i+(j j-1) \star \operatorname{ser}) ; \operatorname{opht}(1)=\operatorname{ht}\{1,1\}(1,1)$; 


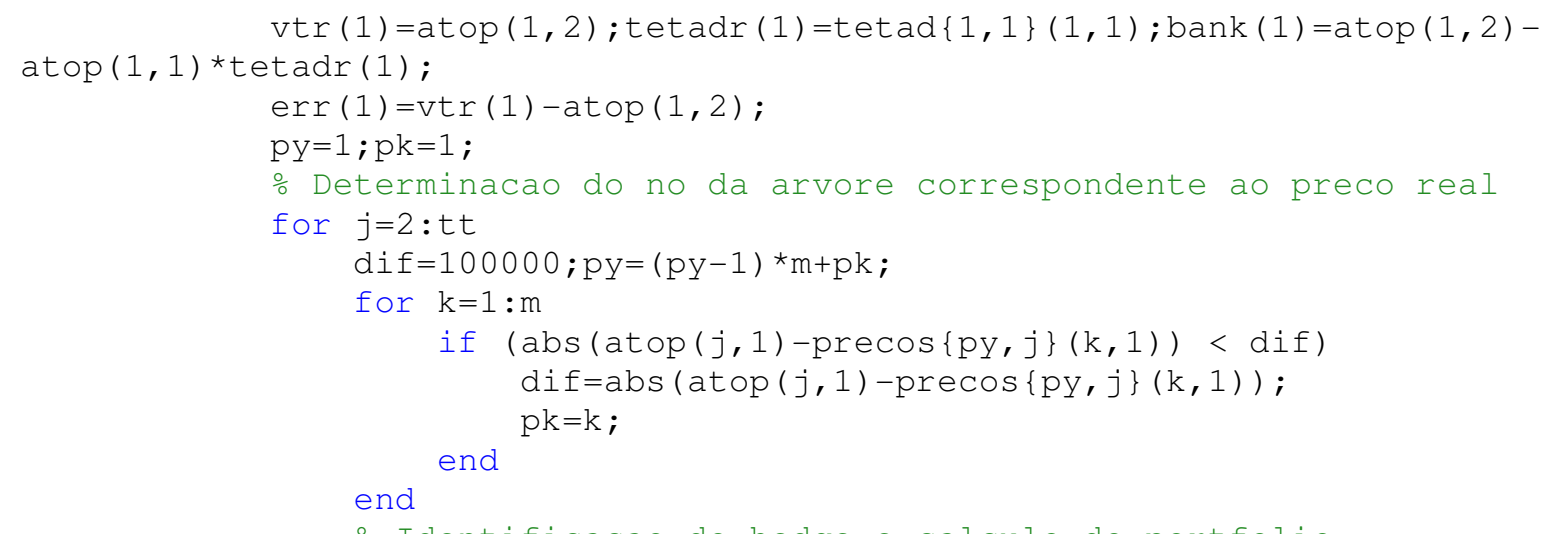

replicante \% Identificacao do hedge e calculo do portfolio

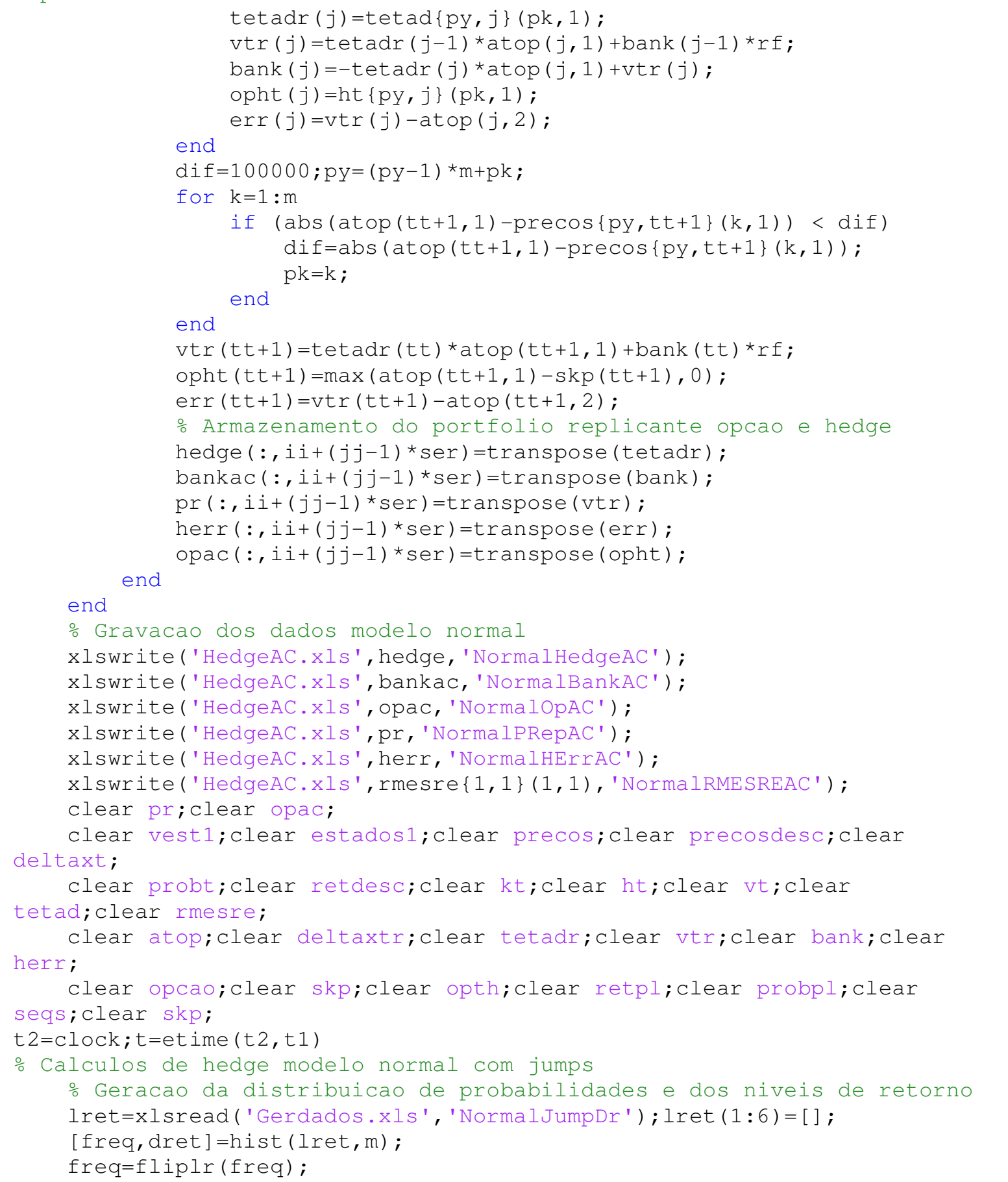




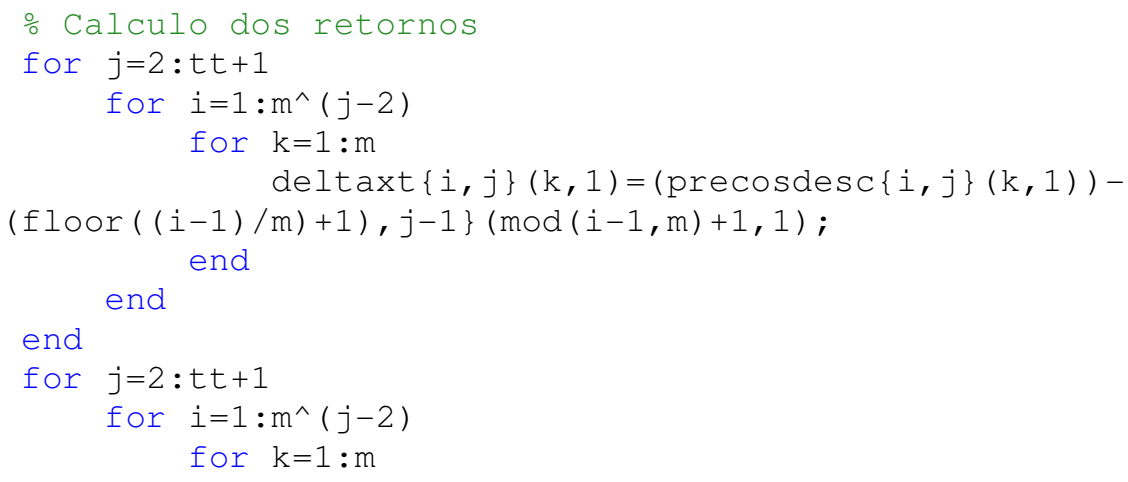

retdesc $\{i, j\}(k, 1)=(\operatorname{deltaxt}\{i, j\}(k, 1)) /(\operatorname{precosdesc}\{(\operatorname{floor}((i-1) / m)+1), j-$ $1\}(\bmod (i-1, m)+1,1))$; end

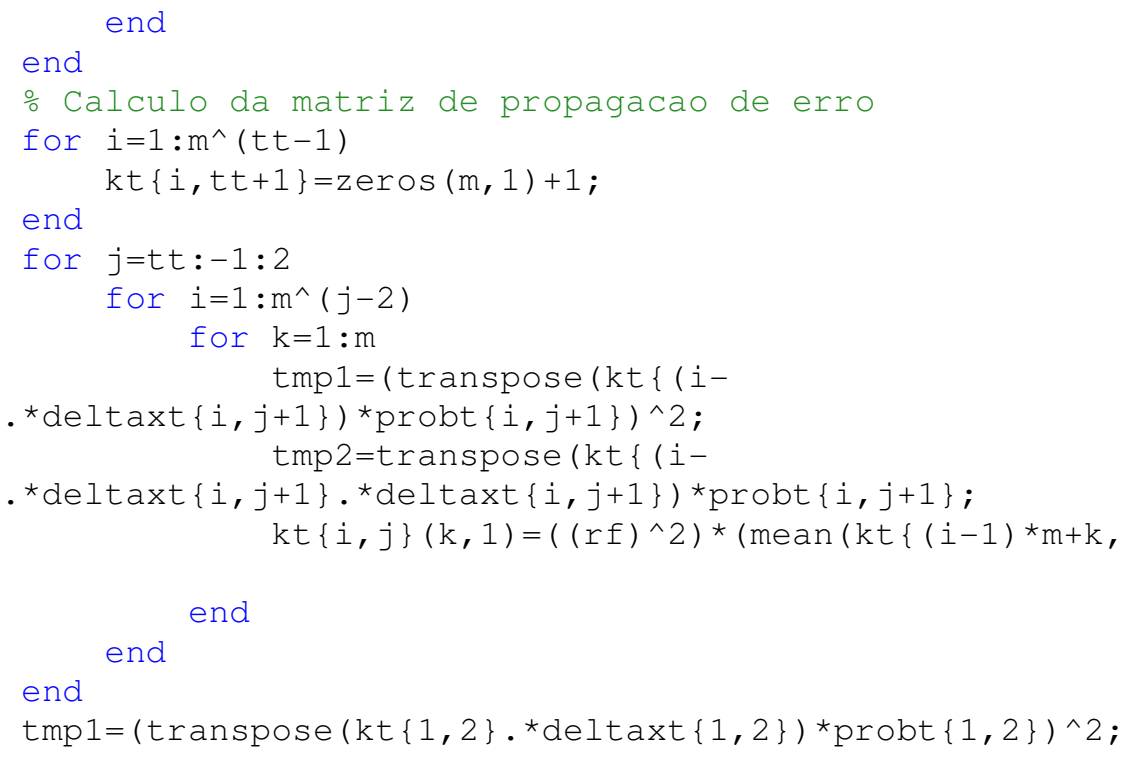

$\operatorname{tmp} 2=\operatorname{transpose}(\operatorname{kt}\{1,2\} . * \operatorname{deltaxt}\{1,2\} . * \operatorname{deltaxt}\{1,2\}) * \operatorname{probt}\{1,2\}$;

for $i=1: m$

end

$\operatorname{kt}\{1,1\}(i, 1)=\left((r f)^{\wedge} 2\right) *(\operatorname{mean}(k t\{1,2\})-t m p 1 / \operatorname{tmp} 2)$;

- Cálculo do processo de valor medio

for $i=1: m^{\wedge}(t t-1)$

end

$h t\{i, t t+1\}=\max (\operatorname{precos}\{i, t t+1\}-\operatorname{skp}(i i+(j j-1) * \operatorname{ser}), 0)$;

for $j=t t:-1: 2$

for $i=1: m^{\wedge}(j-2)$

for $k=1: m$

tmpl $=$ transpose $(k t\{(i-$

$\left.\left.1){ }^{*} m+k, j+1\right\} . * \operatorname{deltaxt}\{i, j+1\}\right) * \operatorname{probt}\{i, j+1\}$;

tmp2 $=$ transpose $(k t\{(i-$

$1) \star m+k, j+1\} . * \operatorname{deltaxt}\{i, j+1\}$. deltaxt $\{i, j+1\}) * \operatorname{probt}\{i, j+1\}$;

$h t\{i, j\}(k, 1)=((r f \wedge 2) / k t\{i, j\}(k, 1)) *(\operatorname{transpose}((k t\{(i-1) * m+k, j+1\}-$

$(\operatorname{tmp} 1 / \operatorname{tmp} 2) . * k t\{(i-1) * m+k, j+1\} . * \operatorname{deltaxt}\{i, j+1\}) \cdot *(h t\{(i-$

$1) * m+k, j+1\} / r f))) *(\operatorname{probt}\{i, j+1\})$;

end

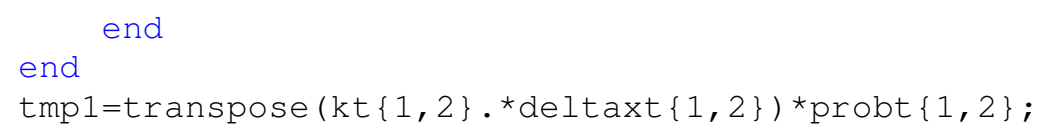

$\operatorname{tmp} 2=\operatorname{transpose}\left(\operatorname{kt}\{1,2\} .{ }^{*} \operatorname{deltaxt}\{1,2\} .{ }^{\star} \operatorname{deltaxt}\{1,2\}\right) * \operatorname{probt}\{1,2\}$; 
for $i=1: m$

$h t\{1,1\}(i, 1)=\left(\left(\operatorname{rf}^{\wedge} 2\right) / k t\{1,1\}(1,1)\right) *(\operatorname{transpose}((k t\{1,2\}-$ $\left.\left.\left.(\operatorname{tmp} 1 / \operatorname{tmp} 2) .{ }^{\star} \operatorname{kt}\{1,2\} .{ }^{*} \operatorname{deltaxt}\{1,2\}\right) . *(\operatorname{ht}\{1,2\} / \operatorname{rf})\right)\right) *(\operatorname{probt}\{1,2\})$; end o Cálculo do erro

for $i=1: m^{\wedge}(t t-1)$

end rmesre $\{i, t t+1\}(:, 1)=\operatorname{zeros}(m, 1)$;

for $j=t t:-1: 2$

for $i=1: m^{\wedge}(j-2)$

for $k=1: m$

tmp $1=\left(\right.$ transpose $\left(k t\{(i-1) * m+k, j+1\} \cdot{ }^{*} h t\{(i-\right.$

$\left.\left.\left.1){ }^{*} m+k, j+1\right\} .{ }^{\star} h t\{(i-1) * m+k, j+1\}\right)\right) * \operatorname{probt}\{(i-1) \star m+k, j+1\}$; tmp2 $=($ transpose $(k t\{(i-1) * m+k, j+1\} . * h t\{(i-$

$1) \star m+k, j+1\} . * \operatorname{deltaxt}\{(i-1) * m+k, j+1\}) * \operatorname{probt}\{(i-1) * m+k, j+1\}) \wedge 2$; tmp3 $=$ transpose $(k t\{(i-1) * m+k, j+1\} . * \operatorname{deltaxt}\{(i-$

$1) \star m+k, j+1\} . * \operatorname{deltaxt}\{(i-1) \star m+k, j+1\}) * \operatorname{probt}\{(i-1) * m+k, j+1\}$; rmesre $\{i, j\}(k, 1)=$ transpose (rmesre $\{(i-$

$1) \star m+k, j+1\}) * \operatorname{probt}\{(i-1) \star m+k, j+1\}+\operatorname{tmp} 1-k t\{i, j\}(k, 1) *\left((h t\{i, j\}(k, 1))^{\wedge} 2\right)-$ tmp2/tmp3;

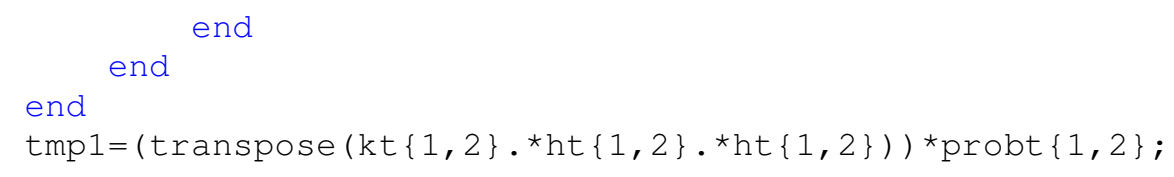

$\operatorname{tmp} 2=\left(\operatorname{transpose}\left(\mathrm{kt}\{1,2\} .{ }^{\star} \operatorname{ht}\{1,2\} \cdot{ }^{\star} \operatorname{deltaxt}\{1,2\}\right){ }^{\star} \operatorname{probt}\{1,2\}\right) \wedge 2 ;$

$\operatorname{tmp} 3=\operatorname{transpose}\left(\operatorname{kt}\{1,2\} . * \operatorname{deltaxt}\{1,2\} .{ }^{*} \operatorname{deltaxt}\{1,2\}\right) * \operatorname{probt}\{1,2\}$; rmesre $\{1,1\}(1,1)=\operatorname{transpose}(\operatorname{rmesre}\{1,2\}) * \operatorname{probt}\{1,2\}+\operatorname{tmp} 1-$ $\operatorname{kt}\{1,1\}(1,1) *\left((\operatorname{ht}\{1,1\}(1,1))^{\wedge} 2\right)-\operatorname{tmp} 2 / \operatorname{tmp} 3$;

\% Cálculo do hedge otimo dinamico e do portfolio replicante $\operatorname{vt}\{1,1\}=\operatorname{ht}\{1,1\}$;

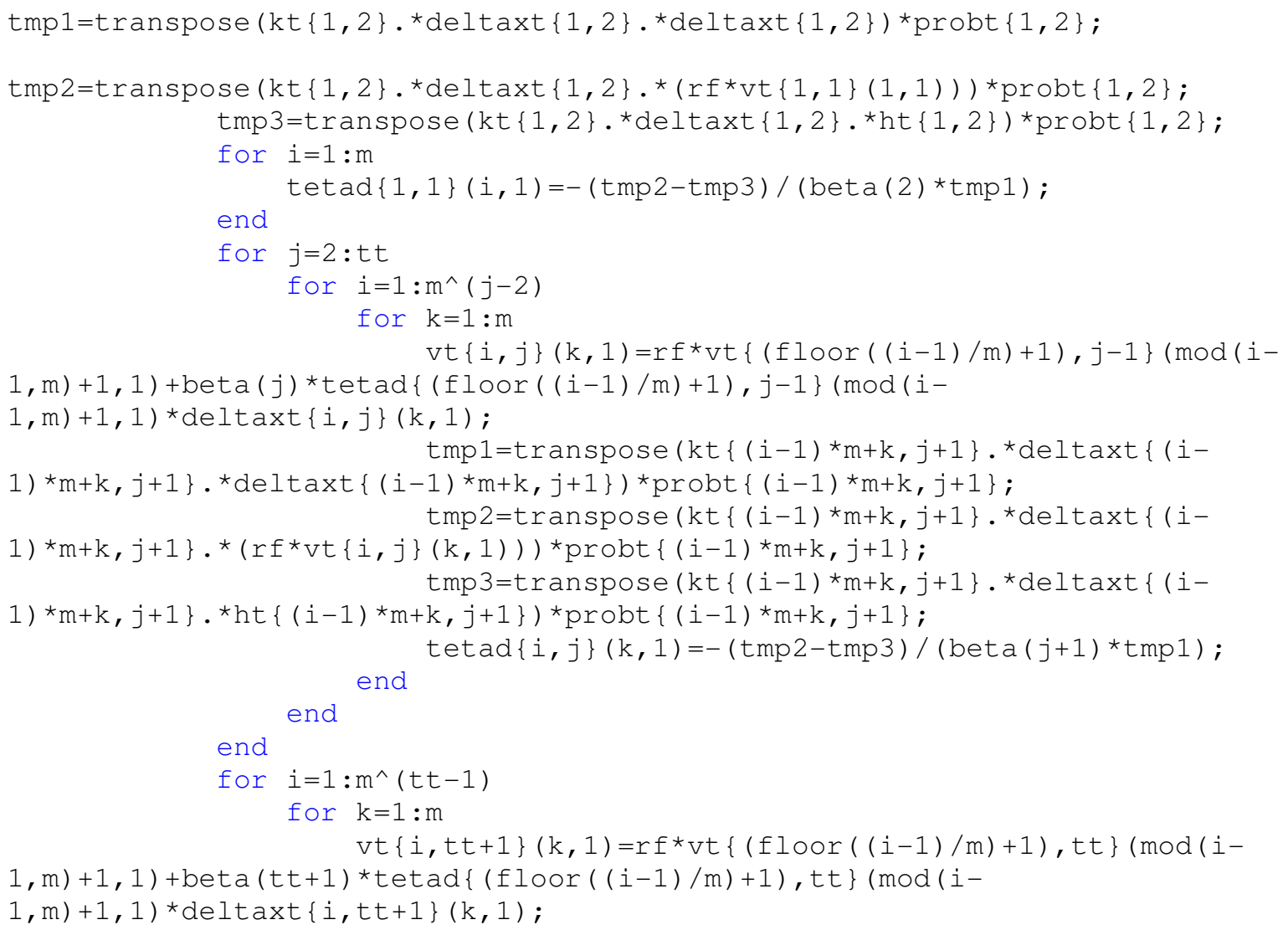


end

end

\% Execucao da estrategia

o Cálculo do hedge otimo dinamico e do portfolio replicante

atop $(:, 1)=\operatorname{seqs}(:, i i+(j j-1) * \operatorname{ser})$;

atop $(:, 2)=\operatorname{opcao}(:, i i+(j j-1) * \operatorname{ser}) ;$ opht $(1)=\operatorname{ht}\{1,1\}(1,1)$;

$\operatorname{vtr}(1)=\operatorname{atop}(1,2) ; \operatorname{tetadr}(1)=\operatorname{tetad}\{1,1\}(1,1) ; \operatorname{bank}(1)=\operatorname{atop}(1,2)-$

$\operatorname{atop}(1,1) * \operatorname{tetadr}(1)$;

$\operatorname{err}(1)=\operatorname{vtr}(1)-\operatorname{atop}(1,2)$

$\mathrm{py}=1 ; \mathrm{pk}=1$;

o Determinacao do no da arvore correspondente ao preco real

for $j=2: t t$

dif $=100000 ; p y=(p y-1) * m+p k$;

for $\mathrm{k}=1: \mathrm{m}$

if $(\operatorname{abs}(\operatorname{atop}(j, 1)-\operatorname{precos}\{p y, j\}(k, 1))<\operatorname{dif})$

dif $=a b s(\operatorname{atop}(j, 1)-\operatorname{precos}\{p y, j\}(k, 1))$;

$\mathrm{pk}=\mathrm{k}$;

end

end

- Identificacao do hedge e calculo do portfolio

replicante

tetadr $(j)=$ tetad $\{\mathrm{py}, j\}(\mathrm{pk}, 1)$;

$\operatorname{vtr}(j)=\operatorname{tetadr}(j-1)$ *atop $(j, 1)+\operatorname{bank}(j-1)$ *rf;

$\operatorname{bank}(j)=-\operatorname{tetadr}(j) * \operatorname{atop}(j, 1)+\operatorname{vtr}(j)$;

opht $(j)=h t\{p y, j\}(p k, 1)$;

$\operatorname{err}(j)=\operatorname{vtr}(j)-\operatorname{atop}(j, 2)$;

end

dif $=100000 ; \mathrm{py}=(\mathrm{py}-1) * \mathrm{~m}+\mathrm{pk}$;

for $k=1: m$

if $(\operatorname{abs}(\operatorname{atop}(t t+1,1)-\operatorname{precos}\{\mathrm{py}, t t+1\}(k, 1))<\mathrm{dif})$

dif $=a b s(\operatorname{atop}(t t+1,1)-\operatorname{precos}\{p y, t t+1\}(k, 1))$; $\mathrm{pk}=\mathrm{k}$;

end

end

$\operatorname{vtr}(t t+1)=\operatorname{tetadr}(t t) * a t o p(t t+1,1)+$ bank $(t t) * r f ;$

opht $(t t+1)=\max (\operatorname{atop}(t t+1,1)-\operatorname{skp}(t t+1), 0)$;

$\operatorname{err}(t t+1)=\operatorname{vtr}(t t+1)-\operatorname{atop}(t t+1,2)$;

- Armazenamento do portfolio replicante opcao e hedge

hedge $\left(:, i i+(j j-1){ }^{*}\right.$ ser $)=$ transpose $($ tetadr $)$;

bankac $(:, i i+(j j-1) *$ ser $)=$ transpose (bank) ;

pr $(:, i i+(j j-1)$ *ser $)=$ transpose (vtr);

herr $(:, i i+(j j-1) *$ ser $)=$ transpose $(\operatorname{err})$;

end

opac $(:, i i+(j j-1) *$ ser $)=$ transpose (opht) ;

end

\% Gravacao dos dados modelo normal com jumps

xlswrite('HedgeAC.xls', hedge, 'NormalJumpHedgeAC' ) ;

xlswrite ('HedgeAC.xls', bankac, 'NormalJumpBankAC') ;

xlswrite ('HedgeAC.xls', opac, 'NormalJumpOpAC' ) ;

xlswrite('HedgeAC.xls', pr, 'Normal JumpPRepAC' );

xlswrite ('HedgeAC.xls', herr, 'NormalJumpHErrAC') ;

xlswrite ('HedgeAC.xls', rmesre $\{1,1\}(1,1)$, 'Normal JumpRMESREAC' ) ;

clear pr;clear opac;

clear vest1;clear estadosi;clear precos;clear precosdesc;clear

deltaxt;

clear probt;clear retdesc;clear kt;clear ht;clear vt;clear

tetad;clear rmesre;

clear atop;clear deltaxtr;clear tetadr;clear vtr;clear bank;clear herr;

clear opcao;clear skp;clear opth;clear retpl;clear probpl;clear

seqs; clear skp; 


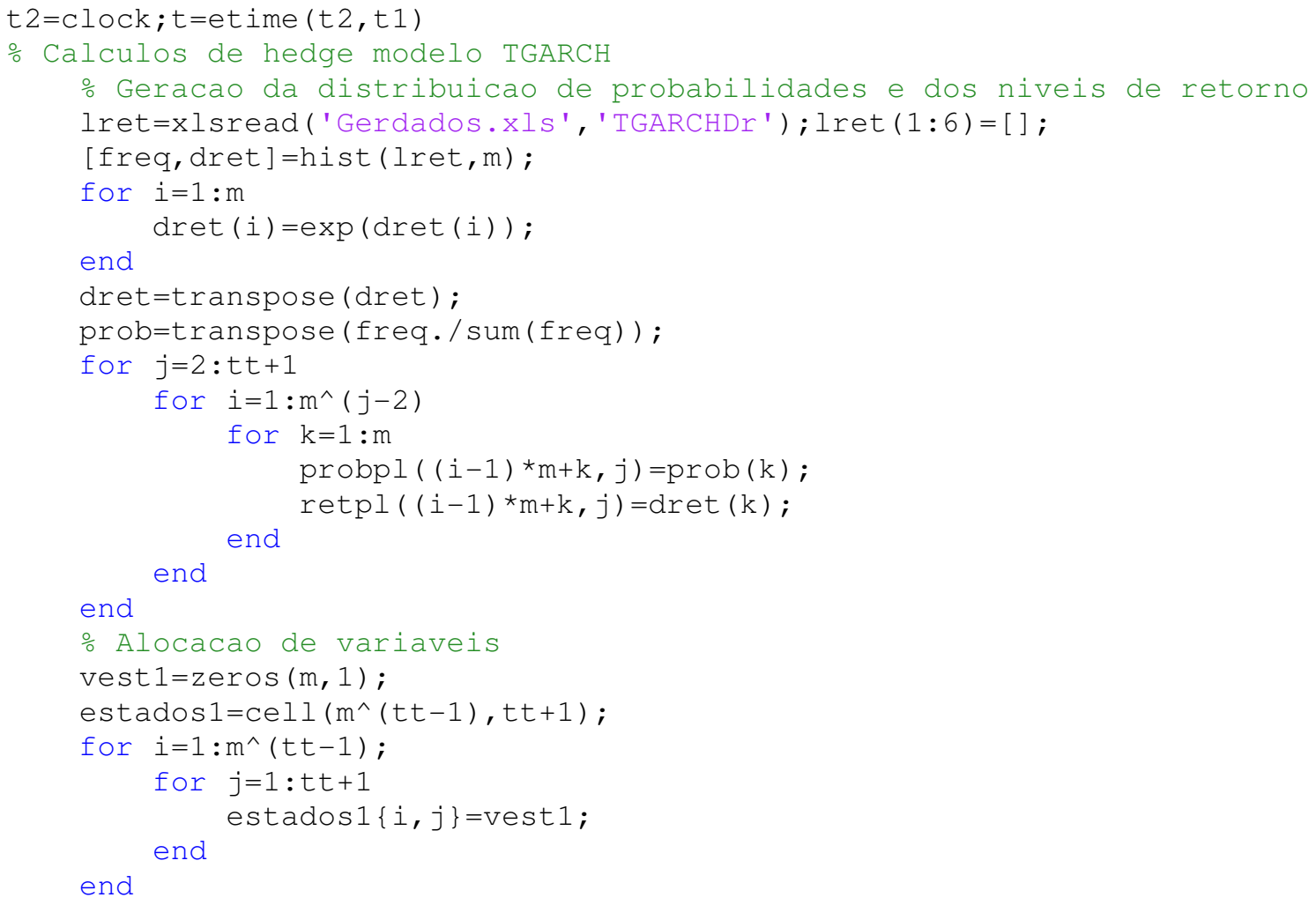

precos=estados 1 ; precosdesc=estados 1 ; deltaxt=estados 1 ; probt=estados 1 ; retde $\mathrm{sc}=\mathrm{estados} 1$

$\mathrm{kt}=$ estados1; ht=estados 1 ; $\mathrm{vt}=$ estados 1 ; tetad=estados 1 ; rmesre=estados 1 ;

for $j=2: t t+1$

for $i=1: m^{\wedge}(j-2)$

for $k=1: m$

$\operatorname{probt}\{i, j\}(k, 1)=\operatorname{probpl}((i-1) * m+k, j)$; end

end

end

- Entrada de dados modelo TGARCH

seqs $=x l$ sread ( 'Gerdados.xls' ', 'TGARCHSeqS' ) ;

opcao=xlsread ('Gerdados.xls', 'TGARCHOS' ) ;

$\operatorname{skp}=\operatorname{seqs}(1,:)$;

- Calculo dos precos e retornos descontados

for $j j=1$ : ser

for $i i=1:$ seq

\% Construcao da arvore de precos

for $i=1: m$

$\operatorname{precos}\{1,1\}(i, 1)=\operatorname{seqs}(1, i i+(j j-1) * \operatorname{ser})$;

end

precosdesc $\{1,1\}(i, 1)=\operatorname{seqs}(1, i i+(j j-1)$ *ser $)$;

for $j=2: t t+1$

for $i=1: m^{\wedge}(j-2)$

for $k=1: m$

$\operatorname{precos}\{i, j\}(k, 1)=\operatorname{precos}\{(f \operatorname{loor}((i-1) / m)+1), j-$

$1\}(\bmod (i-1, m)+1,1) *(\operatorname{retpl}(k, j))$;

end

end

end

for $j=2: t t+1$

for $i=1: m^{\wedge}(j-2)$

for $k=1: m$ 


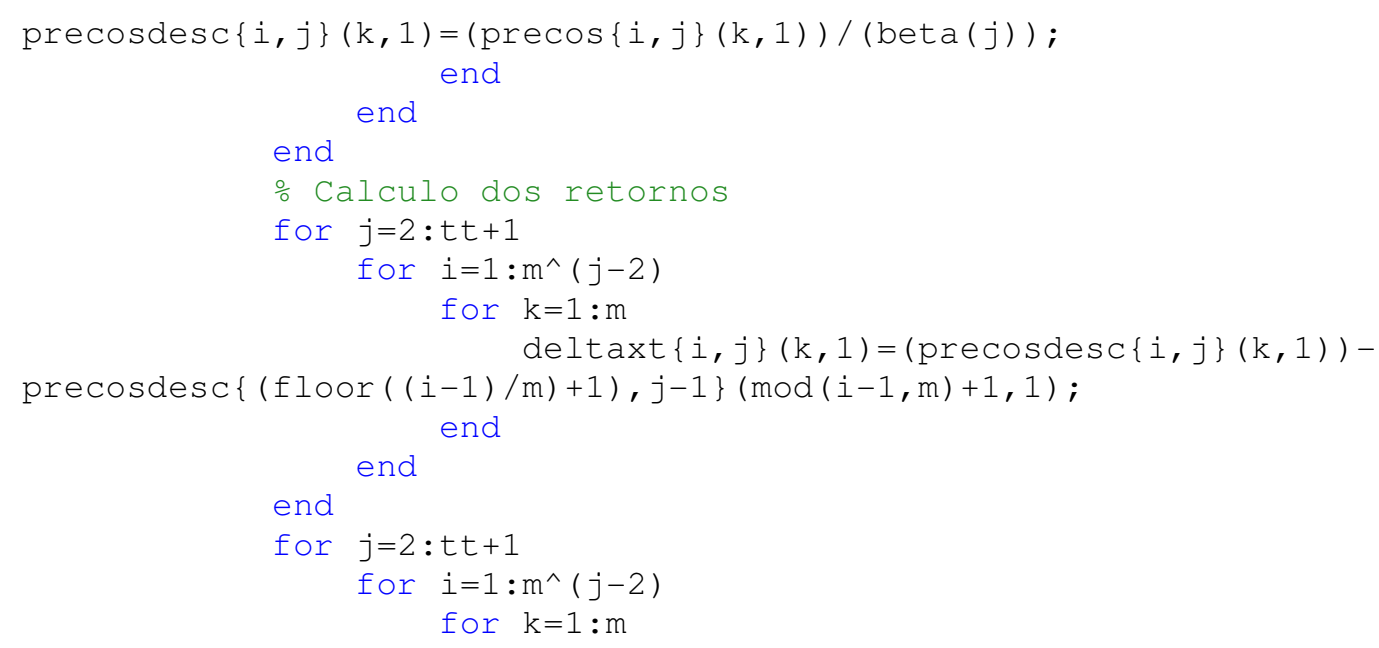

retdesc $\{i, j\}(k, 1)=(\operatorname{deltaxt}\{i, j\}(k, 1)) /(\operatorname{precosdesc}\{(f \operatorname{loor}((i-1) / m)+1), j-$ $1\}(\bmod (i-1, m)+1,1))$; end end

end

- Calculo da matriz de propagacao de erro

for $i=1: m^{\wedge}(t t-1)$

$\operatorname{kt}\{i, t t+1\}=\operatorname{zeros}(m, 1)+1$;

end

for $j=t t:-1: 2$

for $i=1: m^{\wedge}(j-2)$

for $\mathrm{k}=1: \mathrm{m}$

tmp $1=($ transpose $(k t\{(i-$

$\left.\left.\left.1){ }^{*} m+k, j+1\right\} .{ }^{*} \operatorname{deltaxt}\{i, j+1\}\right){ }^{*} \operatorname{probt}\{i, j+1\}\right)^{\wedge} 2$;

tmp $2=$ transpose $(k t\{(i-$

$1) \star m+k, j+1\} . * \operatorname{deltaxt}\{i, j+1\} . * \operatorname{deltaxt}\{i, j+1\}) * \operatorname{probt}\{i, j+1\} ;$

$\operatorname{tmp} 1 / \operatorname{tmp} 2)$;

$k t\{i, j\}(k, 1)=((r f) \wedge 2) *(\operatorname{mean}(k t\{(i-1) * m+k, j+1\})-$

end

end

end

$\operatorname{tmp} 1=(\operatorname{transpose}(\operatorname{kt}\{1,2\} . * \operatorname{deltaxt}\{1,2\}) * \operatorname{probt}\{1,2\}) \wedge 2 ;$

tmp2 $=\operatorname{transpose}\left(\mathrm{kt}\{1,2\} .{ }^{\star} \operatorname{deltaxt}\{1,2\} .{ }^{\star} \operatorname{deltaxt}\{1,2\}\right) * \operatorname{probt}\{1,2\}$;

for $i=1: m$

$\operatorname{kt}\{1,1\}(i, 1)=\left((\operatorname{lf})^{\wedge} 2\right) *(\operatorname{mean}(\operatorname{kt}\{1,2\})-\operatorname{tmp} 1 / \operatorname{tmp} 2)$;

end

\% Cálculo do processo de valor medio

for $i=1: m^{\wedge}(t t-1)$

$h t\{i, t t+1\}=\max (\operatorname{precos}\{i, t t+1\}-\operatorname{skp}(i i+(j j-1) * \operatorname{ser}), 0)$;

end

for $j=t t:-1: 2$

for $i=1: m^{\wedge}(j-2)$

for $\mathrm{k}=1: \mathrm{m}$

tmpl=transpose $(k t\{(i-$

$1) * m+k, j+1\} \cdot * \operatorname{deltaxt}\{i, j+1\}) * \operatorname{probt}\{i, j+1\} ;$

tmp2 $=$ transpose $(\mathrm{kt}\{(i-$

$1) \star m+k, j+1\} . * \operatorname{deltaxt}\{i, j+1\} . * \operatorname{deltaxt}\{i, j+1\}) * \operatorname{probt}\{i, j+1\} ;$

$h t\{i, j\}(k, 1)=\left(\left(r f^{\wedge} 2\right) / k t\{i, j\}(k, 1)\right) *(\operatorname{transpose}((k t\{(i-1) * m+k, j+1\}-$

$\left.(\operatorname{tmp} 1 / \operatorname{tmp} 2) \cdot{ }^{*} \mathrm{kt}\left\{(i-1){ }^{*} \mathrm{~m}+\mathrm{k}, j+1\right\} .{ }^{\star} \operatorname{deltaxt}\{i, j+1\}\right) . *(h t\{(i-$

$1) * m+k, j+1\} / r f))) *(\operatorname{probt}\{i, j+1\})$;

end 
end

end

tmpl=transpose $\left(k t\{1,2\} .{ }^{*} \operatorname{del} \operatorname{taxt}\{1,2\}\right) * \operatorname{probt}\{1,2\}$;

$\operatorname{tmp} 2=\operatorname{transpose}\left(\operatorname{kt}\{1,2\} \cdot{ }^{*} \operatorname{deltaxt}\{1,2\} \cdot{ }^{\star} \operatorname{deltaxt}\{1,2\}\right) * \operatorname{probt}\{1,2\}$;

for $i=1: m$

$\operatorname{ht}\{1,1\}(i, 1)=((\operatorname{rf\wedge } 2) / k t\{1,1\}(1,1)) *(\operatorname{transpose}((k t\{1,2\}-$

$\left.\left.\left.(\operatorname{tmp} 1 / \operatorname{tmp} 2) \cdot{ }^{\star} \mathrm{kt}\{1,2\} \cdot{ }^{*} \operatorname{deltaxt}\{1,2\}\right) \cdot *(\operatorname{ht}\{1,2\} / r f)\right)\right) *(\operatorname{probt}\{1,2\})$;

end

\% Cálculo do erro

for $i=1: m^{\wedge}(t t-1)$

rmesre $\{i, t t+1\}(:, 1)=\operatorname{zeros}(m, 1)$;

end

for $j=t t:-1: 2$

for $i=1: m^{\wedge}(j-2)$

for $\mathrm{k}=1: \mathrm{m}$

tmp $1=($ transpose $(k t\{(i-1) * m+k, j+1\} . * h t\{(i-$

$1) \star m+k, j+1\} . * h t\{(i-1) * m+k, j+1\})) * \operatorname{probt}\{(i-1) * m+k, j+1\} ;$

tmp2 $=($ transpose $(k t\{(i-1) * m+k, j+1\} . * h t\{(i-$

$1) \star m+k, j+1\} . * \operatorname{deltaxt}\{(i-1) * m+k, j+1\}) * \operatorname{probt}\{(i-1) * m+k, j+1\}) \wedge 2 ;$

tmp3 $=$ transpose $(k t\{(i-1) * m+k, j+1\} . * \operatorname{deltaxt}\{(i-$

$\left.1) \star m+k, j+1\} . * \operatorname{deltaxt}\left\{(i-1){ }^{*} m+k, j+1\right\}\right){ }^{*} \operatorname{probt}\left\{(i-1){ }^{*} m+k, j+1\right\}$; rmesre $\{i, j\}(k, 1)=$ transpose (rmesre $\{(i-$

$1) \star m+k, j+1\}) * \operatorname{probt}\{(i-1) * m+k, j+1\}+\operatorname{tmp} 1-k t\{i, j\}(k, 1) *\left((h t\{i, j\}(k, 1))^{\wedge} 2\right)-$ tmp2/tmp3;

end

end

end

$\operatorname{tmp} 1=\left(\operatorname{transpose}\left(\mathrm{kt}\{1,2\} .{ }^{\star} \mathrm{ht}\{1,2\} .{ }^{*} \mathrm{ht}\{1,2\}\right)\right) \star \operatorname{probt}\{1,2\}$;

$\operatorname{tmp} 2=\left(\operatorname{transpose}\left(\operatorname{kt}\{1,2\} .{ }^{\star} \operatorname{ht}\{1,2\} .{ }^{\star} \operatorname{deltaxt}\{1,2\}\right) \star \operatorname{probt}\{1,2\}\right) \wedge 2 ;$

$\operatorname{tmp} 3=\operatorname{transpose}\left(\operatorname{kt}\{1,2\} . * \operatorname{deltaxt}\{1,2\} .{ }^{*} \operatorname{deltaxt}\{1,2\}\right) * \operatorname{probt}\{1,2\}$;

rmesre $\{1,1\}(1,1)=\operatorname{transpose}(\operatorname{rmesre}\{1,2\}) * \operatorname{probt}\{1,2\}+\operatorname{tmp} 1-$

$\operatorname{kt}\{1,1\}(1,1) *\left((\operatorname{ht}\{1,1\}(1,1))^{\wedge} 2\right)-\operatorname{tmp} 2 / \operatorname{tmp} 3$;

\% Cálculo do hedge otimo dinamico e do portfolio replicante $\operatorname{vt}\{1,1\}=h t\{1,1\}$;

$\operatorname{tmp} 1=\operatorname{transpose}(\operatorname{kt}\{1,2\} . * \operatorname{deltaxt}\{1,2\} . * \operatorname{deltaxt}\{1,2\}) \star \operatorname{probt}\{1,2\}$;

$\operatorname{tmp} 2=\operatorname{transpose}\left(\operatorname{kt}\{1,2\} .{ }^{\star} \operatorname{deltaxt}\{1,2\} .{ }^{*}\left(\operatorname{rf}{ }^{*} \operatorname{vt}\{1,1\}(1,1)\right)\right){ }^{\star} \operatorname{probt}\{1,2\}$;

tmp3=transpose $(k t\{1,2\} . * \operatorname{deltaxt}\{1,2\} . *$ ht $\{1,2\}) * \operatorname{probt}\{1,2\}$;

tetad $\{1,1\}(1,1)=-(\operatorname{tmp} 2-\operatorname{tmp} 3) /(\operatorname{beta}(2) * \operatorname{tmp} 1)$;

for $j=2: t t$

for $i=1: m^{\wedge}(j-2)$

for $k=1: m$

$\operatorname{vt}\{i, j\}(k, 1)=r f * v t\{(f l o o r((i-1) / m)+1), j-1\}(\bmod (i-$

$1, m)+1,1)+\operatorname{beta}(j) * \operatorname{tetad}\{(f \operatorname{loor}((i-1) / m)+1), j-1\}(\bmod (i-$

$1, m)+1,1) * \operatorname{deltaxt}\{i, j\}(k, 1)$;

tmpl $1=$ transpose $(k t\{(i-1) * m+k, j+1\} . *$ deltaxt $\{(i-$

$\left.1) \star m+k, j+1\} *{ }^{*} \operatorname{deltaxt}\{(i-1) * m+k, j+1\}\right) * \operatorname{probt}\{(i-1) * m+k, j+1\}$; tmp2 $=$ transpose $(k t\{(i-1) * m+k, j+1\} . * \operatorname{deltaxt}\{(i-$

$1) * m+k, j+1\} . *(r f * v t\{i, j\}(k, 1))) * \operatorname{probt}\{(i-1) * m+k, j+1\}$; tmp3 $=$ transpose $(k t\{(i-1) * m+k, j+1\} . * \operatorname{deltaxt}\{(i-$

$1) \star m+k, j+1\} . * h t\{(i-1) * m+k, j+1\}) * \operatorname{probt}\{(i-1) * m+k, j+1\}$; $\operatorname{tetad}\{i, j\}(k, 1)=-(\operatorname{tmp} 2-\operatorname{tmp} 3) /(\operatorname{beta}(j+1) * \operatorname{tmp} 1)$; end end

end

for $i=1: m^{\wedge}(t t-1)$

for $\mathrm{k}=1: \mathrm{m}$ 
$\mathrm{vt}\{i, \mathrm{t} t+1\}(\mathrm{k}, 1)=\mathrm{rf} * \mathrm{vt}\{(\mathrm{floor}((\mathrm{i}-1) / \mathrm{m})+1), \mathrm{tt}\}(\bmod (i-$ $1, m)+1,1)+\operatorname{beta}(t t+1) * \operatorname{tetad}\{(f \operatorname{loor}((i-1) / m)+1), t t\}(\bmod (i-$

$1, \mathrm{~m})+1,1) * \operatorname{deltaxt}\{i, \mathrm{t} t+1\}(\mathrm{k}, 1)$;

end

end

- Execucao da estrategia

o Cálculo do hedge otimo dinamico e do portfolio replicante atop $(:, 1)=\operatorname{seqs}(:, i i+(j j-1) * \operatorname{ser})$;

atop $(:, 2)=\operatorname{opcao}(:, i i+(j j-1) * \operatorname{ser}) ;$ opht $(1)=\operatorname{ht}\{1,1\}(1,1)$;

$\operatorname{vtr}(1)=\operatorname{atop}(1,2) ; \operatorname{tetadr}(1)=\operatorname{tetad}\{1,1\}(1,1) ; \operatorname{bank}(1)=\operatorname{atop}(1,2)-$

atop $(1,1) * \operatorname{tetadr}(1)$;

$\operatorname{err}(1)=\operatorname{vtr}(1)-\operatorname{atop}(1,2)$;

$\mathrm{py}=1 ; \mathrm{pk}=1$;

\% Determinacao do no da arvore correspondente ao preco real

for $j=2: t t$

dif $=100000 ; p y=(p y-1) * m+p k$;

for $\mathrm{k}=1: \mathrm{m}$

if $(\operatorname{abs}(\operatorname{atop}(j, 1)-p r e c o s\{p y, j\}(k, 1))<\operatorname{dif})$

dif=abs $(\operatorname{atop}(j, 1)-\operatorname{precos}\{p y, j\}(k, 1))$;

$\mathrm{pk}=\mathrm{k}$;

end

end

\% Identificacao do hedge e calculo do portfolio

replicante

tetadr $(j)=$ tetad $\{\mathrm{py}, j\}(\mathrm{pk}, 1)$;

$\operatorname{vtr}(j)=\operatorname{tetadr}(j-1)$ *atop $(j, 1)+\operatorname{bank}(j-1)$ *rf ;

$\operatorname{bank}(j)=-\operatorname{tetadr}(j) * \operatorname{atop}(j, 1)+\operatorname{vtr}(j)$;

opht $(j)=h t\{p y, j\}(p k, 1)$;

end

$\operatorname{err}(j)=\operatorname{vtr}(j)-\operatorname{atop}(j, 2)$;

dif $=100000 ; \mathrm{py}=(\mathrm{py}-1) * \mathrm{~m}+\mathrm{pk}$;

for $\mathrm{k}=1: \mathrm{m}$

if $(\operatorname{abs}(\operatorname{atop}(t t+1,1)-\operatorname{precos}\{\mathrm{py}, t t+1\}(k, 1))<\mathrm{dif})$

dif $=a b s(\operatorname{atop}(t t+1,1)-\operatorname{precos}\{\mathrm{py}, t t+1\}(k, 1))$;

$\mathrm{pk}=\mathrm{k}$;

end

end

$\operatorname{vtr}(t t+1)=$ tetadr $(t t) * a t o p(t t+1,1)+$ bank $(t t) * r f$;

opht $(t t+1)=\max (\operatorname{atop}(t t+1,1)-\operatorname{skp}(t t+1), 0)$;

$\operatorname{err}(t t+1)=\operatorname{vtr}(t t+1)-\operatorname{atop}(t t+1,2)$;

o Armazenamento do portfolio replicante opcao e hedge

hedge ( : , i $i+(j j-1){ }^{*}$ ser $)=$ transpose (tetadr $)$;

bankac $(:, i i+(j j-1) *$ ser $)=$ transpose $($ bank $)$;

$\operatorname{pr}(:, i i+(j j-1) *$ ser $)=$ transpose (vtr);

herr $(:, i i+(j j-1)$ *ser $)=$ transpose (err) ;

opac $(:, i i+(j j-1) *$ ser $)=$ transpose (opht) ;

end

end

- Gravacao dos dados modelo TGARCH

xlswrite ('HedgeAC.xls', hedge, 'TGARCHHedgeAC' ) ;

xlswrite ('HedgeAC.xls', bankac, 'TGARCHBankAC') ;

xlswrite ('HedgeAC.xls', opac, 'TGARCHOpAC') ;

xlswrite('HedgeAC.xls', pr, 'TGARCHPRepAC');

xlswrite ('HedgeAC.xls', herr, 'TGARCHHErrAC') ;

xlswrite ('HedgeAC.xls', rmesre $\{1,1\}(1,1)$, 'TGARCHRMESREAC' ) ;

clear pr;clear opac;

clear vest1; clear estadosi; clear precos;clear precosdesc; clear

deltaxt;

clear probt;clear retdesc;clear kt;clear ht;clear vt;clear

tetad;clear rmesre; 


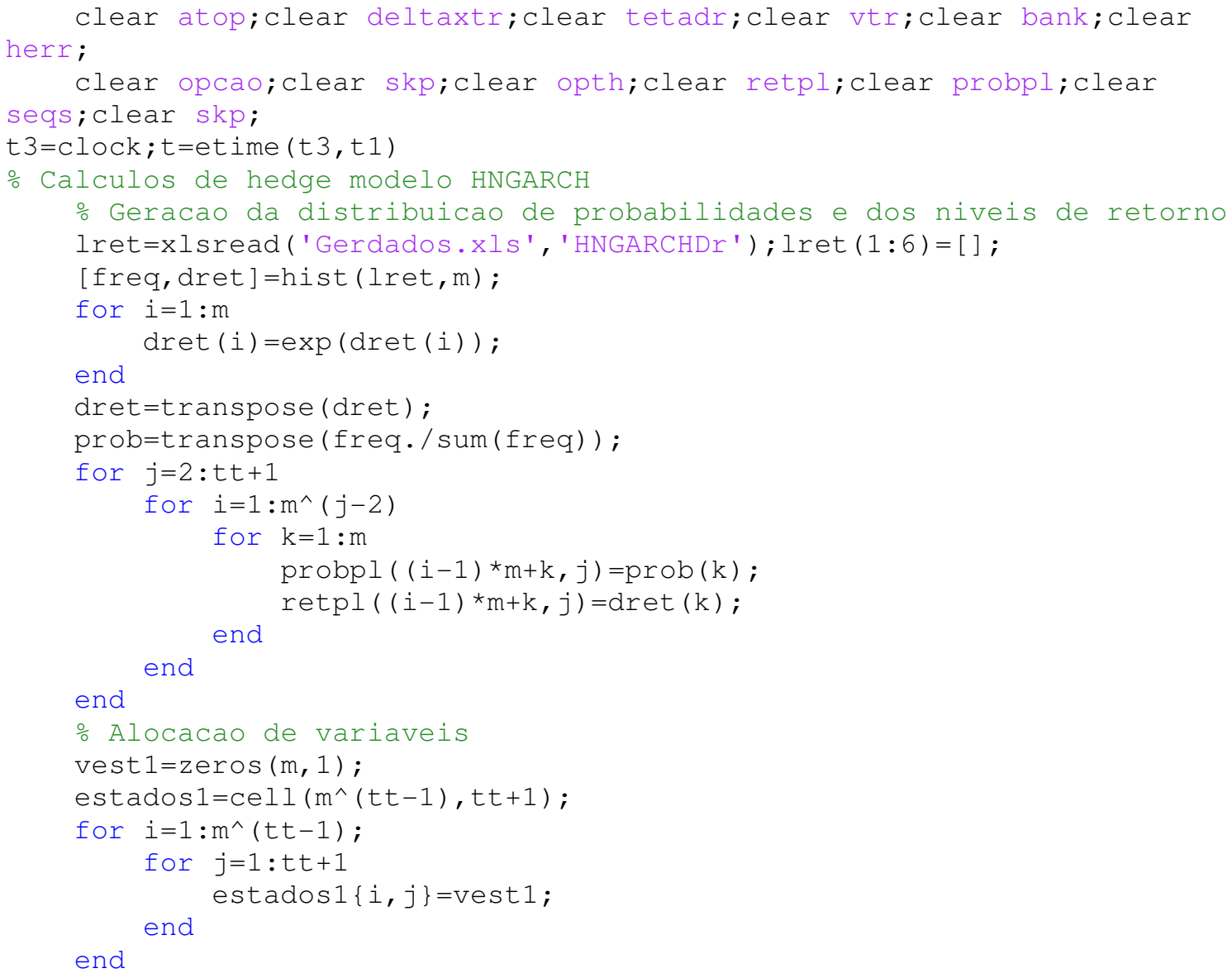

precos=estados 1 ; precosdesc=estados 1 ; deltaxt=estados 1 ; probt=estados 1 ; retde $\mathrm{sc}=e \mathrm{stados} 1$;

$\mathrm{kt}=e s t a d o s 1 ; \mathrm{ht}=e s t a d o s 1$; $\mathrm{vt=estados} 1$; tetad=estados 1 ; rmesre=estados 1 ;

for $j=2: t t+1$

for $i=1: m^{\wedge}(j-2)$

for $k=1: m$

probt $\{i, j\}(k, 1)=\operatorname{probpl}((i-1) * m+k, j)$;

end

end

\% Entrada de dados modelo TGARCH

seqs=xlsread ('Gerdados.xls', 'HNGARCHSeqS' ) ;

opcao=xlsread ('Gerdados.xls', 'HNGARCHOS' ) ;

$\operatorname{skp}=\operatorname{seqs}(1,:)$;

o Calculo dos precos e retornos descontados

for $j j=1:$ ser

for $i i=1:$ seq

\% Construcao da arvore de precos

for $i=1: m$

$\operatorname{precos}\{1,1\}(i, 1)=\operatorname{seqs}(1, i i+(j j-1) * \operatorname{ser})$;

$\operatorname{precosdesc}\{1,1\}(i, 1)=\operatorname{seqs}\left(1, i i+(j j-1){ }^{*} \operatorname{ser}\right)$;

end

for $j=2: t t+1$

for $i=1: m^{\wedge}(j-2)$

for $k=1: m$

$\operatorname{precos}\{i, j\}(k, 1)=\operatorname{precos}\{(f \operatorname{loor}((i-1) / m)+1), j-$

$1\}(\bmod (i-1, m)+1,1)$ * $(\operatorname{retpl}(k, j))$;

end

end

end 
$\left.(\operatorname{tmp} 1 / \operatorname{tmp} 2) \cdot{ }^{\star} k t\{(i-1) * m+k, j+1\} \cdot * \operatorname{deltaxt}\{i, j+1\}\right) \cdot *(h t\{(i-$

$1) * m+k, j+1\} / r f))) *(\operatorname{probt}\{i, j+1\})$;

end

end

end

$\operatorname{tmp} 1=\operatorname{transpose}\left(\operatorname{kt}\{1,2\} .{ }^{*} \operatorname{deltaxt}\{1,2\}\right) * \operatorname{probt}\{1,2\}$;

$\operatorname{tmp} 2=\operatorname{transpose}\left(\operatorname{kt}\{1,2\} .{ }^{*} \operatorname{deltaxt}\{1,2\} .{ }^{*} \operatorname{deltaxt}\{1,2\}\right) * \operatorname{probt}\{1,2\}$;

ht $\{1,1\}(1,1)=\left(\left(\operatorname{rf}^{\wedge} 2\right) / \mathrm{kt}\{1,1\}(1,1)\right) *(\operatorname{transpose}((\mathrm{kt}\{1,2\}-$

$\left.\left.\left.(\operatorname{tmp} 1 / \operatorname{tmp} 2) .{ }^{\star} \mathrm{kt}\{1,2\} .{ }^{*} \operatorname{deltaxt}\{1,2\}\right) . *(\operatorname{ht}\{1,2\} / \operatorname{rf})\right)\right) \star(\operatorname{probt}\{1,2\})$;

- Cálculo do erro

for $i=1: m^{\wedge}(t t-1)$

rmesre $\{i, t t+1\}(:, 1)=\operatorname{zeros}(m, 1)$;

end

for $j=t t:-1: 2$

for $i=1: m^{\wedge}(j-2)$

for $k=1: m$

tmpl $=($ transpose $(k t\{(i-1) * m+k, j+1\} . * h t\{(i-$

$1) \star m+k, j+1\} . * h t\{(i-1) * m+k, j+1\})) * \operatorname{probt}\{(i-1) \star m+k, j+1\}$;

tmp2 $=\left(\right.$ transpose $\left(k t\{(i-1) * m+k, j+1\} \cdot{ }^{\star} h t\{(i-\right.$

$\left.\left.\left.1){ }^{\star} m+k, j+1\right\} .{ }^{*} \operatorname{deltaxt}\left\{(i-1){ }^{*} m+k, j+1\right\}\right){ }^{*} \operatorname{probt}\left\{(i-1){ }^{*} m+k, j+1\right\}\right)^{\wedge} 2$;

tmp $3=\operatorname{transpose}\left(k t\{(i-1) * m+k, j+1\} \cdot{ }^{*} \operatorname{deltaxt}\{(i-\right.$

$1) \star m+k, j+1\} . * \operatorname{deltaxt}\{(i-1) * m+k, j+1\}) * \operatorname{probt}\{(i-1) * m+k, j+1\}$; rmesre $\{i, j\}(k, 1)=$ transpose $(r \operatorname{rmesre}\{(i-$

$1) * m+k, j+1\}) * \operatorname{probt}\{(i-1) * m+k, j+1\}+\operatorname{tmp} 1-k t\{i, j\}(k, 1) *\left((h t\{i, j\}(k, 1))^{\wedge} 2\right)-$ tmp2/tmp3;

end

end

end

$\operatorname{tmp} 1=\left(\operatorname{transpose}\left(\operatorname{kt}\{1,2\} \cdot{ }^{\star} \mathrm{ht}\{1,2\} \cdot{ }^{\star} \mathrm{ht}\{1,2\}\right)\right) \star \operatorname{probt}\{1,2\} ;$

$\operatorname{tmp} 2=\left(\operatorname{transpose}\left(\operatorname{kt}\{1,2\} .{ }^{\star} \operatorname{ht}\{1,2\} .{ }^{\star} \operatorname{deltaxt}\{1,2\}\right){ }^{*} \operatorname{probt}\{1,2\}\right) \wedge 2 ;$

$\operatorname{tmp} 3=\operatorname{transpose}\left(k t\{1,2\} \cdot{ }^{*} \operatorname{deltaxt}\{1,2\} \cdot{ }^{*} \operatorname{deltaxt}\{1,2\}\right) * \operatorname{probt}\{1,2\}$;

rmesre $\{1,1\}(1,1)=\operatorname{transpose}(\operatorname{rmesre}\{1,2\}) * \operatorname{probt}\{1,2\}+\operatorname{tmp} 1-$

$\mathrm{kt}\{1,1\}(1,1) *\left((\operatorname{ht}\{1,1\}(1,1))^{\wedge} 2\right)-\operatorname{tmp} 2 / \operatorname{tmp} 3$;

o Cálculo do hedge otimo dinamico e do portfolio replicante $\operatorname{vt}\{1,1\}=h t\{1,1\}$;

$\operatorname{tmp} 1=\operatorname{transpose}(k t\{1,2\} \cdot * \operatorname{deltaxt}\{1,2\} \cdot * \operatorname{deltaxt}\{1,2\}) * \operatorname{probt}\{1,2\}$;

$\operatorname{tmp} 2=\operatorname{transpose}\left(\mathrm{kt}\{1,2\} .{ }^{*} \operatorname{deltaxt}\{1,2\} . *(\operatorname{rf} * \mathrm{vt}\{1,1\}(1,1))\right){ }^{*} \operatorname{probt}\{1,2\}$;

tmp3=transpose $\left(\operatorname{kt}\{1,2\} .{ }^{*} \operatorname{deltaxt}\{1,2\} .{ }^{\star} \operatorname{ht}\{1,2\}\right) * \operatorname{probt}\{1,2\}$;

tetad $\{1,1\}(1,1)=-(\operatorname{tmp} 2-\operatorname{tmp} 3) /(\operatorname{beta}(2) * \operatorname{tmp} 1)$;

for $j=2: t t$

for $i=1: m^{\wedge}(j-2)$

for $k=1: m$

vt $\{i, j\}(k, 1)=r f * v t\{(f \operatorname{loor}((i-1) / m)+1), j-1\}(\bmod (i-$

$1, m)+1,1)+\operatorname{beta}(j) * \operatorname{tetad}\{(\operatorname{floor}((i-1) / m)+1), j-1\}(\bmod (i-$

$1, m)+1,1) * \operatorname{deltaxt}\{i, j\}(k, 1)$;

tmpl $1=$ transpose $(k t\{(i-1) * m+k, j+1\} . *$ deltaxt $\{(i-$

$1) \star m+k, j+1\} . * \operatorname{deltaxt}\{(i-1) * m+k, j+1\}) * \operatorname{probt}\{(i-1) * m+k, j+1\}$; tmp2 $=$ transpose $(k t\{(i-1) * m+k, j+1\} . * \operatorname{deltaxt}\{(i-$

$1) * m+k, j+1\} . *(r f * v t\{i, j\}(k, 1))) * \operatorname{probt}\{(i-1) * m+k, j+1\}$; tmp3 =transpose $(k t\{(i-1) * m+k, j+1\} * * \operatorname{deltaxt}\{(i-$

$1) \star m+k, j+1\} . * h t\{(i-1) * m+k, j+1\}) * \operatorname{probt}\{(i-1) * m+k, j+1\}$; tetad $\{i, j\}(k, 1)=-(\operatorname{tmp} 2-\operatorname{tmp} 3) /(\operatorname{beta}(j+1) * \operatorname{tmp} 1)$; end end

end

for $i=1: m^{\wedge}(t t-1)$ 
for $k=1: m$

$\mathrm{vt}\{i, \mathrm{tt}+1\}(\mathrm{k}, 1)=\mathrm{rf} * \mathrm{vt}\{(\mathrm{floor}((\mathrm{i}-1) / \mathrm{m})+1), \mathrm{tt}\}(\bmod (i-$

$1, m)+1,1)+\operatorname{beta}(t t+1) * \operatorname{tetad}\{(f \operatorname{loor}((i-1) / m)+1)$, tt $\}(\bmod (i-$

$1, m)+1,1) * \operatorname{deltaxt}\{i, t t+1\}(k, 1)$;

end

end

- Execucao da estrategia

o Cálculo do hedge otimo dinamico e do portfolio replicante $\operatorname{atop}(:, 1)=\operatorname{seqs}(:, i i+(j j-1) * \operatorname{ser})$;

atop $(:, 2)=\operatorname{opcao}(:, i i+(j j-1) * \operatorname{ser}) ; \operatorname{opht}(1)=\operatorname{ht}\{1,1\}(1,1)$;

$\operatorname{atop}(1,1) * \operatorname{tetadr}(1)$;

$\operatorname{vtr}(1)=\operatorname{atop}(1,2) ; \operatorname{tetadr}(1)=\operatorname{tetad}\{1,1\}(1,1) ; \operatorname{bank}(1)=\operatorname{atop}(1,2)-$

$\operatorname{err}(1)=\operatorname{vtr}(1)-\operatorname{atop}(1,2) ;$

$\mathrm{py}=1 ; \mathrm{pk}=1$;

\% Determinacao do no da arvore correspondente ao preco real

for $j=2: t t$

dif $=100000 ; \mathrm{py}=(\mathrm{py}-1) * \mathrm{~m}+\mathrm{pk}$;

for $\mathrm{k}=1: \mathrm{m}$

if $(\operatorname{abs}(\operatorname{atop}(j, 1)-\operatorname{precos}\{\operatorname{py}, j\}(k, 1))<\operatorname{dif})$

dif $=a b s(\operatorname{atop}(j, 1)-\operatorname{precos}\{p y, j\}(k, 1))$;

$\mathrm{pk}=\mathrm{k}$;

end

end

replicante

\% Identificacao do hedge e calculo do portfolio

tetadr $(j)=$ tetad $\{\mathrm{py}, j\}(\mathrm{pk}, 1)$;

$\operatorname{vtr}(j)=\operatorname{tetadr}(j-1) * \operatorname{atop}(j, 1)+\operatorname{bank}(j-1) * r f ;$

$\operatorname{bank}(j)=-\operatorname{tetadr}(j) * \operatorname{atop}(j, 1)+\operatorname{vtr}(j)$;

opht $(j)=h t\{p y, j\}(p k, 1)$;

end

$\operatorname{err}(j)=\operatorname{vtr}(j)-\operatorname{atop}(j, 2)$;

dif $=100000 ; p y=(p y-1) * m+p k$;

for $\mathrm{k}=1: \mathrm{m}$

if $(\operatorname{abs}(\operatorname{atop}(t t+1,1)-p r e c o s\{p y, t t+1\}(k, 1))<$ dif)

dif $=a b s(\operatorname{atop}(t t+1,1)-\operatorname{precos}\{p y, t t+1\}(k, 1))$; $\mathrm{pk}=\mathrm{k}$;

end

end

$\operatorname{vtr}(t t+1)=\operatorname{tetadr}(t t) * a t o p(t t+1,1)+$ bank $(t t) * r f ;$

opht $(t t+1)=\max (\operatorname{atop}(t t+1,1)-\operatorname{skp}(t t+1), 0)$;

$\operatorname{err}(t t+1)=\operatorname{vtr}(t t+1)-\operatorname{atop}(t t+1,2)$;

\% Armazenamento do portfolio replicante opcao e hedge

hedge $\left(:, i i+(j j-1){ }^{*}\right.$ ser $)=$ transpose $($ tetadr $)$;

bankac $(:, i i+(j j-1) *$ ser $)=$ transpose $($ bank $)$;

$\operatorname{pr}(:, i i+(j j-1) *$ ser $)=$ transpose (vtr);

$\operatorname{herr}(:, i i+(j j-1) *$ ser $)=$ transpose $(\operatorname{err})$;

end

opac $(:, i i+(j j-1) *$ ser $)=$ transpose (opht) ;

end

- Gravacao dos dados modelo HNGARCH

xlswrite ('HedgeAC.xls', hedge, 'HNGARCHHedgeAC' ) ;

xlswrite ('HedgeAC.xls', bankac, 'HNGARCHBankAC' );

xlswrite ('HedgeAC.xls', opac, 'HNGARCHOpAC' );

xlswrite ('HedgeAC.xls', pr, 'HNGARCHPRepAC' );

xlswrite ('HedgeAC.xls', herr, 'HNGARCHHErrAC' ) ;

xlswrite ('HedgeAC.xls', rmesre $\{1,1\}(1,1)$, 'HNGARCHRMESREAC' ) ;

clear pr;clear opac;

clear vest1; clear estadosi;clear precos;clear precosdesc; clear

deltaxt;

clear probt;clear retdesc;clear kt;clear ht;clear vt;clear

tetad; clear rmesre; 


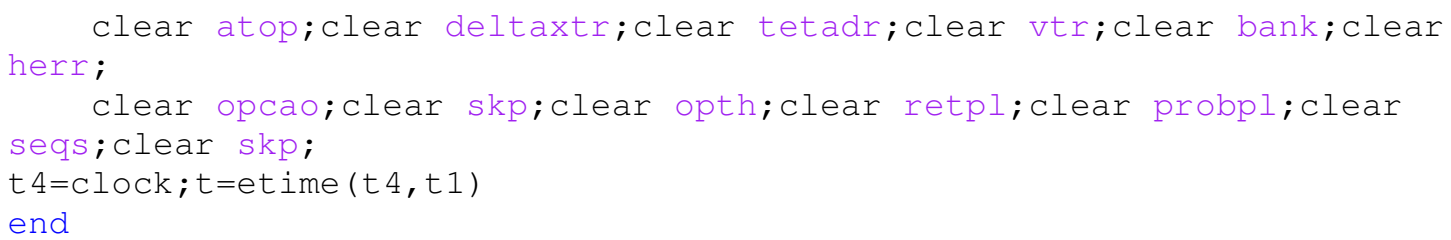

\subsection{Programa para estimação do modelo HN}

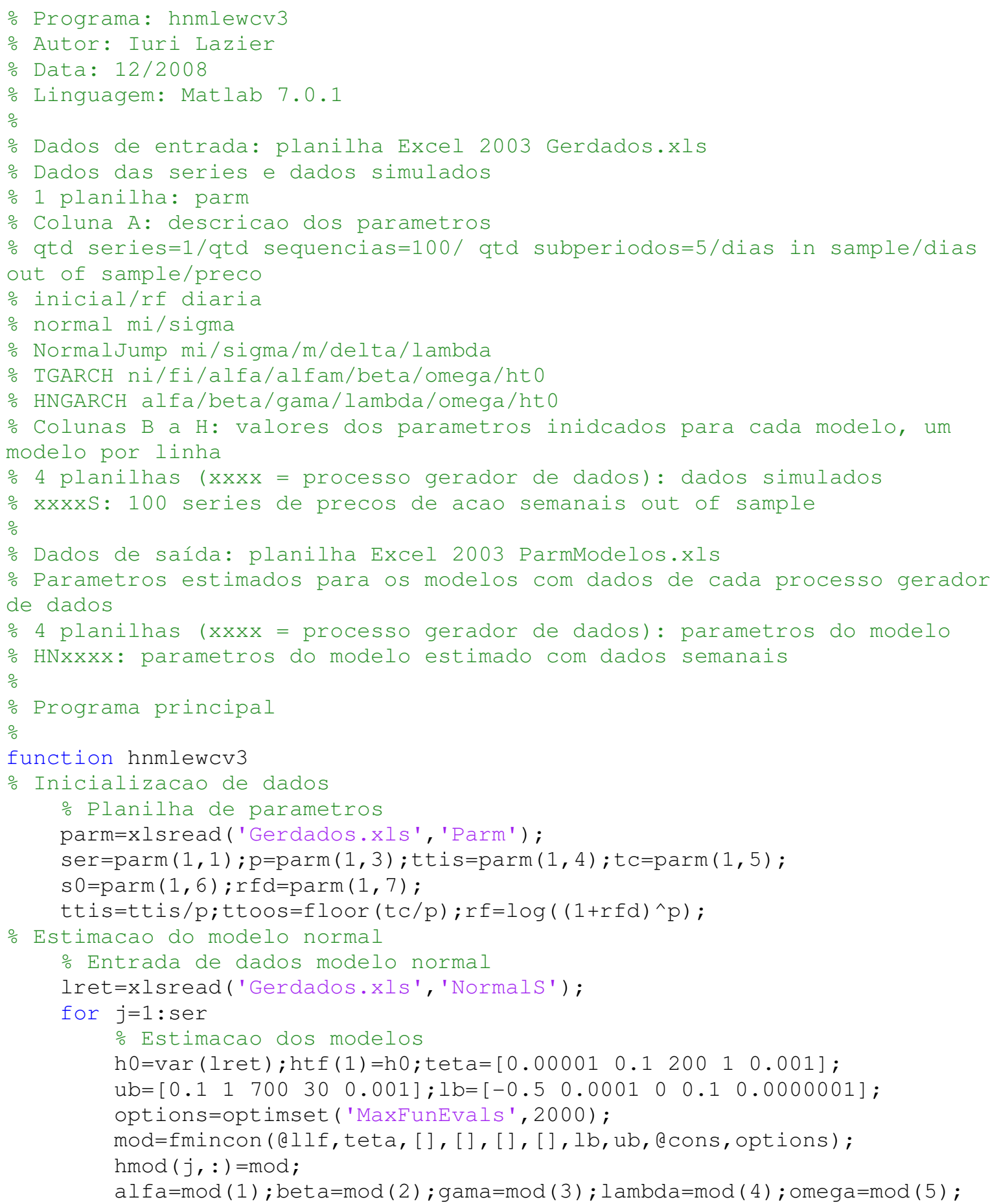


end

- Gravacao dos parametros do modelo

xlswrite ('ParmModelos.xls', hmod, 'HNNormal' ) ;

o Estimacao do modelo normal com jumps

\% Entrada de dados modelo normal com jumps

lret $=x l$ sread ('Gerdados.xls', 'NormalJumps' ) ;

for $j=1$ : ser

- Estimacao dos modelos

h0=var (lret); htf $(1)=$ h0; teta $=\left[\begin{array}{llllll}0.00001 & 0.1 & 100 & 1 & 0.001\end{array}\right]$;

$\mathrm{ub}=\left[\begin{array}{lllll}0.1 & 1 & 700 & 30 & 0.001\end{array}\right] ; \mathrm{l} b=\left[\begin{array}{lllll}-0.1 & 0.0001 & 0 & 0.1 & 0.0000001\end{array}\right]$;

options=optimset ( 'MaxFunEvals' , 2000);

mod=fmincon ( allf, teta, [], [], [], [], lb, ub, acons, options) ;

$\operatorname{hmod}(j,:)=\bmod$;

alfa=mod ( 1 ); bet $a=\bmod (2) ; \operatorname{gama}=\bmod (3) ; l$ ambda=mod ( 4 ) ; omega=mod ( 5 ) ;

end

- Gravacao dos parametros do modelo

xlswrite ('ParmModelos.xls', hmod, 'HNNormalJump' ) ;

- Estimacao do modelo TGARCH

\% Entrada de dados modelo TGARCH

lret $=x l$ sread ('Gerdados.xls', 'TGARCHS' ) ;

for $j=1$ : ser

o Estimacao dos modelos

h0=var (lret); htf $(1)=$ h0; teta $=\left[\begin{array}{llllll}0.00001 & 0.1 & 80 & 1 & 0.001\end{array}\right]$;

$\mathrm{ub}=\left[\begin{array}{llllll}0.1 & 1 & 700 & 30 & 0.001\end{array}\right] ; \mathrm{l}=\left[\begin{array}{lllll}-0.1 & 0.0001 & 0 & 0.1 & 0.0000001\end{array}\right]$;

options=optimset ( 'MaxFunEvals', 2000);

mod=fmincon ( @llf, teta, [], [], [ ], [ ], lb, ub, econs, options) ;

$\operatorname{hmod}(j,:)=\bmod$;

alfa=mod ( 1 ) ; beta=mod (2) ; gama=mod (3) ; lambda=mod ( 4 ) ; omega=mod (5) ;

end

\% Gravacao dos parametros do modelo

xlswrite ('ParmModelos.xls', hmod, 'HNTGARCH' ) ;

- Estimacao do modelo HNGARCH

o Entrada de dados modelo HNGARCH

lret $=x l$ sread ('Gerdados.xls', 'HNGARCHS' ) ;

for $j=1$ : ser

\% Estimacao dos modelos

h0=var (lret); htf (1)=h0; teta $=\left[\begin{array}{llllll}0.00001 & 0.1 & 100 & 0.001\end{array}\right]$;

$\mathrm{ub}=\left[\begin{array}{llllll}0.1 & 1 & 700 & 30 & 0.001\end{array} ; 1 \mathrm{~b}=\left[\begin{array}{llllll}-0.1 & 0.0001 & 0 & 0.1 & 0.0000001\end{array}\right] ;\right.$

options=optimset ( 'MaxFunEvals', 2000);

mod=fmincon ( @llf, teta, [], [], [], [], lb, ub, acons, options) ;

$\operatorname{hmod}(j,:)=\bmod$;

alfa $=\bmod (1) ;$ bet $a=\bmod (2) ; \operatorname{gama}=\bmod (3) ; l \operatorname{ambda}=\bmod (4) ; \operatorname{omega}=\bmod (5)$;

end

- Gravacao dos parametros do modelo

xlswrite ('ParmModelos.xls', hmod, 'HNHNGARCH' );

function $r=l$ lf (teta)

for $i=2:$ ttis +1

htf $(i)=\operatorname{teta}(5)+\operatorname{teta}(2) * h t f(i-1)-\operatorname{teta}(1) *(((\operatorname{lret}(i-1)-r f-$

teta $(4) * \operatorname{htf}(i-1)-\operatorname{teta}(3) * \operatorname{htf}(i-1)) \wedge 2) / \operatorname{htf}(i-1))$;

end

$r=-(-(1 / 2) * \operatorname{sum}(\log ($ htf $))-($ ttis $/ 2) * \log (2 * p i)-(1 / 2) * \operatorname{sum}((($ lret $-r f-$

teta (4) . *transpose (htf)) .^2)./transpose (htf)));

end

function [c ceq] $=$ cons (teta)

$c=\left[-\operatorname{htf}+0.0000001 \operatorname{teta}(2)+\operatorname{teta}(1) *\left((\operatorname{teta}(3))^{\wedge} 2\right)-1\right] ; \operatorname{ceq}=[] ;$ end

end 


\subsection{Programa para teste da estratégia $\mathrm{HN}$}

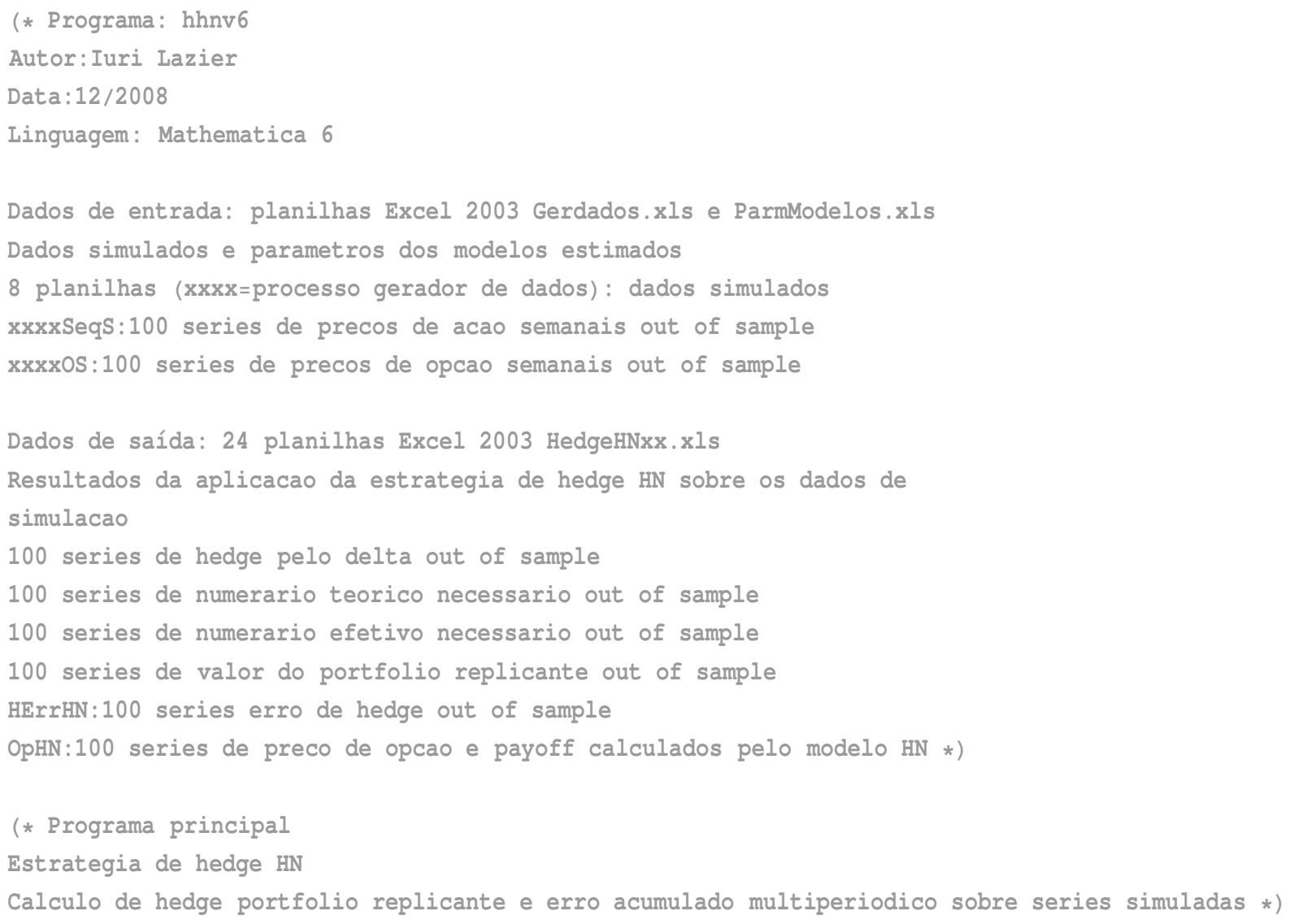


(* Inicializacao de dados

Arquivo Gerdados.xls

Planilha de parametros do modelo primeira linha quantidade de series in-

sample quantidade de sequencias out-of-sample numero de dias do subperiodo numero de dias insample numero de dias out-of sample preco inicial taxa livre de risco dia util em seguida uma linha para cada serie de cada modelo

Sequencia de planilhas para cada um dos modelos normal normal com jumps tgarch

e hngarch contendo retornos diarios in-sample precos diarios in-sample retornos diarios ourof-sample retornos semanais out-of-sample precos semanais out-

of sample precos de opcao semanais out-of-sample termos autorregressivos in-

sample para os modelos tgarch e hngarch

Arquivo ParmModelos.xls

Planilha de parametros do modelo HN estimado para retornos semanais in-

sample para series correspondentes aos modelos geradores normal normal com jumps

tgarch hngarch *)

(* Funcao Caracteristica *)

$a\left[t t_{-}, t t o o s 1_{-}, \varphi_{-}, r_{-}\right]:=$

$\left(a[t t+1, t \operatorname{toos} 1, \varphi, r f]+\varphi \mathrm{rf}+\mathrm{b}[t t+1, t \operatorname{toos} 1, \varphi] \omega-\frac{1}{2} \log [1-2 \alpha b[t t+1, t t o o s 1, \varphi]]\right)$

$\mathrm{b}\left[t t_{-}, t \operatorname{toos} 1_{-}, \varphi_{-}\right]:=\left(\varphi(\lambda+\gamma)-\frac{1}{2} \gamma^{2}+\beta \mathrm{b}[t t+1, t \cos 1, \varphi]+\frac{(1 / 2)(\varphi-\gamma)^{2}}{1-2 \alpha \mathrm{b}[t t+1, t \cos 1, \varphi]}\right)$

$\mathrm{c} 1\left[t t_{-}, t t o o s 1_{-}, s t_{-}, k k_{-}, r f_{-}, h t 1_{-}\right]:=$

$\left(\frac{1}{2} s t+\frac{\operatorname{Exp}[-r f(t t o o s 1-t t)]}{\pi}\right.$

NIntegrate $\left[\operatorname{Re}\left[\frac{k k^{-\dot{i} \phi} s t^{\dot{\mathbf{i}} \phi+1} \operatorname{Exp}[a[t t, t \operatorname{coos} 1, \dot{\mathbf{i}} \phi+1, r f]+\mathrm{b}[t t, t t o o s 1, \dot{\mathbf{i}} \phi+1] h t 1]}{\dot{\mathbf{i}} \phi}\right]\right.$,

$\{\phi, 0, \infty\}$, Method $\rightarrow\{$ "GlobalAdaptive", "MaxErrorIncreases" $\rightarrow 500000$,

"SingularityHandler" $\rightarrow$ Automatic $\}$, MaxRecursion $\rightarrow 28$, PrecisionGoal $\rightarrow$ 8]

$\mathrm{c} 2\left[t t_{-}, t t o o s 1_{-}, s t_{-}, k k_{-}, r f_{-}, h t 1_{-}\right]:=$

$(k k \operatorname{Exp}[-r f(t t o o s 1-t t)]$

$\left(\frac{1}{2}+\frac{1}{\pi}\right.$ NIntegrate $\left[\operatorname{Re}\left[\frac{k k^{-\dot{\mathbf{r}} \phi} s t^{\dot{\mathbf{i}} \phi} \operatorname{Exp}[a[t t, t t o o s 1, \dot{\mathbf{i}} \phi, r f]+b[t t, t t o o s 1, \dot{\mathbf{i}} \phi] h t 1]}{\dot{\mathbf{i}} \phi}\right]\right.$,

$\{\phi, 0, \infty\}$, Method $\rightarrow\{$ "GlobalAdaptive", "MaxErrorIncreases" $\rightarrow 500000$,

"SingularityHandler" -> Automatic\}, MaxRecursion $\rightarrow$ 28, PrecisionGoal $\rightarrow$ 8]))

(* Entrada de dados - todos os modelos *)

parm = Import ["Gerdados.xls", "XLS"];

ser $=\operatorname{parm}[[1,1,2]] ; \operatorname{seq}=\operatorname{parm}[[1,1,3]] ; p=\operatorname{parm}[[1,1,4]] ;$ ttis = parm $[[1,1,5]]$;

tc $=\operatorname{parm}[[1,1,6]] ; \mathrm{s} 0=\operatorname{parm}[[1,1,7]] ; \operatorname{rfd}=\operatorname{parm}[[1,1,8]]$;

ttoos $=$ Floor $[t c / p] ;$ ttoos $1=$ ttoos $+1 ; r f=\log \left[(1+r f d)^{\wedge} p\right]$; ttis = ttis $/ p$;

modelos = Import $[$ "ParmModelos.xls", "XLS"];

normal $=\operatorname{modelos}[[2,1]] ; \operatorname{normal} j u m p=\operatorname{modelos}[[3,1]] ; \operatorname{tgarch}=\operatorname{modelos}[[4,1]] ;$

hngarch $=\operatorname{modelos}[[5,1]]$; 


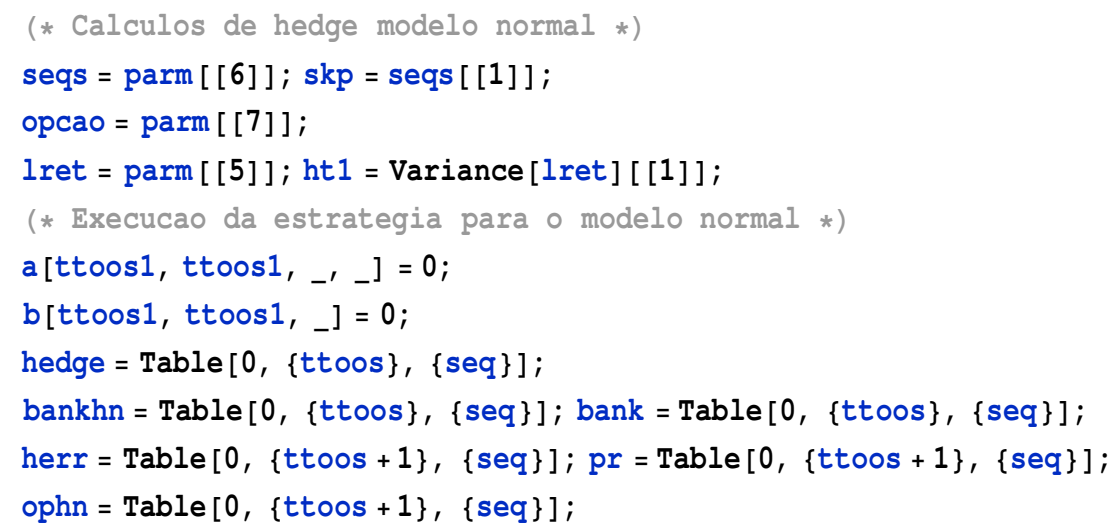

For $[j=1, j \leq \operatorname{ser}, j++, \alpha=\operatorname{normal}[[1]] ; \beta=\operatorname{normal}[[2]] ; \gamma=\operatorname{normal}[[3]]+\operatorname{normal}[[4]]+0.5$;

$\lambda=-0.5 ; \omega=\operatorname{normal}[[5]] ;$ For $[i=1, i \leq \operatorname{seq}, i++, t t=1 ; \operatorname{st}=\operatorname{seqs}[[1,(j-1) * \operatorname{ser}+i]] ;$

$\mathrm{kk}=\operatorname{skp}[[(j-1) * \operatorname{ser}+i]] ;$ integ $=\operatorname{Re}[\mathrm{c} 1[t t, t$ toos1, st, kk, rf, ht1] $]$;

hedge $[1,(j-1) * \operatorname{ser}+i]]=$ integ $/ \operatorname{segs}[[1,(j-1) * \operatorname{ser}+i]]$;

integ $=\operatorname{Re}[\mathrm{c} 2[\mathrm{tt}, \mathrm{ttoos} 1, \mathrm{st}, \mathrm{kk}, \mathrm{rf}, \mathrm{ht1}]] ;$ bankhn $[1,(j-1) * \operatorname{ser}+i]]=-$ integ;

$\operatorname{ophn}[[1,(j-1) * \operatorname{ser}+i]]=\operatorname{seqs}[[1, i+(j-1) * \operatorname{ser}]] *$ hedge $[1,(j-1) * \operatorname{ser}+i]]+$

$\operatorname{bankhn}[[1,(j-1) * \operatorname{ser}+i]] ; \operatorname{pr}[[1,(j-1) * \operatorname{ser}+i]]=$ opcao $[[1, i+(j-1) * \operatorname{ser}]] ;$

$\operatorname{bank}[[1,(j-1) * \operatorname{ser}+i]]=-\operatorname{hedge}[[1,(j-1) * \operatorname{ser}+i]] * \operatorname{seqs}[[1, i+(j-1) * \operatorname{ser}]]+$

$\operatorname{pr}[[1, i+(j-1) * \operatorname{ser}]]$;

$\operatorname{herr}[[1,(j-1) * \operatorname{ser}+i]]=\operatorname{pr}[[1,(j-1) * \operatorname{ser}+i]]-$ opcao $[[1,(j-1) * \operatorname{ser}+i]] ;$

For $[k=2, k \leq t$ toos,$k++, t t=k ; \operatorname{st~}=\operatorname{seqs}[[k,(j-1) * \operatorname{ser}+i]] ; k k=\operatorname{skp}[[(j-1) * \operatorname{ser}+i]]$;

$\left.\operatorname{lr}=\log \left[\operatorname{seqs}\left[k_{,}(j-1) * \operatorname{ser}+i\right]\right] / \operatorname{seqs}[[k-1,(j-1) * \operatorname{ser}+i]]\right] ; \operatorname{lret}[[1]]=\{l r\} ;$

lret $=\operatorname{RotateLeft}[$ lret $] ;$ ht1 $=\operatorname{Variance}[$ lret $][1]] ;$ integ $=\operatorname{Re}[\mathrm{cl}[\mathrm{tt}$, ttoos1, st, kk, rf, ht1] ] ;

hedge $[k,(j-1) * \operatorname{ser}+i]]=$ integ $/ \operatorname{segs}[[k,(j-1) * \operatorname{ser}+i]]$;

integ $=\operatorname{Re}[\mathrm{c} 2[t \mathrm{t}, \mathrm{ttoos} 1, \mathrm{st}, \mathrm{kk}, \mathrm{rf}, \mathrm{ht} 1]] ;$ bankhn$[[\mathrm{k},(j-1) * \operatorname{ser}+i]]=-$ integ;

$\operatorname{ophn}[[k,(j-1) * \operatorname{ser}+i]]=\operatorname{seqs}[[k, i+(j-1) * \operatorname{ser}]] *$ hedge $[k,(j-1) * \operatorname{ser}+i]]+$

bankhn $[k,(j-1) * \operatorname{ser}+i]]$;

$\operatorname{pr}[k,(j-1) * \operatorname{ser}+i]]=\operatorname{hedge}[[k-1,(j-1) * \operatorname{ser}+i]] * \operatorname{segs}[[k,(j-1) * \operatorname{ser}+i]]+$

$\operatorname{bank}[[k-1,(j-1) * \operatorname{ser}+i]] *(1+r f)$;

$\operatorname{bank}[k,(j-1) * \operatorname{ser}+i]]=-\operatorname{hedge}[[k,(j-1) * \operatorname{ser}+i]] * \operatorname{segs}[[k, i+(j-1) * \operatorname{ser}]]+$

$\operatorname{pr}[k,(j-1) * \operatorname{ser}+i]] ;$

$\operatorname{herr}[[k, i+(j-1) * \operatorname{ser}]]=\operatorname{pr}[[k, i+(j-1) * \operatorname{ser}]]-$ opcao $[[k, i+(j-1) * \operatorname{ser}]]] ;$

$\operatorname{pr}[[$ ttoos $+1,(j-1) * \operatorname{ser}+i]]=$ hedge $[$ ttoos, $(j-1) * \operatorname{ser}+i]] * \operatorname{seqs}[[$ ttoos $+1, i+(j-1) * \operatorname{ser}]]+$ bank [ [ttoos, $(j-1) * \operatorname{ser}+i]] *(1+r f)$;

ophn $[[$ ttoos $+1,(j-1) * \operatorname{ser}+i]]=\operatorname{Max}[\operatorname{seqs}[[t t o o s+1, i+(j-1) * \operatorname{ser}]]-\operatorname{skp}[[(j-1) * \operatorname{ser}+i]], 0]$;

herr $[[$ ttoos $+1,(j-1) * \operatorname{ser}+i]]=$

$\operatorname{pr}[[$ ttoos $+1,(j-1) * \operatorname{ser}+i]]-$ opcao $[$ ttoos $+1,(j-1) *$ ser $+i]]]]$;

(* Gravacao de dados modelo normal *)

Export ["HedgeHN11.xls", pr, \{"Sheets", "NormalPRepHN"\}];

Export ["HedgeHN12.xls", hedge, \{"Sheets", "NormalHedgeHN"\}] ;

Export ["HedgeHN13.xls", bankhn, \{"Sheets", "NormalBankFHN"\}];

Export ["HedgeHN14.xls", bank, \{"Sheets", "NormalBankHN"\}];

Export ["HedgeHN15.xls", herr, \{"Sheets", "NormalHErrHN"\}];

Export ["HedgeHN16.xls", ophn, \{"Sheets", "NormalOpHN"\}];

Remove ["Global ‘ *] 
(* Inicializacao de dados

Arquivo Gerdados.xls

Planilha de parametros do modelo primeira linha quantidade de series in-

sample quantidade de sequencias out-of-sample numero de dias do subperiodo numero de dias insample numero de dias out-of sample preco inicial taxa livre de risco dia util em

seguida uma linha para cada serie de cada modelo

Sequencia de planilhas para cada um dos modelos normal normal com jumps tgarch

e hngarch contendo retornos diarios in-sample precos diarios in-sample retornos diarios ourof-sample retornos semanais out-of-sample precos semanais out-

of sample precos de opcao semanais out-of-sample termos autorregressivos in-

sample para os modelos tgarch e hngarch

Arquivo ParmModelos.xls

Planilha de parametros do modelo HN estimado para retornos semanais in-

sample para series correspondentes aos modelos geradores normal normal com jumps

tgarch hngarch *)

(* Funcao Caracteristica *)

$a\left[t t_{-}, t t o o s 1_{-}, \varphi_{-}, r_{-}\right]:=$

$\left(a[t t+1, t \operatorname{toos} 1, \varphi, \mathrm{rf}]+\varphi \mathrm{rf}+\mathrm{b}[t t+1, t \operatorname{toos} 1, \varphi] \omega-\frac{1}{2} \log [1-2 \alpha \mathrm{b}[t t+1, t t o o s 1, \varphi]]\right)$

$\mathrm{b}\left[t t_{-}, t \operatorname{toos} 1_{-}, \varphi_{-}\right]:=\left(\varphi(\lambda+\gamma)-\frac{1}{2} \gamma^{2}+\beta \mathrm{b}[t t+1, t \cos 1, \varphi]+\frac{(1 / 2)(\varphi-\gamma)^{2}}{1-2 \alpha \mathrm{b}[t t+1, t \cos 1, \varphi]}\right)$

$\mathrm{c} 1\left[t t_{-}, t t o o s 1_{-}, s t_{-}, k k_{-}, r f_{-}, h t 1_{-}\right]:=$

$\left(\frac{1}{2} s t+\frac{\operatorname{Exp}[-r f(t t o o s 1-t t)]}{\pi}\right.$

NIntegrate $\left[\operatorname{Re}\left[\frac{k k^{-\dot{i} \phi} s t^{\dot{\mathbf{i}} \phi+1} \operatorname{Exp}[a[t t, t t o o s 1, \dot{\mathbf{i}} \phi+1, r f]+b[t t, t t o o s 1, \dot{\mathbf{i}} \phi+1] h t 1]}{\dot{\mathbf{i}} \phi}\right]\right.$,

$\{\phi, 0, \infty\}$, Method $\rightarrow\{$ "GlobalAdaptive", "MaxErrorIncreases" $\rightarrow 500000$,

"SingularityHandler" $\rightarrow$ Automatic $\}$, MaxRecursion $\rightarrow 28$, PrecisionGoal $\rightarrow 8$ ]

$\mathrm{c} 2\left[t t_{-}, t t o o s 1_{-}, s t_{-}, k k_{-}, r f_{-}, h t 1_{-}\right]:=$

$(k k \operatorname{Exp}[-r f(t t o o s 1-t t)]$

$\left(\frac{1}{2}+\frac{1}{\pi}\right.$ NIntegrate $\left[\operatorname{Re}\left[\frac{k k^{-\dot{i} \phi} s t^{\dot{\mathbf{i}} \phi} \operatorname{Exp}[a[t t, t t o o s 1, \dot{\mathbf{n}} \phi, r f]+b[t t, t t o o s 1, \dot{\mathbf{i}} \phi] h t 1]}{\dot{\mathbf{i}} \phi}\right]\right.$,

$\{\phi, 0, \infty\}$, Method $\rightarrow\{$ "GlobalAdaptive", "MaxErrorIncreases" $\rightarrow 500000$,

"SingularityHandler" -> Automatic $\}$, MaxRecursion $\rightarrow 28$, PrecisionGoal $\rightarrow$ 8])

(* Entrada de dados - todos os modelos *)

parm = Import ["Gerdados.xls", "XLS"];

$\operatorname{ser}=\operatorname{parm}[[1,1,2]] ; \operatorname{seq}=\operatorname{parm}[[1,1,3]] ; p=\operatorname{parm}[[1,1,4]] ;$ ttis $=\operatorname{parm}[[1,1,5]]$;

tc $=\operatorname{parm}[[1,1,6]] ; s 0=\operatorname{parm}[[1,1,7]] ; \operatorname{rfd}=\operatorname{parm}[[1,1,8]]$;

ttoos $=$ Floor $[t c / p] ;$ ttoos $1=$ ttoos $+1 ; r f=\log \left[(1+r f d)^{\wedge} p\right]$; ttis = ttis $/ p$;

modelos = Import $[$ "ParmModelos.xls", "XLS"];

normal $=\operatorname{modelos}[[2,1]] ; \operatorname{normal}$ jump $=\operatorname{modelos}[[3,1]] ; \operatorname{tgarch}=\operatorname{modelos}[[4,1]] ;$

hngarch $=\operatorname{modelos}[[5,1]]$; 


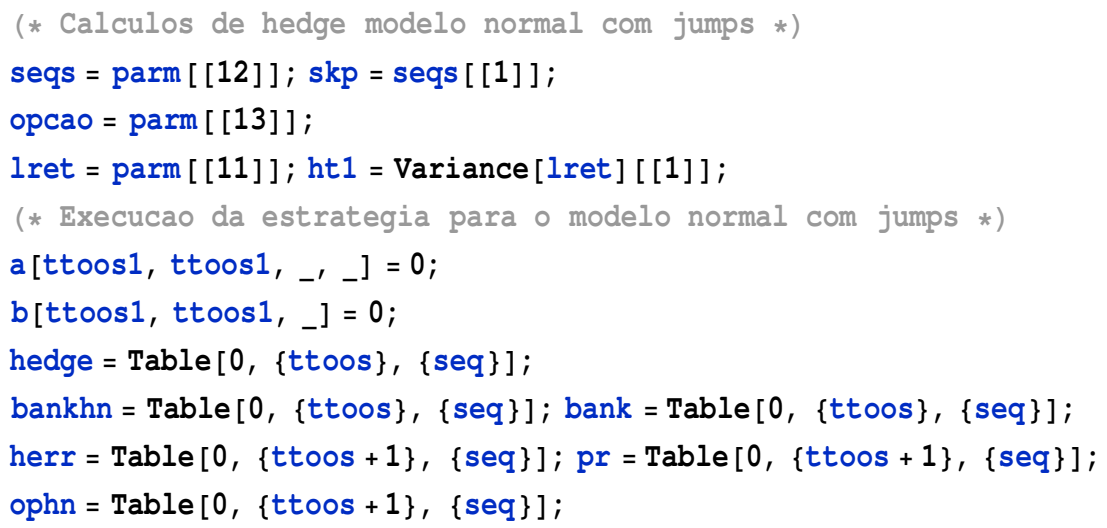

For $[j=1, j \leq \operatorname{ser}, j++, \alpha=\operatorname{normal}[[1]] ; \beta=\operatorname{normal}[[2]] ; \gamma=\operatorname{normal}[[3]]+\operatorname{normal}[[4]]+0.5$;

$\lambda=-0.5 ; \omega=\operatorname{normal}[[5]] ;$ For $[i=1, i \leq \operatorname{seq}, i++, t t=1 ; \operatorname{st}=\operatorname{seqs}[[1,(j-1) * \operatorname{ser}+i]] ;$

$\mathrm{kk}=\operatorname{skp}[[(j-1) * \operatorname{ser}+i]] ;$ integ $=\operatorname{Re}[\mathrm{c} 1[t t, t t o o s 1, s t, \mathrm{kk}, \mathrm{rf}, \mathrm{ht} 1]] ;$

hedge $[1,(j-1) * \operatorname{ser}+i]]=$ integ $/ \operatorname{segs}[[1,(j-1) * \operatorname{ser}+i]]$;

integ $=\operatorname{Re}[\mathrm{c} 2[t t, \mathrm{ttoos} 1, \mathrm{st}, \mathrm{kk}, \mathrm{rf}, \mathrm{ht1}]] ; \operatorname{bankhn}[[1,(j-1) * \operatorname{ser}+i]]=-$ integ ;

$\operatorname{ophn}[[1,(j-1) * \operatorname{ser}+i]]=\operatorname{segs}[[1, i+(j-1) * \operatorname{ser}]] *$ hedge $[[1,(j-1) * \operatorname{ser}+i]]+$

bankhn $[[1,(j-1) * \operatorname{ser}+i]] ; \operatorname{pr}[[1,(j-1) * \operatorname{ser}+i]]=$ opcao $[[1, i+(j-1) * \operatorname{ser}]] ;$

$\operatorname{bank}[[1,(j-1) * \operatorname{ser}+i]]=-\operatorname{hedge}[[1,(j-1) * \operatorname{ser}+i]] * \operatorname{seqs}[[1, i+(j-1) * \operatorname{ser}]]+$

$\operatorname{pr}[[1, i+(j-1) * \operatorname{ser}]]$;

$\operatorname{herr}[[1,(j-1) * \operatorname{ser}+i]]=\operatorname{pr}[[1,(j-1) * \operatorname{ser}+i]]-$ opcao $[[1,(j-1) * \operatorname{ser}+i]] ;$

For $[k=2, k \leq t$ toos, $k++, t t=k ; \operatorname{st~}=\operatorname{segs}[[k,(j-1) * \operatorname{ser}+i]] ; k k=\operatorname{skp}[[(j-1) * \operatorname{ser}+i]]$;

$l r=\log [\operatorname{seqs}[[k,(j-1) * \operatorname{ser}+i]] / \operatorname{seqs}[[k-1,(j-1) * \operatorname{ser}+i]]] ; \operatorname{lret}[[1]]=\{1 r\} ;$

lret $=\operatorname{RotateLeft}[$ lret $] ;$ ht1 $=\operatorname{Variance}[$ lret $][1]] ;$ integ $=\operatorname{Re}[\mathrm{cl}[\mathrm{tt}$, ttoos1, st, kk, rf, ht1] ] ;

hedge $[k,(j-1) * \operatorname{ser}+i]]=$ integ $/ \operatorname{segs}[[k,(j-1) * \operatorname{ser}+i]]$;

integ $=\operatorname{Re}[\mathrm{c} 2[t \mathrm{t}, \mathrm{ttoos} 1, \mathrm{st}, \mathrm{kk}, \mathrm{rf}, \mathrm{ht} 1]] ;$ bankhn$[[\mathrm{k},(j-1) * \operatorname{ser}+i]]=-$ integ;

$\operatorname{ophn}[[k,(j-1) * \operatorname{ser}+i]]=\operatorname{seqs}[[k, i+(j-1) * \operatorname{ser}]] *$ hedge $[k,(j-1) * \operatorname{ser}+i]]+$

bankhn $[k,(j-1) * \operatorname{ser}+i]]$;

$\operatorname{pr}[[k,(j-1) * \operatorname{ser}+i]]=\operatorname{hedge}[[k-1,(j-1) * \operatorname{ser}+i]] * \operatorname{segs}[[k,(j-1) * \operatorname{ser}+i]]+$

$\operatorname{bank}[[k-1,(j-1) * \operatorname{ser}+i]] *(1+r f)$;

$\operatorname{bank}[[k,(j-1) * \operatorname{ser}+i]]=-\operatorname{hedge}[[k,(j-1) * \operatorname{ser}+i]] * \operatorname{segs}[[k, i+(j-1) * \operatorname{ser}]]+$

$\operatorname{pr}[k,(j-1) * \operatorname{ser}+i]] ;$

$\operatorname{herr}[[k, i+(j-1) * \operatorname{ser}]]=\operatorname{pr}[[k, i+(j-1) * \operatorname{ser}]]-$ opcao $[[k, i+(j-1) * \operatorname{ser}]]] ;$

$\operatorname{pr}[[$ ttoos $+1,(j-1) * \operatorname{ser}+i]]=$ hedge $[$ ttoos, $(j-1) * \operatorname{ser}+i]] * \operatorname{seqs}[[$ ttoos $+1, i+(j-1) * \operatorname{ser}]]+$ bank [ [ttoos, $(j-1) *$ ser $+i]] *(1+\mathrm{rf})$;

ophn $[[$ ttoos $+1,(j-1) * \operatorname{ser}+i]]=\operatorname{Max}[\operatorname{seqs}[[t t o o s+1, i+(j-1) * \operatorname{ser}]]-\operatorname{skp}[[(j-1) * \operatorname{ser}+i]], 0]$;

herr $[$ ttoos $+1,(j-1) *$ ser $+i]]=$

$\operatorname{pr}[[$ ttoos $+1,(j-1) * \operatorname{ser}+i]]-$ opcao $[$ ttoos $+1,(j-1) * \operatorname{ser}+i]]]]$;

(* Gravacao de dados modelo normal com jumps *)

Export ["HedgeHN21.xls", pr, \{"Sheets", "NormalJumpPRepHN"\}] ;

Export ["HedgeHN22.xls", hedge, \{"Sheets", "NormalJumpHedgeHN"\}] ;

Export ["HedgeHN23.xls", bankhn, \{"Sheets", "NormalJumpBankFHN"\}];

Export ["HedgeHN24.xls", bank, \{"Sheets", "NormalJumpBankHN"\}] ;

Export ["HedgeHN25.xls", herr, \{"Sheets", "NormalJumpHErrHN"\}];

Export ["HedgeHN26.xls", ophn, \{"Sheets", "NormalJumpOpHN"\}] ;

Remove ["Global`*"] 
(* Inicializacao de dados

Arquivo Gerdados.xls

Planilha de parametros do modelo primeira linha quantidade de series in-

sample quantidade de sequencias out-of-sample numero de dias do subperiodo numero de dias insample numero de dias out-of sample preco inicial taxa livre de risco dia util em

seguida uma linha para cada serie de cada modelo

Sequencia de planilhas para cada um dos modelos normal normal com jumps tgarch

e hngarch contendo retornos diarios in-sample precos diarios in-sample retornos diarios ourof-sample retornos semanais out-of-sample precos semanais out-

of sample precos de opcao semanais out-of-sample termos autorregressivos in-

sample para os modelos tgarch e hngarch

Arquivo ParmModelos.xls

Planilha de parametros do modelo HN estimado para retornos semanais in-

sample para series correspondentes aos modelos geradores normal normal com jumps

tgarch hngarch *)

(* Funcao Caracteristica *)

$a\left[t t_{-}, t t o o s 1_{-}, \varphi_{-}, r_{-}\right]:=$

$\left(a[t t+1, t \operatorname{toos} 1, \varphi, \mathrm{rf}]+\varphi \mathrm{rf}+\mathrm{b}[t t+1, t \operatorname{toos} 1, \varphi] \omega-\frac{1}{2} \log [1-2 \alpha \mathrm{b}[t t+1, t t o o s 1, \varphi]]\right)$

$\mathrm{b}\left[t t_{-}, t \operatorname{toos} 1_{-}, \varphi_{-}\right]:=\left(\varphi(\lambda+\gamma)-\frac{1}{2} \gamma^{2}+\beta \mathrm{b}[t t+1, t \operatorname{toos} 1, \varphi]+\frac{(1 / 2)(\varphi-\gamma)^{2}}{1-2 \alpha \mathrm{b}[t t+1, t \cos 1, \varphi]}\right)$

$\mathrm{c} 1\left[t t_{-}, t t o o s 1_{-}, s t_{-}, k k_{-}, r f_{-}, h t 1_{-}\right]:=$

$\left(\frac{1}{2} s t+\frac{\operatorname{Exp}[-r f(t t o o s 1-t t)]}{\pi}\right.$

NIntegrate $\left[\operatorname{Re}\left[\frac{k k^{-\dot{i} \phi} s t^{\dot{\mathbf{i}} \phi+1} \operatorname{Exp}[a[t t, t t o o s 1, \dot{\mathbf{i}} \phi+1, r f]+b[t t, t t o o s 1, \dot{\mathbf{i}} \phi+1] h t 1]}{\dot{\mathbf{i}} \phi}\right]\right.$,

$\{\phi, 0, \infty\}$, Method $\rightarrow\{$ "GlobalAdaptive", "MaxErrorIncreases" $\rightarrow 500000$,

"SingularityHandler" $\rightarrow$ Automatic $\}$, MaxRecursion $\rightarrow 28$, PrecisionGoal $\rightarrow 8$ ])

$\mathrm{c} 2\left[t t_{-}, t t o o s 1_{-}, s t_{-}, k k_{-}, r f_{-}, h t 1_{-}\right]:=$

$(k k \operatorname{Exp}[-r f(t t o o s 1-t t)]$

$\left(\frac{1}{2}+\frac{1}{\pi}\right.$ NIntegrate $\left[\operatorname{Re}\left[\frac{k k^{-\dot{i} \phi} s t^{\dot{\mathbf{i}} \phi} \operatorname{Exp}[a[t t, t t o o s 1, \dot{\mathbf{n}} \phi, r f]+b[t t, t t o o s 1, \dot{\mathbf{i}} \phi] h t 1]}{\dot{\mathbf{i}} \phi}\right]\right.$,

$\{\phi, 0, \infty\}$, Method $\rightarrow\{$ "GlobalAdaptive", "MaxErrorIncreases" $\rightarrow 500000$,

"SingularityHandler" -> Automatic $\}$, MaxRecursion $\rightarrow 28$, PrecisionGoal $\rightarrow$ 8])

(* Entrada de dados - todos os modelos *)

parm = Import ["Gerdados.xls", "XLS"];

ser $=\operatorname{parm}[[1,1,2]]$; seq $=\operatorname{parm}[[1,1,3]] ; p=\operatorname{parm}[[1,1,4]]$; ttis = parm $[[1,1,5]]$;

tc $=\operatorname{parm}[[1,1,6]] ; \mathrm{s} 0=\operatorname{parm}[[1,1,7]] ; \operatorname{rfd}=\operatorname{parm}[[1,1,8]]$;

ttoos $=$ Floor $[$ tc $/ \mathrm{p}]$; ttoos $1=$ ttoos $+1 ; \mathrm{rf}=\log \left[(1+\mathrm{rfd})^{\wedge} \mathrm{p}\right]$; ttis = ttis / p;

modelos = Import $[$ "ParmModelos.xls", "XLS"];

normal $=\operatorname{modelos}[[2,1]] ;$ normal jump $=\operatorname{modelos}[[3,1]] ; \operatorname{tgarch}=\operatorname{modelos}[[4,1]]$;

hngarch $=\operatorname{modelos}[5,1]]$; 


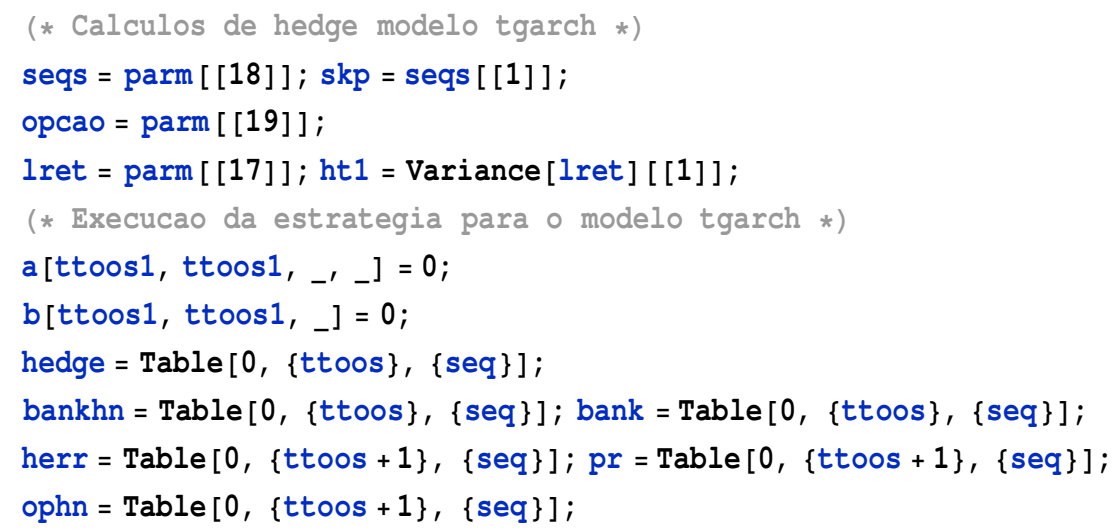

For $[j=1, j \leq \operatorname{ser}, j++, \alpha=\operatorname{normal}[[1]] ; \beta=\operatorname{normal}[[2]] ; \gamma=\operatorname{normal}[[3]]+\operatorname{normal}[[4]]+0.5$;

$\lambda=-0.5 ; \omega=\operatorname{normal}[[5]] ;$ For $[i=1, i \leq \operatorname{seq}, i++, t t=1 ; \operatorname{st}=\operatorname{seqs}[[1,(j-1) * \operatorname{ser}+i]] ;$

$\mathrm{kk}=\operatorname{skp}[[(j-1) * \operatorname{ser}+i]] ;$ integ $=\operatorname{Re}[\mathrm{c} 1[t t, t t o o s 1, s t, k k, r f, h t 1]] ;$

hedge $[1,(j-1) * \operatorname{ser}+i]]=$ integ $/ \operatorname{segs}[[1,(j-1) * \operatorname{ser}+i]]$;

integ $=\operatorname{Re}[\mathrm{c} 2[t t, \mathrm{ttoos} 1, \mathrm{st}, \mathrm{kk}, \mathrm{rf}, \mathrm{ht1}]] ; \operatorname{bankhn}[[1,(j-1) * \operatorname{ser}+i]]=-$ integ ;

$\operatorname{ophn}[[1,(j-1) * \operatorname{ser}+i]]=\operatorname{seqs}[[1, i+(j-1) * \operatorname{ser}]] *$ hedge $[1,(j-1) * \operatorname{ser}+i]]+$

$\operatorname{bankhn}[[1,(j-1) * \operatorname{ser}+i]] ; \operatorname{pr}[[1,(j-1) * \operatorname{ser}+i]]=$ opcao $[[1, i+(j-1) * \operatorname{ser}]] ;$

$\operatorname{bank}[[1,(j-1) * \operatorname{ser}+i]]=-\operatorname{hedge}[[1,(j-1) * \operatorname{ser}+i]] * \operatorname{segs}[[1, i+(j-1) * \operatorname{ser}]]+$

$\operatorname{pr}[[1, i+(j-1) * \operatorname{ser}]]$;

$\operatorname{herr}[[1,(j-1) * \operatorname{ser}+i]]=\operatorname{pr}[[1,(j-1) * \operatorname{ser}+i]]-$ opcao $[[1,(j-1) * \operatorname{ser}+i]] ;$

For $[k=2, k \leq t$ toos, $k++, t t=k ; \operatorname{st~}=\operatorname{segs}[[k,(j-1) * \operatorname{ser}+i]] ; k k=\operatorname{skp}[[(j-1) * \operatorname{ser}+i]]$;

$l r=\log [\operatorname{seqs}[[k,(j-1) * \operatorname{ser}+i]] / \operatorname{seqs}[[k-1,(j-1) * \operatorname{ser}+i]]] ; \operatorname{lret}[[1]]=\{1 r\} ;$

lret $=\operatorname{RotateLeft}[$ lret $] ;$ ht1 $=\operatorname{Variance}[$ lret $][1]] ;$ integ $=\operatorname{Re}[\mathrm{cl}[\mathrm{tt}$, ttoos1, st, kk, rf, ht1] ] ;

hedge $[k,(j-1) * \operatorname{ser}+i]]=$ integ $/ \operatorname{segs}[[k,(j-1) * \operatorname{ser}+i]]$;

integ $=\operatorname{Re}[\mathrm{c} 2[t \mathrm{t}, \mathrm{ttoos} 1, \mathrm{st}, \mathrm{kk}, \mathrm{rf}, \mathrm{ht} 1]] ;$ bankhn$[[\mathrm{k},(j-1) * \operatorname{ser}+i]]=-$ integ;

$\operatorname{ophn}[[k,(j-1) * \operatorname{ser}+i]]=\operatorname{segs}[[k, i+(j-1) * \operatorname{ser}]] *$ hedge $[k,(j-1) * \operatorname{ser}+i]]+$

bankhn $[k,(j-1) * \operatorname{ser}+i]]$;

$\operatorname{pr}[k,(j-1) * \operatorname{ser}+i]]=\operatorname{hedge}[[k-1,(j-1) * \operatorname{ser}+i]] * \operatorname{segs}[[k,(j-1) * \operatorname{ser}+i]]+$

$\operatorname{bank}[[k-1,(j-1) * \operatorname{ser}+i]] *(1+r f)$;

$\operatorname{bank}[[k,(j-1) * \operatorname{ser}+i]]=-\operatorname{hedge}[[k,(j-1) * \operatorname{ser}+i]] * \operatorname{segs}[[k, i+(j-1) * \operatorname{ser}]]+$

$\operatorname{pr}[k,(j-1) * \operatorname{ser}+i]]$;

$\operatorname{herr}[[k, i+(j-1) * \operatorname{ser}]]=\operatorname{pr}[[k, i+(j-1) * \operatorname{ser}]]-$ opcao $[[k, i+(j-1) * \operatorname{ser}]]] ;$

$\operatorname{pr}[[$ ttoos $+1,(j-1) * \operatorname{ser}+i]]=$ hedge $[$ ttoos, $(j-1) * \operatorname{ser}+i]] * \operatorname{seqs}[[$ ttoos $+1, i+(j-1) * \operatorname{ser}]]+$ bank [ [ttoos, $(j-1) *$ ser $+i]] *(1+$ rf $)$;

ophn $[$ ttoos $+1,(j-1) * \operatorname{ser}+i]]=\operatorname{Max}[\operatorname{seqs}[[t t o o s+1, i+(j-1) * \operatorname{ser}]]-\operatorname{skp}[[(j-1) * \operatorname{ser}+i]], 0]$;

herr $[[$ ttoos $+1,(j-1) * \operatorname{ser}+i]]=$

$\operatorname{pr}[[$ ttoos $+1,(j-1) * \operatorname{ser}+i]]-$ opcao $[$ ttoos $+1,(j-1) *$ ser $+i]]]]$;

(* Gravacao de dados modelo tgarch *)

Export ["HedgeHN31.xls", pr, \{"Sheets", "TGARCHPRepHN"\}] ;

Export ["HedgeHN32.xls", hedge, \{"Sheets", "TGARCHHedgeHN"\}] ;

Export ["HedgeHN33.xls", bankhn, \{"Sheets", "TGARCHBankFHN"\}];

Export ["HedgeHN34.xls", bank, \{"Sheets", "TGARCHBankHN"\}];

Export ["HedgeHN35.xls", herr, \{"Sheets", "TGARCHHErrHN"\}];

Export ["HedgeHN36.xls", ophn, \{"Sheets", "TGARCHOpHN"\}] ; 
Remove ["Global '*"]

(* Inicializacao de dados

Arquivo Gerdados.xls

Planilha de parametros do modelo primeira linha quantidade de series in-

sample quantidade de sequencias out-of-sample numero de dias do subperiodo numero de dias insample numero de dias out-of sample preco inicial taxa livre de risco dia util em seguida uma linha para cada serie de cada modelo

Sequencia de planilhas para cada um dos modelos normal normal com jumps tgarch

e hngarch contendo retornos diarios in-sample precos diarios in-sample retornos diarios ourof-sample retornos semanais out-of-sample precos semanais out-

of sample precos de opcao semanais out-of-sample termos autorregressivos in-

sample para os modelos tgarch e hngarch

Arquivo ParmModelos.xls

Planilha de parametros do modelo HN estimado para retornos semanais in-

sample para series correspondentes aos modelos geradores normal normal com jumps

tgarch hngarch *)

(* Funcao Caracteristica *)

$a\left[t t_{-}, t t o o s 1_{-}, \varphi_{-}, r_{-}\right]:=$

$\left(a[t t+1, t \cos 1, \varphi, r f]+\varphi r f+b[t t+1, t \cos 1, \varphi] \omega-\frac{1}{2} \log [1-2 \alpha b[t t+1, t t o o s 1, \varphi]]\right)$

$\mathrm{b}\left[t t_{-}, t \operatorname{toos} 1_{-}, \varphi_{-}\right]:=\left(\varphi(\lambda+\gamma)-\frac{1}{2} \gamma^{2}+\beta \mathrm{b}[t t+1, t \operatorname{toos} 1, \varphi]+\frac{(1 / 2)(\varphi-\gamma)^{2}}{1-2 \alpha \mathrm{b}[t t+1, t \cos 1, \varphi]}\right)$

$\mathrm{c} 1\left[t t_{-}, t t o o s 1_{-}, s t_{-}, k k_{-}, r f_{-}, h t 1_{-}\right]:=$

$\left(\frac{1}{2} s t+\frac{\operatorname{Exp}[-r f(t t o o s 1-t t)]}{\pi}\right.$

NIntegrate $\left[\operatorname{Re}\left[\frac{k k^{-\dot{i} \phi} s t^{\dot{\mathbf{n}} \phi+1} \operatorname{Exp}[a[t t, t t o o s 1, \dot{\mathbf{n}} \phi+1, r f]+b[t t, t t o o s 1, \dot{\mathbf{i}} \phi+1] h t 1]}{\dot{\mathbf{i}} \phi}\right]\right.$,

$\{\phi, 0, \infty\}$, Method $\rightarrow\{$ "GlobalAdaptive", "SingularityHandler" $\rightarrow$ Automatic $\}$,

MaxRecursion $\rightarrow 17$, PrecisionGoal $\rightarrow 5$, WorkingPrecision $\rightarrow 8$ ]

$\mathrm{c} 2\left[t t_{-}, t t o o s 1_{-}, s t_{-}, k k_{-}, r f_{-}, h t 1_{-}\right]:=$

$(k k \operatorname{Exp}[-r f(t t o o s 1-t t)]$

$\left(\frac{1}{2}+\frac{1}{\pi}\right.$ NIntegrate $\left[\operatorname{Re}\left[\frac{k k^{-\dot{i} \phi} s t^{\dot{i} \phi} \operatorname{Exp}[a[t t, t t o o s 1, \dot{i} \phi, r f]+b[t t, t t o o s 1, \dot{i n} \phi] h t 1]}{\dot{i} \phi}\right]\right.$,

$\{\phi, 0, \infty\}$, Method $->\{$ "GlobalAdaptive", "SingularityHandler" $\rightarrow$ Automatic $\}$,

MaxRecursion $\rightarrow 17$, PrecisionGoal $\rightarrow 5$, WorkingPrecision $\rightarrow 8]$ ))

(* Entrada de dados - todos os modelos *)

parm = Import ["Gerdados.xls", "XLS"];

$\operatorname{ser}=\operatorname{parm}[[1,1,2]] ; \operatorname{seq}=\operatorname{parm}[[1,1,3]] ; p=\operatorname{parm}[[1,1,4]] ;$ ttis $=\operatorname{parm}[[1,1,5]]$;

tc $=\operatorname{parm}[[1,1,6]] ; s 0=\operatorname{parm}[[1,1,7]] ; \operatorname{rfd}=\operatorname{parm}[[1,1,8]]$;

ttoos $=$ Floor $[$ tc $/ \mathrm{p}]$; ttoos $1=$ ttoos $+1 ; \mathrm{rf}=\log \left[(1+\mathrm{rfd})^{\wedge} \mathrm{p}\right]$; ttis = ttis $/ \mathrm{p}$;

modelos = Import [ ParmModelos.xls", "XLS"] ;

normal $=\operatorname{modelos}[[2,1]] ; \operatorname{normal}$ jump $=\operatorname{modelos}[[3,1]] ; \operatorname{tgarch}=\operatorname{modelos}[[4,1]] ;$

hngarch $=\operatorname{modelos}[[5,1]]$; 


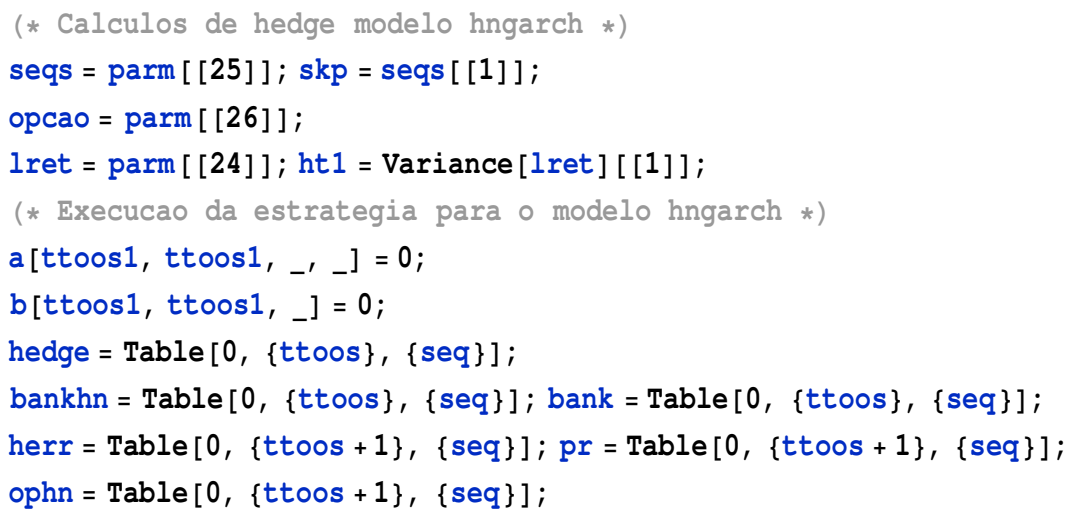

For $[j=1, j \leq \operatorname{ser}, j++, \alpha=\operatorname{normal}[[1]] ; \beta=\operatorname{normal}[[2]] ; \gamma=\operatorname{normal}[[3]]+\operatorname{normal}[[4]]+0.5 ;$ $\lambda=-0.5 ; \omega=\operatorname{normal}[[5]] ;$ For $[i=1, i \leq \operatorname{seq}, i++, t t=1 ; \operatorname{st}=\operatorname{seqs}[[1,(j-1) * \operatorname{ser}+i]]$; $\mathrm{kk}=\operatorname{skp}[[(j-1) * \operatorname{ser}+i]] ;$ integ $=\operatorname{Re}[\mathrm{c} 1[t t, \mathrm{ttoos} 1, \mathrm{st}, \mathrm{kk}, \mathrm{rf}, \mathrm{ht} 1]] ;$ hedge $[[1,(j-1) * \operatorname{ser}+i]]=$ integ $/$ segs $[[1,(j-1) * \operatorname{ser}+i]]$; integ $=\operatorname{Re}[\mathrm{c} 2[t \mathrm{t}, \mathrm{ttoos} 1, \mathrm{st}, \mathrm{kk}, \mathrm{rf}, \mathrm{ht1}]] ; \operatorname{bankhn}[[1,(j-1) * \operatorname{ser}+i]]=-$ integ ; $\operatorname{ophn}[[1,(j-1) * \operatorname{ser}+i]]=\operatorname{segs}[[1, i+(j-1) * \operatorname{ser}]] *$ hedge $[[1,(j-1) * \operatorname{ser}+i]]+$ $\operatorname{bankhn}[[1,(j-1) * \operatorname{ser}+i]] ; \operatorname{pr}[[1,(j-1) * \operatorname{ser}+i]]=$ opcao $[1, i+(j-1) * \operatorname{ser}]]$; $\operatorname{bank}[[1,(j-1) * \operatorname{ser}+i]]=-\operatorname{hedge}[[1,(j-1) * \operatorname{ser}+i]] * \operatorname{seqs}[[1, i+(j-1) * \operatorname{ser}]]+$ $\operatorname{pr}[[1, i+(j-1) * \operatorname{ser}]]$;

$\operatorname{herr}[[1,(j-1) * \operatorname{ser}+i]]=\operatorname{pr}[[1,(j-1) * \operatorname{ser}+i]]-$ opcao $[1,(j-1) * \operatorname{ser}+i]] ;$

For $[k=2, k \leq t$ toos, $k++, t t=k ; \operatorname{st~}=\operatorname{segs}[[k,(j-1) * \operatorname{ser}+i]] ; k k=\operatorname{skp}[[(j-1) * \operatorname{ser}+i]]$; $\operatorname{lr}=\log [\operatorname{seqs}[k,(j-1) * \operatorname{ser}+i]] / \operatorname{seqs}[[k-1,(j-1) * \operatorname{ser}+i]]] ; \operatorname{lret}[[1]]=\{1 r\} ;$ lret $=\operatorname{RotateLeft}[$ lret $] ;$ ht1 $=$ Variance [lret $][1]]$; integ $=\operatorname{Re}[\mathrm{cl}[\mathrm{tt}, \mathrm{ttoos} 1, \mathrm{st}, \mathrm{kk}, \mathrm{rf}, \mathrm{ht} 1]]$; hedge $[k,(j-1) * \operatorname{ser}+i]]=$ integ $/ \operatorname{seqs}[[k,(j-1) * \operatorname{ser}+i]]$; integ $=\operatorname{Re}[\mathrm{c} 2[t t, t$ toos $1, \mathrm{st}, \mathrm{kk}, \mathrm{rf}, \mathrm{ht} 1]] ; \operatorname{bankhn}[[\mathrm{k},(j-1) * \mathrm{ser}+\mathrm{i}]]=-$ integ; $\operatorname{ophn}[[k,(j-1) * \operatorname{ser}+i]]=\operatorname{segs}[[k, i+(j-1) * \operatorname{ser}]] *$ hedge $[k,(j-1) * \operatorname{ser}+i]]+$ bankhn $[[k,(j-1) *$ ser $+i]]$;

$\operatorname{pr}[[k,(j-1) * \operatorname{ser}+i]]=\operatorname{hedge}[[k-1,(j-1) * \operatorname{ser}+i]] * \operatorname{seqs}[[k,(j-1) * \operatorname{ser}+i]]+$ bank $[k-1,(j-1) * \operatorname{ser}+i]] *(1+r f)$;

$\operatorname{bank}[[k,(j-1) * \operatorname{ser}+i]]=-\operatorname{hedge}[[k,(j-1) * \operatorname{ser}+i]] * \operatorname{seqs}[[k, i+(j-1) * \operatorname{ser}]]+$ $\operatorname{pr}[k,(j-1) * \operatorname{ser}+i]] ;$

$\operatorname{herr}[[k, i+(j-1) * \operatorname{ser}]]=\operatorname{pr}[[k, i+(j-1) * \operatorname{ser}]]-$ opcao $[k, i+(j-1) * \operatorname{ser}]]] ;$

$\operatorname{pr}[[$ ttoos $+1,(j-1) * \operatorname{ser}+i]]=$ hedge $[$ ttoos, $(j-1) *$ ser $+i]] *$ segs $[[$ ttoos $+1, i+(j-1) * \operatorname{ser}]]+$ bank [ [toos, $(j-1) *$ ser $+i]] *(1+\mathrm{rf})$;

ophn $[[$ ttoos $+1,(j-1) * \operatorname{ser}+i]]=\operatorname{Max}[\operatorname{segs}[[t t o o s+1, i+(j-1) * \operatorname{ser}]]-\operatorname{skp}[[(j-1) * \operatorname{ser}+i]], 0]$;

herr $[[$ ttoos $+1,(j-1) * \operatorname{ser}+i]]=$

$\operatorname{pr}[[$ ttoos $+1,(j-1) * \operatorname{ser}+i]]-$ opcao [ [tooos $+1,(j-1) *$ ser $+i]]]]$;

(* Gravacao de dados modelo hngarch *)

Export ["HedgeHN41.xls", pr, \{"Sheets", "HNGARCHPRepHN"\}] ;

Export ["HedgeHN42.xls", hedge, \{"Sheets", "HNGARCHHedgeHN"\}] ;

Export ["HedgeHN43.xls", bankhn, \{"Sheets", "HNGARCHBankFHN"\}] ;

Export ["HedgeHN44.xls", bank, \{"Sheets", "HNGARCHBankHN"\}];

Export ["HedgeHN45.xls", herr, \{"Sheets", "HNGARCHHErrHN"\}];

Export ["HedgeHN46.xls", ophn, \{"Sheets", "HNGARCHOpHN"\}] ; 